Georgetown University Round Table on Languages and Linguistics 1977

\title{
Linguistics and Anthropology
}

Muriel Saville-Troike

Editor 

4 


\section{Georgetown University Round Table on Languages and Linguistics 1977}

\section{Linguistics and Anthropology}

\section{Muriel Saville-Troike}

Editor

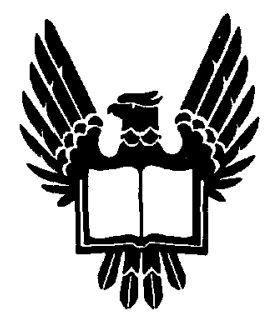

Georgetown University Press, Washington, D.C. 20057 


\section{BIBLIOGRAPHIC NOTICE}

Since this series has been variously, and confusingly, cited as: Georgetown University Monograph Series on Languages and Linguistics, Monograph Series on Languages and Linguistics, Reports of the Annual Round Table Meetings on Linguistics and Language Study, etc., beginning with the 1973 volume, the title of the series was changed.

The new title of the series includes the year of a Round Table and omits both the monograph number and the meeting number, thus: Georgetown University Round Table on Languages and Linguistics 1977, with the regular abbreviation GURT 1977. Full bibliographical references should show the form:

Charles A. Ferguson. 1977. Linguistics as anthropology. In:

Georgetown University Round Table on Languages and Linguistics 1977. Edited by Muriel Saville-Troike. Washington, D. C., Georgetown University Press. 1-12.

Copyright $\odot 1977$ by Georgetown University. All rights reserved Printed in the United States of America

Library of Congress Catalog Card Number: $58-31607$ ISBN $0-87840-112-1$ 
CONTENTS

INTRODUCTION

Muriel Saville-Troike

Chairman, Georgetown University Round Table 1977

OPENING REMARKS

James E. Alatis

Dean, School of Languages and Linguistics

Muriel Saville-Troike

xvii

LINGUISTICS, ANTHROPOLOGY, AND ST. PATRICK'S DAY

R. Ross Macdonald

Georgetown University

xix

OPENING SESSION

Chairman: R. Ross Macdonald, Georgetown University

Charles A. Ferguson

Linguistics as anthropology

Richard Bauman

Linguistics, anthropology, and verbal art:

Toward a unified perspective, with a special discussion

of children's folklore 
iv / CONTENTS

METHODS AND MODELS IN LINGUISTICS AND ANTHROPOLOGY

Chairman: Francis P. Dinneen, S. J., Georgetown University

Mary Ritchie Key

Males, females, and linguistic and cultural categories

Joel Sherzer

The ethnography of speaking: A critical appraisal

Gillian Sankoff

Variability and explanation in language and culture:

Cliticization in New Guinea Tok Pisin

Cecil H. Brown

Lexical universals and the human language faculty

ACQUISTTION OF COMMUNICATIVE COMPETENCE

Chairman: Robert J. Di Pietro, Georgetown University

Erica McClure

Aspects of code-switching in the discourse of

bilingual Mexican-American children

Ben G. Blount

Parental speech to children: Cultural patterns

LINGUISTIC RELATIVITY

Chairman: William Sturtevant, Smithsonian Institution

Michael Silverstein

Cultural prerequisites to grammatical analysis

Sally McLendon

Cultural presuppositions and discourse analysis:

Patterns of presupposition and assertion of

information in Eastern Pomo and Russian narrative

SOCIOLINGUISTICS AND COMMUNICATION

Chairman: James E. Alatis, Georgetown University 
John J. Gumperz

Sociocultural knowledge in conversational inference

Eugene A. Nida

Translating means communicating: A sociolinguistic theory of translation

APPLICATIONS OF LINGUISTICS AND ANTHROPOLOGY

Chairman: Robert Lado, Georgetown University

John Munby

Applying sociocultural variables in the specification

of communicative competence

231

H. Ned Seelye

Teaching the cultural context of intercultural

communication

Orlando Taylor

The sociolinguistic dimension in standardized testing

LANGUAGE AND SOCIETY

Chairman: José Vázquez, National Institute of Education

Shirley Brice Heath

Language and politics in the United States

Joshua A. Fishman

Language, ethnicity, and racism 



\section{IN TRODUCTION}

For the past twenty-eight years, it has been the tradition of Georgetown University's School of Languages and Linguistics to bring scholars from multiple disciplines together to focus on various aspects of language and its study. The interdisciplinary nature of the Georgetown University Round Tables on Languages and Linguistics has been an essential element in the contributions to the study of language which these meetings have made, largely by providing a forum for scholars with overlapping interests--but often quite different perspectives, foci, and methods--to talk and listen to one another.

The disciplines brought together for this twenty-eighth annual Round Table are linguistics and anthropology, and the focus is on language in its cultural context. It seems particularly appropriate for us to highlight the interdependence and integration of these two fields at a time when the theoretical spotlight in linguistics is returning to the analysis of language as a product of sociocultural developments, a medium for social interaction, and a means for group as well as individual expression.

The plenary speakers of this Round Table (GURT 1977), whose presentations are included in the present volume, are primarily anthropological linguists (or linguistic anthropologists), but it is indicative of the scope and integration of interest in the cultural context of language that they include several who would be more centrally identified with the fields of sociology, political science, translation, speech, bilingual education, or foreign language instruction. All are working on the cutting edge of developments in their particular areas of linguistic theory and application, yet each has made a special effort to meet the communication challenges of an interdisciplinary conference such as this by placing the data, conclusions, and theoretical constructs and implications which they present in a historical and theoretical context. 
The papers are arranged in the order in which they were presented, and under the labels which were attached to each session of the program, but other dimensions for arrangement or consideration were clearly possible. The ethnography of speaking model reviewed and extended by Sherzer, for instance, is an important aspect of the work reported by Bauman, McClure, Blount, McLendon, Gumperz, and Munby. Another example is the paper by Key on the relation of malefemale language to categorization and behavior, which could have been grouped with those on linguistic relativity instead of those on ethnosemantics and variable usage. The papers will be commented on under the heading of the session in which they were delivered.

\section{Opening Session}

Ferguson introduces the nature and theme of this conference, presenting 'Linguistics as Anthropology'. He considers the view of linguistics as a 'branch' of anthropology a valid perspective for language research, different in subject matter and research methods from other perspectives (e.g. linguistics as a branch of cognitive psychology). The anthropological perspective is concerned with language in culture and society as studied by nonexperimental anthropological methods. Ferguson distinguishes three features of this perspective: it is holistic, cross-cultural, and historical. He further explores three of its methods: elicitation, naturalistic observation, and participant observation. An interesting point raised is that as we question the autonomy of phonology or syntax, we might also well question the autonomy of the field of linguistics itself.

Bauman, in taking an integrated perspective of language, culture, and verbal art, exemplifies an interdisciplinary approach to scholarship: in this case, linguistics, anthropology, and folklore. He also exemplifies the sense of historical perspective and tradition which was in evidence throughout the conference: in this case, a continued unifying tradition from Johann Gottfried von Herder and the brothers Grimm through Franz Boas and Edward Sapir. Bauman's paper makes a contribution to performance analysis within the framework of the ethnography of speaking, especially in the area of children's acquisition of performative competence.

\section{Methods and Models in Linguistics and Anthropology}

The intent of this session was to illustrate something of the diversity of theoretical perspectives on language phenomena existing within the field of anthropological linguistics, and the contributions which each may make to the understanding of linguistic processes. Sherzer discusses the historical development of the ethnography of speaking, its 
present state, and issues which need future consideration. The ethnography of communication is an approach which brings ethnographic methodology to language, an approach which focuses on the nature and interrelation of components in a speech event, and their function within the cultural context of a speech community. This approach has not only made a significant contribution to linguistic methodology, but also to a redefinition of language and the scope of concern in linguistic description and analysis. It has thus far been primarily concerned with collecting empirical data on communication in many parts of the world. Sherzer calls for more future attention to comparative studies and the positing (and testing) of universal generalizations. He also points out the need for more languageacquisition studies which go beyond the usual aspects of phonology, morphology, syntax, and semantics and the need to attend more to intragroup variation.

Sankoff, in her study of Tok Pisin (a creole spoken in New Guinea) represents a perspective which focuses on variation, and on how heterogeneity of language within a single speech community is relevant to issues concerning the relation between language and culture. In this paper, she examines the cliticization of subject pronouns in the language, analyzing data collected over a span of 85 years. Variability provides important clues as to the nature of change.

Brown presents data collected within another major tradition within anthropological linguistics, that of ethnosemantics, and relates them to questions of central concern in recent linguistic theory--the extent and nature of language universals. These universals have been interpreted as evidence for an innate language faculty. Brown considers two models of this 'faculty': the 'detailed wiring model', which proposes that humans start life with very specific knowledge about language wired in their brains; and the 'information processing model', which also proposes that humans are wired for language but with a somewhat less extensive circuitry than that implied in the former. This paper discusses which of these two models appears most promising in light of ethnosemantic data on lexical universals which have been recently described. These universals involve severe constraints upon the order in which languages lexically encode basic color classes and categories of botanical life forms. Brown concludes there is much support for the 'information processing model' of the human language faculty, and only marginal support for the 'detailed wiring model'.

Key considers linguistic categories by and in reference to males and females from a variety of theoretical perspectives. She perceives social attitudes and the role-relationships of males and females in a society as being reflected in language categories, forms, and uses; she also raises the issue that intentional and official language change, such as reclassification of females within the law, might well result in 
changed attitudes, expectation, and perhaps even social behavior, rather than being merely their reflection. Variable usage occurs during periods of transition, and indicates social change in progress.

\section{Acquisition of Communicative Competence}

In this session, acquisition is explored both in aspects of child language usage and parental speech to children. McClure, in her description of the code-switching behavior of Mexican-American children, gives importance to the description of the community in which data is collected; she includes information on the interaction patterns (and barriers) between Anglo and Mexican-American children as well. She finds the children's situational switching to be most dependent on the identity of participants, with topic, setting, and discourse type relatively less important than for adults. She documents that with age there is increasing discrimination in appropriate code selection; more consideration is also given by older children to such factors as relative proficiency of speaker and hearer in both languages. McClure reports that stylistic switching in children as well as adults is sometimes used to mark emphasis, focus, elaboration, clarification, attention getting, or shift in mode, topic, or addressee.

Blount presents a review and summary of the study of parental speech as input to the development of children's linguistic competence, an area of study in which the shift of emphasis has paralleled the shift in much of descriptive linguistics--from a narrow focus on the language code in isolation to added concern with its function in enculturation and social interaction. Parental speech is not a traditional area of inquiry for linguistic anthropology. Blount points out both the value of an anthropological perspective to more centrally linguistic concerns, and the value of an understanding of parental speech to the field of anthropology as well. It is cultural information which is being transmitted, by language form, function, and content. The importance of children's involvement as participants in interaction is a fairly recent discovery, as opposed to early emphasis on the importance of repetition of adult forms or later speculation on the importance of speech that is passively overheard. Blount provides data on Spanish and English parental speech, and 'father speech' vs. 'mother speech' in each language.

\section{Linguistic Relativity}

Interest in the question of linguistic relativity never entirely disappeared, even during those years when it was not considered a reputable topic for public discussion by many linguists. The reemergence of scholarly attention to this subject is a clear sign of 
the shift taking place at this time in the issues which are considered 'interesting'. Silverstein places current concerns in historical and theoretical perspective by relating philosophy, anthropological linguistics, and pragmatics. He discusses distinct kinds of meaningfulness in speech, among them context-independent referentiality, indexical referentiality, and nonreferential indexical functions, each of which has a theory of the cultural constitution of speech as meaningful social behavior as its analytic and descriptive prerequisite. The necessary anthropologically informed basis for grammatical description is contrasted with various attempts to assimilate a full 'pragmatics' of speech to the explicit grammatical theories now current, grounded as these theories are in the native speaker consciousness about language function embodied in a particularly Western ideology of reference. A parallel is drawn with Pike's argument against an autonomous phonemic analysis, and with Whorf's analysis of referentiality. Silverstein also comments on the limitations of introspection in the study of language, whether by linguist or informant.

McLendon likewise includes philosophy (in addition to linguistics and anthropology) in her perspective on the analysis of language. Her discussion focuses on the significance of cultural information (including social organization) in the production and interpretation of discourse. She argues that each mode of performance involves a distinct mode of verbal behavior in underlying competence. McLendon concentrates on one variety of discourse in her discussion, the narration of myths and fairytales, using data from two widely divergent languages and cultures, Eastern Pomo myth and 19th century Russian fairytales.

\section{Sociolinguistics and Communication}

Both papers in this session deal with sociocultural influences on meaning as it is interpreted during communicative events. Gumperz explores how social knowledge is used for interpretation and response in the course of ongoing conversation. He reviews relevant developments in the ethnography of speaking, linguistic pragmatics, and ethnomethodology, and builds on these in proposing the outline of a theory of how social knowledge is stored in the mind, retrieved from memory, and integrated with grammatical knowledge in the act of conversing.

Nida focuses on the influence which culture and situation specific factors have on the interpretation of meaning across languages. Drawing examples from years of experience in translation, Nida shows how meaning is dependent on the attitudes, expectations, and potential responses of the receptors, as well as the message and intent 
of the transmitters. Expanding the cross-disciplinary dimensions of the Round Table in another direction, be adds considerations from the field of rhetoric in discussing the analysis and interpretation of discourse.

\section{Applications of Linguistics and Anthropology}

Munby applies techniques and concepts from the ethnography of speaking to the teaching of English as a foreign language; he focuses on the social functions of language, and the communicative needs of the learner. The model which he suggests for syllabus design provides descriptive features for the settings in which the target language will most likely be needed, probable interaction variables (identification of the participants in relevant communicative events and specification of their social relationships), and the key and tone of such interactions. Munby provides a partial inventory of social relationships that are coded in his system, which follow from the nature of both role-relationships and setting.

Seelye, bringing to the discussion the perspective of bilingual education, addresses very practical procedures to use in teaching cross-cultural communication. He suggests three steps in teaching cultural concepts: the identification of intercultural communication skills which can be taught (the goals of cultural instruction), the formulation of student performance objectives, and the development of goal-related learning activities. The cultural goals which Seelye outlines deal with developing such concepts as cultural relativity, sociocultural factors in interaction, conventional behaviors, and the cultural connotations of words and phrases. He includes a sample unit which illustrates goal-related learning activities.

A third area for the application of linguistics and anthropology is standardized testing, particularly with regard to the removal (or at least reduction) of bias in the construction, administration, and effect of tests. Taylor calls on linguists not only to take a scholarly interest in this field, but to take a more activist role in countering the bias and discrimination which has been caused at least in part by lack of understanding about language and cultural differences on the part of test makers, administrators, and interpreters. Taylor emphasizes that bias affects any group that does not speak mainstream varieties of English, including those who speak English as a second language. Biased results on tests reinforce social biases, myths, stereotypes, and expectations. 
Heath examines the current relation of language and politics in the United States in a historical context and with reference to theoretical research on the nature of language and politics. Three principal issues--multilingualism, literacy, and 'legalese'--are discussed, and Heath documents changes in attitudes on these issues during the history of the United States. The interplay of constitutional and statutory law in relation to these issues is also examined. Heath calls for specific kinds of linguistic and anthropological research on language and politics in order to provide input for policy makers in education, consumer affairs, and programs of social intervention.

In the final paper of GURT 1977, Fishman outlines his explorations into the social history and social theory of language and ethnicity. The scope of his study ranges from classical Hebrew and classical Greek to the 20th century, a historical sweep which includes the medieval, the renaissance, the reformation, the industrial revolution, and the 'rebirth of ethnicity' in the past decade. Historically, the concept of ethnicity and its link to language has been related to philosophy, religion, politics, economics, and social change, as well as to linguistics, anthropology, and sociology. It is Fishman's thesis that ethnic and linguistic diversity contributes to the humanness of man.

The contributions of the Georgetown University Round Table on Languages and Linguistics 1977 attest to the realization that linguistics needs the perspectives of anthropology (as well as of philosophy, sociology, psychology, and other disciplines) if it is to deal significantly with its chosen subject matter, language, and that--at least for the foreseeable future--a single theory, a single set of questions, or a single means for data acquisition and analysis could not begin to account for the complexities of communication. 



\section{OPENING REMARKS}

\section{JAMES E。ALATIS}

Dean, School of Languages and Linguistics

Georgetown University

Good evening, ladies and gentlemen. On behalf of Georgetown University and the School of Languages and Linguistics, I am honored to welcome you to the Georgetown University Round Table on Languages and Linguistics 1977. In keeping with the traditions of the Round Table, we have brought together some of the world's foremost scholars and leading practitioners: not only as speakers in the plenary session this evening and through Saturday, but as presentors in the interest groups which have just concluded, as chairmen and coordinators of various facets of the program, and as discussants. and participants--including all of you to whom I am now speaking. We wish to thank you for your interest, your cooperation, and your presence.

In selecting a topic for the 1977 Round Table, I felt that it was timely to provide a forum within which the current state of awareness of relations between anthropology and linguistics, and between language and other aspects of culture, could be explored. Linguistics and anthropology have traditionally shared a closer intellectual kinship than perhaps any other two of the social and behavioral sciences; this kinship long antedates the emergence of either of these as clearly defined disciplines, having been evident in the work of Jakob Grimm in Germany, of Thomas Jefferson in this country, as well as in the work of most American linguists in the middle of this century. There was a regrettable period within linguistics in the 1960 s when 'anthropological linguist' became a term of disparagement for someone primarily interested in 'mere' factual data rather than 'powerful' abstract formalist theory. Fortunately, today we are witnessing 
again a growing rapprochement between the two fields, as linguists have become increasingly interested in substantive information, and as the search for explanation and understanding in linguistics has carried inquiry into meaning and the social context and constraints of language use. Thus, linguistics is, in keeping with the times, rediscovering some of its own 'Roots'.

It is interesting to note that whereas it has been the usual situation ever since the days of Franz Boas for linguistics courses to be taught in anthropology departments, Georgetown University School of Languages and Linguistics must be one of the few institutions where anthropology courses are taught in the linguistics department. Hopefully, this may become part of a trend which will contribute to bringing the two fields back to the close relationship they have traditionally had in the United States, and help erase some of the disciplinary boundaries which have served as artificial barriers to efforts to better understand the world around us.

I want to take this opportunity to congratulate Dr. Muriel SavilleTroike for the highly professional manner in which she has organized the Round Table this year and for the splendid speakers she has brought together on the theme of 'Linguistics and Anthropology'.

Again, may I welcome you to Georgetown University, and to our Round Table on Languages and Linguistics 1977. Thank you. 


\section{OPENING REMARKS}

\section{MURIEL SAVILLE-TROIKE}

Chairman, Georgetown University Round Table on Languages and Linguistics 1977

In past years, I have listened to each Round Table chairman express thanks for all the help and cooperation he or she has received. Never before have I appreciated the extent of the help and cooperation which is required to implement a conference such as this; and never again will I consider the expression of thanks, such as I am about to make, merely a perfunctory part of the welcoming comments. Of course, I cannot mention all who deserve recognition here, but I would like to acknowledge a few people who have had central roles in this Round Table. First is Dean James Alatis, whose support, flexibility, and generosity I especially appreciate. Next, I wish to thank my associate chairman, Mary Owens, who has really done all of the work and who has allowed me to remain blissfully ignorant of most of the minor details involved in chairing a conference, as well as many of the major problems. She and I were aided by many students, faculty, and staff here at Georgetown University, who deserve our sincere thanks for the many hours they have contributed to many aspects of planning and implementation.

Finally, I would like to thank our speakers. It has been a pleasure working with them in organizing a program which demonstrates the rapid convergence of interest in linguistics and anthropology, and contributes to reuniting these two disciplines which time hath almost put asunder. We may be grateful to the speakers for giving so generously of their time and expertise to help make this collective speech event an occasion of lasting significance. My thanks to all.

And now, I would like to turn this opening session over to the chairman of the Georgetown University Department of Linguistics, 
xviii / OPENING REMARKS

Professor Ross Macdonald, whom I have asked to make a few comments of his own appropriate to this occasion and this date, the seventeenth day of March. 
LINGUISTICS, ANTHROPOLOGY, AND ST. PATRICK'S DAY

\section{R. ROSS MACDONALD}

Georgetown University

It seems I am to talk to you about St. Patrick.

'Do you mean', I demurred, when this was first suggested to me, 'that I am expected to link St. Patrick, Georgetown University, the Round Table, Linguistics and Anthropology together in one talk?'

'That is the idea', I was told, 'and it should be less than ten minutes.'

'But I'm not Irish', I replied, ' $\mathrm{I} m$ a Scot.'

'Well, you can bring the Scots in too', was the reply.

'But it is also Italian Reunification Day, and the anniversary of the death of Giovanni Battista Pergolesi', I pointed out. 'Could I not sing a few arias from one of his lesser known operas, instead?'

'You will speak on St. Patrick or nothing', I was told. 'And under no circumstances will you sing.'

Well, I set to work, and I amassed a few facts and a great deal of speculation and mythology--rather too much, in fact. However, it has been impressed upon me that if I cut out all of the shure's and the begorra's, I may be able to cut this talk down to less than ten minutes. Here goes.

\section{St. Patrick or nothing}

Chapter I: Historical background. The islands of Britain and Ireland were occupied at a very early date by the people we call the Picts. Most of what we know about the Picts comes from other peoples who just could not refrain from commenting on the quaint customs of these people. 
One of the customs of the Picts--this is the anthropology bit--was that land and property descended in the female line. Just as any American boy can grow up to be president, any Pictish boy could grow up to be king. All he had to do was marry the queen, or marry the king's youngest daughter and wait. (It is thought by some that this old Pictish arrangement is reflected in many of our children's stories, where the low-born but clever young hero marries the youngest of the princesses and immediately finds that he is next in line for the throne.) Another Pictish custom involved the men. They would, on certain occasions, and particularly in time of war, take off their clothes and paint themselves blue with a vegetable dye called woad. This has been suggested as the reason the Romans called them Picti, or 'the painted people'.

Many years later, this picturesque custom inspired the Song of the Woad, which would be particularly appropriate for this occasion because it is sung to the same melody as the Georgetown Alma Mater. I dare not sing it to you, but I feel sure that you all remember the words:

Woad's the stuff to show men!

Woad to fright your foe men!

Mix it to

A brilliant blue,

And rub it on your back and your abdomen!

Truly a stirring song!

Chapter II: The coming of the Celts. One must mind one's P's and Q's in dealing with the Celts. The Q-Celts came first and occupied all of Ireland, and all but the north of Britain. Centuries later, a first wave of P-Celts appeared and occupied southern Britain. A new wave occupied the same area and also pressed up the west coast, leaving only the far northeast in the blue hands of the Picts.

Chapter III: The coming, and going, of the Romans. Centuries later again, the Romans took over the south part of Britain. In due course, Christianity came to this area. Towards the end of the Roman period, the south of Britain was harried by Saxons, by Picts, and by groups of pirates and marauders from Ireland; the Irish name for these pirates and marauders seems to have been something like Scot, with the result that the Romans named these people Scotti. Eventually, around the year 410 , the Romans were no longer capable of defending Britain, and withdrew their legions. 
Chapter IV: St. Patrick. Towards the end of the Roman occupation, in the year 389 by the Dionysian reckoning, a boy was born, probably in Banwen in what is now Wales. His father was a decurion in the Roman army, a middle-class landowner, and a Christian; his mother may well have been a P-Celt. The boy grew up to be a coordinate bilingual. His Latin name was Patricius; his British name was Sucat, which means 'warlike'; as far as is known he was neither patrician nor warlike. When he was about sixteen years of age, in 405 , he was captured by the Scotti in one of their frequent raids, and was carried off to Ireland, where he was made a slave and was set to tending livestock.

During his stay in Ireland, Patrick learned Q-Celtic; his Q-Celtic name was Cothrige. He also learned that the Christians of the south of Ireland were only loosely organized, and were addicted to the Pelagian heresy, while the people of the north were utterly heathen. Literacy was a rarity; the only writing system was the Ogham, and knowledge was memorized rather than written.

After six years, Patrick managed to escape to Gaul, where he stayed in a monastery for some three years, and whence he returned to Britain. Here he found the Romans gone, and the country ever more a prey to raiders. It was still half a century before the organization of British resistance by King Arthur and his Round Table.

But Patrick was seized with the ambition to bring Christianity and the Latin language and alphabet to the Irish. He saw visions which urged him to become 'the voice of the Irish'. He begged the Church to consecrate him to this task.

After some delays and disappointments--another missionary was sent to Ireland, but failed to create any impression--St. Patrick was authorized to set out.

He went to northern Ireland, soon established a good rapport with one of the kings of Ulster, and converted him and his people to Christianity. One success led to another; Patrick travelled widely, including a journey to the Eternal City, and a firm connection was established between Ireland and Rome. Latin became the language of religion, and the Latin alphabet was widely used, for those times.

In 461 Patrick died, aged 72. His work did not die.

Chapter V: Aftermath. Some time after the death of St. Patrick, the Scotti of Ulster, now Christianized, organized a large and probably retaliatory raid on north Britain. They conquered the nearby British first, and then the more remote Picts of the northeast, establishing Scotland as we know it today. With them came Christianity, which flourished, not only in Scotland but also in Northumbria and even farther south. 
Through the dark ages, when the barbarians were sweeping across Europe and jeopardizing the continuity of Roman civilization, Ireland remained an unsullied center of religion and of learning. Medieval European society was later to owe a great deal to the beneficent influences emanating from St. Patrick's Ireland.

Had it not been for St. Patrick, some of the circumstances under which we are meeting here tonight might have been considerably changed. Take my case, for example. My ancestors came from the northeast of Scotland, and were undoubtedly largely Picts. Had it not been for St. Patrick and the Scotti, I would probably be standing here addressing you now attired only in bright blue cosmetics, the while wondering which of the youths courting my younger daughter would gain her hand, and so be in line to succeed to the dignity of Professor of Linguistics at Georgetown University.

Indeed, there is a great deal for which we must thank St. Patrick. 


\section{LINGUISTICS AS ANTHROPOLOGY}

\section{CHARLES A. FERGUSON}

\section{Stanford University}

In recent years linguistics has been called a 'branch of cognitive psychology' (e.g. Chomsky 1972:1), and this point of view has given us valuable insights into the nature of human language. However, on this occasion, I want to discuss linguistics as a branch of anthropology, the official view of the American Anthropological Association, which recognizes linguistics along with archaeology, physical anthropology, social/ cultural anthropology, and folklore as an anthropological discipline. Many linguists, of course, prefer to think of our field as autonomous and to assume that the 'scientific study of language' (Constitution of the Linguistics Society of America) by its own approaches and methods of investigation arrives at valuable conclusions about its own unique subject matter. At this time, however, when our cherished autonomies of phonology and syntax seem less certain than they once did, perhaps some of the uncertainty may be carried to the field as a whole, so that we may be less sure of the autonomy of linguistics itself. In any case, what would it mean to say linguistics is a branch of science $X$, such as psychology or anthropology? Perhaps it would mean that if the theory of science $X$ were fully formalized, then the theory of linguistics would be a discernible component within it; or it might mean that the fundamental principles of linguistics are all provable theorems within the larger science; or it might mean some vaguer notion of inclusion or other relationship. I would prefer, at least for this discussion, to see these 'branching' statements about linguistics as being simply alternative perspectives for the study of language or the work of linguists.

To say that linguistics is a branch of psychology for me means to adopt, on the one hand, the perspective of concern for psychological reality or the relation of language and mind (although many will 
shudder at these formulations) and, on the other hand, the method of experimentation, which, for all its drawbacks, provides a means of validation which people outside our field can understand and evaluate. In part we are talking about the flourishing field of psycholinguistics inhabited by psycholinguists, linguists, and others who adopt this perspective. It was over twenty years ago that the Social Science Research Council started a Committee on Linguistics and Psychology to explore the possibilities of this perspective (Osgood and Sebeok 1954) and in a decade the committee did its work well, aided in due course by Chomsky's new claims about language and his famous review of Skinner. Now the field of psycholinguistics has its own journals and professional identification, and its perspective has become a familiar and respected one to most linguists (cf. Dingwall 1971, Clark and Clark 1977).

To say that linguistics is a branch of anthropology for me means, on the one hand, to adopt the perspective of concern for the role of language in culture and society (cf. Hymes 1964) and also the predominantly nonexperimental research methods used by anthropologists. This is no new and unfamiliar perspective for American linguists, since the anthropological tradition has always been an important stream in American linguistics, and the founding of the LSA can be seen as the recognition by philologists and anthropologists working with language that they were interested in the same phenomena and were looking for the same fundamental principles. Anthropological linguistics is certainly alive and functioning in America today; witness the fact that most of the panelists in this year's Round Table are professional anthropologists working with language. Yet it is true that in recent years the majority of linguistics students in the United States have had little or no anthropology in their training, the production of anthropologists with extensive linguistics training has been very limited, and the anthropological perspective has been weakened and almost lost. The activities of the SSRC Committee on Sociolinguistics, which has existed for over a decade, have contributed somewhat to an anthropological perspective, but the increasingly recognized field of sociolinguistics consists to a considerable extent of quantitative studies of social dialectology and sociological studies of language use in education and national life (cf. Shuy 1972). Let us examine three features of an anthropological perspective for linguistics which deserve rediscovery and reemphasis among linguists. The anthropological approach to the study of human behavior is, among other things, holistic, cross-cultural, and historical.

1. Holistic. Anthropologists look at any human social phenomena, whether marriage customs, folktales, economic patterns, artistic efforts, religion, or language, in terms of the whole culture or society 
in which they occur. They look for interconnections among these apparently different phenomena, and they look for pervasive patterns of social organization and shared values. Linguists, ever since the rise of structuralism in the early part of the century, have had a holistic view of language, i.e. they have looked at any set of language phenomena, whether relative clauses, verb tenses, vowel systems, or semantic fields, in terms of the whole language in which they occur. But linguists have kept inside language itself, venturing out into nonlinguistic behavior only for certain stock language-and-culture issues or for external histories of language change.

The anthropological style of doing linguistics asks that the linguists turn their attention to the social contexts in which language behavior occurs, to whole acts of expression and communication in which language typically has a central role, and to the whole community or society in which the norms and expectations of language use are shared.

Actually, it is too much of a leap for the linguists to move from their autonomous grammars to consideration of whole cultures or whole communication networks, a leap for which the linguists' methods are obviously inadequate. The first step in this anthropological direction is to extend the linguists' concern from relatively homogeneous varieties of language to more heterogeneous varieties 1 and to different varieties interacting in the same specific context or in the same speech community. It is a pleasure to note that some of the most exciting developments in current linguistic research come from linguists who are taking precisely this step. The NWAVE Conferences here at Georgetown give solid evidence of this activity (Bailey and Shuy 1973), but I would like to point to several kinds of studies which I find particularly appealing and promising.

First, let me mention the so-called 'short a' in Philadelphia English. This is a prime field for investigating the lengthening, tensing, and raising processes which /ae/ is undergoing in many varieties of English, duly footnoted in Chomsky and Halle (1968:205-206). Several years ago, Arvilla Payne studied the pronunciation of some New York families who had recently moved into King of Prussia, a town in the Philadelphia speech area (Payne 1975). Because of the detailed previous studies of the short $a$ in the New York and Philadelphia area (Trager 1930, Ferguson 1972, Labov 1966, Cohen 1969), it was possible to trace the gradual phonological adjustment of these incoming families as they brought their New York distribution of the contrasting $/ \Re /$ and $/ \bar{a} /$ into line with the different Philadelphia distribution. Anthropologists could not ask for a more precise and insightful account of the processes of acculturation, and linguists are treated to an analysis which reveals the gentle, persistent ebb and flow of interdialectal variation which is a fundamental aspect of human language behavior. 
Even further from traditional linguistic studies of idiolects, overall patterns, or idealized uniform languages is the investigation of fluctuating intermediate varieties in diglossia situations. Scholars have long noted the substantial differences between Classical Arabic and the spoken dialects, and linguists have written grammars of both, but the intermediate varieties which are used in many situations have rarely been described (Ferguson 1959, 1960). Now T. F. Mitchell is engaged in an extensive investigation of just these kinds of Arabic (Mitchell 1976) and is trying to characterize in significant ways the intermingling of elements from each extreme as well as unique structural and functional characteristics of the varieties in question. It is a task for which his linguistic training provides inadequate preparation, althe'gh the fact that he was heavily influenced by Firth, the great advocate of polysystemic accounts of language, may have prepared him more than most of us to deal with it. Processes of koineization and standardization are widespread linguistic phenomena, and this fearless anthropological approach will bring us nearer to an understanding of them.

Beyond these phenomena of interdialectal changes and the use of intermediate varieties, there are language phenomena still further removed from our usual grammar writing. We are discovering that the often maligned and still more often ignored phenomenon of codeswitching between two languages has its own linguistic structure and pattern of use (cf. Gumperz and Hernandez-Chavez 1969, Sankoff 1972). And who would have thought in 1957 that twenty years later the study of pidginization and creolization processes and related phenomena would be a major preoccupation of American linguists (cf. Hymes 1971, Bickerton 1975)? All these examples of extending the scope of linguistics to more heterogeneous and fluctuating language behavior represent, as I have noted, only the first step.

The second step is to extend the scope of investigation altogether outside linguistic structure as traditionally recognized, to include nonverbal behavior and considerations of use and function. It is a pleasure to realize that in this direction also there is much activity that is exciting, some of it under the label of pragmatics still closely tied to formal models of the grammar of natural languages, but much of it not easily relatable to linguistic models. Let us take one topic as illustrative of the new development: the explication of patterns of interrogation. The traditional linguistic concern was to identify interrogative structures in English or another language and write an explicit grammar which could in one way or another account for them within the total framework of the grammatical structure of the language, and which would be revealing about universal properties of language. Imaginative and insightful work of this kind is still going on, as witness Lauri Karttunen's recent paper on the syntax and 
semantics of questions from the perspective of Montague grammar (Karttunen 1977), or Noam Chomsky's Irvine paper on fronting in WH-questions (Chomsky, forthcoming). But beginning with Bolinger's impressive monograph of 1957, students of human language have been looking at questions in very different ways. Scholars are recognizing, for example, that nonverbal replies to questions may occupy the same communicative slot as verbal replies and must be analyzed with them. .It is clear that sentences in the form of questions may serve other functions such as directives, reassurances, replies, greetings, or the correction of information. It seems likely that as soon as children learn the formal structure of questions, they learn also that questions may be used for noninterrogative purposes and that nonquestions may be used interrogatively. Researchers are showing us that conversational exchanges of questions and answers, and questions and answers within questions and answers, have structures and are as complex and rule-governed as the sentential syntax more familiar to the linguist. Teachers' questions in the classroom turn out not to be seeking information at all--teachers rarely ask questions to which they do not know the answers--but to have very different functions. As a sample of studies dealing with questions in these ways, see Ervin-Tripp 1976, Frake 1964, Garvey 1975, Goffman 1977, Merritt 1976, Sinclair and Coulthard 1975.

In the last few years, we have had a mini-explosion of knowledge about questions and questioning, much of it not integrated at all into current linguistic models, but most of it representing movement toward the holistic approach of anthropological research. To the extent that this kind of research is conducted by linguists or people with linguistic sophistication, the issue arises: 'What do we do with our linguistic theory?' That issue is too big to be resolved here, but I can give the gist of my opinion. We should bring our theory along with us and make whatever use of it we can, sometimes perhaps stretching it a little to accommodate new material, but we should not be inhibited by it. We are bound to discover many things about human language which require different assumptions from our usual theories. There is no possibility in the near future of having a 'new paradigm' in linguistics which will incorporate all the new information that is pouring in, and we must simply learn to live without a unifying theory to which all aspects of language can be related. In return, we get new understandings of human language behavior and its underlying principles, and better notions about how language fits in with the rest of human behavior.

2. Cross-cultural. Anthropologists study any community in the perspective of other communities, in the expectation that cultural differences may be extensive and deep. They generally hope to discover universal characteristics of human societies by comparison of 
societies in different parts of the world, different culture areas, different stages of economic organization, and so on. Linguistics in the anthropological style is correspondingly comparative (or contrastive) and cross-cultural. Although the study of the language behavior of a given community or society is holistic in approach, it is undertaken in order to see how the particular society differs from all other societies or possible societies in the structure and use of the language or languages in it, and in order to see in what ways it is systematically similar to other societies (typology), and how it manifests the language characteristics of all societies (universals). Linguists generally acknowledge the need to compare different languages in order to determine the characteristics of human language as such, but they have been strangely slow to develop the data bases and research methods to do so. If we take up again our topic of interrogative patterns, we must note sadly that Russ Ultan's 1969 paper on interrogative systems was the first cross-linguistic comparison of questions of any magnitude since the 19th century. He looked at the interrogative structures of 79 languages and came up with 23 statements of widespread, near-universal, or universal characteristics of interrogative systems which merit the attention of linguists and other students of human language. It is difficult to understand why linguists have not set up archives of comparable data on linguistic form and function drawn from large numbers of language and speech communities. One problem, of course, is the determination of a representative sample of the world's languages, a problem which Alan Bell has recently explored in a thoughtful paper (Bell, forthcoming); but more important as explanations, however, are the preoccupations of structuralists with the notion that each language must be described in its own terms, and the generativist practice of looking for universals by in-depth analyses of one language and philosophicomathematical discussions of possible grammars.

Some of us have tried the route of comparing a handful of languages for which data are to hand, as in my 1964 article on baby talk (Ferguson 1964) or Henning Wode's recent paper on the acquisition of interrogative structures (Wode 1976). This method is risky since the languages selected tend to be familiar European languages or important world languages or just a convenient set of languages for which the requisite data are available. For many language phenomena the obvious solution is to have an archive of data from an appropriate sample of languages and speech communities accessible for any interested scholars, such as the Stanford Phonology Archive, which has detailed phonetic and phonological data for a carefully selected sample of 200 of the world's languages (Vihman 1977). This kind of archive makes possible studies such as Crothers' recent paper on typology and universals of vowel systems in which he reviews previous 
attempts and offers a new synthesis and some plausible explanatory principles (Crothers, forthcoming). On many topics it is possible to develop a checklist for exploring published data or collecting new data, which will lead directly to useful typologizing. To take a very simple example of language use, the exchange of verbal greetings is probably found in every speech community, although to a very limited extent in some, and it seems always to be related to status distinctions, whether by the linguistic forms of the greetings, by the occasions of their use, by the role of initiator in the exchange, or some other way; yet there is nowhere we can go to check out such a simple fact of language use as whether the junior speaks first (as in some societies) or the senior (as in others). Such a set of facts about a sizeable sample of speech communities, once compiled, could be consulted in relation to hypotheses about the nature of adjacency pairs in conversation, universal patterns of deference behavior, or linguistic marking of role differences (cf. Ferguson 1976).

There is one final point about cross-cultural comparisons and linguistic typologies. Many linguists take the position that a typology is of no interest unless it is related to an explicit theory of language. I would argue the contrary, that empirically based linguistic typologies can offer salutary challenges to explicit theories. Certainly, Greenberg's basic word order typology (Greenberg 1966) has proved to be a highly stimulating challenge to theoreticians, and it was constructed empirically without any very explicit model of syntax.

3. Historical. There is a strong trend of historical study in American anthropology. It appears in one way among physical anthropologists who try to understand the evolution of the human species and the historical processes which have resulted in the present distribution of human population types. It appears full force among archeologists who try to reconstruct the physical and cultural characteristics of the populations whose material remains they study. And it is evident among cultural anthropologists who seek to explain commonalities in cultures by processes of migration, cultural diffusion, and so on.

Linguistics in the anthropological style is concerned with diachrony in at least three ways: the history of languages and speech communities, language development in children, and the evolution of language. Historical linguistics is, of course, a well-established field of inquiry, but it had become almost a marginal area in linguistic research, much outweighed by synchronic description and grammatical theory. Now, however, it is a pleasure to see renewed interest in historical studies and new approaches used. Linguistics now examines sound changes in 
progress and adds functional considerations in diachronic syntax; we are even seeing the beginnings of historical sociolinguistics (Fishman 1966, Bauman 1974, Heath 1977). For some linguists the interest in diachrony has demolished the Saussurian dichotomy, so that their synchronic analyses incorporate diachronic processes and lay out synchronic variation in historical terms (cf. Bailey and Shuy 1973, Bickerton 1975).

The study of child language development is an unusual type of diachrony which poses particular problems in that the data are hard to collect and do not remain constant, but it is at long last paying off on the promise that linguists of the past such as Grammont and Jespersen saw in it. Modern students of child language have gotten past the phase of psycholinguistic experiments to validate linguistic theories, and are now examining interaction processes crossculturally--an anthropological style of linguistic research which is already making important contributions to theories of language.

Before very long, I hope that the study of this kind of language change will be a regular part of the training of all students of linguistics.

Finally, linguists have found their way back to the study of the origin of language, a topic regarded for over 100 years as impossible or at best unprofitable. Increased sophistication in the study of animal communication, human 'neurolinguistics', and the evolution of human physical features has made it possible to reopen this question in what I feel can be called anthropological linguistic terms.

4. Methods. In these concluding remarks about anthropological methods of research I want to list three well-known means of collecting data, in increasing order of potential value of the data. The methods are: elicitation from informants, naturalistic observation, and participant observation. Let me illustrate from the study of the special register of language used in talking to very young children. An example of typical linguistic elicitation is my own study of Arabic baby talk (Ferguson 1956). I asked six speakers of Syrian Arabic about how they spoke to children, recorded their responses, checked them against one another, and interviewed them again. What I discovered was useful and enabled me to make a number of observations about the nature and function of this system in Syrian Arabic, but it suffered from the fact that at no point did I really observe adult Arabs talking to young children.

More recently, Dorothy Wills made some naturalistic observations of parents talking to their children in Austin, Texas, and in fact has tape recordings of the communications. It was possible for her to discover principles about such things as the use of pronouns in this register of English, which no ordinary elicitation procedures would have 
uncovered. There is no substitute for real speech observed under normal conditions of community interaction.

Finally, we have the example of Robert Scollon in Hawaii, recording mother, child, and his own speech in a number of conversational exchanges and other interactions. In this case, it was not only possible for the researchers occasionally to move the conversation in a direction which would give the kind of data one might wait a long time for in nonparticipant observation, but even more important, he discovered in his own behavior some fascinating features of talk to young children which he had not expected and opened up a new line of research (Scollon 1973).

I have said enough to give some idea of what I consider an anthropological perspective in linguistics, and to show why this perspective, among others, should continue and increase in language research. What I would really like, of course, is for all of us to feel fired up with enthusiasm to go out and do some linguistics in the anthropological style, from a holistic point of view, cross-cultural in form, with a historical dimension, and done by participant observation.

\section{NOTE}

1. This may, in any case, be regarded as the natural goal of linguistic description. 'I like to dream of a time when the analysis of a [uniform, static, autonomous, synchronic phonological] system will be regarded as merely a special, limited case in a far more general linguistics which is prepared to deal with data highly heterogeneous dialectally and diachronically' (Ferguson 1957:487).

\section{REFERENCES}

Bauman, Richard. 1974. Speaking in the light: The role of the Quaker minister. In: Explorations in the ethnography of speaking. Edited by R. Bauman and J. Sherzer. London: Cambridge University Press. 144-160.

Bailey, Charles-James N., and Roger W. Shuy. 1973. New ways of analyzing variation in English. Washington: Georgetown University Press.

Bell, Alan. Forthcoming. Language samples. To appear in: Universals of human language. Edited by J. H. Greenberg. Stanford, Calif.: Stanford University Press.

Bickerton, Derek. 1975. The dynamics of a creole system. London: Cambridge University Press.

Bolinger, Dwight. 1957. Interrogative structures of American English in the direct question. University, Ala.: University of Alabama Press. 
Chomsky, Noam. 1972. Language and mind. English edition. New York: Harcourt, Brace, Jovanovich.

Chomsky, Noam. Forthcoming. On WH-movement. To appear in: Formal syntax. Edited by P. Culicover, T. Wasow, and A. Akmejian. New York: Academic Press.

Chomsky, Noam, and Morris Halle. 1968. The sound patterns of English. The Hague: Mouton.

Clark, Herbert H., and Eve V. Clark. 1977. Psychology and language: An introduction to psycholinguistics. New York: Harcourt, Brace, Jovanovich.

Cohen, P. S. 1969. The tensing and raising of 'short a' in Metropolitan New York City. Ph. D. dissertation. Columbia University. Crothers, John. Forthcoming. Typography and universals of vowel systems. In: Universals of human language. Edited by J. H. Greenberg. Stanford, Calif.: Stanford University Press.

Dingwall, William Orr. 1971. Linguistics as psychology: A definition and some initial tasks. In: A survey of linguistic science. Edited by W. O. Dingwall. College Park, Md.: Linguistics Program, University of Maryland. 758-802.

Ervin-Tripp, Susan. 1976. Is Sybil there? The structure of American English directives. Language in Society 5. 25-66.

Ferguson, Charles A. 1956. Arabic baby talk. In: For Roman Jakobson. Edited by M. Halle. The Hague: Mouton. 121-128. Ferguson, Charles A. 1957. Two problems in Arabic phonology. Word 13.460-478.

Ferguson, Charles A. 1959. Diglossia. Word 15.325-340.

Ferguson, Charles A., ed. 1960. Contributions to Arabic linguistics. Cambridge: Harvard University Press.

Ferguson, Charles A. 1964. Baby talk in six languages. American Anthropologist 66(6), Part 2.

Ferguson, Charles A. 1972. 'Short a' in Philadelphia English. In: Studies in linguistics in honor of George L. Trager. Edited by M. E. Smith. The Hague: Mouton. 259-275.

Ferguson, Charles A. 1976. Structure and use of politeness formulas. Language in Society 5.

Fishman, Joshua A. 1966. Language loyalty in the United States. The Hague: Mouton.

Frake, Charles O. 1964. How to ask for a drink in Sukanum. American Anthologist 66(6), Part 2. 127-132.

Garvey, Catherine. 1975. Requests and responses in children's speech. Journal of Child Language 2. 41-63.

Goffman, Erving. 1976. Replies and responses. Language in Society 5. 257-313. 
Greenberg, Joseph H. 1966. Some universals of grammar with particular reference to the order of meaningful elements. In: Universals of language. Edited by J. H. Greenberg. Cambridge, Mass.: MIT Press. 73-113.

Gumperz, John J., and Eduardo Hernandez-Chavez. 1969. Cognitive aspects of bilingual communication. Working Paper No. 33. Language Behavior Research Laboratory, Berkeley.

Heath, Shirley Brice. 1977. A national language academy? Debate in the new nation. International Journal of the Sociology of Language 11.

Hymes, Dell H. 1964. Language in culture and society. New York: Harper and Row.

Hymes, Dell H. 1971. Pidginization and creolization of languages. London: Cambridge University Press.

Karttunen, Lauri. 1977. Syntax and semantics of questions. Philosophy and Language 1. 1.

Klima, Edward S. and Ursula Bellugi-Klima. 1966. Syntactic regularities in the speech of children. In: Psycholinguistic papers. Edited by J. Lyons and R. Wales. Edinburgh: University Press. 183-208.

Labov, William. 1966. The social stratification of English in New York City. Arlington, Va.: Center for Applied Linguistics.

Merritt, Marilyn. 1976. On questions following questions (in service encounters). Language in Society 5. 315-357.

Mitchell, T. F. 1976. Writing with the learned, pronouncing with the vulgar. Public lecture. Linguistic Institute, SUNY Oswego. Osgood, Charles E., and Thomas A. Sebeok, eds. 1954. Psycholinguistics. Supplement to International Journal of American Linguistics 20,10 .

Payne, Arvilla C. 1975. The re-organization of linguistic rules: A preliminary report. Pennsylvania Working Papers on Linguistic Change and Variation $1,6$.

Sankoff, Gillian. 1972. Language use in multilingual societies: Some alternative approaches. In: Sociolinguistics. Edited by J. Pride and J. Holmes. Harmondsworth: Penguin. 33-51.

Scollon, Robert. 1973. The acquisition of discourse. Unpublished $\mathrm{Ph} . \mathrm{D}$. dissertation. University of Hawaii.

Shatz, Marilyn. 1974. The comprehension of indirect directives: Can two-year-olds shut the door? Paper read at summer meeting, LSA, Amherst.

Shuy, Roger, ed. 1972. Georgetown University Round Table on Languages and Linguistics 1972: Sociolinguistics: Current trends and prospects. Washington, D. C.: Georgetown University Press.

Sinclair, J. McH. and R. M. Coulthard. 1975. Towards an analysis of discourse: The English used by teachers and pupils. London: Oxford University Press. 
Snow, Catherine E., and Charles A. Ferguson, eds. 1977. Talking to children: Language input as acquisition. London: Cambridge University Press.

Trager, George L. 1930. The pronunciation of 'short a' in American English. American Speech 5.396-400.

Ultan, Russell. 1969. Some general characteristics of interrogative systems. WPLU 1.41-63a.

Vihman, Marilyn May. 1977. A reference manual and user's guide for the Stanford Phonology Archive. Part 1. Stanford University Department of Linguistics.

Wode, Henning. 1971 (appeared 1975). Some stages in the acquisition of questions by monolingual children. Word 27. 261-310. (=Child Language, special issue consisting of nos. 1-3 of vol. 27). 
LINGUISTICS, ANTHROPOLOGY, AND VERBAL ART: TOWARD A UNIFIED PERSPECTIVE, WITH A SPECIAL DISCUSSION OF CHILDREN'S FOLKLORE

\section{RICHARD BAUMAN}

\section{University of Texas at Austin}

The subject of linguistics, anthropology, and verbal art is an especially gratifying one for a folklorist of my persuasion to deal with, not only because of my own personal commitment to a unified perspective on all three areas, but also because my folklorist's investment in tradition leads me to value that part of our collective scholarly birthright as linguists, anthropologists, and folklorists, that is represented by an integrated vision of language, culture, and verbal art. 1 In the scholarship of recent decades, that unified vision has tended to break down as the various disciplines of linguistics, anthropology, and folklore have asserted their disciplinary autonomy; but it has not always been so, and I believe grounds are firmly established on which that trend can be reversed by those with the interest and commitment to do so.

The sources of this formerly unified vision of language, culture, and folklore are widely known in our various disciplines, but it may be useful to recapitulate briefly aspects of its development which will serve as a frame of reference for our later considerations. The seminal figure was that great precursor of the era of romantic nationalism, Johann Gottfried von Herder. For Herder, the touchstone of a people's distinctiveness, the source that gives rise to and sustains their sense of themselves as a separate, unique social entity, was the possession of a common language. Language embodies the character, the inner being, of a Volk. Moreover, language represents the means of transmitting the distinctive traditions of a Volk across the generations, thus representing the instrument 


\section{4 / RICHARD BAUMAN}

for that progressive cultivation of faculties that Herder identified as culture (Cultur), in what was then a new sense of the word, and an antecedent of subsequent usage in anthropology (Barnard 1965:117118, 142; Kroeber and Kluckhohn 1963:38-41, 285-286). Herder argued (Wilson 1973:827):

A nation . . . has nothing more valuable than the language of its fathers. In it lives its entire spiritual treasury of tradition, history, religion, and principles of life, all its heart and soul. To deprive such a nation of its language, or to demean it, is to deprive it of its sole immortal possession transmitted from parents to children.

'The ignorant child', he wrote further (Herder 1968:45),

listens with curiosity to the tales, which flow into his mind like his mother's milk, like choice wine of his father, and form its nutriment. They seem to him to explain what he has seen: to the youth they account for the way of life of his tribe, and stamp the renown of his ancestors: the man they introduce to the employment suited to his nation and climate, and thus they become inseparable from his whole life.

In Herder's conception, culture and tradition (closely allied concepts) found their highest and truest expression in the poetry of the Volk, its folksong and folklore, which stand as 'the archives of a nationality', 'the imprints of [its] soul' (Wilson 1973:826). From its folklore, 'one can learn the way of thought of a people, its language of feeling' (quoted in Simpson 1921:15, translation mine). Language, culture, and folklore are thus inextricably bound up with one another, and the investigation of any one of them takes place within the larger unified frame of reference constituted by the interrelationships obtaining among all three. Herder's legacy is traceable through many separate lines of inquiry in linguistics, anthropology, and folklore-the nature of the speech community, collective representation, national character, the prefix folk in folklore itself--but it is also, at a remove of two hundred years, one of the forces that makes meaningful a conference on linguistics and anthropology today.

Among the principal figures who have transmitted the Herderian tradition to our own generation, Franz Boas stands as one of the most influential. Boas expressed the conviction on numerous occasions that in linguistics lay the potential for the solution of general anthropological problems. 
It appears that from practical, as well as from theoretical points of view, the study of language must be considered as one of the most important branches of ethnological study, because, on the one hand, a thorough insight into ethnology can not be gained without practical knowledge of language, and, on the other hand, the fumdamental concepts illustrated by human languages are not distinct in kind from ethnological phenomena; and because, furthermore, the peculiar characteristics of languages are clearly reflected in the views and customs of the peoples of the world (Boas 1966[1911]:69).

Instrumental to Boas' linguistic studies, however, were the materials and methods of folklore, as seen in his dedicated concern as fieldworker, editor, and teacher with folkloric texts as linguistic documents and ethnographic data, and his adaptation of analytical perspectives on the diffusion of folktales to the study of language and to culture (Hymes 1961).

If I may be permitted the invocation of one more ancestor figure, as an exemplar of the spirit in which language, culture, and folklore constitute a unitary whole, I would mention Sapir, but for whose inspiring model I might myself be in a more profitable line of work today. His 'Abnormal Types of Speech in Nootka' (1963[1915]), for all the dryness of its title, demonstrates the fertility of his unified vision. In that essay, what is introduced as 'an interesting linguistic and cultural problem', namely, 'the use in speech of various devices implying something in regard to the status, sex, age, or other characteristics of the speaker, person addressed, or person spoken to, without any direct statement as to such characteristics' (179), becomes a wide-ranging exploration of a type of stylistic resource for speaking that illuminates and is illuminated by the analysis of verbal art forms including myths, songs, and ritual speech.

The principal factor contributing to the undoing of the unified Herderian perspective on language, culture, and folklore was the assertion and pursuit of disciplinary autonomy on the part of linguistics. As linguistics established itself as a discipline in its own right, defining its proper subject matter as the langue half of the Saussurian dichotomy, there emerged as well a distinctively linguistic perspective on verbal art. Cultural anthropologists, on the other hand, tended for the most part to pursue a different line of inquiry vis-a-vis folklore, concentrating on the interrelationship between folklore and culture. Each retained its interest in folklore materials, but dropped out, according to its special disciplinary concerns, either the linguistic or cultural segment of the formerly unified field.

Thus in linguistics, largely under the influence of the Russian formalists and the Prague School, the focus of interest and analysis 
was quite expectedly on the patterning of formal linguistic features in texts, sometimes including folkloric texts. The frame of reference for such linguistically oriented approaches to verbal art is a conception of language which gives primacy, either tacitly or explicitly, to the referential function of language, the propositional content of utterances. The nature of verbal art, or poetic language, is then viewed as derivative, in some sense, from language in its referential mode. It may be seen, for example, in terms of deviation from the rules of the grammar, in fact as lying outside the range of the grammar, as exemplified in Katz's treatment of semi-sentences (1964). A related notion is labeled by the term 'foregrounding', after the Prague School, the maximized 'use of the devices of the language in such a way that this use itself attracts attention and is perceived as uncommon* (Havránek 1964[1932]:10). In some formulations, poetic language is viewed not so much in terms of the grammar, but in contrast to--rather, in violation of--the norms of 'everyday', 'ordinary' language, as in Leech's Linguistic Guide to English Poetry (1969). Nor is it necessary to state the nature of poetic language in terms of deviation or violation; some would identify it in terms of the 'multiplicity of additional formal laws restricting the poet' $s$ free choice of expressions' (Fónagy 1965:72; emphasis in original). In sum, 'many features which, in various combinations, are characteristic of poetic language, [are] explained by two main principles: secondary structures superimposed on language, and deviations from normal structures' (Bierwisch 1971:91).

This is not the place to develop an extended analysis or critique of modern linguistic approaches to verbal art; others have performed these tasks quite effectively (e.g. Fish 1973, Hymes 1973, Stankiewicz 1974). My purpose at this point is to indicate the main thrust of linguistic perspectives on verbal art in recent decades as these developed out of linguistics itself.

The anthropological engagement with verbal art took a different direction, maintaining the Herderian view of folklore as the collective expression of a people, a projection of their culture, and investigating the relationship between the two. The direction was set by Boas' explorations of folklore as a reflection of culture, rooted in the play of imagination with the events of human life . . particularly those that stir the emotions of the people' (1916:880), complemented by Malinowski's conception of myth and other folklore forms as vehicles for expressing the ideological component, or charter, of institutions. While notions of precisely how and why folklore 'reflects' culture, or validates the social structure, were the subject of scholarly debate and development, the basic empirical, analytical, and presentational strategies remained much the same throughout: collect cultural data through the practice of ethnography (observation and interview) and 
record folkloric materials in the form of texts. Then, to elucidate the relationship between folklore and culture, compare or conflate the two bodies of data. If the ethnographic component is of primary presentational concern, introduce an additional, complementary dimension by showing how cultural or social factors are reflected or validated in the expressive forms of folklore. If the folklore is the focus of interest, present sufficient ethnographic information, either in the form of an introductory sketch as a preface to the texts, or as an extended exegesis of specific items. Only occasionally, despite Malinowski's stricture (1926:24) that 'the whole nature of the performance, the voice and the mimicry, the stimulus and the response of the audience mean as much to the natives as the text; and the sociologist should take his cue from the natives', is attention given to the immediate circumstances of folkloric performance; when the dominant conception of folklore is as collective representation, the expression of society as a whole, the circumstances of performance, while perhaps colorful, are not seen to be of much analytical importance.

It is precisely these circumstances of performance, however, that have emerged in the last few years as a focal point around which a reintegration of linguistics, anthropology, and folklore may be effected. The conceptual framework for this reintegration is provided by the ethnography of speaking (Hymes 1962: Gumperz and Hymes 1964, 1972; Bauman and Sherzer 1974, 1975; Sherzer 1977). The task of the ethnographer of speaking is to identify and analyze the dynamic interrelationships among the linguistic, social, and cultural resources available to the members of a speech community for the conduct of speaking, and the competence of individual members of the community, as these are manifested in what Harold Garfinkel called at an earlier Georgetown University Round Table 'speaking praxis', toward the formulation of descriptive theories of speaking as cultural systems in particular societies. In formulating the conceptual framework and program for the ethnography of speaking, Dell Hymes (1974:59) has identified his perspective quite explicitly as deriving in part from the Herderian legacy; it is founded on a synthesis which draws in equal measure from linguistics, anthropology, and literature.

It is only natural that verbal art has figured prominently among the concerns of the ethnography of speaking, since to participant and analyst alike the verbal art forms of a culture and the situations in which they are concentrated represent the most attractive, conspicuous, and powerful sectors of the speech activity of any community. At least one critic has suggested, in fact, that attention to verbal art occupies a disproportionately large place in published work on the ethnography of speaking, when measured against the larger general charter of the field (Bloch 1976:233). He does not, of course, argue 
against the importance or interest of this range of speech activity. Rather, his very legitimate concern is that the study of more mundane forms of speaking should receive more attention than they have been accorded. Freely conceding the validity of this argument, one may nevertheless point out that ethnographic studies of verbal art forms have highlighted and contributed to our understanding of certain factors with rather broad linguistic and anthropological relevance, such as the nature of performance (contra the Chomskian tendency to dismiss it as lying outside the proper range of linguistic concern), the generic organization of speaking in social interaction (Hymes 1972), and the emergent nature of situated utterances. All this notwithstanding, from the folklorist's point of view, the ethnography of speaking has had an enormously stimulating and illuminating effect, in providing a conceptual and methodological framework that comprehends symbolic and expressive means, artistic act, esthetic response, and situational and cultural context within one unified frame of reference.

Much of the work in folklore informed by the ethnography of speaking has centered around the concept of performance. At first, the term 'performance' was utilized principally as a means of directing attention away from the traditional folkloristic preoccupation with texts, the things of folklore, to folklore as action, the doing of folklore. This usage of performance was helpful in fostering the desired reorientation, because it conveyed the dual sense of performance as artistic action and performance as artistic event, both of which were central to the performance approach to folklore (Paredes and Bauman 1972). Before long, however, it became clear that a more rigorous conception of performance was called for, defining performance as a mode of verbal communication, a way of speaking. In an attempt to contribute toward the development of such a conception, I have proposed the following preliminary formulation (Bauman 1975a: 293):

Performance as a mode of spoken verbal communication consists in the assumption of responsibility to an audience for a display of communicative competence. This competence rests on the knowledge and ability to speak in socially appropriate ways. Performance involves on the part of the performer an assumption of accountability to an audience for the way in which communication is carried out, above and beyond its referential content. From the point of view of the audience, the act of expression on the part of the performer is thus marked as subject to evaluation for the way it is done, for the relative skill and effectiveness of the performer's display of competence. Additionally, it is marked as available for the enhancement of experience, through the present enjoyment 
of the intrinsic qualities of the act of expression itself. Performance thus calls forth special attention to and heightened awareness of the act of expression, and gives license to the audience to regard the act of expression and the performer with special intensity.

Thus conceived, performance is a mode of language use, a way of speaking. The implication of such a concept for a theory of verbal art is this: it is no longer necessary to begin with artful texts, identified on independent formal grounds and then reinjected into situations of use, in order to conceptualize verbal art in communicative terms. Rather, in terms of the approach being developed here, performance becomes constitutive of the domain of verbal art as spoken communication.

This much is theory--what of practice? The ethnography of speaking has begun to move beyond its first programmatic state in the area of folklore, as in others, and this is a useful occasion on which to indicate some of the linguistically relevant substantive directions in which it has moved, and to suggest some of the lines of inquiry that are likely to be pursued in the near future. Much of what follows in this next section is framed in comparativist terms, because the developing capacity for generalization is the clearest sign that the field is approaching a degree of maturity. Since the time of the Grimms, the most persistent comparativist tradition in folklore has centered on textual variation as it relates to diffusion and the tracing of origins. Conceptually and methodologically, this tradition derives largely from nineteenth century Indo-Europeanist philology. The ethnography of speaking, however, has opened up new possibilities for comparative research.

To begin with a relatively modest but clearly indicative example, consider the phenomenon of canonical parallelism, the pervasive repetition, with systematic variation, of phonic, grammatical, and semantic structures, that has been identified by Jakobson $(1960,1966$, 1968 ) as quintessential to much of the world's oral poetry. Jakobson himself has provided us with a series of linguistic analyses of parallelism in various specific traditions that serve as a model and standard for all succeeding work. However, the potential contribution of ethnographic studies to the exploration of parallelism beyond the level of formal patterning of linguistic features in texts is already apparent, in revealing the relationship between the resources for and patterning of parallelistic constructions and other sociocultural patterns and structures. For example, Joel Sherzer has analyzed an elaborate ethnobotanical taxonomy of hot pepper from the San Blas Cuna, of a kind that might well be of interest to an ethnobotanist 
(Sherzer 1974). Sherzer's interest, however, is in the fact that this taxonomy constitutes the structural framework for a curing chant, in which it is projected, taxon by taxon, onto a parallelistic verse pattern. The use of the taxonomy in the construction of the chant allows for the lengthening of the overall performance, which is valued by the Cuna as both medically effective and esthetically pleasing as a form of verbal art.

Gary Gossen's contrasting analysis (1974) of parallelism in Chamula reveals that the proliferation of increasing numbers of dyadic sets on the same theme, going beyond the individual couplet, becomes for the Chamula speaker a means of expressing increasing amounts of metaphorical heat, and thus marking a finely graded scale of formality and symbolic significance. The verbal structures emergent in performance may thus be made continuously consistent with the speaker's feelings, the symbolic significance of his message, and the demands of the context, through the relative proliferation of parallel couplets.

To cite a third example, James Fox (1974) has shown that on the Indonesian Island of Roti, individuals speak the particular dialect of their own local area in everyday, colloquial speech, but utilize the complex of dialect differences on the island as the primary resource in the construction of parallelistic structures characteristic of formal, ritual speech.

Further examples could be adduced, but these three should suffice to make the point that the ethnographic investigation of verbal art can add an additional powerful dimension to the insights of linguistic analysis by illuminating the resources employed in the production of an artistic utterance, and the relationship between the formal patterns that characterize that utterance and broader sociocultural patterns and structures.

Perhaps the broadest problem that confronts the ethnographer of verbal art is the nature and extent of the domain of verbal art within particular societies. In place of the naive relativism which simply asserts that every group has its folklore, ethnographic investigation is providing a fund of data on which to base comparative studies of the culture-specific patterns and functions that characterize the realm of verbal art in different societies (cf. Hymes 1966). Just as speaking itself as a cultural system varies from society to society, so too does the nature and extent of the realm of verbal art. For the St. Vincentians, for example, artistic verbal performance pervades a very wide spectrum of speech activity, ranging from oratory to storytelling, to gossip, even to speaking with a speech impediment. Instead, the seventeenth century Quakers, because of basic ambivalent attitudes toward speaking in general, restricted performance to a very narrow range of forms and activities centering around 
religious worship (Abrahams 1970; Abrahams and Bauman 1971; Bauman 1974, 1975b). Through comparison of the ethnographic accounts now accumulating in the literature, we can begin to develop some generalizations about the variable role of artistic expression in human social life. We are even at the point where it is beginning to be possible to investigate such matters in an areal perspective. We have, for example, the ethnographic accounts of Gossen for the Chamula (1972, 1974a, 1974b), Bricker for the Zinacanteco (1974), and Stross for the Tenejapa Tzeltal (1974) (closely related Mayan-speaking groups in the state of Chiapas), all of which attend in a linguistically sensitive way to the place of verbal art within the larger context of speaking in general, and as it relates to general cultural patterning principles.

It should be admitted that the data base constituted by the ethnographic literature on.verbal art, like that of the ethnography of speaking in general, is somewhat skewed, because of the tendency of ethnographers of speaking to devote their attention to societies in which speaking is a cultural focus and in which there is a relatively rịch sphere of verbal art. Studies of societies in which speaking is the focus of less self-conscious attention and in which the domain of verbal art is less salient and extensive are clearly called for in order to redress this imbalance (cf. Bauman 1972, 1974).

There is a related dimension of the comparative problem that represents an exciting, if as yet unfulfilled area for investigation. In a laudable and generally productive effort to get away from the persistent notion that the only province of folklore is peasants and primitives, folklorists have increasingly asserted that any kind of groupness can constitute the social base of folklore (Dundes 1965:2). The difficulty here, once again, lies in the basically naive relativism of this view, for there have been almost no systematic and anthropologically informed attempts to relate the generic, formal, or social interactional organization of verbal art forms to specific kinds of social structures, since Durkheim's correlation of proverbs with mechanically solidary societies (Durkheim 1966[1893]:170-171). Perhaps the most significant recent exception is the cross-cultural study by Roberts and Forman (1972) of riddling as an expressive model of interrogation, in which they reveal an association between riddling and high political integration, and more than one level of jurisdictional hierarchy beyond the local community, among other variables.

In recent years, there have been a few signs of interest on the part of linguistic anthropologists and sociolinguists in the general problem of the relationship between social structure and language or speaking, but the general line of inquiry has not been widely pursued (cf. Gumperz 1962; Swadesh 1971; Habermas 1971; Hymes 1974). 
The work in this area that seems to me to bear the most immediate relevance and applicability to social structure and verbal art is that of Basil Bernstein. Bernstein's work is rich, complex, and controversial, though the most controversial aspects are not implicated in the matters to be discussed here. To my knowledge, no student of verbal art has made any direct application of his insights to the substantive study of specific forms, except for Bernstein himself in his review of the Opies' Lore and Language of Schoolchildren (1971a[1960]). Consequently, and because of space limitations, I can only suggest in a hypothetical way what kinds of applications might be made.

Consider Bernstein's concept (1971b:169) of restricted code, a speech style that is characterized by relative simplification and rigidity in syntax; a narrow range of vocabulary across certain semantic fields; relative lack of verbal elaboration of the speaker's intentions; speed; fluency; reduced articulatory cues; and discontinuous, condensed, and local meanings, involving a low level of syntactic and vocabulary selection where the 'bow' rather than the 'what' of the communication is important. Any folklorist familiar with the work of Albert Lord on Yugoslav oral epic poetry (1960), or Emeneau's account of Toda oral poetry (1958) will recognize the close, almost point-by-point correspondence between the form, style, and performance of these verbal art forms and the characteristics of the restricted code. The following, for example, is taken from Emeneau's description:

Every theme in Toda culture and every detail of the working out of every theme have been provided with one or several set patterns of words and turns of phrase for use in song . . . a limited and tightly closed technique (1958:318).

The Toda technique is of extreme interest in this matter of fixed phraseology, since it seems to and actually does operate almost completely with formulaic language, as does no other oral composition that we know of so far. The corpus that I am operating with consists of roughly 10,000 or 11,000 couplets, i. e., two dimensional structures, and I doubt whether in this sizeable body of material there is found any paired song unit which does not recur at least once. Most paired units recur again and again (1958:321).

We must come to the conclusion that the Todas in their poetry aim neither at universality nor at the poet's individual expression of his own psyche. The technique, as it has been evolved, has as its aim a generalization of all that makes the Todas Todas (1958:324). 
This simple juxtaposition of Bernstein and Emeneau will suffice, I think, to suggest how Bernstein's ideas might provide a base on which to draw together for investigation speech styles, verbal art forms, social structures, and systems of social relations. The traditional, highly marked esthetic genres that have been of central interest to folklorists partake most heavily of the features of restricted code; the extent to which various forms display the features of the contrasting elaborated code and the social structural implications of this are no less amenable to controlled investigation. The point is that Bernstein supplies a framework within which to investigate such fundamental problems as the social structures that may engender specific verbal art forms, those which subsequently sustain their currency or contribute to their demise, and the structures of social relations that foster or inhibit their performance. Mary Douglas (1973) has begun to explore the implications of Bernstein's work for the study of other symbolic forms like ritual; the time seems more than opportune for investigations of verbal art in the terms he suggests as well.

Bernstein, in his review of the Opies' work referred to earlier, pointed out how the peer group folklore repertoire of children constitutes an almost pure example of 'restricted code'. Bernstein's review was the first major statement of the sociolinguistic importance of children's folklore, and though not itself developmentally oriented, it converged with Hymes' work on the acquisition of communicative competence in a period of burgeoning interest in language acquisition, to stimulate interest in the relationship between language acquisition and children's folklore. The first extended exploration of this relationship was the product of the collaboration of a folklorist and a linguist, written some years ago, but only recently published (Sanches and Kirshenblatt-Gimblett 1976). The paper employs a somewhat oversimplified stepwise model of language acquisition, in demonstrating that 'children in their speech play . . . focus on components of language in which they are already competent' (Sanches and KirshenblattGimblett 1976:13), but it must be credited for the innovativeness of its conception and the careful formal analyses of the range of children's folklore forms it contains. It was certainly a powerful stimulus to my own research in this area.

I would like to proceed now to a more extended account of this research, to serve as a substantive counter to the summary and programmatic discussion I have presented thus far, and to exemplify in somewhat more depth the kind of integration of linguistic, anthropological, and folkloric concerns that may occur under the stimulus of the ethnography of speaking.

As I mentioned earlier, I have been working for some time on a conception of artistic verbal performance as the assumption of responsibility to an audience for a display of communicative 


\section{4 / RICHARD BAUMAN}

competence, a willingness to be accountable to and evaluated by the audience for the relative skill and effectiveness displayed in the act of expression, the way in which the communication is carried out, above and beyond its referential content (Bauman 1975a). The notion of communicative competence is central here, the knowledge and ability to speak in socially appropriate ways; this is not simply a matter of using correct grammar but of operating appropriately within a community's system of norms of interaction and interpretation (Hymes 1971a). An interest in how children acquire and develop this communicative competence, and how they develop artistic verbal performance skills as well, led me to my work in children's verbal folklore, that is, the traditional, formalized speech play and verbal art forms that are engaged in and maintained by the children themselves.

Thus far, I have concentrated my attention on five-to-eight yearold children. Five is the age when children generally enter into the peer group and begin to participate in its folklore; by eight, they are quite competent in a range of folklore and related forms, including those I have termed 'solicitational routines'. These forms, familiar to folklorists--and parents--as riddles, knock-knocks, catches, and related verbal routines, are the subject of these remarks. 2

I have labeled these forms 'solicitational routines' because my perspective is basically social interactional. I am interested in the social business that gets done in the doing of these routines, and the unifying factor that brings them all together is solicitation. The notion of 'solicitation' derives from the work in classroom discourse of Bellack and his colleagues (1966), and Sinclair and Coulthard (1975). In the terms employed here, a solicitation is a speech act, the function of which is to elicit a verbal or physical (kinesic) response. Solicitations of the former type are termed elicitations, while solicitations of the latter type are termed directives. I am dealing here solely with solicitational routines that build upon elicitation, though there are also ones that build upon directives. Following Hymes (1971b:58), I use the term 'routine' to designate sequential organizations beyond the sentence, either as activities of one person, or as the interaction of two or more persons. Ours are all of the latter type. Solicitational routines are distinguished by the fact that they incorporate within their formal structure a dyadic social interactional exchange consisting of at least one solicitation plus a response.

Solicitational routines are small forms, largely ignored or considered as trivial or corny by most adults. Why bother with them? If the intensity of the children's own interest in them is not enough, one might suggest that solicitational routines are expressive models (Roberts and Forman 1972) of a kind of interrogation and interaction 
that is ubiquitous in the school setting, and that competence in solicitation is fundamental to a speaker's ability to manipulate his communicative environment--to take the lead in interaction, to get information, to provoke a desired response. Moreover, insofar as they represent performance forms for the children, and are saturated with figurative language, homonymy, punning, and other forms of ambiguity, solicitational routines represent an early and selfmotivated form of folkloric involvement for the children who do them. They are the stuff of verbal art. I hope in this brief summary to suggest how interesting and complex they really are; I want principally to suggest in a relatively broad and general way the nature of part of the repertoire, some general developmental tendencies, and how these relate to the development of communicative competence. I should add that although we have collected data on solicitational routines from black, white, and Mexican-American children, this brief paper outlines our findings solely with regard to the white children (McDowell 1974 reports on aspects of the research on Mexican-American children).

Our first interest is in the five-year-old child, just entering the peer group and coming into contact with and exposure to other children engaging in verbal folklore. Most children of this age are exposed either directly or secondarily to other children of a range of ages: siblings, schoolmates, playmates, neighbors, cousins, etc. Among the forms current in the child's communicative environment are traditional forms of solicitational routines. The five-year-old child is stimulated to engage in like activity by his desire to belong to the peer group. What happens?

It is clear that he does not start right off performing the traditional items correctly. The acquisition of this ability takes time and requires a process of development. This process, which begins around five, is essentially fully developed in the eight-year-old child. Space permits me only to trace the stages of this process with regard to two contrasting forms, riddles and knock-knocks. Again, the emphasis will be on communicative aspects and implications; the cognitive aspects are equally fascinating and complex, but there has been some good work done on them already (Park 1972, Shultz 1974, SuttonSmith 1976, Whitt and Prentice 1977).

In the traditional riddles in the repertoire of the children we worked with, the elicitations are all in question form. 3 As traditional items, the elicitations are essentially fixed in wording, ready-made utterances. Moreover, the elicitations are characterized by what riddle scholars have called a block element, an element designed to mislead or confuse the person to whom the riddle is posed. Competent performance of a traditional riddle requires the child to do the elicitation correctly and also to be prepared to give the correct answer if the other person 
does not know or cannot guess it. With competently performed traditional riddles as done by eight-year-olds as our frame of reference, let us consider the efforts of five-year-olds.

The first things five-year-olds tend to do toward riddling are what we call descriptive routines. In these descriptive routines, the elicitation is in the form of a question, but the question is not readymade, traditional, but rather newly coined by the child himself, following one of the syntactic patterns characteristic of the traditional riddles. In its most common form, the descriptive routine calls upon the other child to identify an object by describing it in the elicitation in terms of one or more (usually more) of its salient attributes. For example, 'What's big and has black and white stripes?' ('A zebra'.) Note that there is no block element here; the description is meant to be accurate, and it is often sufficient for the object to be guessed correctly. What is happening here is that the five-year-old child who is posing a descriptive routine is picking up on aspects of the formal and social interactional structure of riddles, their routinized nature, but is not yet ready to comprehend or perform riddles in all their complexity. What kind of competence does the descriptive routine demonstrate?

Clearly, the child does comprehend the basic structure of the riddle routine: elicitation in the form of a question, using a syntactic frame characteristic of traditional riddles. He also understands that the routine involves and legitimizes the asking of a question to which the questioner already knows the answer; this is not questioning for the purpose of getting information. Moreover, the child recognizes and exploits the social interactional power that accrues to a questioner. To ask a question is to exert control over another's communicative behavior, because a question is understood to call for an answer (cf. Schegloff and Sacks 1974[1973]: 238-245). There is a further status-enhancing aspect inherent in the posing of a solicitational routine, including a descriptive routine, namely, that it is a vehicle for the display of knowledge as well as communicative competence. However, there does tend to be a collaborative aspect to descriptive routines; they are characteristically marked by a willingness on the part of the poser for the answer to be guessed. In these terms, descriptive routines are largely about the encoding and conveying of information in communicatively effective ways.

At the next level, beyond the straight descriptive routines, the power and control aspects of the solicitational routine come to the fore, in what we call potent elicitations. For example, 'What color is blood?' 'Red'. 'Nope, it's blue and black'. At this stage, the child is picking up on the fact that true riddles are puzzling questions, but because he cannot yet understand the ambiguities in true riddles, he sees them as puzzling questions with arbitrary answers, 
to use Sutton-Smith's phrase (1976). However, he is also exploiting the fact that doing a solicitational routine allows the poser always to be right, whatever answer he gives.

Because of the nature of the potent elicitations, they are not much reinforced by others. Having no chance to guess them correctly, and seeing the answers as making no sense once they are provided by the poser, those to whom the potent elicitations are posed are not much motivated to sustain the interaction. This helps to prompt a shift to potent elicitations of another kind. For example, "What do you call people?' 'I don't know, what?' 'Doodoo people.'

Here the answer is equally arbitrary, from an informational point of view, but these potent elicitations pick up on a functional potential inherent in solicitational routines, namely, the possibility of using them to entertain. Potent elicitations of this latter type exploit the fascination of young children with the taboo subjects of sexuality and the scatological. Using routines of this kind, the child can still maintain control over the interaction, but he can also elicit and hold the participative energy of others, by entertaining them, making them laugh.

Interestingly, these taboo potent elicitations drop way off in the performance of children six years and older. Descriptive routines continue, but develop in two ways. One trend is for the descriptions to get more extended, as in 'What is red . . . and here's a eagle and a snake and has . . . white and then has a green? It's red and a green thing and then on the white thing, there's a little snake and a eagle and then on ... . there's a green stripe. What is it?' This was posed by a six-year-old girl to a classmate following a consideration in school of the Mexican flag. The boy to whom she posed it answered it correctly. In descriptive routines like this, the child is moving toward more complete and effective encoding of descriptive information by stringing together more descriptive elements in the elicitiation.

Other descriptive routines take a different turn. They pick up an element of potency, by making the description less effective, introducing a note of ambiguity, thus bringing them closer to true riddles. For example, 'What is sometimes black and red?' 'I don't know.' 'You don't know what a flower is? I mean a rose.' Here, the description is ambiguous, insufficient to allow for the referent to be guessed easily, and the hearer's failure to do so makes it possible for the poser of the question to give extra emphasis to the other child's incompetence and, by implication, her own superior knowledge.

During the seventh year, a major shift occurs in the child's competence in solicitational routines. Remember that all the forms I have been discussing thus far involve newly coined elicitations, within the general framework of the solicitational routine. During the seventh year, however, a recognition of the riddle as a traditional form 
emerges, the awareness that there exists a stock of ready-made solicitational routines to be used. Most likely, this comes about as a result of the children's having heard the same items a number of times from their older peers. With the onset of this awareness, children begin to undertake to perform the traditional items in place of coining their own. Thus the standard of reference for fashioning and evaluating a performance shifts from coining elicitations according to the formal requirements of the routines to the correct, accurate doing of ready-made ones. The display of competence is now a matter of being able to show that you know and can do items that belong to the repertoire of the group (cf. Bernstein 1971a[1960]). The routines are learned and memorized as fixed forms, including the fixed answer as well.

The importance of correct doing is pointed up, paradoxically, by the number of flawed attempts that occur in the solicitational routines of six-year-old children. Even among seven-year-olds these flawed attempts remain at around $30 \%$. For example, 'What did the mean frog say to the nice frog ?' 'What?' 'I hope you crick' (instead of 'croak'). What is happening here is that the children's recognition of the ready-madeness of the item outstrips their full comprehension of the riddles' ambiguities, homonymy, reversals, inversions, etc.; riddles require more of them cognitively than they are capable of achieving. Without full comprehension, the child relies on the rote memorization of apparently arbitrarily linked elicitations and responses. Thus, imperfect learning, flawed transmission, faulty memory, or misunderstanding can make for flawed performance, but the impulse is clearly there to reproduce the item correctly in ready-made form. Flawed performance notwithstanding, though, social interactional power and control still accrue to the performer of the routine.

The final step in the developmental progression is the correct performance of traditional riddles. Such performances become increasingly prevalent during the eighth year, and by the time the children reach their ninth year, the incidence of pre-riddles, of the kinds I have discussed, is down below 5\%. The new element that enters in here, above and beyond the derivation of social interactional power and control and the opportunity to display one's knowledge and communicative ability by the correct doing of materials from the group's collective repertoire, is the derivation of enjoyment from playing with the linguistic wrinkles in the language that are at the core of true riddles. Homonymy, punning, metaphor, and other forms of ambiguity are the essence of these traditional riddles, and the older children are finally recognizing them for what they are.

Let us now consider knock-knocks, which stand in some degree of contrast with riddles. The treatment of this form will be more 
summary, aimed principally at highlighting the points of contrast between the two different forms of solicitational routine in the performance of five- to eight-year-old children.

The knock-knock form differs from the riddle in that it represents a small formalized five-line dialogue, a little drama, with some strongly fixed and constant elements that are readily apparent. 'Knock, knock.' 'Who's there?' 'Olive.' 'Olive who?' 'Olive (=I love) you.' Lines one and two, the elicitational summons (knockknock) and the response ('Who's there?'), are constants. Line three is the first variable element, a response to the 'Who's there?' of line two. Line four, while not constant, has a clear and simple production rule: line three plus 'Who?' Finally, line five has a number of clearly specifiable production rules. The basic form always involves a transformation of line three plus other elements, but there are several ways of accomplishing this. There is, in effect, considerable variation in line five from one item to another.

Over all--unlike riddles which first appear to young children as real elicitations, though with routinized aspects--knock-knocks are readily apparent as set off from everyday speech, as framed minidramas. They cannot be anything but speech play forms, and are unmistakable for anything else. Every child in our population from whom we collected knock-knocks, from the very youngest five-yearold, performed at least one routine with the frame correctly done. So, unlike riddles, there is a thrust toward correct doing in the performance of knock-kmocks right from the start on the part of both participants. The development that takes place has altogether to do with the two variable lines, three and five.

The developmental process again reflects the fact that the fiveyear-old child does not have the capacity to comprehend the linguistic and cognitive subtleties of true knock-knocks. Nor does he recognize whole routines as traditional. In consequence, he starts out generating his own third and fifth lines. For our purposes, we may identify three general developmental stages in the acquisition of competence in the doing of knock-knocks.

To get at the first of these, it is necessary to be aware that in the competent doing of traditional knock-knocks, the entire text is known by the initiator all the way through to the end. This being so, line five is the frame of reference for line three, its source. Line three is known to be a part of a larger unit, already in view. In the first stage of knock-knocks, however, this is not the case. What happens is this. The initiator opens with his elicitational summons, 'knockkmock.' He gets back another elicitation, 'Who's there?' His response to 'who's there?' is essentially spontaneous, and attends only to that elicitation, not to what needs to be accomplished in line five. The responses are either proper names or nouns naming objects. 
The proper names are overwhelmingly drawn from the immediate situational environment. This use of one's own or a peer's name, incidentally, is an indication that despite the children's recognition of knock-knocks as framed routines, they tend to construct line three as if it were a real situation involving presenting oneself at the door. Line four builds on line three: line three (noun) plus 'who?' Line five again appears to be a relatively spontaneous response to the elicitation in line four. In the earliest forms, line five simply adds a second proper name or object to the one given in line three, also drawn from the situational environment, but otherwise semantically unrelated to the first one. For example: 'Knock, knock.' 'Who's there?' 'Um ... Laurel' (own name). 'Laurel who?' 'Laurel Erin' (name of present peer). A more developed form involves the provision of further information concerning the person or object named in line three. 'Knock-knock, 'Who's there?' 'Sun.' 'Sun who?' 'Sun up.'

The second stage we would identify represents an advance over the first in that here the initiator does have in view from the beginning the complete unit to be given in line five, and constructs line three by taking the first segment of the larger unit. This may be done by breaking line five intralexically, as in, 'Knock-knock.' 'Who's there?' 'Dra-.' 'Dra- who?' 'Dracula.' Or, it may be accomplished by breaking line five interlexically: 'Knock knock.' 'Who's there?' 'Donny.' 'Donny who?' 'Donny Osmond.' These are still newly coined knock-knocks; however, the initiator thinks up the variable element represented by line five himself.

Finally, in the third stage, we get complete ready-made traditional knock-knocks, in which the child repeats, or attempts to repeat, a ready-made routine verbatim. As with riddles, the first attempts are flawed, as in 'Knock-knock.' 'Who's there?' 'Rita.' 'Rita who?' 'Rita I need another kiss.' This brings together in a garbled way elements from two traditional knock-knocks: 'Rita (= read a) good book lately,' and 'Anita (= I need a) -nother kiss, baby.' And again, as with riddles, the final stage is the correct performance of traditional knock-knocks.

What are the implications of this developmental process? Some aspects of the development, of course, mirror the development of riddling competence, discussed earlier, but a number of points having to do specifically with knock-knocks may be suggested. First, there is a concern from the beginning with the correct doing of the whole item. The control which accrues to the initiator by virtue of beginning the routine with a known framework is mitigated in the newly coined knock-knocks by his spontaneous need to come up with lines three and five; to a degree, the elicitations in lines two and four exert some reverse control over the initiator. However, as soon as the whole 
of line five is prepared in advance, the initiator is in complete control of the entire routine.

In the transition from stage one to stage two, the focus of effort shifts from the framework of the routine to language as object. In order to coin a knock-knock in which line three builds toward and is an eventual part of line five, there must be a conception of an utterance as made up of parts--morphophonological or syntactic--that can be separated and recombined, objectified and transformed.

The transition from stage two to stage three shifts the focus to ambiguity in language, the transferability of meaning. Here, too, language is an object, but a much more complex one than in the preceding type.

In all knock-knocks, of every type, it is worth pointing out that the initiator must take the role of the other in a very pronounced way--to have the entire routine framework, and, later, the entire text, in view from the beginning, and to know that by saying 'knock-knock', he is setting in train a process involving himself and another person that will arrive ultimately at a predetermined point. This amounts to a rather complex sociolinguistic and social interactional operation, an exercise in the coordination of one's communication with another.

The very act of solicitation itself represents a basic means of manipulating one's communicative environment, using language to elicit a desired response from another. Performance of solicitational routines involves the child in such basic communicative business as getting and giving information, exercising social interactional control, getting into communicative and interactional synchrony with others, and exercising memory. In addition, the objectification of language that takes place in the doing of solicitational routines may have much to do with a child's preparedness for such basic educational matters as reading and writing (Cazden 1975). Not least important is the fact that solicitational routines focus attention on figurative language, linguistic ambiguity, and framing--some of the basic stuff of verbal art. To a very real extent, solicitational routines are among the first forms of children's social verbal art within the peer group.

This presentation has ranged over a wide spectrum of problems and concerns, in an attempt to convey some indication of the place that investigations of verbal art can occupy in modern linguistic anthropology. I think that place is an important one; the problems and concerns I have outlined are not trivial, nor are they in any way tangential to the broadest concerns of any of the three disciplines involved, though they may be framed in far more limited, controlled, and substantive terms than one finds in the sweeping historical and philosophical formulations of Herder with which I began. Nevertheless, this is the point on which I want to conclude, as I began: the 
reaffirmation of our collective birthright through the unified study of linguistics, anthropology, and verbal art.

\section{NOTES}

1. Since I employ the terms folklore and verbal art almost interchangeably in this essay, I should note that many other cultural forms and practices in addition to verbal art have been studied under the name of folklore, but verbal art has always been close to the center of the folklorist's concern. For folklorists of a linguistic or anthropological persuasion, verbal art has been the central concern, and it is within this context that I employ the terms as equivalent in this paper.

2. The discussion that follows is a preliminary report on research conducted from 1973 to 1976 in conjunction with the Early Elementary Division of the Southwest Educational Development Laboratory, Austin, Texas, under the sponsorship of the National Institute of Education. Part of this research effort included the collection of solicitational routines from 54 Anglo boys and 54 Anglo girls, in the 5-8 age range, in Austin, Texas. Margaret Brady, Andrea Meditch, and Dorothy Stroman all contributed to the data gathering and analysis on which this discussion is based.

3. This is not meant to apply to all riddles, simply to those in our corpus.

\section{REFERENCES}

Abrahams, Roger D. 1970. A performance-centered approach to gossip. Man 5:290-301.

Abrahams, Roger D., and Richard Bauman. 1971. Sense and nonsense in St. Vincent. American Anthropologist 73:762-772. Barnard, F. M. 1965. Herder's social and political thought. Oxford: Clarendon Press.

Bauman, Richard. 1972. The La Have Island general store: Sociability and verbal art in a Nova Scotia community. Journal of American Folklore 85:330-343.

Bauman, Richard. 1974. Speaking in the light: The role of the Quaker minister. In: Explorations in the ethnography of speaking. Edited by Richard Bauman and Joel Sherzer. New York: Cambridge.

Bauman, Richard. 1975a. Verbal art as performance. American Anthropologist 77:290-311.

Bauman, Richard. 1975b. Quaker folk linguistics and folklore. In: Folklore: Communication and performance. Edited by Dan BenAmos and Kenneth S. Goldstein. The Hague: Mouton. 
Bauman, Richard, and Joel Sherzer, eds. 1974. Explorations in the ethnography of speaking. New York: Cambridge.

Bauman, Richard, and Joel Sherzer. 1975. The ethnography of speaking. In: Annual review of anthropology, Vol. 4. Edited by Bernard J. Siegel. Palo Alto: Annual Reviews.

Bellack, Arno, Herbert Kliebard, Ronald Hyman, and Frank Smith. 1966. The language of the classroom. New York: Teachers College Press.

Bernstein, Basil. 1971a[1960]. Review of: The lore and language of schoolchildren, by Opie and Opie. In: Class, codes, and control, by Basil Bernstein. London: Routledge and Kegan Paul.

Bernstein, Basil. 1971b. A socio-linguistic approach to socialization: With some reference to educability. In: Class, codes and control, by Basil Bernstein. London: Routledge and Kegan Paul. Bierwisch, Manfred. 1971. Modern linguistics. The Hague: Mouton. Bloch, Maurice. 1976. Review of: Explorations in the ethnography of speaking, edited by Richard Bauman and Joel Sherzer. Language in Society 5:229-234.

Boas, Franz. 1916. Tsimshian mythology. 31st Annual Report of the Bureau of American Ethnology.

Boas, Franz. 1966[1911]. Introduction, Handbook of American Indian languages. Reprinted with J. W. Powell, Indian linguistic families of America north of Mexico. Lincoln: University of Nebraska.

Bricker, Victoria R. 1974. The ethnographic context of some traditional Mayan speech genres. In: Explorations in the ethnography of speaking. Edited by Richard Bauman and Joel Sherzer. New York: Cambridge.

Cazden, Courtney. 1975. Play with language and metalinguistic awareness. In: Dimensions of language experience. Edited by Charlotte B. Winsor. New York: Teachers College Press. Douglas, Mary. 1973. Natural symbols. New York: Vintage. Dundes, Alan, ed. 1965. The study of folklore. Englewood Cliffs, N. J.: Prentice-Hall.

Durkheim, Émile. 1966[1893]. The division of labor in society. New York: Free Press.

Emeneau, Murray B. 1958. Oral poets of South India--The Todas. Journal of American Folklore 71:312-324.

Fish, Stanley E. 1973. How ordinary is ordinary language? New Literary History 5:40-54.

Fónagy, Ivan. 1965. Form and function of poetic language. Diogenes 51:72-110.

Fox, James. 1974. Our ancestors spoke in pairs. In: Explorations in the ethnography of speaking. Edited by Richard Bauman and Joel Sherzer. New York: Cambridge. 
Gossen, Gary. 1972. Chamula genres of verbal behavior. In: Toward new perspectives in folklore. Edited by Américo Paredes and Richard Bauman. Austin: University of Texas.

Gossen, Gary. 1974a. To speak with a heated heart: Chamula canons of style and good performance. In: Explorations in the ethnography of speaking. Edited by Richard Bauman and Joel Sherzer. New York: Cambridge.

Gossen, Gary. 1974b. Chamulas in the world of the sun. Cambridge, Mass. : Harvard.

Gumperz, John, 1962. Types of linguistic communities. Anthropological Linguistics 4:28-40.

Gumperz, John, and Dell Hymes, eds. 1964. The ethnography of communication. American Anthropologist 66(6), Part 2.

Gumperz, John, and Dell Hymes, eds. 1972. Directions in sociolinguistics. New York: Holt, Rinehart and Winston.

Habermas, Jurgen. 1971. Knowledge and human interests, Boston: Beacon.

Havránek, Bohuslav. 1964[1932]. The functional differentiation of the standard language. In: A Prague School reader on esthetics, literary structure, and style. - Edited by Paul L. Garvin. Washington, D. C.: Georgetown University Press.

Herder, Johann Gottfried von. 1968. Reflections on the philosophy of the history of mankind, abridged and with an Introduction by Frank E. Manuel. Chicago: University of Chicago.

Hymes, Dell. 1961. Review of: The anthropology of Franz Boas. Journal of American Folklore 74:87-90.

Hymes, Dell. 1962. The ethnography of speaking. In: Anthropology and human behavior. Edited by Thomas Gladwin and William C. Sturtevant. Washington, D. C.: Anthropology Society of Washington.

Hymes, Dell. 1966. Two types of linguistic relativity. In: Sociolinguistics. Edited by William Bright. The Hague: Mouton.

Hymes, Dell. 1971a. Competence and performance in linguistic theory. In: Acquisition of language: Models and methods. Edited by Renira Huxley and Elisabeth Ingram. London: Tavistock.

Hymes, Dell. 1971b. On linguistic theory, communicative competence and the education of disadvantaged children. In: Anthropological perspectives on education. Edited by Murray L. Wax, Stanley Diamond, and Frederick O. Gearing. New York: Basic Books.

Hymes, Dell. 1972. The contribution of folklore to sociolinguistic research. In: Toward new perspectives in folklore. Edited by Américo Paredes and Richard Bauman. Austin: University of Texas. 
Hymes, Dell. 1973. An ethnographic perspective. New Literary History 5:187-201.

Hymes, Dell. 1974. Speech and language: On the origins and foundations of inequality among speakers. In: Language as a human problem. Edited by Einar Haugen and Morton Bloomfield. New York: Norton.

Jakobson, Roman. 1960. Linguistics and poetics. In: Style in language. Edited by Thomas A. Sebeok. Cambridge, Mass.: MIT.

Jakobson, Roman. 1966. Grammatical parallelism and its Russian facet. Ig. 42:399-429.

Jakobson, Roman. 1968. Poetry of grammar and grammar of poetry. Lingua 21:597-609.

Katz, Jerrold J. 1964. Semi-sentences. In: The structure of language. Edited by Jerry A. Fodor and Jerrold J. Katz. Englewood Cliffs, N. J.: Prentice-Hall.

Kroeber, A. L., and Clyde Kluckhohn. 1963. Culture: A critical review of concepts and definitions. New York: Vintage.

Leech, Geoffrey N. 1969. A linguistic guide to English poetry. London: Longmans.

Lord, Albert. 1960. The singer of tales. Cambridge, Mass.: Harvard.

Malinowski, Bronislaw. 1926. Myth in primitive psychology. New York: Norton.

McDowell, John. 1974. Interrogative routines in Mexican-American children's folklore. Austin, Texas: Working Papers in Sociolinguistics No. 20.

Paredes, Américo, and Richard Bauman, eds. 1972. Toward new perspectives in folklore. Austin: University of Texas.

Park, Rose. 1972. An investigation of riddles of children ages 5-14. Ph. D. dissertation, Columbia University.

Roberts, John M., and Michael L. Forman. 1972. Riddles: Expressive models of interrogation. In: Directions in sociolinguistics. Edited by John Gumperz and Dell Hymes. New York: Holt, Rinehart and Winston.

Sanches, Mary, and Barbara Kirshenblatt-Gimblett. 1976. Children's traditional speech play and child language. In: Speech play. Edited by Barbara Kirshenblatt-Gimblett. Philadelphia: University of Pennsylvania.

Sapir, Edward. 1963[1915]. Abnormal types of speech in Nootka. In: Selected writings of Edward Sapir. Edited by David G. Mandelbaum. Berkeley and Los Angeles: University of California. Schegloff, Emmanuel, and Harvey Sacks. 1974[1973]. Opening up closings. In: Ethnomethodology. Edited by Roy Turner. Harmondsworth: Penguin. 
Sherzer, Joel. 1974. Semantic systems, discourse structure, and the ecology of language. Austin, Texas: Working Papers in Sociolinguistics No. 17.

Sherzer, Joel. 1977. The ethnography of speaking: A critical appraisal. In: Georgetown University Round Table on Languages and Linguistics, 1977. Edited by Muriel Saville-Troike. Washington, D. C.: Georgetown University Press. [this volume, 43-57].

Shultz, Thomas R. 1974. Development of the appreciation of riddles. Child Development 45:100-105.

Simpson, Georgiana R. 1921. Herder's conception of 'Das Volk'. Chicago: University of Chicago.

Sinclair, J. McH., and R. M. Coulthard. 1975. Towards an analysis of discourse. London: Oxford University.

Stankiewicz, Edward. 1974. Structural poetics and linguistics. In: Linguistics and adjacent arts and sciences (Current trends in linguistics, Vol. 12). Edited by Thomas A. Sebeok. The Hague: Mouton.

Stross, Brian. 1974. Speaking of speaking: Tenejapa Tzeltal metalinguistics. In: Explorations in the ethnography of speaking. Edited by Richard Bauman and Joel Sherzer. New York Cambridge.

Sutton-Smith, Brian. 1976. A developmental structural account of riddles. In: Speech play. Edited by Barbara KirshenblattGimblett. Philadelphia: University of Pennsylvania.

Swadesh, Morris. 1971. The origin and diversification of language. Edited by Joel F. Sherzer. Chicago: Aldine.

Whitt, J. Kenneth, and Norman Prentice. 1977. Cognitive processes in the development of children's enjoyment and comprehension of joking riddles. Developmental Psychology 13:129-136.

Wilson, William A. 1973. Herder, folklore, and romantic nationalism. Journal of Popular Culture 6:819-835. 
MALES, FEMALES, AND LINGUISTIC AND CULTURAL CATEGORIES

\section{MARY RITCHIE KEY}

\section{University of California at Irvine}

It seems appropriate that a conference on linguistics and anthropology should be concerned both with the language that males and females use and the language that is used about males and females. A recent article in the Los Angeles Times notes that the sexual revolution and women's liberation have brought about changes in American society with which our language has not yet come to terms, particularly in matters of address. Social secretaries 'are having nervous breakdowns, protocol offices are pretending it doesn't exist, hostesses are agonizing . . . Working wives who are addressed as Mrs. so and so are enraged, nonworking wives who are addressed as Ms. are enraged, husbands and wives who have different names are furious at being considered single.' We are having great protocol problems in trying to decide how to talk about each other. We do not know what word to use for males and females living together in the unmarried state: companion, roommate, boyfriend, girlfriend, lover, mistress, mate, and so forth.

Fortunately, a good sense of humor continues to emerge through the agony and rage. In a letter to the editor of Newsweek a reader commented on the changing roles in the priesthood. He wrote, 'We Episcopal priests are usually called "Father". Now with the ordination of women to the priesthood, do we get to be known as "The Mamas and the Papas" [a well known group of popular music performers]?' A furniture store in Los Angeles recently held a sale on chairs which they advertised as a 'Sale for Chair-Persons'. Some of the humor comes forth unwittingly; for example, a student in a freshman English class wrote, 'Gender in English tells us if a man is male, female, or neuter'. Nor was this student to be outdone by the mayor of one of 
our largest cities who defended his position on integrating women in the police force with: 'We're going to offer police jobs to qualified women regardless of their sex'.

All of this confusion and ambivalence results from the rapid rate of change which is going on; we are in a state of transition. What brought about this social upheaval? It is doubtful that it comes about either because of the female's assertiveness and ingenuity or because of the male's generosity. More likely, technology and medicine have driven human beings to reconsider social roles. Men, for example, have a different attitude toward war in this atomic and napalm century. Men are defining themselves as less aggressive. People are living beyond the child rearing stages and beyond the retirement age. Furthermore, within the last century, education has become commonplace for the masses. Since the land grant institutions emerged in 1870, higher education has been increasingly available to women and men of all classes. Whatever its cause, the redefining of male and female roles in American society may be one of the most significant changes in the 20 th century, and this redefinition is certainly having its impact on the language.

The study of linguistic categories can sometimes give insights into the relationship of male and female to each other and to their environment. These categories may be thought of as the correlation between linguistic groupings (or sets) and the linguistic/nonlinguistic behavior. I became interested in linguistic categories when I was working with indigenous languages in South America. In studying American Indian languages one soon becomes aware that other languages and cultures group things differently from Indo-European peoples. Linguistic categories, presumably, are ultimately an outgrowth of a human being's concept of reality and an attempt to cope with it. 'Reality' is not always what is out there, but the cultural group's collective perception of what is out there. The way in which this perception is categorized in the language and culture of the group both guides and constrains the behavior of its members.

Linguistic and cultural classifications may be true to the facts of nature; or they may be invented artifacts not necessarily in accord with nature. Categories may or may not be logical. Physical characteristics are often used to classify such things as gases, liquids, and solids; colors, shapes, and sizes. Function is frequently used to classify occupations, supernatural beings, instruments, transportation crafts, men and women. Categories may overlap and intersect; men and women may be classified by their physical characteristics as well as by their functional behavior. It is a truism of anthropological linguistics, which needs to be better known, that categories are not equatable across cultures. For example, the category 'edible', in a particular culture might or might not include snails, rotten eggs, 
truffles, and dog meat. Cultural constraints on edibility are reflected as restrictions on what lexical items might occur as the object of the verb 'eat' in different languages.

The learning of linguistic as well as cultural categories begins with the infant at the prelinguistic stages in the acquisition of communicative competence (Key 1977:29-33). One of the first category distinctions learned is that of animate and inanimate. The infant soon learns which things are dangerous and which are benign; it gradually learns what is edible and what is nonedible. Children may construct their own linguistic form for certain categories. One child I observed used [š̃̌sT] for a class of events which included the sounds of a lawn mower, vacuum cleaner, airplane, and automobile.

What methodology can be used for discovering the categories distinguished in a language? They are rarely discovered by direct questioning. A systematic study of the acquisition of communicative competence can give some insight into the categories of the particular culture. Observing nonnormal behavior might bring to light some interesting cognitive categories. In addition, the violations of selectional restrictions and category memberships by nonnative speakers can be very revealing. Thus, the distinction 'human' vs. 'nonhuman' is very significant in Spanish in body part terms. English leg is lexicalized in Spanish as pierna if it is [+ Human], but as pata if it is [- Human]; similarly, English neck is Spanish cuello or pescuezo and English liver is hígado or pano.

The analysis of pronominal forms is one way of approaching the categories distinguished in the language. Pronominal forms in English make up an interesting and complex set that incorporate features of gender and number. The third person singular pronoun it generally refers to inanimate objects; but it may also be used to refer to humans, as in Who was it? I believe it was John. They is usually used for a plural subject, but they (or one of its inflected forms) is commonly found in popular usage for a singular human referent in ambiguous situations, as a means of avoiding an arbitrary choice of his or her, where this choice is required by the language (or the awkward alternative his/her, e.g. Someone left their books on the table. Gender distinctions are constructed on the basis of these pronoun substitution classes.

Anomalies by native speakers can also point to covert categories in language use. I have noted examples of anomalous constructions where the pronoun referent is not the same gender as the sex of the precedent, for example, in baby talk, insults, and in the language of homosexuals and comedians (Key 1975:93-95).

Recent studies have focused on the referents and groupings that comprise males and females. Examples of language use in natural 
(not contrived) situations have been collected to discover the actual definitions of such terms as the average man the generic he man and mankind. The study by Collins (1977) is the first that $I$ know of that treats the reasonable man as this term is used in law; and for this reason it is a particularly valuable contribution to the understanding of male/female linguistic/cultural categories.

The definition of reasonable and the list of human types that could be included in the term the reasonable man has to do with the functions permitted human beings, either by the laws of nature (childbirth or suckling an infant, for example), or by the rules of society. Females have not been included in the categories of humans who function as 'thinkers' until relatively recent times. Less than a hundred years ago it was seriously held, at least by some scholars, that genius could only be a masculine trait (Key 1975:15). Old ideas die hard, and their linguistic reflections frequently live after them. Bette Davis was recently honored with the Life Achievement Award-- the first woman to be so honored by the American Film Institute. The head of AFI acknowledged her great worth; but he went on to note that 'It is less difficult for a woman to be celebrated for ber genius than to be forgiven for it'.

At the turn of the century there were also beliefs current that women differed from men in not having souls (Key 1975:15, 19), leading George Bernard Shaw to comment, 'Men are waking up to the perception that in killing women's souls they have killed their own'. Such views, while mainly a reflection of deeper attitudes, nevertheless undoubtedly had some effect on the behavior and expectations of males and females. These cultural-linguistic constructs can become powerful regulators of human affairs by being used to rationalize discrimination toward particular groups. For example, the 16th century Spanish classification of Indians as gente sin razón, i. e., 'people without reason', justified treating them legally as animals.

In my book on male-female language I have noted several illustrations of references to women in classificatory groupings which were intended to be pejorative: 'the blind, the lame, and the women'; 'scotch, horses, and ladies'; 'crime, violence, sex, and women' (Key 1975:82-84). Females were classified at one time, for example in contract law, in the same category with 'minors, the mentally incapacitated, and sometimes special groups such as married women, convicts, and aliens'. In earlier times, the State of New York worded its franchise law to include everyone but women, minors, convicts, and idiots. Today, in Section 415.5 of the Penal Code of California, women are still classified with children. The article by Collins (1977) shows that at one time the law did not require a woman's conduct to come up to 'the standard required of a reasonable man; her conduct was only what was to be expected of a woman, as such'. 
Modifying the inventory of items within a cultural/linguistic category can be an enormously complex matter, for it may involve resultant changes in behavior toward the item or by the person that is shifted from one category to another. Since within a system nothing takes place in isolation, the other members of the category are also affected. The reclassification of females within the law now going on will inevitably result in changed expectations of responsibilities and rights. Certain protections that females had when they were classed with the legally imcompetent will be lost when they are shifted from that category. If women are reclassified simply as adults, they will be expected to bear equal responsibilities with men. But the reclassification can have, and is already beginning to have, far-reaching effects on the behavior of men toward women, and the cultural expectations which both groups have toward themselves and toward each other.

Despite the magic that is often associated with words, simply changing labels (e.g. chairman $\rightarrow$ chairperson; stewardess $\rightarrow$ cabin attendant; postman $\rightarrow$ letter carrier) does not necessarily change behavior, though it may. I am not under any illusion that the extensive public attention being given to these aspects of language will necessarily induce modifications in social roles, though it could have some impact simply by raising the issues from an unconscious to a conscious level. But institutions such as law may be directly affected by overtly changing the classification, or even the label, of an item.

Linguists, and even anthropological linguists concerned with the relation of language and culture, have too long ignored the power of the word in influencing thought and behavior. Whorf's classic study of the effect of the label empty on gasoline drums, on the behavior of people in the vicinity of the drums, stands out almost by virtue of its uniqueness. Probably not since the 17th century disappearance of the distinction between thou and you has such rapid cultural change overtaken the language. How these changes will be reflected in the language and in language use, and how these will in turn affect behavior, is a significant subject deserving of careful study. I hope that linguists, who have so much to contribute to our understanding of such processes, will not miss the opportunity.

\section{REFERENCES}

Bertalanffy, L. von. 1955. An essay on the relativity of categories. Philosophy of Science 22.4:243-263.

Boas, Franz. 1911. On grammatical categories. Introduction to the Handbook of American Indian Languages, Bureau of American Ethnology-B 40, Part I. Washington, D. C.: Smithsonian Institution. Reprinted by Georgetown University Press, Washington, 
D. C. Partially reprinted in: Language in culture and society. Edited by Dell Hymes. New York: Harper and Row, 1964. 121123.

Bolinger, Dwight. 1969. Categories, features, attributes. BRNO Studies in English 8.37-41.

Brinton, Daniel. 1885. The philosophic grammar of American languages: As set forth by Wilhelm von Humboldt. American Philosophical Society.

Chomsky, Noam. 1965. Aspects of the theory of syntax. Cambridge, Mass.: MTT Press.

Cole, Peter, and Jerrold M. Sadock 1977. Syntax and semantics, Vol. 8: Grammatical relations. New York: Academic Press.

Collins, Ronald K. L. 1977. Language, history, and the legal process: A profile of the 'Reasonable Man'. Rutgers-Camden Law Journal 8. 2:311-323.

Deese, James. 1969. Conceptual categories in the study of content. In: The analysis of communication content: Developments in scientific theories and computer techniques. Edited by George Gerber and others. New York: John Wiley and Sons. 39-56. Jespersen, Otto. 1924. The philosophy of grammar. New York: W. W. Norton and Company [1965].

Key, Mary Ritchie. 1971. A language-category test from a composite culture. Duplicated. Santa Ana, Calif.: Orange County Department of Education.

Key, Mary Ritchie. 1972. Linguistic behavior of male and female. Linguistics 88.15-31.

Key, Mary Ritchie. 1975. Male/female language: With a comprehensive bibliography. Metuchen, N.J.: Scarecrow Press.

Key, Mary Ritchie. 1976. Development of paralinguistic and kinesic expression of roles. Paper presented at the Conference on Language, Children, and Society, Ohio State University.

Key, Mary Ritchie. 1977. Nonverbal communication: A research guide and bibliography. Metuchen, N. J.: Scarecrow Press.

Sapir, Edward, and Morris Swadesh. 1946. American Indian grammatical categories. Word 2:103-112. Reprinted in: Language in culture and society. Edited by Dell Hymes. New York: Harper and Row, 1964. 101-107.

Shaw, George Bernard. In: A Shavian guide to the intelligent woman. Edited by Barbara Bellow Watson. New York: W. W. Norton, 1964.

Whorf, Benjamin Lee. 1945. [Written and circulated in 1937]. Grammatical categories. Lg. 21.1:1-11. Reprinted in: Language, thought, and reality. Edited by John B. Carroll. New York: IIIT Press and John Wiley, 1956. 87-101. 
THE ETHNOGRAPHY OF SPEAKING:

A CRITICAL APPRAISAL

JOEL SHERZER

University of Texas at Austin

The ethnography of speaking has arrived at a critical moment in its development. It has been recognized as a field or an approach within linguistic anthropology and sociolinguistics. It has individuals who admit to practicing it, and has books, articles, and sessions at professional meetings which bear its name. It has made both empirical and theoretical contributions to the study of language, culture, and society. At the same time there are a number of critical issues with regard to the study of language and speech with which the ethnography of speaking must come to terms if it is to progress beyond its present stage. The major focus of this paper is a discussion of such issues. I begin with a brief history of the ethnography of speaking as a background to the current situation. I then summarize its accomplishments to date. Finally, I discuss certain basic issues which future research must deal with seriously. I draw on some of my own research as an example of the kinds of directions the ethnography of speaking can take.

The ethnography of speaking began in the early 1960 s with a series of papers by Dell Hymes calling for the emergence of a field, or rather an approach to language and speech, to deal with aspects of language and speech that fall between or otherwise escape established disciplines such as anthropology, linguistics, and sociology (see especially Hymes 1962 , 1964). Essentially, his argument was that language and speech have a patterning of their own, as have social organization, politics, religion, and economics, and therefore merit attention by anthropologists and cannot be taken for granted as somehow 'given', or everywhere the same. This patterning is not identical to the grammar 
of a language in the traditional sense; yet it is linguistic as well as cultural in organization and thus merits attention by linguists.

Hymes introduced the notion of the speech event as central to the ethnography of speaking and argued that analysis of speech events requires study of the interrelationships among a number of components or factors. Basically, these factors are settings, participants, purposes, verbal or textual organization in terms of constituent acts, key or manner of delivery, linguistic varieties used, norms of interaction, and genres. The careful study of these components of speaking in their own terms, with regard to both terminology and patterned organization, as well as of the relationship between the functions of speech and these components, leads to a description that captures each society's unique cultural organization of language and speech.

Collections of papers published in the mid and late $60 \mathrm{~s}$ and early 70 s (Gumperz and Hymes 1964, Bright 1966, Gumperz and Hymes 1972, Kochman 1972) helped to further and to develop this field. These papers described aspects of language and speech previously overlooked or treated as secondary or marginal by anthropologists, sociologists, and linguists. The titles of these papers are indicative of their focus: 'Rhetoric, logic, and poetics in Burundi'; 'Culture patterning of speech behavior'; 'Baby talk in six languages'; 'How to ask for a drink in Subanun'; 'Signifying and marking: Two AfroAmerican speech acts'; 'Sequencing in conversational openings'; 'Social meaning in linguistic structures'; 'Code-switching in Norway'.

In the $1970 \mathrm{~s}$, a new group of researchers, most of them at the $\mathrm{Ph}$. $\mathrm{D}$. dissertation stage, went to a variety of societies around the world, specifically to carry out field research in the ethnography of speaking. This research has led to a number of dissertations, articles, and books (see especially Bauman and Sherzer 1974, Sanches and Blount 1975). It has now become possible--even necessary--to assess critically the results of the enterprise so far--achievements, failures, directions for future research.

First, it is useful to state briefly just what the ethnography of speaking is and what its goals are. My formulation may differ in some ways from that of other ethnographers of speaking, but it should be broad enough to serve as a basis for discussion here. Most generally, the ethnography of speaking is a description in cultural terms (ethnography) of the patterned uses of language and speech (speaking) in a particular group, institution, community, or society. More specifically, the ethnography of speaking is concerned with the following:

(1) the (socio) linguistic resources available in particular communities (such resources being not just grammar in the traditional sense, but rather a set or complex of linguistic potentials 
for social use and social meaning, including linguistic variables (as in the work of Labov); styles, forms, and terms of reference and address (as in the work of Brown, Ervin-Tripp, and others); lexical relationships; relationships between utterances such as entailment and presupposition, etc.);

(2) the use and exploitation of these resources in discourse (speech acts, events, and situations) and in social interaction (agreeing, disagreeing, showing deference and respect, cajoling, etc.);

(3) the patterned interrelationships and organizations of these various types of discourse and social interaction in the community;

(4) the relationship of these patterns of speaking to other aspects and domains of the culture of the community--social organization, religion, economics, politics, etc.

A complete ethnography of speaking would deal with each of these topics or subareas. 1 Work to date has tended to focus on particular ones--e.g. the description of linguistic resources, organized as styles or ways of speaking (men's/women's speech, baby talk, etc.), the analysis of particular speech events (greetings, drinking encounters, etc.), or the role of speaking in a particular segment of social or cultural life--politics, religion, etc.

Now let us turn to the critical assessment. 2 More than ten years of research in the ethnography of speaking have resulted in the collection of a very interesting set of empirical data concerning the patterning of language and speech in societies around the world. These data have served to demonstrate quite clearly that such patterning does occur; that there are significant cross-cultural differences; that the use and the role of language cannot be taken for granted as being everywhere the same. These data have also served as a useful antidote to theorizing about language use and the role of language in society, a reminder that this role cannot be intuited on the basis of one's own experience or projected from a single language, culture, or society onto others. At the same time, theories about language and its use, in such fields as philosophy, linguistics, anthropology, and sociology, have had considerable influence on the development of the ethnography of speaking, with the result that a dialectical relationship is now coming to exist between theory and data, each one feeding the other and taking from it as well. Witness the influence of AustinSearle speech act theory, of Grice's conversational maxims and implicatures, of generative semantics, of Goffman's frame analysis on ethnographic approaches to language and speech. Following are examples of fascinating and intriguing data uncovered by the ethnography of speaking and their implications for current theories about language in use. 
(1) In the Vaupés region of the Northwest Amazon in South America, as reported by Jackson (1974) and Sorensen (1972), individuals typically speak three languages; many speak four or five; some understand as many as ten. The language learning process continues all through life. The Vaupés is a testing ground for questions of bilingualism, speech community, and language acquisition. The major function of this linguistic diversity seems to be marriage regulation and not the expression of social meaning in face-to-face interaction, as is the case of most of the multilingual situations that have been studied by sociolinguists. At the very least, there is no oneto-one association between the selection of a particular language in talk and social meaning, since all individuals have different although overlapping repertoires.

(2) The Tenejapa Tzeltal, as reported by Stross (1974), have $416+$ monolexemic terms for types of talk. This situation raises questions about the degree of lexical elaboration and focus possible within a single cultural domain, especially the domain of talk about talk, and the implications of such elaboration for language attitudes and language use in general.

(3) Antiguan peasants, as reported by Reisman (1974) follow a conversational pattern which Reisman labels contrapuntal, according to which several voices participate simultaneously. There is no turn-taking rule, as there seems to be in middle class American society, according to which all participants should stop talking while one of them holds the floor.

(4) In Malagasy society, as reported by Keenan (1976), the Gricean conversational maxim 'be informative', while appropriate for analysis, is marked, in the sense that individuals are more often expected not to be informative in conversational interchanges, not to provide the specific information requested. Keenan provides an explanation of the Malagasy pattern in terms of ethnographic assumptions and ground rules, arguing that the actualization of such maxims depends on socially relevant features of the interactional setting, in Malagasy as well as American society.

(5) Among the Luo, as reported by Blount (1975), and among the Wolof, as reported by Irvine (1974), aspects of social structure emerge from verbal interactions between and among individuals, rather than being mechanically determined by them or being superficial expressions of them. Luo genealogical structure is created by means of a conversation among village elders. Status ranking between two Wolof individuals is affected by the manipulation of rules of greeting. 
(6) Among the Cuna, as reported by Sherzer (1974), two patterns of ceremonial speech contrast with one another. One, rather similar to the European tale-singing structure described by Lord (1960), involves creative elaboration, development, and manipulation of traditional topics and themes. The other involves word-for-word repetition of fixed 'texts'. These two patterns, cooccurring within the cultural organization of a single society, represent two distinct, almost opposite ways of storing, transmitting, and performing oral tradition and knowledge.

(7) In some American Indian communities, as reported by Philips in a series of papers, the social and cultural organization and patterning of language and speech is distinctively Indian, even though the original (Indian) languages of the communities are no longer in active use. This situation is an important corrective for theories of language use that utilize particular languages and their terminology as the starting point for analysis. It also serves as a warning to such applied projects as bilingual education programs that there is much more to communication than the language spoken.

The ethnography of speaking has thus amassed a growing collection of ethnographic tidbits from around the world, relating to various theories of language and language use, either as confirmation or as refutation or corrective. At the same time, in spite of the theoretical and methodological impetus provided by Gumperz, Hymes, and others, recent research has offered relatively little new theoretical or methodological perspective of its own which draws on this valuable ethnographic data. There are a number of serious issues within the ethnography of speaking which demand attention. These have been pointed to by practitioner and by critics. In addition to being both theoretical and methodological in nature, they involve as well the relationship between theory and practice, a relationship which is of increasing concern to ethnographers of speaking in particular and to sociolinguists generally.

First, there are a number of theoretical issues. Every society investigated by ethnographers of speaking has tended to be studied entirely in terms peculiar to that society or to a particular researcher. The result is that each new study, while it might offer fascinating new data about speech patterns, is difficult to compare with studies of other societies carried out by different researchers. Until and unless precise cross-cultural comparison and typology is possible, the ethnography of speaking will be restricted to empirical data collecting with increasingly limited returns.

There are parallels within both linguistics and anthropology. With regard to phonological systems, it is possible to ask about any language 
such questions as: is the distinction between voiced and voiceless stops phonemically relevant? Can the language be characterized as a one-, two-, or three-stop series language? With regard to syntax, it is possible to talk of VO or OV languages. Similarly, in the area of kinship, one can talk of Hawaiian systems or Crow-Omaha systems.

In the ethnography of speaking, there is as yet no comparable precision. This is not to say that analysts have not proposed features and dichotomies. They have. Some common ones are formality/informality; direct/indirect or allusive; simplified/elaborated. But these features and dichotomies have not been defined in a precise enough way to know whether allusiveness for the Cuna is comparable to allusiveness for the Malagasy or the Hongot; whether the formality/informality distinction among the Maori is in any way comparable to that same distinction as it applies to middle class Anglo society. Or to put it in more universal terms: is the formality/informality distinction everywhere relevant and if so, how is it manifested among the Maori, middle class Anglos, the Wolof, etc. ? 3

So one critical need in the ethnography of speaking is for the development of precise, cross-culturally valid terms and definitions for features, dichotomies, and patterns. This would in turn make possible more meaningful, less ad hoc formalization, the positing of types (areal, evolutionary, etc.), and precise theoretical generalizations.

This leads to a second issue--the relationship between speaking patterns and other sociocultural patterns found in a society--social structural, political, ecological, economic, religious, etc. There are anthropological theorists who would always see one of these aspects of a society as basic, whether this aspect is economic, political, or social structural. Such a view would always have speech patterns as secondary, superficial reflections of the more basic structures. Ethnography of speaking is not yet developed or sophisticated enough to provide reliable answers to this crucial question for most societies. One of its failings so far has been not to attack this problem seriously, precisely because of its efforts to demonstrate that speaking itself is a structured and patterned domain. There is evidence that in some societies or situations speech itself can play a primary role in defining or determining sociological structures. This is the import of the studies by Blount and Irvine referred to earlier. In these cases the discourse can be said to have an emergent rather than a predetermined structure and it confers a corresponding emergent structure on certain sociological patterns ${ }^{4}-$-genealogy in the case of the Luo and relative status hierarchy in the case of the Wolof. If ethnography of speaking succeeds in achieving greater precision in the description of speaking types, with a cross-cultural validity, then theoretical advancement with regard to the relationship between 
speaking and other socio-cultural-economic patterns and structures will be possible.

Related to both of these issues is a third, which has to do with the relationship between typological and universal generalizations on the one hand, and cross-cultural differences and particularities on the other. Again, because of its focus on empirical particularities and peculiarities around the world, the ethnography of speaking has not been prone to posit universals of either the formal or the substantive type, to borrow Chomsky's distinction. There is a need to begin to posit such universal generalizations, as a set of hypotheses to be tested in particular cases. Such universals would have to do with different aspects of speaking, such as:

(1) The components, factors, and functions involved in speech, their organization and relationship.

(2) Speech acts and events. First, are such acts and events as greeting, leave-taking, and command universal? In fact, what is the set of universal speech acts? Second, are there universal principles of the organization of speech acts into larger units of discourse, of the type that philosophers such as Grice or sociologists such as Sacks have posited?

(3) The expression of social-interactional meanings, such as distance, closeness, deference, politeness, insult. Here, some universals have been suggested. 5 Goffman (1972), for example, has pointed to rules of attenuation, which operate in greeting behavior and are no doubt relevant in many forms and processes of social interaction. But such attenuation rules can take quite different forms in different societies. And it is a challenge for analysts to find and interpret them. In rough terms, Goffman has pointed out that in American society (especially middle class Anglo) greetings are more expansive and more special the longer the time elapsed since two individuals have last interacted. In many American Indian communities such absence leads to silence and deliberate avoidance of overt interactional communication at the moment of reestablishment of contact (see Basso 1972). Is such a pattern a counterexample to the Goffman attenuation rule? Or is it rather an American Indian expression of a special greeting and thus a fascinating validation of the attenuation rule?

In my research among the Cuna Indians of Panama, I have found the silence-deliberate avoidance pattern used as a greeting. But there is another pattern, which also seems to be rather widespread among American Indians. This second pattern consists of a ritualized or ceremonial conversation or dialog between two individuals, in which each speaks in a 
series of lines and the other responds with a single word after each line. This ceremonial dialog is used by chiefs in front of an audience, but it is also used by others in the privacy of their homes. These two Cuna greeting types, both apparently American Indian areal communicative patterns, point to a more basic question which might be asked in any society: what is the set of communicative means and strategies available for dealing with interactional situations in which the relationship between two individuals needs to be reestablished or reaffirmed?

(4) Acquisition of language and speech. There is tremendous interest in the processes involved in the acquisition of language. Most of this interest has focused on relatively narrow aspects of phonology, morphology, syntax, and semantics. But children also acquire the entire speaking system of their community, what has been called communicative competence. Both the universal and the particular aspects of this acquisition process need to be studied. 6

Still another serious issue within the ethnography of speaking, and one that is relevant for ethnography generally, has to do with the relationship between ceremonial and ritual speech on the one hand, and more everyday, colloquial, and seemingly banal speech, on the other. Ethnography of speaking has been criticized for focusing on special uses of speech, and for a fascination with ritual, ceremonial, verbally artistic, and other marked and special uses of speech. While some ethnographers of speaking have paid attention to such colloquial forms as greetings and ordinary conversation, ethnography of speaking--like ethnography in general--has been attracted by events which are most striking to the outsider and probably most special or marked to the insiders of a community as well. Related to this is the tendency to focus on societies (American Black, Cuna, etc.) in which speaking is a cultural focus. To have a more universal validity and acquire more theoretical adequacy, the ethnography of speaking must be able to account for banal and everyday uses of speech as well as for ritual and ceremonial events. The challenge is to analyze the subtleties of everyday communicative behavior, the structure of hints, suggestions, and avoidances, which occur not as public, formal events, but as part of the most everyday face-to-face interaction in societies around the world. This is in part a methodological issue and is discussed as such in what follows. But it is a theoretical issue as well. The most valuable analyses will account for both the ceremonial and the everyday, as well as for possible links between them.

Here again I would like to draw examples from my own research among the Cuna Indians. There are certain communicative patterns which cut across and link all Cuna styles and ways of speaking, from 
the chanting of chiefs about Cuna myth and history, through communication by medicinal specialists with the spirits of good and evil, to the most ordinary verbal interactions between any individuals. One of these patterns is reporting and quoting. In all forms of Cuna speaking, speakers tend to present information, opinions, and experiences not directly as their own, but as reports of and, typically, as quotes of, what others did or said. This process is both a discourse pattern and a rhetorical strategy. There are often various levels of embedding at the discourse level which must be attended to. It would be interesting to know to what degree this pattern of multiple embeddings is uniquely Cuna, and to what degree it is characteristic of American Indian discourse or of preliterate societies in general.

Another pattern that cuts across most forms and genres of Cuna speech, from the ceremonial and ritual to the everyday, is that of advising. Cuna individuals are constantly advising each other, just as medicinal specialists advise spirits in their special language. In fact, it is on the basis of, and by means of, reporting and quotation that advising often takes place.

A third basic Cuna speaking pattern is that of interpretation. Not only are the linguistic and rhetorical subtleties of a Cuna chief's chants and speeches interpreted for an audience by a chief's spokesman; all speech, including informal conversation, involves constant reformulations and explanations of what has just been said.

Such patterns as reporting, advising, and interpreting are no doubt found everywhere in the world. What I emphasize here is a particular salience they have in a Cuna ethnography of speaking, in which they serve to relate the various forms of Cuna verbal life, from the most ceremonial and ritual to the most colloquial and everyday. A Cuna bilingual education program, for example, that was ethnographically as well as linguistically adequate, would want to build such patterns into classroom interaction.

A final theoretical issue has to do with the relationship between the ethnography of speaking and the ethnography of communication. While both terms have been used for the field I am discussing here, I think it is fair to say that there is as yet no real ethnography of communication, in that almost all research has focused almost exclusively on language and speech. It is true that there is increasing interest in various modes of communication, verbal and nonverbal. Rather than separate out particular streams of communication for isolated analysis, however, an ethnography of communication would ask, in any society: what are the various modes of communication, verbal and nonverbal, and how do they interrelate in the context of actual communicative acts and events in the society's overall theory of communication? 
I now turn to certain methodological issues. Ethnographers of speaking have for the most part employed the method of participantobservation. This is based on the principle on which the validity of anthropological field work ultimately depends: that by immersing oneself in a community for a period of one year or more, it is possible for an investigator to come to terms with the patterned cultural behaviors of that community. This method is coupled with others, such as those developed in anthropological linguistics and ethnoscience, survey research, and the analysis of textual material recorded in actual, natural contexts.

But this methodology is open to criticism of several types. First, in every community, variation exists in patterns of speaking and this variation itself is patterned. To date, most of the research concerned with sociolinguistic variation has dealt with aspects of grammar, especially phonology, morphology, and syntax, and has achieved considerable refinement in statistical analysis. One of the challenges for the ethnography of speaking is to deal with variation in patterns of speaking in analogously principled ways. The kinds of basic questions to be asked are: what types of speech variation are possible within communities? how is this variation related to social class, sex, role, and individual differences in particular societies? is such variation related to the evolution through time of the overall system? It is probably especially with regard to the nonceremonial, to everyday communicative patterns, that statistical analysis will provide the most interesting results.

This methodological issue leads to another methodological issue, one of the most critical issues within the ethnography of speaking. It is related to a theoretical issue I have already raised, namely, that in addition to the description of broad speaking patterns, the ethnography of speaking must be able to analyze the most subtle of communicative behavior of the type that occurs every day, what Goffman (1976) has aptly called the laconicity of talk, the fact that most often in social life it is the unsaid that lies behind the said that must be analyzed. It is out of such laconicity that much of the day-to-day sociocultural meanings in the lives of individuals are expressed and created. Is it possible for an outsider in a community to ever seriously comprehend such communicative behavior on the basis of one or even a series of field trips, even if he speaks the language?

Often ethnographers of speaking have relied heavily on native terminologies and taxonomies at the expense of other modes and levels of analysis. In fact, the elicitation of native terminological systems for speech acts and events, ways and styles of speaking, etc., has been considered one of the goals of description. But the kinds of subtle uses of language to which Goffman and other analysts of the strategies of social interaction have pointed in our own society 
require very different modes of analysis. Elicitation and analysis of lexicon are insufficient. While some degree of comparable subtlety has been uncovered with regard to other societies, this issue points to the crucial need for training individuals in ethnography of speaking (as in anthropology and linguistics generally) to carry out research in their own societies and communities, as native researchers and analysts, as native participant-observers.

Related to both of these methodological issues is the fact that much of ethnography of speaking research to date has been carried out in societies outside the United States and quite different from our own society. USA-oriented research is crucial in several respects. It provides a testing ground for all of the theoretical and methodological issues I have discussed here. One aspect of this testing ground, of course, is that analyses are open to constant critical scrutiny by all members of the society. Modern societies like that of the United States are particularly challenging to ethnography, which has developed most of its technique and approach in relatively small, relatively homogeneous societies. In complex societies such as that of the United States, members of the community, as well as analysts, often have to work out and understand communicative patterns that are much more variable, overlapping, and changing than those typically found in the more homogeneous and tradition-oriented societies in which anthropologists have tended to carry out field research. But the United States provides more than a testing ground for method and theory. It is also a testing ground for practice and application. One of the motivations for the ethnography of speaking in particular, and sociolinguistics more generally, has been relevance in the solution of social problems, especially those concerned with communication. It has been argued that by carrying out ethnography of speaking research in various communities as well as in such institutions as law, medicine, and education, we will have a better understanding of the reasons for conflict and failure. Important research initiatives in this direction can be cited. 7 But much more research is needed. There is still a woefully small amount of published, available information dealing with the ethnography of speaking of our own society.

I began this critical assessment and appraisal of the ethnography of speaking by stressing the need for cross-cultural comparison and validity, and I end it with a call for research in American society. I intend no contradiction. Reliable information and analysis concerning other societies will continue to provide relevant questions to be asked in our own society, and vice versa. The questions I have raised here are intended to be more than suggestions for future research; they are issues which must be faced, if the ethnography of speaking is to be more than a passing fad. 8 


\section{NOTES}

1. While there is no book with the title 'Ethnography of speaking of the X', a number of books dealing with particular societies or institutions have appeared in the last few years, whose basic thrust or orientation is the ethnography of speaking. Examples are Bricker (1973), Foster (1974), Gossen (1974), and Salmond (1975). CalameGriaule (1965) derives from another tradition.

2. Since I have been associated personally with the development of the ethnography of speaking and am co-editor of a recent collection of papers on the subject, I permit myself this liberty of offering rather harsh criticism, with the aim of advancing the field. A particularly useful critique, which has influenced my thinking here, is Bloch (1976). Grimshaw (1974) also discusses some of the issues raised here.

3. Important first steps have been taken. Hymes (1972) discusses possible cross-cultural manifestations of such dichotomies and dimensions as voluble/taciturn, elaborate/restrained, and personal/positional. Bloch (1975) proposes a set of features which ideally distinguish everyday speech acts from formalized speech acts.

4. According to the school of sociology known as ethnomethodology, discourse and social organization always have an emergent structure.

5. Brown and Levinson (n. d.) propose a universal theory of linguistic politeness.

6. Recent work in the study of language acquisition provides significant steps in this direction. Thus, Ervin-Tripp and MitchellKernan (1977) consists of papers on children's discourse, and Snow and Ferguson (1976) deals with parental input in the acquisition process, as does the paper by Blount in this volume (117-138).

7. For ethnography of speaking in educational settings, see Cazden, John, and Hymes (1972). For analyses of communicative misunderstandings and conflicts in United States society, see Erickson (1976) and Gumperz (1976).

8. The ideas expressed in this paper reflect many conversations I have had with Dell Hymes. Hymes' own work has always shown an awareness of and concern with the issues I discuss here. Collaboration with Regna Darnell (Sherzer and Darnell 1972) and, more recently, with Richard Bauman (Bauman and Sherzer 1974, 1975) has also influenced my thinking. Richard Bauman commented on an earlier draft of this paper, as did Dina Sherzer and Brian Stross.

\section{REFERENCES}

Basso, K. 1972. 'To give up on words': Silence in Western Apache culture. In: Language and social context. Edited by P. P. 
Giglioli. Harmondsworth, Middlesex, England: Penguin. 67-86.

Bauman, R., and J. Sherzer, eds. 1974. Explorations in the ethnography of speaking. Cambridge, England: Cambridge University Press.

Bauman, R., and J. Sherzer. 1975. The ethnography of speaking. In: Annual Review of Anthropology, Vol. 4. Palo Alto, Calif.: Annual Reviews, Inc. 95-119.

Bloch, M. 1975. Introduction. In: Political language and oratory in traditional society. Edited by M. Bloch. New York: Academic Press. 1-28.

Bloch, M. 1976. Review of: Explorations in the ethnography of speaking. Edited by R. Bauman and J. Sherzer. Language in Society 5. 229-234.

Blount, B. G. 1975. Agreeing to agree on genealogy: A Luo sociology of knowledge. In: Sociocultural dimensions of language use. Edited by M. Sanches and B. G. Blount. 117-135.

Bricker, V. 1973. Ritual humor in Highland Chiapas. Austin, Texas: University of Texas Press.

Bright, W., ed. 1966. Sociolinguistics. The Hague: Mouton.

Brown, P., and S. Levinson. n. d. Universals in linguistic usage. To appear in: Communicative strategies in social interaction. Edited by E. Goody. Cambridge, England: Cambridge University Press.

Calame-Griaule, G. 1965. Ethnologie et langage: La parole chez les Dogon. Paris: Gallimard.

Cazden, C., V. John, and D. Hymes, eds. 1972. Functions of language in the classroom. New York: Teachers College Press, Columbia University.

Erickson, F. 1976. Gatekeeping encounters: A social selection process. In: Anthropology and the public interest. Edited by P. Sanday. New York: Academic Press. 111-145.

Ervin-Tripp, S., and C. Mitchell-Kernan, eds. 1977. Child discourse. New York: Academic Press.

Foster, M. 1974. From the earth to beyond the sky: An ethnographic approach to four Longhouse Iroquois speech events. National Museum of Man Mercury Series. Canadian Ethnology Service Paper No. 20, Ottawa, Canada.

Goffman, E. 1972. Relations in public. New York: Harper and Row.

Goffman, E. 1976. Replies and responses. Language in Society 5. 257-313.

Gossen, G. 1974. Chamulas in the world of the sun: Time and space in a Maya oral tradition. Cambridge, Mass.: Harvard University Press. 
Grimshaw, A. 1974. Data and data use in an analysis of communicative events. In: Explorations in the ethnography of speaking. Edited by R. Bauman and J. Sherzer. 419-424.

Gumperz, J. G. 1976. Language, communication, and public negotiation. In: Anthropology and the public interest. Edited by P. Sanday. New York: Academic Press. 273-292.

Gumperz, J. G., and D. Hymes, eds. 1964. The ethnography of communication. American Anthropologist 66(6), Part 2.

Gumperz, J. G., and D. Hymes, eds. 1972. Directions in sociolinguistics: The ethnography of communication. New York: Holt, Rinehart, and Winston.

Hymes, D. 1962. The ethnography of speaking. In: Anthropology and human behavior. Edited by T. Gladwin and W. C. Sturtevant. Washington, D. C.: Anthropological Society of Washington. 13-53. Hymes, D. 1964. Introduction: Toward ethnographies of communication. In: The Ethnography of communication. Edited by J. G. Gumperz and D. Hymes. 1-34.

Hymes, D. 1972. Models of the interaction of language and social life. In: Directions in sociolinguistics: The ethnography of communication. Edited by J. G. Gumperz and D. Hymes. 35-71.

Irvine, J. 1974. Strategies of status manipulation in the Wolof greeting. In: Explorations in the ethnography of speaking.

Edited by R. Bauman and J. Sherzer. 167-191.

Jackson, J. 1974. Language identity of the Colombian Vaupês Indians. In: Explorations in the ethnography of speaking. Edited by R. Bauman and J. Sherzer. 50-64.

Keenan, E. O. 1976. The universality of conversational postulates. Language in Society 5.67-80.

Kochman, T., ed. 1972. Rappin' and stylin' out: Communication in urban Black America. Urbana, ㅍll.: University of nlinois Press. Lord, A. 1960. The singer of tales. Cambridge, Mass.: Harvard University Press.

Philips, S. 1972. Participant structures and communicative competence: Warm Springs children in community and classroom. In: Functions of language in the classroom. Edited by C. Cazden, V. John, and D. Hymes. 370-394.

Philips, S. 1974. Warm Springs 'Indian Time': How the regulation of participation affects the progression of events. In: Explorations in the ethnography of speaking. Edited by R. Bauman and J. Sherzer. 92-109.

Philips, S. 1976. Some sources of cultural variability in the regulation of talk. Language in Society 5.81-95.

Reisman, K. 1974. Contrapuntal conversations in an Antiguan village. In: Explorations in the ethnography of speaking. Edited by R. Bauman and J. Sherzer. 110-124. 
Salmond, A. 1975. Hui: A study of Maori ceremonial gatherings. Wellington, New Zealand: A. H. and A. W. Reed.

Sanches, M. , and B. G. Blount, eds. 1975. Sociocultural dimensions of language use. New York: Academic Press.

Sherzer, J. 1974. Namakke, sunmakke, kormakke: Three types of Cuna speech event. In: Explorations in the ethnography of speaking. Edited by R. Bauman and J. Sherzer. 263-282.

Sherzer, J., and R. Darnell. 1972. Outline guide for the ethnographic study of speech use. In: Directions in sociolinguistics: The ethnography of communication. Edited by J. G. Gumperz and D. Hymes. 548-554.

Snow, C., and C. F. Ferguson, eds. 1976. Language input and acquisition. Cambridge, England: Cambridge University Press.

Sorenson, A. P., Jr. 1972. Multilingualism in the Northwest Amazon. In: Sociolinguistics. Edited by J. B. Pride and J. Holmes. Harmondsworth, Middlesex, England: Penguin. 78-93.

Stross, B. 1974. Speaking of speaking: Tenejapa Tzeltal metalinguistics. In: Explorations in the ethnography of speaking. Edited by R. Bauman and J. Sherzer. 213-239. 

VARIABILITY AND EXPLANATION

IN LANGUAGE AND CULTURE:

CLITICIZATION IN NEW GUINEA TOK PISIN

\section{GILLIAN SANKOF F}

\section{Université de Montréal}

1.0 In the last ten or fifteen years, we have come a long way from the 'one language equals one culture' assumption that once characterized much of our thinking about the relationships between language and culture. No longer can it be maintained, in any strict or simple sense, that 'language is the mirror of culture', for we now know that in many societies there is widespread bi- and multi-lingualism, and that even where there exists what people call 'one language', it is never totally uniform, or totally stable.

In the innocent one-language, one-culture days, linguistic differentiation was explained in terms of a split-and-divergence model, i.e. as the result of the separation and isolation of populations. Dialect and even language levelling was thought to be the unavoidable consequence of language contact. Today, a great deal more is known about the relationship between social and linguistic facts. Largely through the work of John Gumperz, we know, for example, that linguistic differences can be maintained, even created, within speech communities where the segments of the population concerned are in 'regular and frequent interaction' (Gumperz 1964:137).

After all, we have only to note the numerous differences (now de- 0 scribed for many communities--compare e.g. Key, this volume) between men's and women's speech to come to the conclusion that speech differences can be maintained among interacting groups. Similar observations can be made about generational differences in situations of very rapid language change, as is the case in creolization--for example, in the New Guinea situation I discuss in this paper. The sex and generational differences have one thing in common: the creation and 
maintenance of linguistic differences among sub-segments of a population not caused by isolation or lack of contact between the subsegments in question.

This lack of linguistic homogeneity, which has been well documented in numerous studies of variability over the last decade, has raised a number of questions which are crucial in rethinking the problem of the relationship between language and culture. First, what are the sources and functions of linguistic heterogeneity (at whatever level) that one finds? Second, how much such heterogeneity can be tolerated (i. e. without seriously impeding communication), and in what areas of language?

My own work on language variation has led me to take issue with the position that language is autonomous, a Saussurian 'système où tout se tient'. Rather, I have come to see that much of the structured variation that exists in language can be ascribed to the social nature of its use, and to the plurality of functions that it serves. Thus, the study of linguistic variability also leads to the rejection of a one-toone relationship between form and function. What remains problematic, then, is just how, and to what extent, these functions influence the shape of language.

I am not, however, advocating 'functionalism' as a panacea for understanding the relationships between language, society, and culture, especially in light of the fact that in several disciplines 'functionalism' seems recently to have run its course. Indeed, it has been widely criticized in social anthropology as not constituting an explanation at all. Critics note that within this framework, aspects of culture and social institutions were construed as a kind of homeostatic system (one analyzed the correlation of, say, bride wealth and divorce rates as mutually interdependent, necessary to each other), but that it was difficult to say what might cause any cultural fact or social institution to be some other way.

In contrast to this, however, I think that approaches identified as 'functionalist' within linguistics have always had an explanatory thrust. 1 This is because the problem has been conceived in essence as one of explaining linguistic facts in terms of nonlinguistic facts. More subtly put, one looks at the influence of nonlinguistic considerations on the explanation of linguistic facts. So in linguistics, it seems, no contradiction is felt to exist between explanation and functionalism. Kuno, for example, has recently claimed that 'wide varieties of linguistic phenomena are in fact primarily controlled by nonsyntactic factors', listing among these factors such things as 'the speaker's belief about the universe that he lives in presupposition, discourse influences, perceptual strategies' and so on (Kuno 1975: 276). 
Until very recently, few twentieth century American linguists have adopted a functionalist position. It is no accident, however, that, for many years, the principal champion of such a view in the United States has been a scholar whose work has been centrally concerned with relating anthropology and linguistics. I speak, of course, of Dell Hymes (e.g. 1964, 1969), who has written (1969:112) as follows.

A sociolinguistic critique . . . is structural, in seeking to show the existence of structural relationships in language, and in the use of language, beyond those usually taken into account by linguists. It is also functional, in that discovery of new structural relationships depends upon the recognition of the functions they serve.

He argues for 'the priority, plurality, and problematic (empirical) status of the functions of speech' (Hymes 1969:113).

But for many years, the majority of modern American grammarians did not embark on the functionalist project, perhaps--at least in part--for the following reasons: (a) the seductive orderliness of synchronic linguistic structure, viewed as an abstract formal system (whether from a structuralist or generative perspective) in itself overpowered other problems and perspectives, giving linguists plenty to work on without getting their hands dirty; (b) the distastefulness, especially to those holding a relativist position, of functionalist arguments when pushed to the extreme (viz. critiques of Martinet's conception of 'functional load'). One is easily led into considering how 'well adapted' a particular form is to the function it is supposed to serve, or to analyzing a particular synchronic state as being 'better adapted' than a previous one, etc. To our ears, the following quotation (Frei 1929:22; my translation) sounds old-fashioned, somewhat Durkheimian, and certainly overly mechanistic:

The functional cycle is constituted by a stimulus (the deficits); a means (the processes); an end (linguistic needs). And as in biology, the stimulus creates the function and the function the organ, in linguistics the deficit awakens a need (in any case always latent) which in turn triggers the process which satisfies it.

As an alternative to falling into teleological circularity, or having to make distasteful comments on 'utility', then, how much more pleasant to consider linguistic change as simply the reanalysis or reorganization of formal rules!

I think that a way out of some of the traps of overly mechanistic functionalism involves a clear recognition of both the multifunctionality 
of language, as stressed by Hymes, and some of what Hockett (1963) has called the 'design features' of language, which seem to be structurally important and enduring. As an example, I examine a case of dynamic tension between a discourse function--foregrounding or topicalization--and a language pattern feature--morphosyntactic regularization. In describing this tension, I am going to look at innovation in speaker strategies as discourse-related. My view is that we can describe as syntacticization processes the transition between what initially appear to be ad hoc speaker strategies and what later can be fairly confidently described as syntactic rules.

2.0 The specific example discussed in this paper concerns the cliticization of subject pronouns in New Guinea Tok Pisin, during the period 1885-1970.2 The data on which this analysis is based are taken from four historical stages of the language.

I. 1885. Hearings of the Royal Commission on Recruiting Polynesian (sic) Labourers in New Guinea and Adjacent Islands. Queensland. These data are both copious and to be used with caution. They consist of thousands of question-answer pairs where the judge questioned several hundred labourers about the conditions of their employment on the Queensland sugar plantations. Transcription of the responses appears somewhat anglicized; the official view was, after all, that the labourers spoke English more or less well (or not at all, in which case an interpreter was used). Responses which cite what was said at the time a labourer was hired appear closer to what we imagine the language to have been like (e.g. using me as a subject pronoun more frequently, as opposed to the $\underline{I}$ in most responses to the judge).

II. 1911. Churchill's 'Beach-La-Mar', a compendium of sources (mainly accounts by travellers, including ships' captains and European residents of various islands), dating mainly from around 1900. Again, the quality of the data is variable, and care must be exercised.

III. 1930s. Hall's (1943) account provides texts collected in New Guinea (mainly the Sepik region) by various anthropologists in the 1930s.

IV. 1971. Recordings collected by Suzanne Laberge and myself of: (a) adult ('pidgin') speakers of Tok Pisin and (b) children and adolescent ('creole') speakers of Tok Pisin.

Cliticization of the subject pronoun $\underline{i}$ 'he' seems to have taken place between 1885 and 1935, and our data on the first three periods indicate this quite clearly. 
2.1 Stage I (1885). Of a sample of approximately 750 sentences containing subjects, the subject noun phrase consisted in over $99 \%$ of cases of either (a) a single noun, sometimes with, but generally without, modifiers as in (1), or more rarely, several conjoined nouns as in (2), or (b) a pronoun, as in (3)-(6). Pronoun subjects represented about $73 \%$ of subjects; the rest were noun subjects.

(1) Boatswain gammon me. ('The boatswain lied to me') (399) ${ }^{3}$

(2) Sister, father, and all people belong a me plenty cry. (484)

(3) We fellows no savez talk. Dixon talked. (517)

(4) Me no count him. (77)

(5) I no savez count him moons. (235)

(6) He say all same, 'three yams go work'. (330)

A few remarks are in order with respect to these sentences. Concerning the subject pronouns, the three which clearly dominate are $\underline{\mathbf{I}}$ (244 cases), he (124 cases) and you (109 cases). There are enough instances of me (18) for us to be sure that it was being used as a subject pronoun at this time, but we have no way of telling to what extent the $\underline{I}$ ' $s$ in the text represent 'corrections' or changes made in transcribing the hearings (I shows up to a limited extent in Stage II, and completely disappears in subsequent stages). 4

We can also be quite sure that he was functioning as a strong pronoun. First, there are no alternates (as with $\underline{\mathrm{I}} \underline{\mathrm{me}}$ ); him ( $>$ em, the current form) shows up for the first time in subject position in Churchill's 1911 materials. Second, he remains in significant proportions in the 1911 texts, and its descendant $\underline{i}$ is still with us; thus it is not the figment of the transcriber's imagination that I suspect $I$ of being.

But we also see the beginnings of $\underline{i}$ 's cliticization. There are five sentences (of some 200 with noun subjects) in which the noun is followed by he. This was clearly a little-used option in the grammar, or perhaps a strategy which was just being invented, and at least one of our examples would appear to indicate that it had contrastive force.

(7) Q. Did you talk to captain at Townsville? (496)

R. No; Jack he talked.

Contrast this with the more usual Dixon talked in (3). A second example shows another case of 'switch reference': this time the subject you is replaced by ship in the second speaker's response.

(8) Q. Then you went along ship?

R. Yes, and ship he go. (548) 
In the other three sentences using $\mathrm{N}+$ he $+\mathrm{V}$, the subject noun phrases are two fellow moon and three fellow moon, as in (9), all unusual in having relatively long (i. e. other than one-word) subjects.

(9) Two fellow moon he die, one fellow come up, then you go back. (554)

For comparison's sake, let us consider briefly the object pronoun him. There are far fewer cases of him than he occurring as an independent pronoun--only seven, one example of which is given as (4). But there is again evidence of the beginning cliticization of him, in that there are seven further sentences with $\mathrm{V}+$ him \pm NPcomplement, as in (5). This is fairly similar to the number of subject NP's occurring with the 'candidate clitic' he. However, recall that the proportion for he was five of 200 sentences with noun subjects; here there are seven of only 80 sentences with noun complements. Of the verbs occurring with him, several in current Tok Pisin have an obligatory -im suffix: count, call, hear, and feel. Modern descendants of like and finish take the $-i m$ suffix when used transitively. The four others (took get, shut, and tell) have not survived in modern Tok Pisin.

2.2 Stage II (1900-1910). Churchill's data look remarkably modern compared to the situation of Stage I. The most dramatic change is the cliticization of he (i), evident in the frequency of the NP+ he $+V$ type. Whereas it represented only $2.5 \%$ of all sentences with noun (nonpronominal) subjects in 1885, this type accounts for $65 \%$ of 81 nounsubject sentences I have examined in Churchill's data, as shown in Figure 1. Sentences with $N P+$ he $+V$ are illustrated in (10) and (11); with $\mathrm{NP}+\mathrm{V}$ in (12) and (13).

(10) One fella tree he tambo along you altogether. (Churchill, p. 34)

(11) Pappa belong me he go finish yes'erday. (Churchill, p. 34)

(12) That fellow break plenty match. (Churchill, p. 36)

(13) Plenty boy die. (Churchill, p. 36)

It is unclear from Churchill's data whether he can be analyzed as an agreement phenomenon as discussed in Givón (1976), given that it marked neither number nor gender. Churchill provides numerous examples of its use in four categories: 'masculine', 'feminine', 'neuter', and 'plural', including sentences (14) and (15).

(14) Queen Victoria he look out. (Churchill, p. 42)

(15) All a Malekula man he say. (Churchill, p. 42) 
FIGURE 1. Time course of the successive cliticization of $\underline{i}$ and em.

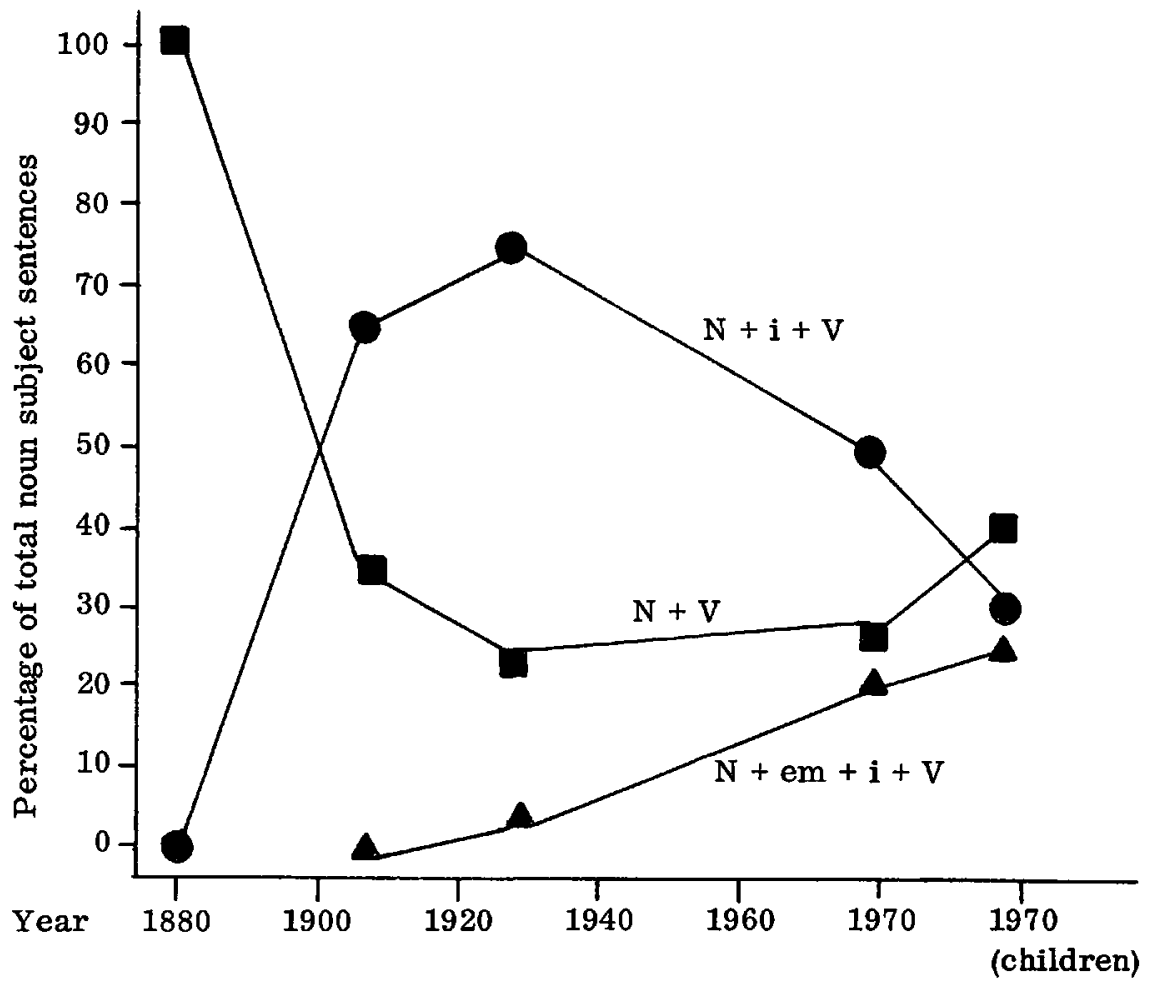

Note, however, that (a) Tok Pisin was already reorganizing its pronominal system to obliterate useless English distinctions such as gender in the third person singular (Churchill cites only four cases of she) and to set up more reasonable categories such as duals; and (b) the English pronominal forms which might have served in marking agreement had almost disappeared from Tok Pisin even at this time (if ever their presence was anything more than transcription error). In addition to she, these include they (only three cases in Churchill) and it (never cited). The 'second wave' of cliticization to be discussed in 3.3 most certainly did involve agreement.

Though I think we can safely say that cliticization of he (i) has taken place by this time, it seems that he (i) still retains some of its force as a strong pronoun. My main reason here (in the absence of any data on stress) is that he still occurs as a sole subject pronoun in a fairly significant number of cases, with only two cases of him occurring as a subject pronoun. He is the sole subject in 60 sentences, or $43 \%$ of the third person subject sentences, including those 
with $\underline{\mathrm{N}+\text { he }}$ ( 53 cases) and $\underline{\mathrm{N}}$ alone ( 28 cases). He as a subject pronoun is illustrated in (16); one of the two sentences with him as subject is cited as (17).

(16) He find him along reef. (Churchill, p. 33)

(17) Him go dead. (Churchill, p. 37)

Him has also made great strides as a clitic. Of 42 complement sentences, 15 have him alone as complement as in (16); 11 have him $+N$ complement. As shown in (18), there is some transcription of $\underline{\text { him }}$ as a suffix.

(18) He make'm one big fennis. (Churchill, p. 33)

There is one somewhat exceptional sentence in Churchill's material which deserves comment from two points of view.

(19) God big fella belong white man him fella he make' $m$ altogether. (Churchill, p. 34)

First, there is the rather odd him fella, a form which has not survived to the present as part of the standard paradigm mipela, yupela, etc., but which seems to represent a productive possibility which keeps cropping up in the language. Hall (1955) mentions its use on one occasion in 1954 as a demonstrative adjective. The interesting thing is that him fella is followed by he, and seems to be a case of a 'strong pronoun' followed by a weak or clitic pronoun. Churchill's data contain several other cases of such constructions: all he (one case); me fellow me (three cases); these two fella they (one case); you me two fellow we (one case); and the doubtful altogether you boy ... you (one case).

$\begin{array}{lll} & \text { Churchill (1911) } & \text { Current usage } \\ \text { 3rd sing. } & \text { em fellow he } & \text { em (i) } \\ \begin{array}{lll}\text { 1st dual (incl.) } \\ \text { 1st pl. (excl.) }\end{array} & \begin{array}{l}\text { you me two fellow we } \\ \text { me fellow me }\end{array} & \begin{array}{l}\text { (yu)mi tupela (i) } \\ \text { mipela (i) }\end{array} \\ \text { 2nd pl. } & \text { you . . . you } & \text { yupela (i) } \\ \text { 3rd dual } & \begin{array}{l}\text { these two fellow they } \\ \text { all he }\end{array} & \begin{array}{l}\text { tupela (i) } \\ \text { ol (i) }\end{array}\end{array}$


These cases seem to represent the initial extension of clitics with strong pronouns, a development subsequent to their use with nouns.

The second thing about sentence (19) is that it is the first case we have of a full noun phrase, followed by a strong pronoun, followed by the clitic he, a development which continues in later stages. It is of interest that the initial noun phrase is long and complex, one of the two factors we shall see later as favouring a pronoun copy.

2.3 Stage III (1930s). All of the trends evident in Churchill's material are continued at this stage. Principally, these trends are the following.

(1) The proportion of NP subjects followed by the clitic i- now represented as such in Hall's orthography) is even higher: of the 100 sentences with full noun phrase subjects, 71 are of the form NP $+\mathbf{i}$ $+\mathrm{V}$.

(2) There is an increasingly small proportion of sentences with ias sole subject (24 cases), and these are almost as clearly restricted to a small set of constructions as they are today, i. e. mainly existential sentences beginning with igat or inogat, as in (20), and in narrative 'overlaid' structures (cf. Grimes 1972), as in (21).

(20) Na em, bifor, i-no gat mun--no gat mun long klawd antap. (Hall, p. 46)

'Now previously there was no moon--there was no moon up in the clouds' (Hall's gloss).

(21) Na em i-no laik askim tufela, em papa i-haid tasol, i-stap. Istap nau, i-tudark nau. (Hall, p. 46)

'Now he did not want to ask the two of them, and the father just kept silent, and stayed there. He stayed there until dark.' (Hall's gloss).

(3) There is a greatly augmented use of i- in combination with other pronouns. Whereas there were eight such cases in Churchill's material, we now see $75 \%$ of pronouns followed by $\underline{i-}$, as em $\underline{i}-$ in (21).

(4) The complement clitic -im now appears to be firmly attached to all the verbs it attaches to today, and no more is said about it in this paper. A detailed discussion may be found in Wurm (1971:22-38). See also Lattey (1973).

(5) Em is firmly established as a subject pronoun (40 cases), as shown in Figure 2.

(6) The most striking development at this stage concerns what appears to be the beginning of a second wave of subject-pronoun 
FIGURE 2. Weakening of pronoun $\underline{i}$ and introduction and spread of em.

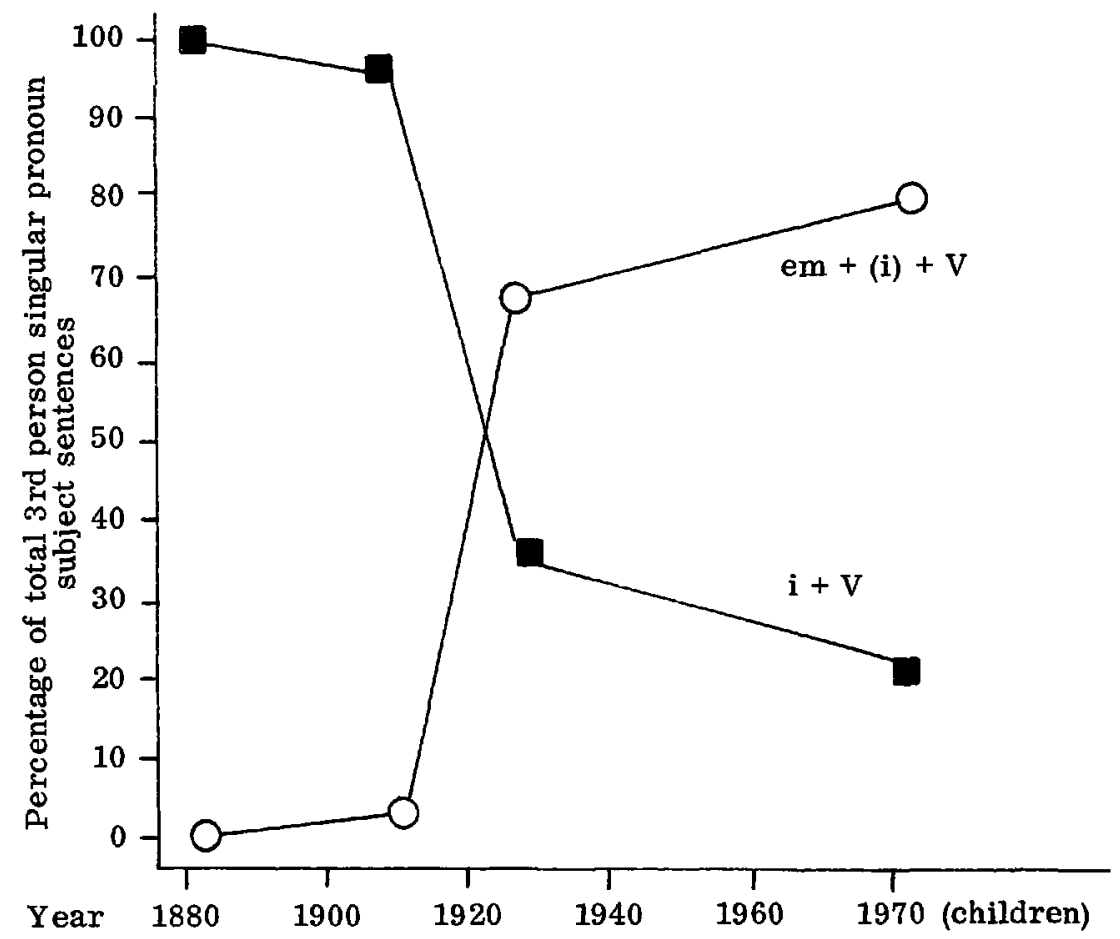

cliticization, i. e. $N+$ pronoun $+i+V$. I have so far found six cases; five with em (sing.) and one with ol (pl. ), as illustrated in (22)-(25).

(22) Putim umben long rot bilong pik, Ngwambwa em i-kisim pik. (Hall, p. 49)

'If we put a net on the road where the pig has been, a spirit of the dead takes the pig' (Hall's gloss).

(23) Mitufela sutim, givim long kandari, Bandarap. Bandarap em i-kukim. (Hall, p. 48)

'The two of us shot it, and gave it to my mother's brother, Bandarap. Bandarap cooked it' (Hall's gloss).

(24) Man i-mekim singsing long Mbabmu, meri em i-go long em, em i-pekpek blut ... (Hall, p. 48)

'Men utter a spell over (Mbabmu); if a woman goes near them, she will have dysentry' (Hall's gloss).

(25) Na papa bilong tufela pikinini, wantaim mama bilong tufela, ol i-go wok saksak long bus. (Hall, p. 46) 
'Now the father of the two children, and their mother, went to cultivate sago in the bush' (Hall's gloss).

In these sentences, even more than was the case with the initial cliticization of he (i), it is clear that the pronoun em performs a particular discourse function, being used in the case of long or complex subject NPs as in (25), where it serves as a reminder of the subject of the verb, and as an emphatic topic-changing marker as in (22)-(24). In (23), for example, the whole story is about the narrator and his hunting companion, referred to throughout as mitufela. The very last sentence, following a string of sentences in which mitufela was the subject, changes the subject to Bandarap, and inserts the pronoun em.

2. 4 Stage IV (1971). The data for this period have been separated into two groups: the adults, who are 'pidgin' or second-language speakers (as indeed were all of the people whose speech we have looked at in the first three stages), and their children, or 'creole' speakers. Though in many ways the grammars of these two groups are very similar with respect to subject clitics, they do differ in some degree. This raises the question of the extent to which these differences are to be accounted for as continuations of previous trends and innovative possibilities developed by second language speakers of Tok Pisin during the first three stages, or in terms of some special properties of 'creolization'. Let us first try to see what is common to both groups, adults and children.

Most importantly, both adults and children show a marked increase in the proportion of noun-subject sentences employing the $\mathrm{N}+$ pronoun $+i+V$ construction type, as illustrated in (26) and (27) (adults) and (28) and (29) (children).

(26) Bifo ol Gieman ol isoim ol bikpela man bifo. (Jack W. 2:2:028)

Before, the Germans taught our forefathers.

(27) Na narapela em iputim blakfela. (Tim D. 13:1:070) And the other guy wore a black one.

(28) Wanpela meri em igo nau, . . . (Paul T., age 11, 5:2:240)

So this woman went ...

(29) Planti kain man olsem ol isave stap long Lae (Joe S., age $11,5: 2: 263$ )

Lots of that kind of people live in Lae.

Among both adults and children, em is used for singular subjects and ol for plurals, but there are several cases of children hesitating over the choice, as in (30), and there may be some tendency among 
children towards generalizing em to plurals as well. Duals, as in (31), pose even more of a problem.

(30) Yu save ol disfela, ol man ol, em, ol, ikilim

disfela wonem ia, meri ia? (Colin $\mathrm{K}$., age 11, 5:2:250)

Do you know those men (who) killed this, uh, woman?

(31) Tupela liklik man em blong, ol blong, wonem, Butibum. (Celia D., age 9, 7:2:098)

The two little boys were from, were from, uh, Butibum.

The more usual pronoun to use with duals is tupela:

(32) Wanpela taim, Jack na mama bilong en tupela isave slip.

(Sogana L., age 11, 8:1:203)

Once upon a time, Jack and his mother were sleeping.

Among the adults of our 1971 sample, $23 \%$ of noun-subject sentences follow the subject noun phrase with a pronoun (em, ol, or tupela) agreeing in number with the subject. Among children, the figure is very similar, $27 \%$. The frequency alone, however, should not necessarily lead us to make any particular statements about whether this represents a 'second wave' of cliticization. It is clear that the former subject pronoun $\mathbf{i}-$ long ago lost its emphatic force as it became a clitic, but em and ol (tupela is of very low frequency) still retain it to some extent. Thus, their inclusion still serves in topic-changes as in (27) and unemphatic contexts like (28).

Data I have assembled on the children show a continuing decrease in i- as sole subject, almost entirely specialized to the existential sentences and overlaps discussed in Stage III. Indeed, the decrease in the proportion of such sentences over the whole time span considered is very regular. They represent one-half of NP subject sentences at Stage I, one-third at Stage II, one-fourth at Stage III, and one-sixth at Stage IV.

This leads us to the main difference between adults and children at Stage IV. As indicated in Figure 1, both groups have less i- in nounsubject sentences than do Hall's Stage III subjects in the 1930s. But the children have even fewer than the adults. This looks like a reversal of the earlier trend, cliticization of $i-$, which as far as our present indications go, seemed to have reached a peak in the 1930s. Smeall (1973) and Woolford (1975) have shown the complex syntactic and phonological conditioning of $\mathbf{i}-$ deletion in our 1971 data, and Woolford's comparison of these data with materials collected by Wurm in the late 1950 s indicates that $\underline{i}-$ was more frequent then, than at the 1930 date indicated in Figure 1. I do not discuss this conditioning here, but it appears that (a) it is not totally related to current 
em-cliticization, i.e. $\mathbf{i}-$ is dropping out a little more rapidly than em is coming in; and (b) it represents a further complexity in the children's grammar, where $i_{2}$ having lost first its semantic and then syntactic weight, could undergo morphophonologically conditioned deletion. And it is in phonology in general that children appear most significantly to differ from adult speakers of Tok Pisin at present (e.g. the differences in stress documented in Sankoff and Laberge 1973).

3. 0 Conclusion. We have followed the vagaries of the progressive grammaticalization of a particular linguistic practice. This practice, the insertion of the pronoun he after a subject noun, appears to have originated as a device marking and emphasizing particular nouns in particular discourse contexts, e.g. topic changes. The progressive grammaticalization has involved loss of the original pragmatic or semantic force, along with greater interaction with other syntactic rules, until such time as the pronoun-clitic loses all force and is subject to the grim reaper, phonological deletion. Overlapping with this is another later but similar wave involving the same kinds of strategic-cum-grammatical processes.

Further work will attempt to clarify the discourse constraints involved in this 'second wave', expanding the analysis to all of Hall's texts (only a small sample was treated here), those of Wurm and Laycock (not treated at all here), and our conversational materials from 1971. It is suggested that these may aid retrospectively in the interpretation of the 'first wave' in the early texts, which are less rich in terms of sequential discourse.

It is clear that change in the pronominal and agreement systems has been very rapid in Tok Pisin. The changes documented in this paper cover a span of only 85 years, implying that at virtually any point within this span, there has been a great deal of variability. Such variability, however, does not appear to have obstructed communication, or to have led to difficulties in language learning. The number of Tok Pisin speakers continued to grow throughout the period, and only very recently (and then only partially) as a result of the birth rate. As innovations having particular discourse functions underwent rapid diffusion, generalization, and regularization, they lost such functions and were subsequently supplemented by other innovations. All of this has led, among other things, to greater redundancy in Tok Pisin. Variability has been not a symptom of disorder, but an indication of growth.

\section{NOTES}

An earlier version of this paper was read at the Conference on Mechanisms of Syntactic Change, organized by Charles Li, Santa 
Barbara, May, 1976. I am very grateful to Suzanne Laberge for the major part she played in the data collection in Papua New Guinea in 1971, and to David Sankoff and Pierrette Thibault for their generous contribution to the data analysis. I also thank the many kind residents of Lae and environs, Papua New Guinea, who permitted us to record them and their children.

1. Most of the work $I$ have in mind is European, including the Prague School, Volosinov in the USSR, Frei and Bauche in Switzerland, Martinet in France, and Halliday in England.

2. This paper, as such, is part of a long-term project to analyze the major morphological and syntactic changes in Tok Pisin from early days through creolization (cf. Sankoff and Brown 1976; Sankoff and Laberge 1973; Sankoff 1976, 1977). A more detailed analysis of cliticization is in preparation.

3. The numbers which follow sentences from the 1885 Royal Commission report designate lines as indicated in the Report. Orthography for the first three stages follows the orthography of the original sources.

4. The only vestige of $I$ in current Tok Pisin is found in the form ating glossed 'perhaps' or 'maybe'. Interestingly, four of Churchill's 10 cases of I occurred with the verb 'think'.

\section{REFERENCES}

Churchill, William. 1911. Beach-La-Mar. Carnegie Institution, Publication 154.

Frei, Henri。 1928. La grammaire des fautes. Reprinted 1971. Geneva: Slatkine.

Givón, Talmy. 1976. Topic, pronoun and grammatical agreement. In: Subject and topic. Edited by Charles Li. New York; Academic Press.

Grimes, Joseph E. 1972. Outlines and overlays. Lg. 48.513-24.

Gumperz, John. 1964. Linguistic and social interaction in two communities. American Anthropologist 66, No. 6, Pt. 2. 137-153.

Hall, Robert A., Jr. 1943. Melanesian Pidgin English. Baltimore: Linguistic Society of America.

Hall, Robert A., Jr. 1955. Innovations in Melanesian Pidgin (NeoMelanesian). Oceania 26.91-109.

Hockett, Charles. 1963. The problem of universals in language.

In: Universals of language. Edited by J. H. Greenberg. Cambridge, Mass.: MIT Press.

Hymes, Dell. 1964. Introduction: Towards ethnographies of communication. American Anthropologist 66, No. 6, Pt. 2. 1-34. 
Hymes, Dell. 1969. Functions of speech and linguistic theory. International Days of Sociolinguistics, 111-44. Rome: Istituto Luigi Sturzo。

Kuno, Susumu。 1975. Three perspectives in the functional approach to syntax. Papers from the Parasession on Functionalism. Chicago Linguistic Society. 276-336.

Lattey, Elsa. 1973. Beyond variable rules. Unpublished.

Queensland. 1885. Proceedings of the Legislative Assembly Session, Brisbane: Royal Commission on Recruiting Polynesian Laborers in New Guinea and the Adjacent Islands.

Sankoff, Gillian。 1976. Political power and linguistic inequality in Papua New Guinea. In: Language and politics. Edited by W. and J. O'Barr. The Hague: Mouton. 283-310.

Sankoff, Gillian. 1977. Creolization and syntactic change in New Guinea Tok Pisin. In: Sociocultural dimensions of language change. Edited by B. Blount and M. Sanches. New York: Academic Press. 119-130.

Sankoff, Gillian, and Penelope Brown. 1976. The origins of syntax in discourse: A case study of Tok Pisin relatives. Lg. 52.631-666. Sankoff, Gillian, and Suzanne Laberge. 1973. On the acquisition of native speakers by a language. Kivung 6:32-47.

Smeall, Christopher. 1975. A quantitative study of variation: Tok Pisin i-. Berkeley Linguistics Society meeting.

Woolford, Ellen. 1975. Variation and change in the i 'predicate marker' of New Guinea Tok Pisin. International Conference on Pidgins and Creoles, Hawaii.

Wurm, Stephen A. 1971. New Guinea Highlands Pidgin: Course materials. Pacific Linguistics Series D, No. 3. 

LEXICAL UNIVERSALS

AND THE HUMAN LANGUAGE FACULTY

CECIL H. BROWN

Northern Illinois University

Language universals provide evidence for innate aspects of linguistic knowledge. Contemporary theoretical linguistics has focused upon uniformities among languages with the idea that these regularities must somehow be built into human minds. Evidence demonstrating universals has been assembled, for the most part, by psycholinguists interested in child language acquisition and by comparativists such as Charles Ferguson and Joseph Greenberg. Psycholinguists and comparativists alike have primarily directed their attention to universals in the phonological and syntactic components of language and most interpretations of language's innate properties have been in terms of phonology and syntax. In this paper I discuss how lexical universals as well, viewed in developmental terms, can contribute to a theory of the human language faculty. 1

Two distinct positions are emerging with regard to the fundamental nature of this faculty. One is associated with observations of Noam Chomsky, especially those recently made by him in Reflections on Language (1975). This interpretation can be called the 'detailed wiring' model. The other position is only now beginning to crystalize as a unified point of view and no single individual can yet be identified as its major spokesman. This interpretation can be called the 'information processing' model.

The detailed wiring model proposes that humans start life with very specific knowledge about language 'wired' or 'programmed' in their brains. These neural specifications could, for example, take the form of particular grammatical rules and/or specific linguistic categories. While Chomsky (1975) is careful not to make extreme claims regarding the nature of programmed linguistic competence, clearly he believes 
that observed regularities across languages are so specific and detailed that they cannot be explained by the relatively simple cognitive machinery usually associated with information processing interpretations.

The information processing model also proposes that humans are wired for language, but with a somewhat less extensive circuitry than that implied by Chomsky. This model views language as largely learned, but the learning itself is explained in trorms of certain inborn mechanisms for processing primary linguistic data. A number of mechanisms have been suggested. For example, I have outlined (Brown 1974) how 'recoding' might figure into the learning and use of language. Recoding, first described by Miller (1956; see also Simon 1974), provides a mechanism which can account for the human ability to organize information of considerable quantity in such a way that it can be easily and quickly recalled. The spontaneity of language use obviously involves some procedure, such as recoding, that serves to increase the span of immediate memory. Kronenfeld (1976) also mentions recoding and several other faculties in connection with presentation of an information processing model of language. 2

Given the relatively small inventory of language universals thus far documented, we are not now in a position to decide which of these two models is more representative of the human language faculty. It is, of course, possible that both detailed wiring and information processing underlie language in some complementary manner. One purpose of this paper is to discuss which of these two models appears most promising in light of explanations that can be brought to bear upon certain lexical universals. The latter include regularities pertaining to the domains of color and folk botany, both of which have been extensively studied by linguistic anthropologists.

Lexical universals: Basic color classes. In 1969, Berlin and Kay compiled an impressive body of cross-linguistic data showing that basic color terms are added to the lexicons of languages in a highly regular manner. Since then, numerous field studies of native color vocabularies have been published. This additional evidence supports Berlin and Kay's general conclusions and has led to only minor changes in the originally described color encoding order. Figure 1 gives the lexical encoding sequence for basic color classes, including latest revisions and amendments (cf. Witkowski and Brown 1977).

In Figure 1 a term in quotation marks refers to the 'focus' of a color category which is the most typical or representative member of that class in the judgment of informants. An expression in uppercase type designates a 'composite' color class (cf. Kay and McDaniel 1975). Composite categories, or 'macro-colors', consist of various combinations of the basic hues (red, yellow, green, and blue) and black and 
FIGURE 1. Color encoding sequence (Witkowski and Brown 1977). Reproduced by permission of the American Anthropological Association from the American Anthropologist 79(1):51, 1977.

This content has been removed due to copyright restrictions. To view the content on $\mathrm{p} .77$, please refer to the print edition of this work.

white. Macro-colors can have variable foci, both intrasocietally and cross-societally. Even so, Berlin and Kay have shown that the foci of all color categories fall into not more than eleven small areas of the color space (cf. Figure 2). When a term has a variable focus, these foci are always chosen from no more than two of these eleven delimited areas.

Languages having less than two basic color terms have not been reported. Languages with two terms (e.g. the Dugum Dani of New Guinea) are at Stage I in the growth or development of color vocabulary. These two terms always label respectively the composite categories 'macro-white' and 'macro-black'. Macro-white includes whites and most warm hues (reds, yellows, oranges, browns, pinks, and purples) and macro-black includes blacks and most cool hues (blues and greens). Figure 2 is a representation of the Berlin and Kay color array or color space. Among other things, it roughly indicates Stage I partitioning or, in other words, the boundary between macrowhite and macro-black--for example, the boundary between the Dani mola and mili, respectively.

The Berlin and Kay color space is defined by the intersection of the dimensions brightness (vertical axis) and hue (horizontal axis). (All hues are maximally saturated for each degree of brightness.) Cool hues (blues and greens) are found near and in the center of the rectangular diagram with warm hues (reds, yellows, etc.) at both ends. Figure 2 locates all eight color foci pertaining strictly to hue. The foci of 'black', 'white', and 'gray' are not indicated in the figure.

The focus of the macro-black category is always 'black', while the focus of the macro-white category is variable. For the Dani, 'red' is the focus for. $70 \%$ of the informants, and 'white' is the focus for the remainder (Heider 1972a, 1972b). Two other composite categories, 'macro-red' and 'grue', occur in the color encoding sequence (cf. 
FIGURE 2. The Berlin and Kay color space showing two term system partitioning, macro-red, and the eight hue foci (Witkowski and Brown 1977)。 Reproduced by permission of the American Anthropological Association from the American Anthropologist 79(1):51, 1977.

This content has been removed due to copyright restrictions. To view the content on p.78, please refer to the print edition of this work.

Figure 1). Macro-red, whose approximate boundary is sketched in Figure 2, is always focused in 'red'. Its range varies from language to language, in some cases including all warm hues and in other instances all warm hues with the exception of yellows. Grue, whose boundary is not given in Figure 2, is focused in either 'green' or 'blue' (Tzeltal Mayan informants, for example, tend to place the focus of their grue category in 'green'; a few informants, however, focus it in 'blue'). The range of grue encompasses: (1) all cool hues (greens and blues), (2) some greens if mostly blues, (3) some blues if mostly greens.

The process leading to the lexical encoding of macro-red at Stage II essentially consists in separating warm hues from light hues 
and white and assigning labels to both new categories (i.e. to macrored and white). Similarly, the encoding of grue involves the separation of all or some of the cool hues from very dark hues and black, and assigning labels to both new categories (i. e. to grue and black). The lexical encoding of other color classes, from Stage IIIb to Stage VII, is, for the most part, accomplished by subdividing the ranges of macro-red and grue.

Lexical universals: Folk botanical life forms. Recently, I have assembled data (Brown 1977) from 105 globally distributed languages showing that folk botanical life form terms are also added to languages in a highly regular manner. Botanical life form terms designate the most inclusive, comprehensive classes of plants (apart from the 'plant kingdom' category) regularly discovered in folk botanical taxonomies. I have shown that five life form taxa, roughly glossed 'tree', 'herb', 'bush', 'grass', and 'vine', are labeled in languages spoken in every major inhabited ecological zone. The distinctive morphological features possessed by plants which determine their inclusion in the latter five categories are of such a general nature that botanical organisms found in all of the world's plant-bearing environments manifest them. These features are the following.

'tree' larger plant (relative to the plant inventory of a particular environment) whose parts are chiefly ligneous (woody).

'herb' smaller plant (relative to the plant inventory of a particular environment) whose parts are chiefly herbaceous (green, leafy, non-woody). (This definition provides for the inclusion of grasses within the class. However, in this paper, unless otherwise indicated, 'herb' is used to refer to a class so defined, but excluding grasses.)

'bush' plant of intermediate size (relative to the plant inventory of a particular environment) whose parts are either ligneous or herbaceous.

'grass' smaller herbaceous plant (relative to the plant inventory of a particular environment) with narrow, often blade-like or spear-shaped leaves.

'vine' plant exhibiting a creeping, twining, or twisting stem habit, whose parts are either ligneous or herbaceous. 
Figure 3 presents the lexical encoding sequence for the five globally distributed, pan-environmental life form classes I have defined here. This is interpreted as a series of stages in the growth of folk botanical life form vocabularies. Languages at Stage 1 have no botanical life forms. At Stage 2 'tree' is lexically encoded. The 'tree' life form of early stage languages often is considerably broader in actual plant membership than the 'tree' of later stage languages. This life form frequently includes bushes and shrubs, and sometimes even ligneous vines, in addition to trees.

FIGURE 3. Folk botanical life form encoding sequence (Brown 1977). Reproduced by permission of the American Anthropological Association from the American Anthropologist 79(2):138, 1977.

This content has been removed due to copyright restrictions. To view the content on p.80, please refer to the print edition of this work.

At Stage 3 a second life form, GRERB, is added. GRERB designates a general category of small herbaceous plants. This life form is never encoded as 'herb', i. e. herbaceous plants excluding grasses, but is always added either as a composite category, 'grass' + 'herb', or simply as 'grass'. When GRERB is encoded as 'grass', it may in fact include a few nongrassy herbaceous plants in addition to grasses. The latter category usually is associated with languages spoken in areas in which smaller herbaceous plants predominantly are grasses. In any case, GRERB life forms of early stage languages characteristically include most, if not all, plants not included in the 'tree' life form.

From Stage 4 to Stage 6 three additional life forms are lexically encoded. Certain encoding options are associated with these stages, resulting in three possible paths for adding botanical life form terms to lexicons (cf. Figure 3). These additional taxa encompass plants 
previously included in GRERB and/or 'tree' at earlier developmental stages. Thus the lexical encoding of 'bush', for example, is achieved by pulling bushes and shrubs from the range of GRERB or 'tree', or from the ranges of both, as the case may be. Thus as life forms are added from Stage 4 to Stage 6, the ranges of GRERB and 'tree' tend to shrink.

While either 'bush' or 'vine' may be lexically encoded immediately after GRERB at Stage 4, 'grass' is never the third botanical life form added. 'Grass' is created by pulling grasses from the range of GRERB, i. e. from the composite category 'grass' + 'herb'. Consequently, when 'grass' is encoded, 'herb' (herbaceous plants excluding grasses) becomes the residue of a previously more comprehensive GRERB life form.

Since completing the botanical life form study (Brown 1977), I have become acquainted with a paper by Dougherty (1977) dealing with acquisition of ethnobotanical nomenclature by American English-speaking children. This paper presents evidence independently supporting some of my conclusions regarding life form encoding regularities. Dougherty reports that three-year-old children initially recognize a tree/ (herbaceous) plant opposition at the life form level. While tree is at first learned as a label for one or two specific and familiar arboreal examples, children soon come to overgeneralize referential use of the term to tallish, woody plants. At approximately the same time, plant is acquired as a label for low, shrubby, herbaceous plants. According to Dougherty, life forms subsequently distinguished by children include plants previously included in tree and in plant, e.g. bushes and grass, respectively. Dougherty's acquisitional study combined with my comparative-diachronic treatment (Brown 1977) suggest a clear linguistic analogue to phylogeny recapitulated by ontogeny.

Explanation of lexical encoding regularities. According to Bormstein (1975), who summarizes ethological, electrophysiological, behavioral, and psychophysical studies, natural categories of hue exist in infrahuman species (e.g. bees, pigeons, monkeys) and in human infants and adults. Bornstein, with Kessen and Weiskopf (1976:201202), has determined experimentally the existence of such categories for human infants. It can now be stated with reasonable confidence that humans are in some manner wired or programmed for partitioning the physically continuous hue spectrum into red, yellow, green, and blue (see also Kay and McDaniel 1975).

The experimental determination of these four natural categories is evidence for innate partitioning of the color space, complementing that assembled by Berlin and Kay (1969). On the other hand, experimentation has yet to reveal any inborn, specific, psychophysical mechanism accounting for the additional fact that color classes are 
lexically encoded in an invariant order. The discovery of a second encoding sequence--involving folk botanical life forms--raises the possibility that constraints pertaining to the addition of basic color terms to vocabularies are equally pertinent to other domains. If lexical encoding constraints are not domain-specific, then the wiring associated with them is probably very general. This would suggest that information processing mechanisms, rather than detailed neural specifications, underlie lexical encoding regularities.

Witkowski and I (1977) have outlined several principles of namingbehavior that figure into an explanation of the color encoding sequence. Elsewhere (Brown 1977), I have incorporated these principles into an explanation of regularities associated with the addition of folk botanical life forms to languages. The following discussion compares the encoding sequences for color and botanical life forms, showing how each is accounted for, at least in part, by the same set of namingbehavior procedures.

The special encoding priorities of macro-white and macro-black in the color encoding sequence, and of 'tree' and GRERB in the life form encoding sequence, can be attributed to the general human tendency to classify by means of binary oppositions. This tendency is particularly apparent in the adjectival component of vocabularies. The oppositional characteristics of dimensional concepts such as height, width, depth, etc., are usually encoded by two terms, and only rarely are finer dimensional distinctions lexically carved out. This results in such familiar adjectival oppositions as wide/narrow, deep/shallow, hard/soft, rough/smooth, sharp/blunt, and so on.

Languages affiliated with Stage I of the color sequence and with Stage 3 of the life form sequence illustrate this tendency. In the case of life forms, Stage 3 languages have added two major botanical categories, 'tree' and GRERB, in which most, if not all, plants are included. Presumably, this is accomplished through recognition of opposing dimensional characteristics of plants. This may involve (1) the dimension 'size' or (2) the dimension 'ligneousness vs. herbaceousness', or, conceivably, both (1) and (2) simultaneously. The life form 'tree' then includes all larger, ligneous plants, and its opposite, GRERB, all smaller, herbaceous plants. Clearly, large plants are usually ligneous and small plants are usually herbaceous so that attention to either dimension (1) or (2) would result in essentially the same contrast, i.e. 'tree' versus GRERB. However, the bulk of evidence suggests 'size' as the critical, underlying dimension.

In Delaware, for example, the 'tree'/GRERB distinction is made through reference to the size of human adults (Miller 1975). The Delaware 'tree' term, hctukw, is used to refer to any plant over human height and the GRERB term, skikw, to plants shorter than humans. GRERB terms are frequently found to name small trees in addition to 
herbaceous plants. Laughlin (1975:29) reports that the Tzotzil Mayan

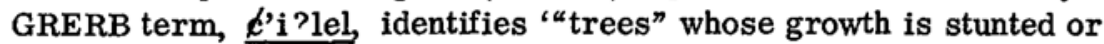
which are collected in their early stages of growth.' In addition, the Huastec Mayan 'x'ohol, naming a class of small herbaceous plants excluding grasses, vines, and bushes (Brown 1972), can be used to label any young or poorly developed tree no more than two or three feet tall. Stephen A. Tyler (personal communication) reports a similar use for the Koya GRERB term, ettu. Conversely, 'tree' terms are occasionally used to name plants, normally classified as GRERB, which have achieved exceptional size. For example, Laughlin (1975:

29) describes the following use for the Tzotzil 'tree' term, te?: '. . . if a species that would normally be classed as a "plant" [ grows with great vigor, it may be identified as a "tree”."

The encoding priority of macro-white and macro-black is likewise ascribed to attention to dimensional concepts and binary opposition. In two term color systems (Stage I languages), oppositional characteristics of both the brightness and hue dimensions (see Figure 2) are lexically encoded by use of only two terms. Macro-white (whiteyellow-red) and macro-black (black-blue-green) oppose light and dark colors along a brightness dimension, and warm and cool hues along a hue dimension, always associating light colors with warm hues and dark colors with cool hues (see Figure 4A). This constitutes a remarkably ingenious way of creating two sets of binary oppositions through the use of only two terms.

FIGURE 4. Binary distinctions pertaining to the encoding of (A) macro-black and macro-white, and (B) macro-red and white (Witkowski and Brown 1977). Reproduced by permission of the American Anthropological Association from the American Anthropologist 79(1):55, 1977.

This content has been removed due to copyright restrictions. To view the content on p.83, please refer to the print edition of this work. 
An equally ingenious solution would lump light colors with cool hues and dark colors with warm hues (i. e. create the macro-categories red-yellow-black and green-blue-white). Such combinations, however, are not found in the color nomenclature literature. Apparently, there is something compelling about combining red-yellow with white rather than with black. The naturalness of the former combination relates to the fact that yellow, one of the four natural color categories identified by Bornstein, is focused in an extremely light part of the color space, while the other three natural categories (red, blue, and green) are focused at intermediate to dark brightness levels (cf. Figure 2). The association of yellow with white is natural and conjunctive. The further natural and conjunctive association of yellow with red (the two are juxtaposed in wavelength order: redyellow-green-blue) results in the macro-white category. It is the extremely offset focus of yellow towards the bright pole of the color space that determines which contrasting aspects of the brightness and hue dimensions are associated when binary oppositions are made.

In the color sequence (cf. Figure 1), macro-red emerges after macro-white and macro-black at Stage $I I$ as the result of another binary opposition (light versus warm). The lexical encoding of macrored in effect represents the separation of brightness from hue in the light-warm range of the color space (see Figure 4B). Similarly, the emergence of grue at Stage IIIa or IV represents separation of brightness and hue in the dark-cool range of the color space (dark versus cool). Thus macro-red is distinguished from an essentially nonhueassociated white, and grue is distinguished from an essentially nonhue-associated black as additional binary oppositions are recognized.

The primacy of binary opposition in categorization accounts for (1) the developmental priority of 'tree' and GRERB vis-a-vis 'bush', 'vine', and 'grass', and (2) the developmental priority of macrowhite and macro-black vis-a-vis macro-red, grue, and other basic color classes. Certain other encoding regularities pertaining to both color categories and folk botanical life form taxa can be described in terms of the framework of 'marking' developed over the years by Greenberg $(1966,1969,1975)$ and others.

Marking frequently finds expression in antonyms such as wide/ narrow and deep/shallow (Greenberg 1966:53). In such pairs one item will be marked and the other unmarked. An unmarked item tends to occur more frequently in language use and, hence, is more salient than its marked opposite. For example, queries concerned with width and depth are more often framed with the unmarked forms 'wide' and 'deep', than with the marked forms 'narrow' and 'shallow'. We customarily ask 'How deep is the river?' not 'How shallow is the river?' In addition, marked items tend to be phonologically more 
complex than unmarked items, suggesting the unmarked term to be older and hence developmentally prior to the marked term.

The same pole of a dimension underlying an adjectival contrast will tend to be unmarked in all languages recognizing the dimension. Greenberg (1966:53), for example, has assembled evidence indicating that 'deep' is universally unmarked while its counterpart, 'shallow', is universally marked. This fascinating result apparently extends to both botanical life form taxa and basic color categories. In the case of life forms, 'tree' or large plant is universally unmarked--in the sense that it is developmentally prior in all languages--and its counterpart, GRERB or small plant, is universally marked. In the case of color (chromatic categories considered alone), a class focused in 'red' is universally unmarked (developmentally prior) and categories having other color foci are universally marked. By fitting these encoding uniformities into the framework of marking, I am simply suggesting that they do not constitute exceptional linguistic regularities. I am also suggesting that plausible explanations eventually brought to bear upon marking uniformities in the adjectival component of language will also bear upon marking uniformities in the domains of color and folk botany.

Occasionally, marking is carried beyond a simple binary distinction. For example, just as GRERB is marked vis-a-vis 'tree', 'bush' is marked vis-a-vis GRERB. 'Bush', GRERB, and 'tree' together form a marking sequence. The lexical encoding of 'bush' involves further attention to the dimension underlying the 'tree'/GRERB or large plant/ small plant opposition. 'Bush' is a plant of intermediate size (relative to the plant inventory of a particular environment) whose parts are either ligneous or herbaceous. 'Bush', in effect, mediates between the oppositional poles 'tree' and GRERB along a 'size' dimension. Only when the 'tree'/GRERB distinction is recognized, and both poles are labeled, will 'bush' be distinguished as a category of botanical organisms that are smaller than the largest plants and larger than the smallest plants in any given environment.

Two distinct marking sequences underlie color encoding uniformities. These sequences are associated respectively with the dimensions brightness and hue. Brightness and hue are interacting dimensions in Stage I languages having two basic color terms. The division of macro-white into macro-red and nonhue-associated white at Stage II represents the first step in the disassociation of these dimensions. By the time grue and nonhue-associated black emerge at Stage IIa or IV, brightness and hue are completely disassociated. (This is an approximate generalization since some yellows may still be associated with white and some blues may still be associated with black at Stage IIII or IV, cf. Bornstein 1973.) Brightness and hue then are gradually dissociated as languages add more basic color terms. 
Originally, Berlin and Kay (1969) placed the encoding of gray in their Stage VII (i. e. after the encoding of black, white, red, yellow, green, blue, and brown). Even then, four of their seven error cases involved the premature appearance of gray. Evidence adduced since then (summarized in Kay 1975) shows many more exceptional cases. Consequently, gray is now considered a 'wild card' color (Kay and McDaniel 1975:33) which can be encoded at any point after the early stages (see Figure 1). The seemingly irregular status of gray relates to the fact that black, white, and gray pertain to a dimension of brightness quite separable from hue.

Gray is marked vis-a-vis black and white. Together they form a dimension (and a marking sequence) distinct from the hue dimension. The brightness dimension is treated similarly to the size dimension underlying 'bush', GRERB, and 'tree'; namely, an opposition is recognized and both poles are labeled, and only later is a middle segment distinguished. Gray, in effect, mediates between the oppositions black and white (just as 'bush' mediates between the oppositions GRERB and 'tree'). Therefore, the encoding of gray is not strange after all. Its 'wild card' status vis-a-vis hue colors merely reflects the fact that it is on a different dimension from them.

The hue dimension underlies the other marking sequence pertaining to color. In Figure 5 the color encoding sequence presented in Figure 1 is reformulated to better account for color data and to clarify how the hue dimension is treated in terms of marking. In this reformulation, only strictly hue categories are considered. In addition, the reformulated sequence deals only with focal colors, not category boundaries.

The basic encoding sequence originally presented by Berlin and Kay (1969) is still present in Figure 5, but it has been weakened somewhat. Focal red is always encoded first (Stage A), then focal yellow, green, and/or blue (Stage B), but in no particular order. (Statistically, focal yellow is most frequently encoded second, with focal green third, and then focal blue.) Similarly, focal brown, pink, purple, and orange (Stage C) are encoded only after all four primary hues--or in a few cases after three--but, again, in no particular order. This reformulation accords with all of the existing color nomenclature data whereas the more strongly formulated encoding sequence of Berlin and Kay contains numerous exceptions. Also, since Figure 5 makes weaker ordering claims, it is less likely to be compromised by accumulating color data.

Figure 5 provides a clear picture of color nomenclature universals. The four natural or wired color categories, red, yellow, green, and blue, are encoded first. Colors designated by Kay and McDaniel (1975) as 'derived' categories, i. e. brown, pink, purple, and orange, 
FIGURE 5. The reformulated encoding sequence for hue (Witkowski and Brown 1977). Reproduced by permission of the American Anthropological Association from the American Anthropologist 79(1):52, 1977.

This content has been removed due to copyright restrictions. To view the content on $\mathrm{p} .87$, please refer to the print edition of this work.

emerge only secondarily. Thus color labeling evidence originally assembled by Berlin and Kay, and the psychophysical evidence recently gathered by Bornstein, dovetail neatly.

In terms of marking, the four derived hue categories are marked vis-a-vis the four natural hue categories. In addition, yellow, green, and blue are marked vis-a-vis red. The special status of red as the universally unmarked pole of the hue dimension is in accord with psychophysical evidence marshalled by Bornstein, Kessen, and Weiskopf (1976), showing that red is especially salient for human infants. In addition to determining experimentally the existence of four natural categories of hue for infants, Bornstein and his collaborators also gathered evidence indicating the special salience of red relative to the other three wired color classes (1976:202).

I have accounted for many regularities associated with the lexical encoding of basic color terms and folk botanical life forms through reference to binary opposition and the framework of marking. Although some aspects of lexical encoding have not been treated, sufficient detail has been provided to arrive at some preliminary evaluation of the contribution of lexical universals to an understanding of innate factors underlying language.

Conclusion. The preceding discussion of lexical uniformities indicates that both detailed wiring and information processing constitute aspects of the human language faculty. Constraints involving color categories, botanical life forms, and adjectival oppositions do 
not, for the most part, appear to be domain-specific, suggesting that the wiring associated with them generally lacks specificity. Binary opposition and marking sequences clearly relate to mental faculties involving information processing rather than detailed wiring. On the other hand, color encoding is in part explained through reference to natural categories of hue which may be wired in some detailed manner into the neural circuitry of humans.

Lexical universals indicate that information processing plays a considerably more important role in shaping actual language than does detailed wiring. Certainly the character of lexicons, especially their adjectival constituents, would be quite different without binary opposition and marking sequences. On the other hand, language would be much the same if humans were not wired for natural categories of hue. Indeed, there is no reason to assume that languages would lack terms for general color classes if humans were not programmed for red, yellow, green, and blue. Lack of specific wiring for botanical categorization, for example, has not prevented lexical encoding of general plant classes. Detailed wiring for color categorization is interesting, but for the most part superfluous to the human language faculty. 3

Lexical universals treated in this paper lend much support to the information processing model of human language and only marginal support to the detailed wiring model. This is somewhat unexpected given the detailed encoding sequences for color classes and folk botanical life forms. We must be careful in the future not to assume too readily--as proponents of detailed wiring occasionally have done-that language universals characterized by particularity are necessarily the product of innate specificity.

\section{NOTES}

I would like to thank a number of people for reading and commenting on an earlier draft of this paper. These include Noam Chomsky, Harold C. Conklin, Janet Wynne Dixon Dougherty, Marshall Durbin, Paul Friedrich, Donn Hart, Terence E. Hays, Albert Heinrich, Eugene Hunn, David B. Kronenfeld, Robert A. Randall, Brian Stross, and Stanley R. Witkowski.

1. Studies of lexical universals by linguistic anthropologists and others not cited in the body of this paper include Nerlove and Romney's (1967) typology of sibling terminologies and Kronenfeld's (1974) refinement of the latter; Witkowski's (1972) treatment of implicational universals in kinship categorization; Berlin's (1972) speculations on the growth of ethnobotanical nomenclature and Berlin et al.'s (1973, 1974; Berlin 1976) proposal of general principles of biological classification; Brown et al.'s (1976) demonstration of extension of the latter principles to nonbiological classification; Williams' (1976) possible law 
of semantic change involving synaesthetic adjectives; Brown's (1976) outline of nomenclatural regularities in human anatomical partonomy (body part systematics) and speculations on the development of partonomic terminology; and Burris' (1976) lexical encoding sequence for geometric figure classes.

2. The other faculties mentioned by Kronenfeld (1976) include the abilities to name, to use names in one-word utterances, to join two names into a single utterance, to embed, to recognize recurrent patterns, and to extract regular language frames from these patterns. 3. Wiring for natural categories of hue almost certainly did not arise in response to selection for language faculties. As mentioned earlier, similar wired color classes have been discovered for infrahuman species, e.g. bees, pigeons, monkeys, as well as for human infants and adults (Bornstein 1975).

\section{REFERENCES}

Berlin, Brent. 1972. Speculations on the growth of ethnobotanical nomenclature. Language in Society 1.51-86.

Berlin, Brent. 1976. The concept of rank in ethnobiological classification: Some evidence from Aguaruna folk botany. American Ethnologist 3. 381-399.

Berlin, Brent, Dennis E. Breedlove, and Peter H. Raven. 1973. General principles of classification and nomenclature in folk biology. American Anthropologist 75. 214-242.

Berlin, Brent, Dennis E. Breedlove, and Peter H. Raven, 1974. Principles of Tzeltal plant classification: An introduction to the botanical ethnography of a Mayan-speaking people of highland Chiapas. New York and London: Academic Press.

Berlin, Brent, and Paul Kay. 1969. Basic color terms: Their universality and evolution. Berkeley: University of California Press.

Bornstein, Marc H. 1973. The psychophysiological component of cultural difference in color naming and illusion susceptibility. Behavior Science Notes 8.41-101.

Bornstein, Marc H. 1975. The influence of visual perception on culture. American Anthropologist 77.774-798.

Bornstein, Marc H., William Kessen, and Sally Weiskopf. 1976. The categories of hue in infancy. Science 191.201-202.

Brown, Cecil H. 1972. Huastec plant taxonomy. Katunob 8(2). 74-84. Brown, Cecil H. 1974. Wittgensteinian linguistics. The Hague: Mouton and $\mathrm{Co}$.

Brown, Cecil H. 1976. General principles of human anatomical partonomy and speculations on the growth of partonomic nomenclature. American Ethnologist 3.400-424. 
Brown, Cecil H. 1977. Folk botanical life forms: Their universality and growth. American Anthropologist 79, 317-342.

Brown, Cecil H., John Kolar, Barbara J. Torrey, Tipawan TrùongQuang, and Phillip Volkman. 1976. Some general principles of biological and non-biological folk classification. American Ethnologist 3. 73-85.

Burris, Harold W., Jr. 1976. A cross-linguistic study of the growth of geometric figure terminology. Manuscript. Northern Illinois University.

Chomsky, Noam. 1975. Reflections on language. New York: Pantheon Books.

Dougherty, Janet Wynne Dixon. 1977. On the acquisition of ethnobotanical nomenclature. Manuscript. University of Illinois.

Greenberg, Joseph H. 1966. Language universals with special reference to feature hierarchies. The Hague: Mouton and Co.

Greenberg, Joseph H. 1969. Language universals: A research frontier. Science 166.473-478.

Greenberg, Joseph H. 1975. Research on language universals, In: The annual review of anthropology. Edited by Bernard J. Seigel, Alan R. Beals, and Stephen A. Tyler. Annual Reviews Inc. 75-93.

Heider, Eleanor Rosch. 1972a. Universals in color naming and memory. Journal of Experimental Psychology 93.10-20.

Heider, Eleanor Rosch. 1972b. Probabilities, sampling and ethnographic method: The case of Dani colour names. Man 7.448-466.

Kay, Paul. 1975. Synchronic variability and diachronic change in basic color terms. Language in Society 4. 257-270.

Kay, Paul, and Chad K. McDaniel. 1975. Color categories as fuzzy sets. Working Paper No. 44, Language Behavior Research Laboratory, University of California, Berkeley.

Kronenfeld, David B. 1974. Sibling typology: Beyond Nerlove and Romney. American Ethnologist 1.489-506.

Kronenfeld, David B. 1976. Innate language? Paper presented at the Annual Meeting of the American Anthropological Association, November 18, 1976, Washington, D. C.

Laughlin, Robert M. 1975. The great Tzotzil dictionary of San Lorenzo Zinacantán. Smithsonian Contributions to Anthropology Number 19. Washington, D. C.: Smithsonian Institution.

Miller, George A. 1956. The magical number seven, plus or minus two. Psychological Review 63.81-97.

Miller, Jay. 1975. Delaware alternative classification. Anthropological Linguistics 17(9). 434-444.

Nerlove, Sara B., and A. Kimball Romney. 1967. Sibling terminology and cross-sex behavior. American Anthropologist 69.179187. 
Simon, Herbert A. 1974. How big is a chunk? Science 183.482-488. Williams, Joseph M. 1976. Synaesthetic adjectives: A possible law of semantic change. Lg. 52.461-478.

Witkowski, Stanley. 1972. Guttman scaling of semantic distinctions. In: Kinship studies in the Morgan centennial year. Edited by Priscilla Reining. Washington, D. C.: The Anthropological Society of Washington. 167-188.

Witkowski, Stanley R., and Cecil H. Brown. 1977. An explanation of color nomenclature universals. American Anthropologist 79. 50-57. 



\section{ASPECTS OF CODE-SWITCHING IN THE DISCOURSE OF BILINGUAL MEXICAN-AMERICAN CHILDREN}

\section{ERICA MCCLURE}

\section{University of Illinois}

0. Introduction. Although multilingualism has existed since antiquity, it is only in the past two decades that scholars have paid more than cursory attention to the significance of the multilingual's alternation among languages. Most research has been concerned with the sociolinguistic parameters of code-switching, and with specifying the conditions under which each language is selected (see, for example, Rubin 1962; Ervin-Tripp 1964; Gumperz 1964; Blom and Gumperz 1972; Gumperz and Hernández-Chavez 1972; Hymes 1972). As the early studies tended to consider factors such as setting, topic, and participants which were unlikely to change within a turn of speech, much less a sentence, the grammatical parameters of code-switching were largely ignored. Consequently, as late as 1975 one finds in the literature such a statement as the following (Lance 1975:143).

The variety found in these sixteen citations suggests that there are perhaps no syntactic restrictions on where switching can occur...

Today, concommitant with the interest in stylistic functions of codeswitching (see, for example, Blom and Gumperz 1972; Gumperz and Hernández-Chavez 1972; McClure and Wentz 1975; Wentz 1976) which may occasion intrasentential code-switching, there is an interest in the description of the grammatical parameters of code-switching (see, for example, Annamalai 1971; Gumperz and Hernández-Chavez 1972; Gingrás 1974; Kachru 1975; Wentz and McClure 1976a; Wentz 1976; Pfaff 1976; Sridhar (to appear in IJSL)). Thus, a substantial 
data base is now being developed on both the formal and functional aspects of code-switching. Yet a gap remains.

Little has been written about code-switching among children. 1 This paper addresses that topic. Both linguistic and sociolinguistic parameters of code-switching are considered. The analysis is based on tape recordings of children ranging in age from three to fifteen. Complete verbal transcripts of 90 hours of tape were situationally annotated and divided into conversations and turns of speaking. Those containing code switches were examined for communicative intent and grammatical structure.

Tape recordings were made in two communities. In the first community, a small city of about 45,000 inhabitants, eight three- and four-year-old Mexican-American children enrolled in a Headstart program were observed in school for six months. In the second community, a small town of about 1,400 inhabitants, the 39 MexicanAmerican children in kindergarten through fourth grade during the two-year period of research, plus three preschool children who were in the care of older children in the sample, were observed at school, at home, in the local park, and in the project mobile home.

1. The communities. Since social structural variables affect language selection patterns, as Barker (1972), Blom and Gumperz (1972), and others note, I include here a very brief description of our research sites. The Mexican-American community in the small city numbers approximately 2,200 . This population is settled out, employment being largely in the local canneries. Most families are concentrated in the eastern section of town, almost all in public housing. The children are concentrated in the neighborhood elementary school where they constitute a large proportion of the enrollment. There is little interaction between the Mexican-American community and the Anglo community, and not much more between the MexicanAmerican community and the Black community, although the two communities are geographically intermingled. The Mexican-American community is itself relatively cohesive despite the diverse origins and varying educational and residential histories of its members. 2

Mexican Americans constitute about 10 percent of the population of the small town and Anglos, the remaining 90 percent. The former are divided into two groups--settled out families (who are more or less permanently resident) and migrant men. There is no barrio nor are there residential clusters. Instead, the Mexican Americans are dispersed throughout the entire community, with the exception of one newer section with only high-cost housing. Two local nurseries are the main source of employment for the Mexican Americans.

Social activity in the community focuses around the churches and schools. There are several churches in town but no Catholic church. 
The minister of one congregation wished to allow the Catholic priest from the neighboring town to conduct services in his building, but the congregation opposed the arrangement. Consequently, since most of the Mexican Americans are Catholic, they must travel four miles to the next town for services. Most attend irregularly.

Athletic activities at the high school (grades 5 through 12) and student performances at both the high school and the elementary school (kindergarten through fourth grade) are major social events for the community. However, in general, the Mexican-American community is only peripherally involved in these activities. Only one MexicanAmerican boy ${ }^{3}$ was a member of a varsity sports team. He and his family participated fully in the round of activities surrounding the football season, but the other Mexican-American families generally do not. Indeed, most have very negative feelings toward the high school. The high school dropout rate stood at 100 percent at the time of our research, no Mexican American having graduated.

In 1972 a bilingual pull-out program was begun in the elementary school. 4 The children of all but two of the Mexican-American families were enrolled in it. 5 During the course of our research, the program sponsored a yearly Mexican-American culture day featuring music, dance, and food. It was the only event we witnessed in which large numbers of Anglo and Mexican-American adults participated jointly. 6 But even on this occasion there was little interaction between the two groups.

While Mexican-American and Anglo children in grades $\mathrm{K}$ through four play together at recess and interact in class, there is a tendency for same ethnicity play groups to form frequently, especially in the case of those children whose English is limited. Interaction between Anglos and Mexican Americans is even more restricted at the high school.

Outside school, few Mexican-American children interact often with Anglos even though residential patterns are such that they have Anglo neighbors. Likewise there is little interaction with other MexicanAmerican children either. Indeed, elementary school children play primarily with siblings after school. This fact is partially explained by the dispersal of the Mexican-American families throughout the community, but it also relates to the lack of social cohesion in the Mexican-American community. This Mexican-American community, unlike that of the city, has neither well-established political leadership nor any community-wide social institutions.

2. Syntactic constraints on code-switching. In discussing codeswitching, many authors have attempted to differentiate it from other phenomena resulting from language contact. Thus, Haugen (1956:40) differentiates among three degrees of convergence: 
(1) switching, the alternate use of two languages;

(2) interference, the overlapping of two languages; and

(3) integration, the regular use of materials from one language in another, so that there is no longer either switching or overlapping, except in a historical sense.

And Gingrás (1974:169-170) states:

It is not always obvious whether we have an instance of codeswitching or of some sort of lexicalization (i.e. borrowing) ... I reserve the term 'substitution' for what an individual does and the term 'lexicalization' for what speakers of a dialect may have done . . . It should also be pointed out that in dealing with observational data, it is difficult to sort out problems of various kinds due to interference between the two codes. Since interference appears to be a result of performance factors (assuming we have the case of a coordinate bilingual who can keep his two codes fairly separate), I will also try to ignore cases of bilingual interference, since $I$ have no interest in performance factors at this time.

Consequently, in studying code-switching, I have tried to concentrate only on those cases where it is obvious (at least to me) that we have an instance of code-switching.

On the other hand, Pfaff (1975:17) concludes that rather than segregating language contact phenomena, it may be advantageous to study their interplay.

While the distinctions should not be obscured, all these can be considered as alternative realizations of underlying meanings and can be tabulated and quantified as such.

It is this position that I adopt here.

Pfaff (1975:5) suggests a classification of three general types or styles of code-switching defined by form and function. The first type, "typical of casual interaction between peers, close friends, or regular associates when conversation centers around every day topics', is characterized by switches occurring either at surface sentence breaks or at independent or dependent clause breaks. Oneor two-word lexical switches are low in frequency. Type two 'is typical of casual or more formal interactions which for one of several reasons, seem to be mainly in Spanish. Whole sentence switches are much more frequent than switches as dependent or independent clauses'. The third type is basically Spanish street talk, 'the jargon 
of the bato loco'. Switching to English is 'mainly for single nouns, verbs, adjectives and set phrases'.

Our data support a different classification, bipartite as opposed to tripartite. The children's code-switching appears to reflect the operation of two separate linguistic devices: code-changing and codemixing.

Code-changing, generally motivated by situational and stylistic factors, is the alternation of languages at the level of the major constituent (e.g. NP, VP, S). The code-change is a complete shift to another language system. All function words, morphology, and syntax are abruptly changed, as in the following examples.

(1) I put the forks en las mesas ('on the tables').

(2) Let's see qué hay en el dos ('what there is on two').

The vast majority of spontaneous code-changes in our data are at the surface structure sentence level. Of our corpus of over 500 codechanges, only $30^{7}$ involved smaller constituents than sentences, of which 19 were noun phrases. A disproportionate number occurred in narratives. Moreover, only one occurred in the speech of a child under nine. Given that nonsentence code-changes appear to be much more frequent in the corpora of Lance, Gingrás, and Pfaff, and that they can be elicited from all the children in sentence-imitation tasks, while random switches cannot, 8 it appears likely that the ability to use nonsentence code-changes productively is acquired relatively late by the child in the process of becoming bilingual. Our younger informants code-changed relatively rarely. Another ability which appears to be developed late by these children is that of handling cross-language ellipsis. In the following examples, the first responses $\left(B_{1}\right)$ are characteristic of the younger children; the second (B2), of the older:

(3) A: ¿Quién tiene hambre? (lit. 'Who has hunger?')

$B_{1}$ : I do.

$B_{2}$ : I am.

(4) A: ¿Cuántos años tiene? (lit. 'How many years has he?')

$B_{1}$ : He gots eight.

B2: He's eight.

(5) A: Who are you calling?

$\mathrm{B}_{1}$ : El doctor. ('the doctor')

$\mathrm{B}_{2}$ : $\mathrm{Al}$ doctor. ('to the doctor') 
(6) A: I don't care.

$B_{1}$ : Yo sí. ('I yes.')

B2: A mí sí. ('to me yes.')

The older children answer as if the previous utterance had been in the language of the response. The younger children's responses look as if they are relexicalizations of responses in the original language. 9

Code-mixing, the other type of code-switching, is the individual's use of opposite language elements which cannot be considered to be borrowed by the community. It occurs when a person is momentarily unable to access a term for a concept in the language which he is using but can access it in another code, or when he lacks a term in the code he is using which exactly expresses the concept he wishes to convey. Code-mixing of color terms by the children studied provides a good example of the former, since detailed analysis shows that for these children color terms in Spanish and English have identical referential and affective meanings. The sentence:

(7) No van a aceptar a una mujer que can't talk business. ('They are not going to accept a woman who ....')

is an example of the latter type of code-mixing. The phrase can't talk business is derived from an idiomatic unit in English which has for the speaker no precise, culturally appropriate Spanish equivalent. Sentences containing code-mixes are generally perceived by the children to be sentences of one language containing elements of the other, unlike those containing code-changes which are felt to begin in one language and change to the other.

Code-mixing takes place within constituents, and there is usually, at some level, an indication that the code-mixed item is marked for use in a sentence of another code. For example, in sentence (7), the use of que instead of who to introduce the relative clause suggests that the phrase is a code-mix and not a code-change, while in (8), the noun phrase the tenedores is marked for use in an English sentence by the article the.

(8) I put the tenedores on the table. ('forks')

Nonetheless, the morphology and phonology of tenedores (/tenedor + es/) is entirely Spanish. Consequently, it is unlikely that, among bilinguals, such an occurrence would represent a lexical borrowing. In the sentence:

(9) I want a motorcycle verde. ('green') 
we can say that the Spanish adjective verde 'green' is code-mixed into an English sentence. Spanish placement of verde indicates it is not a borrowing. The noun phrase a motorcycle verde is marked by a as being an English noun phrase. It could not be used in a Spanish sentence, but un motorcycle verde could, in which case motorcycle might be either a borrowed or code-mixed noun. Its status is ambiguous because there are no clear morphological or syntactic indicators. Phonology is only one clue in disambiguating the status of opposite language elements, because they often contain a mixture of Spanish and English sounds.

While a word may contain phonemes of both languages, there are no examples in the children's speech of words containing morphemes of both languages. There are no code-mixes within a word. Derivational or inflectional affixes occur with a root of the other language only if it has been phonologically adapted (in Gingrás' terms, only if it is a substitution or lexicalization).

Code-mixing seems to parallel borrowing in the relative frequency with which different syntactic categories are involved. Ornstein states (1976:84):

As has been noted, also among other contact cases, Raramuri, in common with other languages, tends to borrow nouns more readily than any other word class. Beyond this, loans from other categories are rare, although, as noted elsewhere here, closer investigation of existing calques needs to be performed. At any rate the literature on borrowing appears to indicate that adjectives tend to follow nouns in frequency, with verbs often next, and other classes less well represented.

Table 1 summarizes our data. They accord with Ornstein's comments about regularities in borrowing except that there are only five codemixed verbs. They also follow the pattern noted by Bloomfield (1933: 464): 'In all cases . . . it is the lower language which borrows predominantly from the upper'. Spanish sentences contain code-mixes far more frequently than English sentences, and it is Spanish which is the lower language and English which is the upper.

In concluding this discussion of the syntactic parameters of the code-switching of the children studied, we may note a developmental pattern. Children 10 who do not have equal or near equal proficiency in both Spanish and English code-switch predominantly at the word level. Most such switches are of nouns but more than a negligible number of interjections and color adjectives may also be found. Such children do little code-changing and most of it is at the sentence level. Children who are fluent bilinguals (in general, the older children) code-switch predominantly at the constituent level. However, for 
TABLE 1. Code-mixing by matrix language and by age.

\begin{tabular}{|c|c|c|c|c|c|c|c|}
\hline \multirow[b]{2}{*}{ In Spanish sentences } & \multicolumn{3}{|c|}{ Informants* } & \multirow[b]{2}{*}{ In English sentences } & \multicolumn{3}{|c|}{ Informants } \\
\hline & Jr. & Sr. & Total & & Jr. & Sr. & Tota \\
\hline \multicolumn{8}{|l|}{ Nouns } \\
\hline (Ind Art) $S+(N) E$ & 18 & 10 & 28 & $(\text { Ind Art })^{* *}+(\mathbb{N})_{S}$ & 3 & 0 & 3 \\
\hline$(\text { Def Art })_{S}+(\mathbb{N})_{E}$ & 21 & 12 & 33 & $(\text { Def Art })_{E}+(\mathrm{N}) \mathrm{S}$ & 3 & 0 & 3 \\
\hline (Poss Adj)S + (N)E & 21 & 8 & 29 & $(\text { Poss Adj) })_{E}+(N)_{S}$ & 2 & 1 & 3 \\
\hline$(\text { Dem Adj })_{S}+(N)_{E}$ & 3 & 0 & 3 & $(\operatorname{Dem} \text { Adj })_{E}+(\mathbb{N})_{S}$ & 1 & 1 & 2 \\
\hline (Numeral) $+(\mathbb{N})_{E}$ & $\mathbf{0}$ & 3 & 3 & (Numeral) $E+(\mathrm{N}) \mathrm{S}$ & 0 & 0 & 0 \\
\hline$\left(\right.$ Prep $_{S}+(\mathrm{N})_{E}$ & 6 & 7 & 13 & $(\text { Prep })_{E}+(\mathbb{N})_{S}$ & 0 & 0 & 0 \\
\hline$(\text { Art })_{S}+(\text { Adj })_{E}+(N)_{E}$ & 3 & 4 & 7 & $(\text { Art })_{E}+($ Adj) $S+(N) S$ & 0 & 0 & 0 \\
\hline$($ Prep $) S+(\text { Adj })_{E}+(N) E$ & 0 & 2 & 2 & $(\text { Prep })_{E}+(\text { Adj })_{S}+(N)_{S}$ & 0 & 0 & $\mathbf{0}$ \\
\hline$(\operatorname{Adj}) S+(N)_{E}$ & 7 & 2 & 9 & $(A d j)_{E}+(N)_{S}$ & 0 & 0 & o \\
\hline \multicolumn{8}{|l|}{ Adjectives } \\
\hline$(A d j)_{E}$ & 9 & 2 & 11 & $($ Adj)s & 0 & 1 & 1 \\
\hline (Adj-color) E & 20 & 8 & 28 & $(A d j-c o l o r)_{S}$ & 0 & 0 & 0 \\
\hline \multicolumn{8}{|l|}{ Verbs } \\
\hline (Verb)E & 2 & 0 & 2 & (Verb)s & 1 & 2 & 3 \\
\hline \multicolumn{8}{|l|}{ Adverbs } \\
\hline$($ Adv-place) $\mathrm{E}$ & 1 & 3 & 4 & $($ Adv-place) $\mathbf{S}$ & 0 & 1 & 1 \\
\hline (Adv-time) $E$ & 1 & 2 & 3 & (Adv-time) $s$ & 0 & 2 & 2 \\
\hline \multicolumn{8}{|l|}{ Conjunctions } \\
\hline (Conj)E & 0 & 0 & 0 & (Conj)s & 1 & 5 & 6 \\
\hline \multicolumn{8}{|l|}{ Others } \\
\hline (Interfection) $\mathbf{E}$ & 7 & 4 & 11 & (Interjection)s & 5 & 4 & 9 \\
\hline$(\text { Epithet })_{E}$ & 1 & 2 & $\underline{3}$ & (Epithet)s & 3 & 0 & 3 \\
\hline Total code mixes & 138 & 75 & 213 & & 22 & 22 & 44 \\
\hline $\begin{array}{l}\text { *Informants are ranked } \\
\text { Junior informants are thos } \\
\text { before } 12 / 31 / 66 \text {, except th } \\
\text { despite his age. } \\
\text { **Nouns occurring with } \\
\text { code-changing since it can }\end{array}$ & $\begin{array}{l}\text { is jun } \\
\text { born } \\
\text { t one } \\
\text { zero }\end{array}$ & in & $\begin{array}{l}r \text { senio } \\
12 / 31 \\
\text { mant } \\
\text { le are }\end{array}$ & $\begin{array}{l}\text { on the basis of their li } \\
6 \text {, while senior inforn } \\
\text { rn } 5 / 14 / 68 \text { ) is classifi } \\
\text { gssified as neither cod } \\
\text { ich they are. }\end{array}$ & & or & ity. \\
\hline
\end{tabular}

them also, code-changing is mainly of sentential level constituents. We should also note that there are children who are competent bilinguals but who virtually never code-switch, and that one of the younger girls code-switches almost incessantly. Table 2 summarizes our data on code-mixing and code-changing by age.

3. Code selection and situation. In verbal interaction, language selection by adult bilinguals has been shown to be partially determined by participants, setting, and topic, Participants and topic have also 
TABLE 2. Code-mixing and code-changing by age and language.

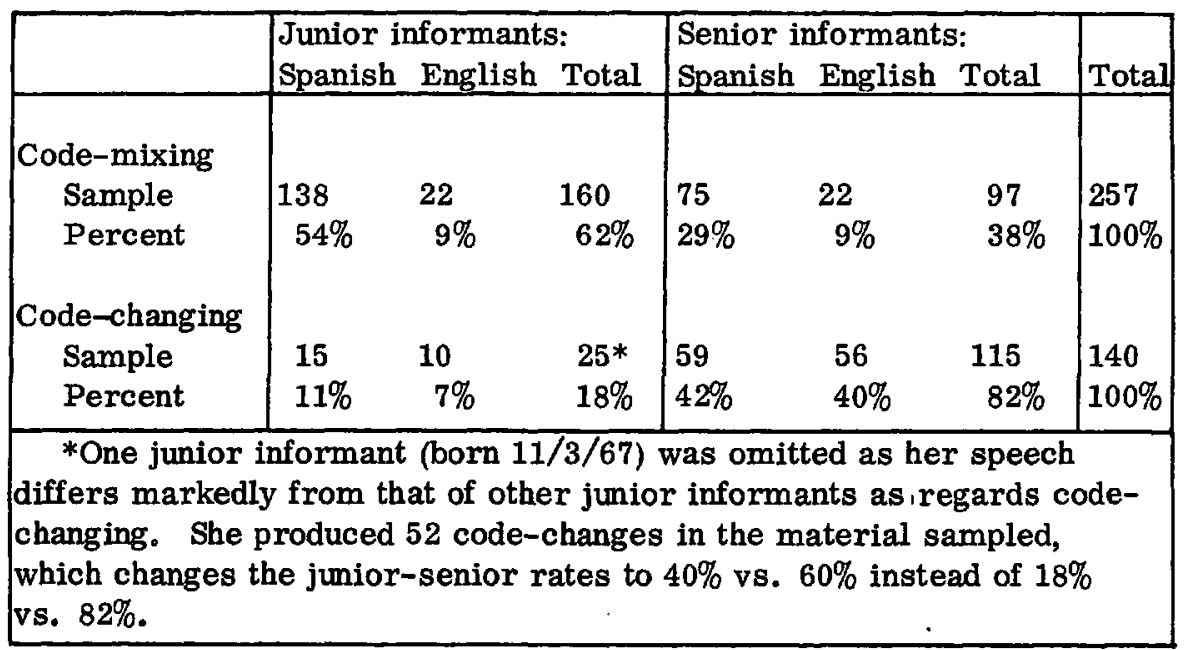

been found to be important in the register variation of monolingual Anglophone children (Fischer 1958; Weeks 1971). Among the children we studied, it appears that the earliest systematic code-switching is a function of the 'participants' category. Such switching occurs not only at junctures between conversations but also between and within turns of speaking. Examples of the latter two types are:

(10) CS (girl, 7): I want to play checkers. $E$ (Anglo researcher): Ask Roli if you can. CS (to boy, 4): ¿ Puedo jugar checkers? ('Can I play checkers?')

(11) P (girl, 9): You have to king me.

D (girl, 6): Do what?

P: $\quad$ You gotta put one on top. (to boy, 4): Mira, comete este. ('Look, eat this!')

Three characteristics of participants are important: language proficiency, language preference, and social identity.

Inappropriate choice of language when addressing a monolingual is rare. For example, although upon first entering school, children with little prior experience with the Anglo community occasionally used Spanish with Anglophone school teachers and pupils, such behavior was no longer observed after the first month of classes. Children lacking even minimal facility in English quickly resorted to one 
of two strategies: silence and passivity or the use of nonverbal communication devices such as gesture to supplement one- or two-word telegraphic utterances. In determining whether it is possible to use a particular language with an individual, young children appear to rely on binary judgments of linguistic competence--either a person knows a language or he does not. Assessments of relative ability do not enter into their decisions about language choice as they tend to do among adults and older children. Thus, those children five years of age or younger who were Spanish dominant spoke to the author in Spanish, the language in which they were most comfortable, despite the fact that in most cases their English was more fluent than her Spanish. Older children make finer discriminations in selecting a code for use with a given individual. They seem to consider both the absolute degree of the hearer's proficiency in both languages and the relative language proficiencies of speaker and hearer. The older children in the second group studied used English almost exclusively in interacting with the author and Spanish almost exclusively in interacting with the four children of the group whose English was rudimentary.

Assessments of language facility also appear to account at least partially for the fact that with preschoolers, older children use Spanish predominantly. However, as this pattern obtains even in the case of the one preschooler in the second group who is equally proficient in Spanish and English, it would appear that the social identity 11 of the preschooler is also a factor. A random selection of fifteen onehour recordings contained 188 utterances directed to preschoolers, 67 percent of which were in Spanish. The English addressed to preschoolers is generally restricted to short, routinized expressions, while Spanish is used for most utterances with high information content. Siblings of preschoolers tend to address more English to them than do other children. In our corpus, 43 percent of the 118 utterances addressed by siblings to preschoolers were in English. Only 22 percent of the 70 utterances addressed by nonsiblings to preschoolers were in English. Perhaps in interaction among siblings the social identity of the preschooler is not always salient. Other identities--such as sibling identity--may take precedence, or identity itself may not be salient and code-selection may be more strongly influenced by other factors.

A good illustration of the fact that language preference and not merely ability is an important consideration is the fact that in the second community one child who is quite fluent in English but prefers Spanish is addressed far more frequently in Spanish than are her peers who prefer to use English. Furthermore, even the very young Spanish-dominant children use English in addressing a young girl 
who, despite the fact that she knows Spanish, refuses to use it with anyone but a monolingual. 12

Social identity is the third property of participants which influences language choice. There appears to be a characteristic pattern of language use associated with every identity relationship. 13 Interactions between children and adults from the Mexican-American community also take place in Spanish.

For teacher-pupil interactions, English has been established as the appropriate language. The advent of a bilingual-bicultural program in 1972 complicated the situation. The instructors in this program were a female Anglo teacher and a Mexican-American teacher's aide, both fluent bilinguals. The former has had great difficulty in sustaining conversations in Spanish with children who know English, especially those who began school before the bilingual program started. The latter has not, although children occasionally address her in English (see Table 3). The difference may be that there is an alternate identity relationship, child-Mexican-American adult, associated with the use of Spanish, which can obtain between the children and the teacher's aide. The corresponding relationship between the children and the teacher, child-Anglo adult is associated with the use of English.

With the researchers, Anglos and Hispanos alike, 14 who attempted to define for themselves an identity outside the children's previously established categories, the children generally used a mixed register in which discourse alternated between Spanish and English with frequent code-mixing and code-changing. However, when interactions with them were defined in terms of identities such as MexicanAmerican adult or Anglo adult, code-switching was minimal.

Identity also affects language choice in interactions among children. Shifting identity relationships among children are often marked by code alternation, just as Blom and Gumperz (1972) have demonstrated among adults. Both peer and sibling interactions are carried on in a mixed register. Interactions between children which involve caretaker-child relationships are almost always in Spanish. It was observed that if a younger child was hurt, he was comforted by an older child in Spanish even though an immediately preceding interaction between the children might have taken place in English. The following sequence is typical:

(12) P (girl, 9): $\mathrm{R}$ (brother, 3): P:

R:

Stop it Roli. You're stupid! You stupid Pat.

P:

Don't hit me! (laughing and holding $R$ off) (trips and begins to cry) ¡Ay, Roli! Mi hijito ¿qué pasó? ('Oh Roli! Honey, what happened?') 
TABLE 3. Percentages of Spanish and English used in various contexts.

\begin{tabular}{|c|c|c|c|c|c|c|}
\hline & 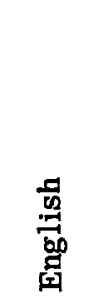 & $\begin{array}{l}\text { 范 } \\
\text { : } \\
\text { कू }\end{array}$ & 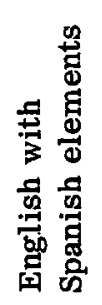 & 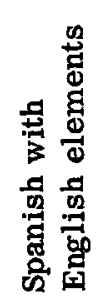 & 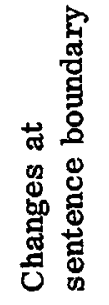 & 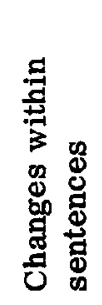 \\
\hline $\begin{array}{l}\text { Interview: Family A } \\
\text { (only the children } \\
\text { control any English) }\end{array}$ & $9 \% *$ & $90 \%$ & $0 \%$ & $0 \%$ & $1 \%$ & $0 \%$ \\
\hline $\begin{array}{l}\text { Interview: Family B } \\
\text { (adults and children } \\
\text { control English) }\end{array}$ & $40 \%$ & $41 \%$ & $0 \%$ & $2 \%$ & $17 \%$ & $0 \%$ \\
\hline $\begin{array}{l}\text { Bilingual classroom } \\
\text { (Anglo teacher only) }\end{array}$ & $61 \%$ & $10 \%$ & $0 \%$ & $10 \%$ & $16 \%$ & $3 \%$ \\
\hline $\begin{array}{l}\text { Bilingual classroom } \\
\text { (Mexican-American } \\
\text { teacher's aide) }\end{array}$ & $4 \%$ & $95 \%$ & $0 \%$ & $1 \%$ & $0 \%$ & $0 \%$ \\
\hline Regular kindergarten & $90 \%$ & $7 \%$ & $1 \%$ & $0 \%$ & $1 \%$ & $1 \%$ \\
\hline $\begin{array}{l}\text { Boys** at project mobile } \\
\text { home (interview situation) }\end{array}$ & $17 \%$ & $72 \%$ & $4 \%$ & $3 \%$ & $3 \%$ & $0 \%$ \\
\hline $\begin{array}{l}\text { Girls at project mobile } \\
\text { home (interview situation) }\end{array}$ & $2 \%$ & $91 \%$ & $0 \%$ & $7 \%$ & $0 \%$ & $0 \%$ \\
\hline $\begin{array}{l}\text { Boys at project mobile } \\
\text { home (free conversation) }\end{array}$ & $78 \%$ & $22 \%$ & $0 \%$ & $0 \%$ & $4 \%$ & $0 \%$ \\
\hline $\begin{array}{l}\text { Girls at project mobile } \\
\text { home (free conversation) }\end{array}$ & $60 \%$ & $31 \%$ & $2 \%$ & $1 \%$ & $5 \%$ & $1 \%$ \\
\hline
\end{tabular}


Likewise, we found that when children assumed a position of authority they issued commands in Spanish. Thus, when one of our research assistants went by herself to collect data from a group of children in the project mobile home rather than in the company of several other researchers, as usual, one of the older boys spontaneously assumed the role of the one responsible for keeping order among the rest. His orders in this role were issued in Spanish. It would appear that behavior in the caretaker-child relationship is patterned after that between parent and child. Children at play have also been observed to switch from Spanish to English when switching from a peer relationship to a teacher-pupil relationship.

Language alternation to mark a shift in identity relationship is, of course, more common among older children than among younger children since the former have access to more identities. We found that as children become older their knowledge of English increases and so does the number of English-associated identity relationships accessible to them. Thus, their use of English increases. Since, in the children's culture, English is less commonly used in those relationships in which females may participate (most being associated with the home) than in which men participate, the sex difference between the amounts of English and Spanish used by the children in free conversation (see Table 3) is not surprising.

The topic of a discourse does not have as large an influence upon language selection in the children studied as do the participants. The children are able to, and in fact do, converse about anything in their experience in both languages. However, the discussion of a few topics is more likely to occur in one language than in the other. Topics related to the family--child care, kinship, and food preparation--are most often discussed in Spanish; whereas sports, school, and holidays such as Halloween and Thanksgiving are more often discussed in English. When a topic which is habitually discussed in one language happens to come up in a conversation in the other language, there is a high incidence of code-mixing and code-changing.

Discourse type also affects language use. The greatest degree of code-switching is manifested in free conversation. In general, codeswitching is strongly inhibited in interrogation 15 and narration. 16

Setting is the last situational variable clearly involved in language choice. But, like the other variables, it alone does not determine choice. Thus, while Spanish is used with greater frequency in the home than in any other place, 17 English is also heard there--more in the case of some families, less in the case of others. Similarly, while English is the only language of instruction and response in the school outside the bilingual classrooms, interactions among MexicanAmericans in the classroom and on the playground are often in Spanish. The community park and project mobile home, the other settings in 
which observations were made, appeared to be neutral with respect to language choice. The interaction of the variables--participants, topic, setting, and discourse type--account for the data presented in Table 3, which is based on a stratified random sample consisting of 10 percent of the transcribed corpus.

The categories of topic, participants, and setting are useful analytic constructs which have enabled the author to account for a large proportion of code-selection behavior. It is probable that the categories of topic and participants, at least, also have some psychological validity for the subjects studied, since metalinguistic comments concerning these categories have been recorded. Examples are provided in the following.

(13) F (boy 4) (to Anglo bilingual elementary school teacher): ¿Como es que hablas como nosotros? ('How come you talk like we do?')

(14) E (boy, 10):

In English or Spanish?

$J$ (Anglo researcher): En español si puedes. ('In Spanish if you can.')

E: Aw, I can't tell that in Spanish.

J: Just try, OK?

4. Code-selection and style. Gumperz and Hernández-Chavez (1972) have shown that code-switching has a stylistic function for adult bilinguals. Our data suggest that style is also a very relevant parameter for analyzing the code-switching of children. We have found that children's code-switching may serve the following stylistic functions.

4.1 Emphasis. Code-switching for emphasis may occur from Spanish to English or from English to Spanish. The majority of such code-switches involve commands. Sixteen of our corpus of 74 codeswitched commands involve repetitions of commands in translation. Sentence (15) is an example.

(15) P (girl, 9): Stay here Roli. i Te quedas aquí!

There are seventeen switches for commands which begin new turns of speaking.

(16) R (boy, 4): I go get it. P (girl, 9): · Hazte, hazte pa'allá! ('Get over, get over there!') 
The remainder are switches for commands within a turn of speaking.

(17) C (girl, 7): Who is that? ¡Pégalo! ('Hit him!')

Following are examples of emphatic code-switches which are not commands. Only six in our entire corpus seem clear-cut. All involve translations.

(18) T (boy 8): Yo soy segundo. I'm second!

(19) R (girl, 0: Ya acabé. Pm done!

(20) C (girl, 7): I can't do it. i No puedo!

4. 2 Focus. 'Focus' is here used to refer to the bringing into prominence of a part of a sentence, in contrast to 'emphasis', here used to apply to the entire sentence. One method of focusing upon a portion of the meaning of a sentence is topicalization. Code-switched topicalized subjects of the type illustrated in example (21) are perhaps used to indicate the ethnicity of the individual who is being discussed. In our data all examples of code-switched topicalizations were Spanish phrases in otherwise English sentences.

(21) E (boy, 8): Este Ernesto, he's cheating. ('This Ernest ...')

Other examples of focus are:

(22) J (boy, 7): Pegó right there. ('He hit ...')

(23) C (girl, 7): Come on give me towel, la toalla. ('. . . the towel.')

4. 3 Elaboration. Occasionally code-switching is used when a child wishes to repeat a message including additional information. Examples are as follows.

(24) R (girl, 7): Yo lo puedo quebrar. Yo lo tambiên . . . lo pu(edo) quebrar. ('I can break it. I can break it too ...')

I can break this easy with my nose.

(25) P (girl, 9): Roli you stay here. Tú quédate 'jito con Suzy. ('Stay with Suzy, Honey!')

4.4 Clarification. The repetition of an utterance in translation appears to function as a means of resolving ambiguity or clarifying a potential or apparent lack of understanding. 
(26) P (girl, 9): (to boy, 3, who knew little English) ¿Qué tiene? . . . Will you watch your cards! ¡Fijate en las cartas!

('What does he have? ... (. . .) Watch the cards!')

(27) C (girl, 7): You(r) dog.

$J$ (Anglo

researcher): You dog? My woof?

C: $\quad$ You(r) dog! ; Tu perro! ('Your dog!')

$\mathrm{J}: \quad$ OK. What about him?

(28) I (Anglo

researcher): ¿Dónde fuiste? ('Where did you go ?')

R (boy, 3): A school. ('To school.')

I: Huh?

R: A (la) escuela. ('To school.')

4.5 Attention attraction or retention. Within a conversation a child may use a code-switch as a device to attract or retain the attention of his audience. It seems likely that such code-switching serves the same function as a raised voice, address forms, gestures, physical contact or eye contact.

(29) M (girl, 9): Now let me do it. Put your feets down. i Mira! ('Look!') It's Leti's turn again. Hi Leti!

(30) M (girl, 9): Yo me voy a bajar, Teresa. Look! ('I'm getting down ...')

Still other cases appear to be a means of avoiding the tedium or insistence caused by multiple repetition. This type of repetition in translation has the impact of a paraphrase, not a repetition.

(31) P (girl, 9): A ver, a ver . . . let me see, let me see. ('Let me see, let me see...')

(32) R (girl, 7): Este es el roof. This the roof. This is the roof. ('This is the roof ...')

4. 6 Mode shift. Children's discourse includes narration, commentary, soliloquy, interrogation, etc. Code-switching sometimes marks a point of transition between these modes. For example, 
code-switching frequently occurs when a child interrupts a story he is telling to make a comment external to the narrative.

(33) T (researcher): Tell me a story.

S (girl, 5): I know a story of pigs and I know a story of Wizard of $\mathrm{Oz}$.

T: The Wizard of Oz? OK. Tell me whichever one you like.

S: $\quad$ OK. (takes a deep breath) Así no va. Espérate. ('Not that way. Wait.') Oh, Sonny and Cher, OK?

T: OK.

S:

Sonny and Cher, it was raining and then Sonny and Cher broke his window ....'

(34) T (boy, 8): $\quad$ (final sentence of story told in Spanish) . . respiran las llantas del tren, $\mathrm{y}$... that's all I could think. (' . . . the train's tires breathe, and . ..')

(35) J (Anglo

researcher): ¿Dónde vive María? ('Where does María live?')

C (girl, 7): $\quad$ María vive en mi casa ('Maria lives in my house.')

Really she is.

(36) Ev (boy, 8): Lo pegó aquí. I saw it. ('He hit him here. ')

Similarly, children often code-switch when interrupting a conversation with a self-directed or rhetorical statement.

(37) R (girl, 7): $\quad$ You love boys!

$\mathrm{J}$ (researcher): (feigns crying)

R:

Why you cry baby. Está llorando. ('He's crying.')

(38) L (girl, 5): Mira mi (hi)jito. La leche de tu mamá. Oh, darn, now what! ('Look, honey. Your mom's milk ...')

Children also switch code when moving out of an interrogative mode, as in the following example. 
(39) J (Anglo researcher): ¿Ése es Tibaldo o David? ('Is that Tibaldo or David?')

E (boy, 12): Éste es mi Davi. I'm going to beat him up. ('This is my Davi ...')

4.7 Topic shift. Code-switching to introduce a new topic is another linguistic device used by the children. They appear to use such a switch to emphasize the fact that they are no longer interested in what is presently being discussed and wish to proceed to a different topic. Examples are as follows.

(40) T (Mexican-American researcher): Dile que es una casa sin techo. ('Tell her that it's a house without a roof.') L (girl, 6): We have a pretty, uh, Christmas tree.

(41) H (girl, 13): $\quad$ Me duela la muela ('My molar hurts') $R$ (girl, 9): $\quad$ Remember when we eat dinners over there at my house, we drink soda.

(42) R (boy, 4): ¿Y dónde mis rabbits? ('And where my rabbits?') L (girl, 6): Ahí están. Les están dando comida ('There they are. They are giving them food')

D (girl, 6): Yo les voy dar comida al pájaro y . . .

R: ('I will give food to the bird and ....') (will) you (be) playing (checkers)?
Yeah, she's gonna wash her hands.

4.8 Addressee shift. I have already discussed the fact that the characteristics of his addressee influence a child's language selection. If he switches addressees and the relevant characteristics of the new addressee are different from those of the previous addressee, a language switch is common. However, sometimes, the relevant characteristics remain the same with an addressee switch, yet a language switch takes place. It seems likely that such a language switch is sometimes used to help clarify the fact that a new person is being addressed, thereby avoiding the necessity of a later message such as 'I'm not talking to you; I'm talking to Maria'. The following instance of code-switching appears to have occurred for that reason. 
H (girl, 13): (To Rosa) Pregintale a Patty. Pregúntale. ('Ask Patty. Ask her.')

(To Patty) Wasn't I at the house?

We also find code-switching associated with a change in addressee when there is an alternation between messages in the second person and messages in the third person.

$$
\begin{gathered}
\text { Cr (girl, 6) (To Anglo researcher): Mira, Rosa está } \\
\text { sacando la lengua. ('Look, Rosa is } \\
\text { sticking out her tongue.') }
\end{gathered}
$$

(45) R (girl, 7)

(To Anglo researcher): Why you cry baby?

(To audience of researchers and MexicanAmerican girls): Esta llorando. ('He is crying.')

Our data do not indicate a uniform developmental sequence in the use of code-switching as a stylistic device. Some older children do not code-switch at all for stylistic reasons in our data, while some younger children do so frequently. Nevertheless, there appear to be some patterns. There are only a few examples of emphatic codeswitching by young children. Perhaps their paucity relates to the fact that most emphatic code-switches involve commands. In our data there are few examples of commands by young children, as most of their recorded interactions were with children older than they, where commands by the younger children were defined as inappropriate. There are no examples of focal code-switching by children under seven years of age. Neither are there examples of elaborative code-switching by children under seven. The latter fact seems strange, as sentence expansion or elaboration within a language is a common strategy of young children (Clark 1974). One might expect that such switching might at least occur in going from English into Spanish, the language young children generally know best. Switching to clarify a meaning by translation appears to be learned quite young. We have many examples from three-year-olds. Likewise, switching to attract or retain attention is learned early. The youngest child for whom we have clear examples of code-switching to mark mode shift is five. The switch marked a shift from the narrative mode to commentary. All our examples of code-switching to mark topic and addressee shift came from children at least six years old. Disregarding age, the commonest types of stylistic code-switching were attention attraction and retention followed by emphatic code-switching. The others were much less common. 
5. Conclusion. It is clear that the studied children's alternation between languages is neither random nor the result of a linguistic deficit. Their code-switching proceeds in accordance with grammatical and functional principles. Socially based principles operating within their speech community permit these children not only to integrate one code into discourse being carried out in another (codemixing) but also to alternate the actual code of the discourse (codechanging). One purpose served by this sophisticated use of linguistic signs is to identify individual bilinguals as members of a particular community. Code-switching for the bilingual also functions to mark situational changes and stylistic expression, perhaps more clearly than does register alternation for the monolingual. The adept use of code-switching by the bilingual can be viewed as analogous to the creative use of language by a skilled monolingual author or orator.

\section{NOTES}

Much of the analysis presented here was developed in collaboration with James Wentz. Earlier versions may be found in McClure and Wentz (1975), Wentz and McClure (1976), and McClure and McClure (1975). The research reported herein was supported in part by the National Institute of Education under grant No. HEW-NIE-NE-G-003-0147.

1. Register variation by children within a language has been discussed by Weeks (1971), Carlson and Anisfeld (1969), and Kernan (1974), among others.

2. Mexican Americans have only recently settled in the city and town discussed here. The adults' educational, linguistic, and residential background varies from some college to a few years of elementary school. All adults speak Spanish, but the dialect or dialects vary. Their English varies from accented fluency to nonexistence. Residential histories also differ widely. Some were born in the southwestern United States, others in Mexico. Some have lived in other communities in the Midwest and some have not.

3. He is the son of the Mexican-American teacher's aide.

4. The program was discontinued at the end of the 1974-1975 school year when a decrease in the enrollment of Spanish-speaking children took place.

5. The parents were all concerned with their children's education, especially with their acquisition of skills in English. In the case of two families, school authorities could not convince the parents that their children's participation in a bilingual, bicultural program would not hamper their acquisition of English.

6. The Mexican-American women came to the school to prepare the food. For many it was a first visit. The Mexican Americans did 
not participate in the PTA or other school-based activities such as scouting.

7. An additional 33 noun phrases consisting of unmodified nouns have not been included here as their status as code-changes is ambiguous.

8. For detailed analysis of the data from the elicited imitation tasks, see McClure and McClure (1975), Wentz and McClure (1972a), and Wentz (1976).

9. See Wentz and McClure (1976b) for a fuller discussion of crosslanguage ellipsis.

10. All of the children began to acquire Spanish before English. Even in homes where siblings speak English, preschool children are addressed primarily in Spanish. While a few of the children were proficient in both languages by age 5 , the majority were strongly Spanish dominant on kindergarten entry. Their acquisition of English was, however, quite rapid thereafter.

11. 'Social identity' is used here as in Goodenough (1969).

12. The use of the term 'identity relationship' also follows Goodenough (1969).

13. This child's teenage siblings are, together with the teenaged children of the Mexican-American teacher's aide, the most integrated into the Anglo community. They use English almost exclusively even in the home, despite their parent's strong preference for the use of Spanish as the home language.

14. The research staff included a female Mexican American, a male Mexican American, a female Puerto Rican, a female Peruvian, two male Anglos, and one female Anglo.

15. Interrogation in English of the preschool children in the small city was an exception. The children often answered English questions with Spanish responses even when they were able to respond in English.

16. Code-switching could, however, be artificially induced in narration by request. See McClure and Wentz (1976) for details.

17. Interestingly, two siblings whose English was rudimentary used it more freely at home than elsewhere. They were the only English-speaking members of the household, and perhaps they felt less inhibited in speaking English there because there was no one to note their errors or difficulties.

\section{REFERENCES}

Annamalai, E. 1971. Lexical insertion in a mixed language. In: Papers from the Seventh Regional Meeting. Chicago: Chicago Linguistic Society. 
Barker, G. 1972. Social functions of language in a MexicanAmerican community. Anthropological Papers of the University of Arizona 22. Tucson, Ariz.: The University of Arizona Press.

Blom, J. P., and J. Gumperz. 1972. Social meaning in linguistic structures: Code-switching in Norway. In: Directions in sociolinguistics. Edited by J. Gumperz and D. Hymes. New York: Holt, Rinehart, and Winston.

Bloomfield, L. 1933. Language. New York Holt, Rinehart, and Winston.

Carlson, P., and Anisfeld, M. 1969. Some observations on the linguistic competence of a two-year-old child. Child Development 40.569-576.

Clark R. 1974. Performing without competence. Journal of Child Language 1. 1-10.

Ervin-Tripp, S。 1964. An analysis of the interaction of language, topic and listener. In: The ethnography of communication. Edited by J. Gumperz and D. Hymes. American Anthropologist 66. 6(II): 86-102.

Fischer, J. 1958. Social influence in the choice of a linguistic variant. Word 14.47-56. (Reprinted in: Language in culture and society. Edited by D. Hymes. New York: Harper and Row.)

Gingras, R. 1974. Problems in the description of Spanish-English intrasentential code-switching. In: Southwest areal linguistics. Edited by G. Bills. San Diego: Institute for Cultural Pluralism.'

Goodenough, Ward H. 1969. Rethinking 'Status' and 'Role': Toward a general model of the cultural organization of social relationships. In: Cognitive anthropology. Edited by S. Tyler. New York: Holt, Rinehart, and Winston.

Gumperz, Jo 1964. Linguistic and social interaction in two communities. In: The ethnography of communication. Edited by J. Gumperz and D. Hymes. American Anthropologist 66.6(II): 137-154.

Gumperz, J., and E. Hernández-Chavez. 1972. Bilingualism, bidialectalism and classroom interaction. In: Functions of language in the classroom. Edited by C. Cazden, V. John, and D. Hymes. New York: Teachers College Press.

Haugen, E. 1956. Bilingualism in the Americas: A bibliography and research guide. American Dialect Society 26.

Hymes, D. 1972. Models of the interaction of language and social life. In: Directions in sociolinguistics. Edited by J. Gumperz and D. Hymes. New York: Holt, Rinehart, and Winston.

Kachru, B. 1975. Toward structuring the form and function of code-mixing: An Indian perspective. Studies in the Linguistic Sciences 5.1. Department of Linguistics, University of nlinois at Urbana. 
Kernan, K. 1974. The acquisition of formal and colloquial styles of speech by Samoan children. Anthropological Linguistics 16(4).

Lance, D. 1975. Spanish-English code-switching. In: El lenguaje de los Chicanos. Edited by E. Hernández-Chavez, A. Cohen, and A. Beltramo. Arlington, Va.: Center for Applied Linguistics. McClure, E。, and M. Mcclure. 1975. Code-switching among Mexican-American children. In: From meaning to sound. Edited by H. Sharifi. Lincoln, Neb.: University of Nebraska.

McClure, E., and J. Wentz. 1975. Functions of code-switching among Mexican-American children. In: Papers from the Parasession on Functionalism. Chicago: Chicago Linguistic Society.

McClure, E., and J. Wentz. 1976. Code-switching in children's narratives. In: 1975 Mid-America Linguistics Conference papers. Lawrence, Kans.: Linguistics Department, University of Kansas. Ornstein, J. 1976. Sociolinguistic constraints on lexical borrowing in Tarahumara: Explorations in 'langue and parole' and 'existential bilingualism'--an approximation. Anthropological Linguistics 18(2):70-93.

Pfaff, C. 1975. Syntactic constraints on code-switching: A quantitative study of Spanish/English. Paper presented at the Linguistic Society of America annual meeting.

Pfaff, C. 1976. Functional and structural constraints on syntactic variation in code-switching. In: Papers from the Parasession on Diachronic Syntax. Chicago: Chicago Linguistic Society.

Rubin, J. 1962. Bilingualism in Paraguay. Anthropological Linguistics 4(I):52-58.

Sridhar, S. (to appear in IJSL). On the functions of code-mixing in Kannada.

Weeks, To 1971. Speech registers in young children. Child Development 42(4):1117-1131.

Wentz, J. 1976. Considerations in the development of a syntactic description of code-switching. University of Illinois Ph. D. dissertation, first draft.

Wentz, J., and E. McClure. 1976a. Aspects of the syntax of the code-switched discourse of bilingual children. In: 1975 MidAmerica Linguistics Conference papers. Lawrence, Kans.: Linguistics Department, University of Kansas.

Wentz, J., and E. McClure. 1976b. Ellipsis in bilingual discourse. In: Papers from the 12th Regional Meeting. Chicago: Chicago Linguistic Society. 



\section{PARENTAL SPEECH TO CHILDREN: \\ CULTURAL PATTERNS}

\section{BEN G. BLOUNT}

\section{University of Texas at Austin}

The study of parental speech is a relatively recent phenomenon. Despite the fact that parents in every society use a special style or mode of speech when they address infants or young children, descriptions of parental speech have been rare until recently. Interest in the subject began to develop in the early $1960 \mathrm{~s}$, due to the remarkable growth of language as a social science. Topics previously marginal to the study of language began to appear; the ethnography of speaking (Hymes 1962), sociolinguistics (Bright 1966), and child language acquisition (Braine 1963; Brown and Bellugi 1964; Miller and Ervin 1964). At a more specific level, codes other than the standard variety of a language became objects of investigations, leading, among others, to advances in pidgin and creole studies (Hymes 1971) and in the study of baby talk (Ferguson 1956; 1964).

During the past 10-15 years, three separate but overlapping approaches to the study of parental speech have materialized: (1) linguistic descriptions of baby talk; (2) analyses of maternal speech as a determinant in child language acquisition; and (3) accounts of parental speech in parent-child interaction and language socialization. This paper reviews major findings and developments in each of these areas, outlining the progression of research from primarily linguistic concerns to social interactional ones. The paper also reports on a project of parental speech in English and in Spanish that attempts to incorporate the three approaches. Although none of the areas is traditional in linguistic anthropology, an anthropological perspective is not only useful but exceptionally well suited to an integrated study of parental speech. The broad perspective of anthropology and its synthetic character offer a promising framework for viewing parental 


\section{8 / BEN G. BLOUNT}

speech as a human activity, encompassing linguistic, social, and biological dimensions. A goal of this paper, ideally, is to demonstrate the potential of anthropology for the study of parental speech and to show that increased understanding of parental speech enriches anthropology. Speech specifically designed for children entails not only linguistic skills but cultural prerequisites. Speakers utilize cultural information for social purposes and with linguistic consequences.

Descriptions of special forms of language, such as baby talk, appeared occasionally in linguistic literature prior to the $1960 \mathrm{~s}$. Casagrande's account of Comanche baby language (1948), the Voegelins' description of mother language in Hidatsa (1954), and Austerlitz's discussion of Gilyak nursery words (1956) are notable cases. These and other studies were summarized in Ferguson (1964), which stimulated interest in this relatively neglected topic.

Ferguson's stated intention was to initiate cross-language studies of baby talk, leading to a general characterization and synchronic classification. The approach was descriptive and taxonomic. The definition of baby talk was constrained by that approach: ' . . . a special form of language which is regarded by a speech community as being primarily appropriate for talking to young children and which is generally regarded as not the normal adult use of language' (1964: 103), and 'baby talk is a relatively stable, conventionalized part of language . . .' and not 'an ephemeral form of speech arising out of adults' imitation of child speech' (1964:105). Three kinds of material were discussed: (1) intonational and paralinguistic phenomena; (2) morphemes, words, and constructions modified from the adult language; and (3) sets of lexical items peculiar to baby talk. Lastly, baby talk was viewed, in terms of usage, as multifunctional, as making easier a child's task of acquiring his or her language, as evoking some aspect of a nurturant-baby situation, and as a form of language in certain kinds of songs and verbal art (1964:111).

Ferguson's analytic treatment of baby talk has served as a framework for classifying the linguistic properties of that register. In a second summary article (1975), he reviewed accounts of baby talk in 15 languages and identified four processes that characterize the register in those languages. These processes are defined as synchronic, that is, those relating a baby talk register to normal adult language, from which it is derived. Reduction is one of the simplifying processes, especially in phonology. Canonical forms in the adult lexicon tend to be reduced toward a reduplicated CVCV. Substitution, assimilation, and generalization also are common processes in the derivation of a baby talk register, all producing a simplified form of the adult language. Not all of the derivational processes, however, lead to simpler structure. Some processes give extra clarity to utterances. 
Repetition of words, phrases, and sentences is a prominent feature of baby talk. As other examples, intonational contours are exaggerated and articulations are deliberate. Another process produces expressive forms, such as diminutive affixes. High pitch is also an expressive feature.

In addition to a list of structural-derivational features of baby talk and a description of derivational processes, Ferguson has provided a catalogue of baby talk uses and functions (1975). The primary use is to speak to young children, and in that respect, a number of acquisition functions are served: communication, self-expression, language teaching, and socialization. Numerous secondary uses are also documented; speech to pets and lovers is often in baby talk register, perhaps to express nurturance, and on a similar basis, persons with disabilities, such as old age, are often addressed with speech laced with baby talk features.

Baby talk is a speech register characterized by a limited number of common, perhaps universal derivational processes and similar structural properties, and it has several uses and functions. It is also culturally patterned. Each community has its own lexical inventory, its own structural patterns, and although the information is sketchy, its own patterns of usage. For example, G. Drachman found that Cypriot Greek baby talk differs in form and process from standard Athenian Greek baby talk (1973). In Cypriot Greek, there is a greater trend to closed syllables, producing a different distribution of parental forms in relation to children's developmental stages (Drachman 1973:181).

A long-range goal of the study of baby talk register is a classification of cultural patterns. Taxonomies of linguistic processes and forms are basic to a classification system, and progress in that area is needed. What is also needed is basic ethnographic information, in terms of participants, forms, uses, and functions. In effect, questions such as who uses baby registers, what features characterize and differentiate those registers, who are the socially appropriate recipients of the registers, and what are the consequences of usage, are still largely unanswered, even on a case study basis and certainly on a comparative basis. Ethnography is a proper framework for collecting information that will begin to provide answers to those and related questions.

Turning to the second area of interest in this topic, the role of parental speech in child language acquisition, the literature reflects a major change during the early $1960 \mathrm{~s}$, coinciding with the rekindling of interest in child language acquisition. Prior to that time parental speech was assumed to be the model toward which children progressed through successive approximations of the adult language. The mechanisms remained largely unexamined and obscure but, to oversimplify, children imitated the adult model in accordance with their capacities, 
and increases in capacity meant improved imitation and advances in language development. The discoveries in 1963-1964 that children's grammar has properties of its own, apparently independent of the adult grammar, led to reevaluation of the importance of parental speech. The pivot-like construction of children's two-word utterances appeared to be based on children's own linguistic rules to accomplish stable word order, and children's speech protocols revealed utterances such as allgone outside, more car, and more high. Parental speech seemed an unlikely source for such combinations.

With the introduction of transformational grammar into child language studies, increased emphasis was placed on an active role for children in acquiring their language, and the role of social environmental influences, including parental speech, was diminished. The emergence of language was viewed, according to one proposal, as a maturational process, an unfolding of innate capacities that appeared according to a maturational schedule (McNeill 1966). Children were considered to possess a Language Acquisition Device, consisting of linguistic universals, a hierarchy of grammatical categories, and basic grammatical relations. It was held that the universal hierarchy of categories organizes preliminary linguistic data, and the set of basic grammatical relations searches the data for corresponding sentence patterns. By measuring the results against the parental model, through time, a child acquires the categories and ordering of relations appropriate to his language.

A parental model is still essential in this innatist approach to child language, but its role is marginal. The child is the active agent in this perspective, acting as a 'miniature scientist', formulating hypotheses about the structure of his or her language, and then checking the hypotheses against the structure of the parental model. The main contribution of experience with the adult model was to aid discovery of the correct, i. e. well-formed, sentence patterns. Even that assistance, however, was considered to be relatively minor. It was held that children's increasing linguistic proficiency could not be attributed to any significant extent to the nature of the speech they heard. Even if children benefited from corrections of their speech and even if the speech directed to them tended to be syntactically simpler, much of what children heard was, indeed, overheard, and much of acquisition must proceed within that framework (Fodor 1966: 108). It was also held that much of the speech to which children were exposed was ungrammatical, containing many false starts, hesitations, and slips of the tongue (Bever, Fodor, and Weksel 1965).

A number of recent studies have indicated that early claims about ungrammaticality of parental speech were exaggerated. To the contrary, the overwhelming majority of parental utterances are well formed, even the utterances made in simplified baby talk registers 
(Blount and Padgug 1977; Halliday 1975). One can also question the claim that overheard speech is a major source of data for children acquiring a language. Interactionally situated speech, in which children are active participants, likely provides a more optimal learning environment. This point will be discussed later.

It is important to reiterate that discussions about parental speech in this period of child language studies were focused on the potential contribution to the acquisition of grammar. The dominant question of the period was how best to account for the fact that children's utterances revealed stable word order from the onset of multiple-word utterances. Was parental speech a determinant, and if so, was there a minimal required input, a threshold requisite? A number of studies were devoted to answering that question.

Brown and associates noted that parents and children in the Harvard study engaged in several dialogue types. Parents engaged in what appeared to be a kind of indirect language coaching or training. Parents frequently expanded their children's utterances, 'filling in' a child's utterance with function words and producing an utterance grammatical by adult standards. They also frequently modeled the children's utterances. Basically, this action repeated a lexical item or items in a child's utterance and contextualized the utterance within a larger framework. The function was to maintain conversation by locating a child's utterance in a context, such as an ongoing activity. Other dialogue types were echoing, produced when a parent had difficulty understanding what a child had said, and prompting, a device for eliciting answers from children (Brown, Cazden, and Bellugi 1969).

Expansions were a likely source of assistance in language acquisition, since they are direct and well-formed responses to children's utterance. To test the role of expansions, Cazden conducted in 1965 an experiment with some nursery school children. One group received 40 minutes of extensive training every day for 12 weeks. All of the utterances in that group were expanded. A second group received 40 minutes of modeling, and a third group received no special training. Language tests compared with ones at the beginning of the study, 12 weeks earlier, showed that the 'expansion' group had not progressed significantly beyond the control group, but considerable advances were made by the 'modeling' group. Cazden concluded that language in ordinary conversation may be more important than language more apparently designed to instruct about language.

An interesting point in Cazden's study was her observation that adults found it almost impossible not to expand children's utterances. One hypothesis is that adults need to check on their understanding of the meaning and intent of the children's often opaque utterances. That may be the case, but conversational constraints may also operate at another level. Young children's utterances are context and activity 
bound; they are running accounts of immediate action in the environment. Parental expansions probably serve not so much as checks on understanding as acknowledgments of the children's accuracy in noting and describing immediate actions. A dual function is thereby served: children's accounts of activities are encouraged, and parents maintain the flow of conversation in terms most apt to the situation at hand, $i . e$. what children have just described.

One function of parental speech is to initiate and sustain parentchild interaction. Toward that end, speech is simplified and clarified in structural terms. Several studies have shown that parents make modifications in their child-directed speech. For example, one woman's speech to her young son, as compared to her speech to an adult, was slower, showed less lexical variety, contained fewer morphemes per utterance, and contained half as many transformations per utterance (Drach 1968). The adult-child speech also showed a greater percentage of questions and imperatives, a finding consistent with observations of adult-child speech in two non-Western languages, Luo and Samoan (Blount 1972).

Another study compared the speech of ten mothers addressing children 18-26 months old, and addressing children over 45 months of age (Broen 1972). In general, it was found that speech to the younger children was slower, more fluent, more repetitive, that it contained less diversity of vocabulary (in a type/token ratio), and that sentence boundaries were more clearly demarcated by pauses.

The pattern that emerges from these and other studies is that parents make a concerted effort to tailor their speech so as to engage young children in verbal interaction. Because of young children's undeveloped communicative skills, parental discourse contains special linguistic and interactional properties. Several studies have noted parental reliance on repetition as a communicative device. For example, Kobashigawa found that in one sample of maternal speech to a 26-month-old child, 34 percent of the mother's utterances were repetitions (1968). He also found that most of the repetitions were not exact. Some features would be varied, if only slightly, so that a repetition would have different intonation, word addition or deletion, or morphological or morphophonemic changes. The alterations did not tend to produce simpler utterances, suggesting that lack of comprehension by the children was not the sole motivation for the repetitions. Kobashigawa suggested that communication, in a semantically meaningful sense, was not the main motivational factor, since expressions like You don't pay income tax, do you? were subject to repetitions. A likely interpretation is that repetitions are used to attract children's attention, to get a response, so that interaction will continue, irrespective of any semantic content. 
Studies designed to investigate the role of parental speech as an aid to child acquisition of syntax have frequently raised questions that extend into an interactional domain. Before that third area-parent-child interaction--is reviewed, however, some additional findings concerning syntax and semantics require attention. One especially important study is Brown's account of determinants in children's acquisition of grammatical morphemes, morphemes such as inflections and prepositions that modulate basic structural meanings (1973). He found that the three children in the Harvard study acquired their first 14 grammatical morphemes in essentially the same order. Brown wanted to know what the determinants of acquisition were, and he found evidence that grammatical complexity, defined in terms of transformations, was a determinant, but that semantic complexity was also a determinant for most of the 14 morphemes.

Brown also tested parental speech as a possible determinant of acquisition order. He wanted to know, specifically, if the frequencies with which parents modeled a particular morpheme showed any effect on the order in which a child acquired the morpheme. Parental usage profiles of the morphemes showed a remarkable consistency and stability across three households (1973:361). Brown concluded that the constancy of parental usage appeared sufficient to account for the regularity in acquisition order among the children. Rank order correlations of the profiles, however, did not show necessary levels of significance, and Brown concluded that frequency of modeling was not a significant variable (1973:379). However, what Brown wanted to measure about parental speech habits was how they might affect the child 'independently of the possible shaping of those habits to fit the child's own inclinations and preferences in the use of the morphemes' (1973:356). Speech samples of the parents were taken from interaction sessions immediately prior to children's advances into the 'grammatical morpheme' stage, and utterances that were imitations or expansions of antecedent child speech were not counted in the profiles. In effect, the parental profiles were defined so as to exclude as much as possible children's influences on parental performance and thus the makeup of the profiles. It is possible, even probable, that parental influence is stronger in interactional contexts where experience is more immediate and where children themselves make a direct contribution, in terms of grammatical morpheme usage, to the unfolding of interaction.

Several recent studies have examined mother-child speech for evidence of a direct relation between input and acquisition. Relationships have been found, but syntactic complexity, or simplification, is not among them. Newport (1976) found in a study of 15 motherdaughter pairs that the acoustic clarity of speech and the referential properties of speech affect language acquisition, but that syntactic 
complexity was not a factor. In another study with nine Dutch-speaking mothers, Snow (1976) found that semantic limitations are largely responsible for the grammatical simplicity of speech to two-year-old children. The mothers limited the semantic content of their utterances to what children could themselves produce.

In still another study, Cross (1975) examined maternal speech among 16 mothers to children in the age range 18-30 months. Each of the mothers also had children in the range 4-6 years, and each child in each age range was accelerated in linguistic competence, as shown by a variety of measures. The rationale for studying accelerated children was that input-acquisition relationships would be more apparent. Twenty-four features of the mothers' speech were coded and correlated with measures of children's linguistic competence. Several of the features were defined on semantic dimensions, e.g. sequential semantic repetitions; several in terms of syntax, e.g. measures of syntactic simplicity; and the remainder as discourse features, such as talkativeness (1975:121-124). The results of the study showed that mothers were sensitive to children's linguistic levels and that the more immature a child's communicative strategies, the finer was the tailoring to allow for the inadequacies. The one exception to that tendency was syntactic complexity, where no significant differences were observed.

Two other findings in the Cross study are noteworthy. She found high negative correlations between children's linguistic levels and their mothers' rates of repetition and paraphrasing. She concluded that 'Repetition of both types seems to be contingent upon the child's ability to process and comprehend his mother's utterances. As his comprehension improves, the signs of non-comprehension would diminish and so would his mother's tendency to repeat her utterances' (1975:129). The second finding was that 55 percent of the mothers' utterances incorporated exactly, or referred to, the topic previously expressed by a child in the interaction. The figure was higher for the younger children (1975:133). This suggests strongly that the ideal context in which language acquisition occurs is one in which an adult gives expression to what a child is capable of intending and, in fact, has attended.

To summarize, when parents interact with young children whose communicative skills are limited, adjustments are made in their speech. Rules can be written for the derivation of the modified register from the standard, adult form of the language, and effects of the simplified speech register on children's acquisition of language can be investigated. As we have seen, however, the overriding concern with syntax in child language studies has conditioned research on the input-acquisition problem. Efforts to establish a determinant link between aspects of parental speech and child syntax have not been 
successful. That is perhaps not surprising when we consider some additional observations made by several individuals working in a variety of Western and non-Western societies (see Brukman 1973 for a summary). Parents rarely correct children's grammar, and they do not appear to concern themselves with teaching grammar. It is not at all clear how they would teach grammar directly, even if they desired to do so, since aspects of grammar operate out of awareness and are difficult to verbalize.

What parents do express interest in is teaching children names of objects and activities and how to use those names. In effect, parents are concerned with referentiality and the truth-content of children's utterances. At a still more fundamental level, they are motivated to engage children in social interaction. Even infants with no linguistic skills and only rudimentary communicative skills are enticed to participate in social interactive exchanges. As children begin to acquire a vocabulary for use in social interaction, parents engineer the interaction to accommodate what skills the children have, still directing their efforts to initiate and sustain interaction, and within that framework, to focus the dialogue on what the children know and are capable of doing. Parental organization of interaction and dialogue facilitates children's learning of interactional skills and referentiality, in essence, their learning to communicate.

Parents begin to structure interaction routines with children who are still in the prelinguistic stages of development. In an East African society, the Luo, parents alter the form and content of their speech to infants when the infants begin to acquire the capacity for attending to the sounds of speech and for imitating, however imperfectly, what they hear (Blount 1971). Parents begin to use more and more lexical items in their speech and fewer nonsense forms and imitations as infants progress in the acquisition of their first few vocabulary items (Blount 1972).

Patterns have also been found in the communication between American mothers and infants only 12 weeks old. Lewis and Freedle found that each member of a mother-infant dyad initiated interactions, vocalized and gestural, and they discovered that the interactions were nonrandom, sequential, and situationally determined (1973).

Detailed longitudinal studies of parent-child interaction have only recently begun to appear. One project has focused on interpersonal communication between parents and children in English-speaking and in Spanish-speaking families in Austin, Texas (Blount and Padgug 1977). 1 The long-range goals are the description of parental speech in English and in Spanish, a comparison of their differences, and an assessment of the roles of parental speech in fostering the acquisition of communicative skills in children. To date, the descriptions and analyses have centered on the parental speech patterns. Features of 
speech modification have been identified, and profiles of feature usage have been established for each of the families and parents in the study (Blount and Padgug 1977).

The differential utilization of features by mothers and fathers has been described, and English and Spanish comparisons have been made to identify cultural differences in feature usage (Blount and Padgug 1976). Lastly, changes in features selection, longitudinally, have been noted in relation to language development (Blount and Kempton 1976). These findings are briefly summarized here. First, some comments about methods and procedures are in order.

Tape recordings were made of parental speech to young children in four English-speaking and four Spanish-speaking families in Austin, Texas. The age range of the children was 9;0-18;0 months for the English speakers and 8;1-13;1 and 18;1 - 22;2 for Spanish speakers. All were children of university students, and none of the children had older siblings. Three of the Spanish-speaking families were from Latin America--one family from Mexico, one from Chile, and one in which the father was from Peru and the mother from Argentina. The fourth family was native to Texas.

Efforts were made to record under as natural conditions as possible. At the beginning of the project, we repeatedly emphasized in discussions with the parents the necessity of obtaining samples of natural interactions. The parents were encouraged to record conversations with their children that were typical of everyday interactions and they were requested to avoid staged productions that would be unrepresentative of children's interactional routines. All the families reported that there were special times of the day when they were most likely to interact with the children, and they attempted to record during those times.

A tape recorder was left with each family for 24-hour periods, ideally every week (on some occasions recordings were made only every two or three weeks). During a 24-hour period, parents would tape approximately 30-45 minutes of interaction. A minimum of ten recordings was made for each child. A summary of the sessions, number of utterances, and ages of the children is given in Table 1.

Observers were not present during the recording sessions. Valuable ethnographic information was thereby sacrificed, but pretesting had shown that the presence of an observer/outsider in the home severely constrained the behavior of the children. That, in turn, interfered with parental speech behavior and naturalness of interaction. The parents all reported that they had no difficulty in making the recordings when only they and the child were present, and none of them felt that the presence of the tape recorder hindered either their or the child's behavior. They all stated that naturalness of setting and interaction was not a problem, and they did not feel that they had 
attempted to teach or instruct the children any more than they would have under other circumstances.

TABLE 1. Summary of recording sessions.

\begin{tabular}{|llll|}
\hline Child & $\begin{array}{l}\text { Number of } \\
\text { sessions }\end{array}$ & Age span & $\begin{array}{l}\text { Number of } \\
\text { parental utterances }\end{array}$ \\
\hline Miranda & 13 & $4 ; 0$ & 1602 \\
Jeanne-Marie & 10 & $2 ; 1$ & 2149 \\
Joelle & 13 & $3 ; 2$ & 1414 \\
Rebecca & 11 & $2 ; 1$ & 697 \\
Adam & 13 & $3 ; 2$ & 3123 \\
Valente & 14 & $2 ; 3$ & 1061 \\
Analisa & 9 & $2 ; 2$ & 672 \\
Christian & 11 & $2 ; 0$ & 1015 \\
Luis & 12 & $2 ; 1$ & 933 \\
& & & \\
\hline
\end{tabular}

The basic units in the transcriptions of the interactions were utterances. An utterance was defined as parental speech offset by children's utterances or by pauses--i.e. interactional turn-taking was the structural criterion. Whatever occurred verbally in a turn was one utterance, whether it was a monosyllabic nonsense form or two or three sentences.

Examination of the utterances by native speakers of English and Spanish led to the identification of 34 prosodic, paralinguistic, and interactional features that characterize the speech as parental. The judgmental criterion was appropriateness of the speech to children and inappropriateness to adults, except in cases with a specialized speech function, such as sarcasm. In effect, the decisions were made on cultural grounds. Native speakers of English and of Spanish listened to each utterance and decided, first, if the utterance was parental speech, and second, what the features were that led to that classification. Initially, only the more obvious features were used-exaggerated intonation, high pitch, falsetto, special lexical items, etc. --but the dual classificational system quickly led to the discovery of other features, and ultimately to a list of 34 , still nonexhaustive. For the purposes of discussion, the features are classified into nine categories, as indicated in Chart 1.

The parental utterances were coded for each of the 34 features, again by native speakers. If a feature occurred at least once in an utterance, it was scored as present, otherwise as absent. Multiple occurrences of a feature in an utterance were not individually scored. The present/absent rate provided a rate measure, not an absolute 
CHART 1. Features and categories of parental speech.

(1) Volume: air
(a) Breathiness
(b) Breath held

(2) Volume: sound
(a) Whisper
(b) Lowered volume
(c) Raised volume

(3) Pitch/Intonation
(a) Falsetto
(b) High pitch
(c) Low pitch
(d) Exaggerated intonation
(e) Singing

(4) Paralinguistic
(a) Alteration
(b) Creaky voice
(c) Tenseness
(d) Nasality
(e) Rounding
(f) Phonetic substitution

(5) Duration
(a) Lengthened voweI
(b) Lengthened consonant
(c) Shortened vowel
(d) Shortened consonant

(6) Tempo
(a) Slow tempo
(b) Fast tempo

(7) Lexicon/Forms
(a) Special lexical items
(b) Nonsense forms
(c) Personal pronoun substi- tution

(8) Grammar
(a) Grammatical deviations
(b) Tag questions

(9) Interaction
(a) Instructional
(b) Hmm?
(c) Attentionals
(d) Turn substitution
(e) Repetition
(f) Imitation
(g) Interpretation

frequency of occurrence for the features. To date, the rate measure profiles have been established for the composite records of parental speech to each of the nine children, i. e. not for the individual, weekly sessions but for all of the sessions for each child. The rate measures for the individual children are given in Tables 2 and 3.

The profiles reveal several interesting points. The most striking is a remarkable uniformity, overall, of rate measures across the children for each feature. Several features have uniformly low rates: breath held, whisper, alteration (phonetic), nasality, phonetic substitution, slow tempo, grammatical deviation, tag questions, and turn substitution all occur at a rate of less than three times per 100 
TABLE 2. Composite rate measures, English.

\begin{tabular}{|c|c|c|c|c|c|}
\hline Features & Rate me: & sures & & & \\
\hline & & Jeanne- & & & \\
\hline & Miranda & Marie & Joelle & Rebecca & Adam \\
\hline Breathiness & 23.3 & 34.4 & 17.5 & 20.8 & 35.5 \\
\hline Breath held & 0.1 & 6.7 & 2.1 & 3.0 & 1.4 \\
\hline Whisper & 2.1 & 3.0 & 5.9 & 3.4 & 3.5 \\
\hline Lower volume & 15.5 & 14.8 & 15.8 & 10.8 & 39.5 \\
\hline Raised volume & 4.5 & 2.7 & 4.7 & 5.7 & 3.8 \\
\hline Falsetto & 18.4 & 8.6 & 3.5 & 11.2 & 5.0 \\
\hline High pitch & 26.0 & 27.7 & 20.8 & 23.1 & 26.7 \\
\hline Low pitch & 6.8 & 13.5 & 5.9 & 5.0 & 3.5 \\
\hline Exaggerated & t & & & & \\
\hline intonation & 67.2 & 73.5 & 61.2 & 77.5 & 64.7 \\
\hline Singing & 0.2 & 0.0 & 0.1 & 0.0 & 0.3 \\
\hline Alteration & 2.7 & 8.4 & 0.1 & 0.4 & 1.3 \\
\hline Creaky voice & 9.6 & 17.2 & 13.0 & 15.1 & 14.9 \\
\hline Tenseness & 3.7 & 15.2 & 12.9 & 15.6 & 9.7 \\
\hline Nasality & 0.1 & 0.3 & 2.9 & 4.2 & 0.2 \\
\hline Rounding & 7.2 & 5.8 & 1.3 & 1.1 & 1.9 \\
\hline Phonetic & & & & & \\
\hline substitution & 0.3 & 0.0 & 0.4 & 0.0 & 0.0 \\
\hline Lengthened vowel & 26.4 & 18.4 & 25.2 & 20.9 & 23.3 \\
\hline Lengthened consonant & 0.6 & 0.1 & 16.2 & 7.5 & 0.4 \\
\hline Shortened vowel & 0.9 & 1.7 & 2.2 & 1.7 & 1.4 \\
\hline Shortened consonant & 0.4 & 0.0 & 0.9 & 7.7 & 0.3 \\
\hline Slow tempo & 5.0 & 3.1 & 2.7 & 7.2 & 4.6 \\
\hline Fast tempo & 2.8 & 5.9 & 4.2 & 5.0 & 2.9 \\
\hline Special lexical item & 15.5 & 7.8 & 7.6 & 1.9 & 8.7 \\
\hline Nonsense forms & 11.4 & 6.3 & 9.5 & 2.3 & 3.2 \\
\hline Personal pronoun & 35 & 50 & 37 & 0.3 & 377 \\
\hline Grammatical & & & & & \\
\hline deviations & 0.8 & 2.0 & 0.4 & 0.1 & 1.3 \\
\hline Tag questions & 1.6 & 1.2 & 2.8 & 2.6 & 2.3 \\
\hline Instructional & 16.6 & 13.3 & 3.2 & 25.5 & 7.6 \\
\hline $\mathrm{Hmm}$ ? & 2.9 & 6.6 & 11.1 & 4.4 & 4.6 \\
\hline Attentionals & 3.2 & 5.3 & 7.2 & 3.0 & 1.9 \\
\hline Turn substitution & 0.2 & 1.6 & 0.4 & 0.4 & 1.3 \\
\hline Repetition & 27.8 & 35.2 & 10.4 & 18.8 & 19.5 \\
\hline Imitation & 4.1 & 6.6 & 2.8 & 6.2 & 9.1 \\
\hline Interpretation & 0.8 & 3.4 & 0.8 & 10.8 & 8.8 \\
\hline Totals & 312.2 & 357.4 & 288.4 & 323.2 & 316.8 \\
\hline
\end{tabular}


TABLE 3. Composite rate measures, Spanish.

\begin{tabular}{|c|c|c|c|c|}
\hline Features & Rate me & sures & & \\
\hline & Valente & Analisa & Christian & Luis \\
\hline Breathiness & 12.9 & 9.2 & 13.5 & 12.1 \\
\hline Breath held & 0.0 & 0.0 & 0.3 & 0.2 \\
\hline Whisper & 2.5 & 3.1 & 3.9 & 1.2 \\
\hline Lower volume & 19.6 & 18.9 & 33.5 & 19.0 \\
\hline Raised volume & 22.9 & 23.7 & 26.6 & 17.8 \\
\hline Falsetto & 9.1 & 3.9 & 15.6 & 13.7 \\
\hline High pitch & 19.3 & 18.3 & 57.5 & 15.4 \\
\hline Low pitch & 5.2 & 4.2 & 8.0 & 2.6 \\
\hline Exaggerated & & & & \\
\hline intonation & 42.0 & 52.2 & 59.7 & 60.0 \\
\hline Singing & 2.4 & 0.7 & 2.3 & 0.9 \\
\hline Alteration & 2.5 & 7.3 & 2.5 & 3.1 \\
\hline Creaky voice & 8.4 & 2.5 & 6.4 & 14.9 \\
\hline Tenseness & 2.5 & 0.6 & 3.2 & 2.4 \\
\hline Nasality & 0.0 & 0.0 & 0.0 & 0.0 \\
\hline Rounding & 2.8 & 0.7 & 3.9 & 2.7 \\
\hline $\begin{array}{l}\text { Phonetic } \\
\text { substitution }\end{array}$ & 0.0 & 0.3 & 0.1 & 0.0 \\
\hline Lengthened vowel & 13.5 & 37.2 & 22.7 & 16.0 \\
\hline Lengthened consonant & 0.7 & 2.7 & 4.2 & 0.3 \\
\hline Shortened vowel & 0.9 & 1.2 & 3.8 & 1.4 \\
\hline Shortened consonant & 0.2 & 1.2 & 1.4 & 0.5 \\
\hline Slow tempo & 4.0 & 4.5 & 15.1 & 2.0 \\
\hline Fast tempo & 19.2 & 18.5 & 44.2 & 30.5 \\
\hline Special lexical item & 9.5 & 2.1 & 5.6 & 7.3 \\
\hline Nonsense forms & 23.0 & 2.6 & 1.2 & 6.1 \\
\hline $\begin{array}{l}\text { Personal pronoun } \\
\text { substitution }\end{array}$ & 26.0 & 24.6 & 4.5 & 28.8 \\
\hline $\begin{array}{c}\text { Grammatical } \\
\text { deviations }\end{array}$ & 0.3 & 0.6 & 10.6 & 1.1 \\
\hline Tag questions & 0.7 & 0.0 & 2.7 & 6.6 \\
\hline Instructional & 27.1 & 45.0 & 30.6 & 33.6 \\
\hline Hmm? & 19.2 & 12.9 & 28.8 & 11.6 \\
\hline Attentionals & 28.5 & 32.0 & 23.8 & 11.6 \\
\hline Turn substitution & 4.0 & 2.2 & 1.9 & 2.4 \\
\hline Repetition & 44.6 & 67.1 & 65.3 & 39.8 \\
\hline Imitation & 12.3 & 1.5 & 10.2 & 15.4 \\
\hline Interpretation & 7.0 & 1.8 & 26.2 & 42.1 \\
\hline Totals & 392.8 & 403.3 & 539.8 & 432.8 \\
\hline
\end{tabular}


utterances, in English and in Spanish. Although low rates were expected on several of the features, others were expected to be higher. Phonetic alteration and substitution and grammatical deviation are often stereotyped characteristics of babyish speech, but they were relatively infrequent in the speech of all 18 parents.

The uniformity of parental speech is most striking when one considers the features with the highest rate scores. In the English samples, exaggerated intonation was the most frequently occurring feature. The highest score was 77.5 per 100 utterances, and the lowest was 61.2 . The average was 68.8 occurrences per 100 utterances. High pitch showed even greater uniformity, with a difference of only 6.9 percent between the highest and lowest scores. Spanish also showed a high degree of similarity on the top-ranked features, repetition, exaggerated intonation, instructional, and attentionals.

For purposes of comparison and summary, the rate measures for each language have been ranked, i. e. with all of the parents combined on the basis of English and Spanish. The rankings are given in Table 4.

If we consider the ten most frequently occurring features in the two languages, we find that six are common to both languages: exaggerated intonation, high pitch, lengthened vowel, repetition, lowered volume, and instructional. Each language has four specific features. In English they are breathiness, creaky voice, tenseness, and falsetto. In Spanish, they are attentionals, fast tempo, raised volume, and personal pronoun substitution.

Both languages are similar, then, in a high utilization of pitch, intonation, vowel duration, and lower volume, on the one hand, and in the use of repetition and instruction, on the other. The Englishspeaking parents relied more heavily on control of air volume and prosodic and paralinguistic features, whereas their Spanish-speaking counterparts showed greater utilization of tempo and interactional features. Exactly what these differences mean in developmental terms is not yet clear, but if one keeps in mind that in all of the families, the initiation and maintenance of interaction with the children was the focus of caretaker-child activity, it can be seen that there are two distinct cultural styles to achieve those ends. In English, parents modulate the prosodic and paralinguistic properties of their speech, and in Spanish, social interactional properties are more readily invoked.

Another expression of cultural differences is in the overall rate of feature usage. Parents in the Spanish sample, as a group, showed a rate of 436.8 features per 100 utterances, whereas English-speaking parents had a rate of 318.8 . Spanish speakers, then, use, comparatively, 37 percent more features.

To consider differences in mother and father speech, rankings of the 12 most frequently occurring features are compared. The mothers' 
TABLE 4. Composite rate measures, relative frequencies, and ranking for each feature, English and Spanish. Relative frequencies are the proportions in which parents use one feature in relation to all of the others.

\begin{tabular}{|c|c|c|c|c|c|c|c|}
\hline \multicolumn{2}{|c|}{$\begin{array}{l}\text { English: } \\
\text { Feature }\end{array}$} & Rate & Prop. & \multicolumn{2}{|c|}{$\begin{array}{l}\text { Spanish: } \\
\text { Feature } \\
\end{array}$} & Rate & Prop. \\
\hline 1. & $\begin{array}{l}\text { Exaggerated } \\
\text { intonation }\end{array}$ & 67.2 & 21.1 & 1. & $\begin{array}{r}\text { Exagg } \\
\text { into }\end{array}$ & 52.4 & 12.0 \\
\hline 2. & Breathiness & 29.1 & 9.1 & 2. & Repetit & 52.2 & 11.9 \\
\hline 3. & High pitch & 25.4 & 8.0 & 3. & High pitch & 31.2 & 8.5 \\
\hline 4. & Repetition & 24.4 & 7.7 & 4. & Instruct & 29.1 & 6.7 \\
\hline 5. & volume & 22.9 & 7.2 & 5. & Atter & 25.8 & 5.9 \\
\hline 6. & Lengthened & & & 6. & Low & 22.7 & 5.2 \\
\hline & vow & 22.5 & 7.1 & 7. & Raised volume 2 & 22,6 & 5.2 \\
\hline 7. & Creaky voice & 14.4 & 4.5 & 8. & Lengthened & & \\
\hline 8. & Instru & 11.2 & 3.5 & & & 20.5 & 4.7 \\
\hline 9. & Tensel & 11.0 & 3.4 & 9. & Fas & 19.6 & 4.5 \\
\hline 10. & $\begin{array}{l}\text { Special lexical } \\
\text { items }\end{array}$ & 8.8 & 2.8 & & $\begin{array}{l}\text { Personal pro- } \\
\text { noun }\end{array}$ & 18.4 & 4.2 \\
\hline 11. & False & 8.5 & 2.5 & 11.5 & Slon & 18.3 & 4.2 \\
\hline 2. & Low & 7.0 & 2.2 & 11.5 & Hmm? & 18.3 & 4.2 \\
\hline 3. & Imit & 6.4 & 2.0 & 13. & Inte & 16.5 & 3.8 \\
\hline 4. & Non & 6.2 & 1.9 & 14. & Bre & 12.2 & 2.8 \\
\hline 5. & $\mathrm{Hmm}$ & 5.6 & 1.8 & 15. & Fal & 11.0 & 2.5 \\
\hline 6. & Inter & 5.0 & 1.6 & 16. & Imit & 10.6 & 2.4 \\
\hline 7. & Slow & 4.3 & 1.3 & 17. & Non & 8.7 & 2.0 \\
\hline 8. & Fast t & 3.9 & 1.2 & 18. & Creal & 8.3 & 1.9 \\
\hline 19.5 & Raise & 3.8 & 1.2 & 19. & Spec & & \\
\hline 19.5 & Rounding & 3.8 & 1.2 & & ite & 6.4 & 1.5 \\
\hline 21.5 & $\begin{array}{l}\text { Personal pro- } \\
\text { noun }\end{array}$ & 3.7 & 1.2 & 20. & $\begin{array}{l}\text { Low } \\
\text { Pho }\end{array}$ & 6.0 & 1.4 \\
\hline 21.5 & Atter & 3.7 & 1.2 & & ati & & \\
\hline 23. & Whisper & 3.3 & 1.0 & & tuti & 3.5 & 0.8 \\
\hline 24. & $\begin{array}{r}\text { Lengthened } \\
\text { consonant }\end{array}$ & 3.2 & 1.0 & & $\begin{array}{r}\text { Gran } \\
\text { dev }\end{array}$ & 3.4 & 0.8 \\
\hline 5. & $\begin{array}{l}\text { Phonetic alter- } \\
\text { ation/substi- } \\
\text { tution }\end{array}$ & 3.0 & 1.0 & $\begin{array}{l}23 . \\
24.3 \\
24.3\end{array}$ & $\begin{array}{l}\text { Rounding } \\
\text { Whisper } \\
\text { Tag quest }\end{array}$ & $\begin{array}{l}2.7 \\
2.6 \\
2.6\end{array}$ & $\begin{array}{l}0.6 \\
0.6 \\
0.6\end{array}$ \\
\hline 6. & Breath held & 2.7 & 0.9 & 24.3 & titution & 2.6 & 0.6 \\
\hline 27. & Tag questions & 2.0 & 0.6 & 27. & Tens & 2.3 & 0.5 \\
\hline $\begin{array}{l}28 . \\
29 .\end{array}$ & $\begin{array}{l}\text { Shortened vowel } \\
\text { Grammatical }\end{array}$ & 1.5 & 0.5 & 28.5 & $\begin{array}{r}\text { Lengthened } \\
\text { consonant }\end{array}$ & 1.9 & 0.4 \\
\hline & & 1.2 & 0.4 & 28.5 & Shor & 1.9 & 0.4 \\
\hline 0.5 & Turn substitution & 1.0 & 0.3 & 30. & Singing & 1.6 & 0.4 \\
\hline 30.5 & $\begin{array}{l}\text { Shortened } \\
\text { consonant }\end{array}$ & 1. & 0.3 & 31. & $\begin{array}{l}\text { Shortened } \\
\text { consonant }\end{array}$ & 0.8 & 0.2 \\
\hline 2. & Nas & 0. & & & $\mathrm{Br}$ & 0.1 & 0.0 \\
\hline 3. & Singing & 0.2 & 0.0 & 33. & Nasality & 0.0 & 0.0 \\
\hline
\end{tabular}


and fathers' records in each language group are combined, allowing us to compare sex differences in feature usage across languages. The rankings are given in Table 5 .

TABLE 5. Ranked composites according to sex and language: 12 most frequent features.

\begin{tabular}{|c|c|}
\hline Mother-English & Father-English \\
\hline $\begin{aligned} \text { 1. } & \text { Exaggerated intonation } \\
\text { 2. } & \text { Breathiness } \\
\text { 3. } & \text { High pitch } \\
\text { 4. } & \text { Lengthened vowel } \\
\text { 5. } & \text { Low volume } \\
\text { 6. } & \text { Repetition } \\
\text { 7. } & \text { Creaky voice } \\
\text { 8. } & \text { Instructional } \\
\text { 9. } & \text { Falsetto* } \\
\text { 10. } & \text { Special lexical item* } \\
\text { 11. } & \text { Tenseness } \\
\text { 12. } & \text { Imitation* }\end{aligned}$ & $\begin{array}{l}\text { 1. Exaggerated intonation } \\
\text { 2. Repetition } \\
\text { 3. Breathiness } \\
\text { 4. Low volume } \\
\text { 5. Tenseness } \\
\text { 6. High pitch } \\
\text { 7. Creaky voice } \\
\text { 8. Instructional } \\
\text { 9. Lengthened vowel } \\
\text { 10. Low pitch* } \\
\text { 11. Breath held* } \\
\text { 12. Phonetic alteration* }\end{array}$ \\
\hline Mother-Spanish & Father-Spanish \\
\hline \begin{tabular}{|rl} 
1. & Repetition \\
2. & Exaggerated intonation \\
3. & High pitch \\
4. & Attentionals \\
5. & Instructional \\
6. & Lengthened vowel \\
7. & Low volume \\
8. & Raised volume \\
9. & Slow tempo \\
10. & Hmm? \\
11. & Personal pronoun \\
& substitution* \\
12. & Fast tempo
\end{tabular} & $\begin{array}{l}\text { 1. Repetition } \\
\text { 2. Exaggerated intonation } \\
\text { 3. Hmm? } \\
\text { 4. Raised volume } \\
\text { 5. High pitch } \\
\text { 6. Instructional } \\
\text { 7. Low volume } \\
\text { 8. Slow tempo } \\
\text { 9. Attentionals } \\
\text { 10. Interpretation* } \\
\text { 11. Fast tempo } \\
\text { 12. Lengthened vowel }\end{array}$ \\
\hline
\end{tabular}

Looking first at the English speakers, we see that mothers and fathers share nine of the 12 ranked features. Moreover, they share five of the top six features: exaggerated intonation, breathiness, high pitch, low volume, and repetition. The other two features show a considerable difference in ranking. Lengthened vowel is fourth in 
the mothers' speech, and ninth in the fathers'. Tenseness is fifth in the fathers' speech and eleventh in the mothers'. The three features which are not shared are: falsetto, special lexical items, and imitation in the mothers' speech (ranked 9th, 10th, and 12th, respectively); low pitch, breath held, and phonetic alteration in the fathers' speech (ranked 10th, 11th, and 12th, respectively). If one further considers the rankings for the individual parents (see Blount and Padgug 1976), two additional contrasts stand out. Mothers consistently score higher on high pitch, and fathers score higher on creaky voice.

We can now summarize mother-father speech in English. The most noticeable aspect of the speech is that mothers and fathers are more alike than they are different. If they are contrasted, however, the features which best characterize mother speech are lengthened vowel, falsetto, and high pitch. Those which best characterize father speech are lowered volume, creaky voice, and secondarily, low pitch and breath held. In effect, mothers rely more on duration and higher pitch registers, and fathers rely more on lower pitch registers and breath control.

Turning now to the Spanish records, one sees that mothers and fathers share eleven of the twelve ranked features. The only nonshared features are personal pronoun substitution for mothers and interpretation for fathers. The internal rankings among the eleven shared features reveal greater reliance on attentionals by mothers and Hmm? and raised volume by fathers. Mothers also score consistently higher on exaggerated intonation, and fathers score higher on fast tempo. As in English, we find that in Spanish mother and father speech are more alike than different. If we focus on the differences, mother speech is best characterized by lengthened vowel, personal pronoun substitution, and exaggerated intonation. Father speech is best accounted for by the features raised volume and fast tempo.

The effects of sex-differentiated speech on child language development are not yet known. They may represent developmental factors in children's learning of sex-specific speech, but that question requires an empirical demonstration. At the moment, we only note that the characteristics of mother speech in English and in Spanish are those that are associated with nurturance in parental speech registers. By contrast, father speech in both languages appears to be more related to the problems of perception and understanding in interaction. English-speaking fathers make their speech lower and more tense, and Spanish-speaking fathers make their speech louder and faster.

The differences, it should be emphasized, are comparative, but they do indicate that specific cultural patterns exist. The definitive characteristics of mother and father speech were consistent across the parents in each language, and we conclude that there are culturally 
appropriate ways for mothers and fathers to speak to their children, in English and in Spanish.

The similarities that are found across languages and across sex lines are likely due to practical requirements that parents face in trying to interact with children who have limited communicative skills. It has been noted that the following features have high occurrence rates in the speech of the majority of the parents: exaggerated intonation, repetition, high pitch, lower volume, lengthened vowel, and instructional. These features are definitive of parental speech primarily because of the demands placed on parent-infant interaction. Parents must first attract an infant's attention, and since infants can distinguish pitch, tone, and volume differences long before they can make semantic distinctions, parents use exaggerated prosodic features abundantly. A second interactional requirement is that attention, once obtained, be focused, and the high usage of repetition and instructional are consistent with that task.

Lastly, we turn to a consideration of developmental patterns in parental speech. At the beginning of the project we had assumed that speech would change significantly over the age range of the children, a range of approximately 9-22 months. Only a few features showed changes in rate measures consistent with age increases. Repetition had a higher rate in speech to the two youngest children than to the older ones in the English sample. Interpretation showed the opposite pattern; it was 3-10 times higher in speech to the two oldest children. Spanish showed a similar pattern for interpretation and slow tempo. Again, it should be recalled that the composite records, not the weekly sessions, are under consideration. Analyses of each child's development might reveal more clear-cut developmental patterns.

The decision was made to examine the functions of various speech features and to look for changes in combinations of features that might express developmental patterns on functional grounds. Not all features appeared to function in the same way to promote and sustain interaction. Some prosodic and paralinguistic features--those involving dimensions of tone, duration, pitch, phonetic quality, and volume--seemed primarily to convey effect, and they were used by parents to attract children's attention. Other features were more directly interactional in character, relating to the sequences of vocalizations by interacting parents and children. Repetition of an utterance and an adult's imitation of a child's vocalizations are examples. These features appeared to function to direct children's attention to speech as an activity. Still other features were used to relate speech to the environment in meaningful, referential ways.

The three functions were assumed to represent parental strategies in interactions with their children. Three interactional strategies were thus posited: (1) affective-interactional, marked by prosodic 
and paralinguistic features and functioning to attract attention; (2) didactic-interactional, marked by interactional features and functioning to focus attention once it had been obtained; and (3) semanticinteractional, marked by features that attribute meaning to the interaction and functioning to relate the interaction to the environment referentially (see Blount and Kempton 1976). Entailment analyses were carried out on the features exaggerated intonation, instructional, imitation, and repetition in relation to each other and to the other features in the study. The goal was to find either entailment or mutual exclusion patterns that would allow us to see distinct patterns and changes in patterns during the 12-13-week developmental period. The entailment analyses indeed showed that diachronic changes did occur for some children. First, there were changes in the entailment relationships between exaggerated intonation and instructional. First issued principally in the context of exaggerated intonation, instructional speech came to be issued principally in the context of normal intonation. Entailment relationships between instructional and imitation showed a similar pattern of development. They tended to be separated in speech to children in the later weeks of the study, and to cooccur in the early sessions.

These patterned aspects of parental speech relate to a telescoped version of developmental social interaction. Parents are confronted with the task of communicating with individuals who do not know what the fundamentals of interaction are. Young children must learn that speech is to be attended to, that their own vocalizations and those of their caretakers warrant attention, that the attention can be sustained, and that within that framework, speech can be exchanged and ultimately serve as a vehicle of meaning. Parental activities establish the groundwork for language socialization by providing children with the fundamental behavior pattern for discovering their language and its appropriate use.

\section{NOTES}

I am indebted to Karen Smith and especially Elise Padgug for their helpful comments and criticisms. Final responsibility for the paper, however, rests with the author.

1. Grants from the Office of Education (OEG-72-3945) and the National Science Foundation (Institutional Grant GU-1598) supported the project on which this discussion is based. Data were collected on parent-child interaction in English-speaking and in Spanish-speaking families in Austin, Texas, during 1972-1973. Assistance with the collection, coding, and analyses of data was provided by Lynne Gomez, Andrea Meditch, Glenn Scott, Marylou White, Ann Williams, and Dorothy Wills. 


\section{REFERENCES}

Austerlitz, $R, 1956$. Gilyak nursery words. Word 12:260-279. Bever, T. G., J. A. Fodor, and W. Weksel. 1965. Theoretical. notes on the acquisition of syntax: A critique of 'contextual generalization'. Psychological Review 72:467-482.

Blount, B. G. 1971. Socialization and the pre-linguistic system of Luo children. Southwestern Journal of Anthropology 27:41-50. Blount, B. G. 1972. Parental speech and language acquisition: Some Luo and Samoan examples. Anthropological Linguistics 14:119130.

Blount, B. G., and W. Kempton. 1976. Child language socialization: Parental speech and interaction strategies. Sign Language Studies 12:251-277.

Blount, B. G., and E. Padgug. 1976. Mother and father speech: Distribution of parental speech features in English and Spanish. Papers and Reports on Child Language Development 12:47-59.

Blount, B. Go, and E. Padgug. 1977. Prosodic, paralinguistic, and interactional features in parent-child speech: English and Spanish. Journal of Child Language 4:1-20.

Braine, M. D. S. 1963. The ontogeny of English phrase structure: The first phase. Lg. 39:1-14.

Bright, W., ed. 1966. Sociolinguistics. The Hague: Mouton. Broen, P. 1972. The verbal environment of the language-learning child. Monograph of American Speech and Hearing Association, 17.

Brown, R. 1973. A first language: The early stages. Cambridge, Mass.: Harvard University Press.

Brown, R., and U. Bellugi. 1964. Three processes in the acquisition of syntax. Harvard Educational Review 34:133-151.

Brown, R., C. Cazden, and U. Bellugi. 1969. The child's grammar from I to III. In: Minnesota Symposia on Child Language, Vol. 11. Edited by J. P. Hill.

Brukman, J. 1973. Language and socialization: Child culture and the ethnographer's task. In: Learning and culture. Proceedings of the American Ethnological Society. Edited by S. Kimball and J. Burnett. Seattle: University of Washington Press.

Casagrande, J. B. 1948. Comanche baby language. IJAL 14:11-14. Cazden, C. B. 1965. Environmental assistance to the child's acquisition of grammar. Ph. D. dissertation, Harvard University. Cross, Toni. 1975. Some relationships between motherese and linguistic level in accelerated children. Papers and Reports on Child Language Development 10:117-135. 
Drach, K. M. 1968. The language of the parent: A pilot study. Working Paper No. 13, Language-Behavior Research Laboratory, University of California, Berkeley.

Drachman, G. 1973. Baby talk in Greek. Working Papers in Linguistics, No. 15. Ohio State University.

Ferguson, C. A. 1964. Baby talk in six languages. American Anthropologist, Part 2, 66:103-114.

Ferguson, C. A. 1975. Baby talk as a simplified register. Papers and Reports on Child Language Development 9:1-27.

Fodor, J. A. 1966. How to learn to talk: Some simple ways. In: The genesis of language. Edited by F. Smith and G. Miller. Cambridge, Mass.: MIT Press.

Halliday, M. A. K. 1975. Learning how to mean. In: Foundations of language development: A multidisciplinary approach. Edited by E. H. and E. Lenneberg. New York- Academic Press; Paris: The UNESCO Press.

Hymes, D. H. 1962. The ethnography of speaking. In: Anthropology and human behavior. Edited by T. Gladwin and W. Sturtevant. Washington, D. C.: Anthropological Society of Washington.

Hymes, D. H., ed. 1971. Pidginization and creolization of languages. The Hague: Mouton.

Kobashigawa, B. 1968. Repetitions in a mother's speech to her child. Working Paper No. 13, Language-Behavior Research Laboratory, University of California, Berkeley.

Lewis, M., and R. Freedle. 1973. Mother-infant dyad: The cradle of meaning. In: Communication and effect: Language and thought. Edited by P. Pliner, L. Krames, and T. Alloway. New York: Academic Press.

McNeill, D. 1966. Developmental psycholinguistics. In: The genesis of language. Edited by F. Smith and G. Miller. Cambridge, Mass.: MIT Press.

Miller, W., and S. Ervin. 1964. The development of grammar in child language. In: The acquisition of language. Edited by $U$. Bellugi and R. Brown. Monograph, Society for Research in Child Development, 29.

Newport, Elissa. 1976. Motherese: The speech of mothers to young children. In: Cognitive theory. Edited by'N. Castellan, D. Pisoni, and G. Potts. Hillsdale, N. J.: Earlbaum.

Snow, C. 1976. An overview of mothers' speech. In: Talking to children: Input and acquisition. Edited by C. Snow and C. Ferguson. Cambridge: Cambridge University Press.

Voegelin, C. F., and F. M. Voegelin. 1954. 'Mother language' in Hidatsa. International Journal of American Linguistics 20:65-70. 
CULTURAL PREREQUISITES

TO GRAMATICAL ANALYSIS

\section{MICHAEL SILVERSTEIN}

\section{The University of Chicago}

To eliminate the facts of grammatical relationship and structure from the analysis and presentation of phonological structure is frequently undesirable because many of the phonological facts are inextricably interwoven with grammatical facts and structural relationships; avoiding the portrayal of this relationship means omitting, completely or at least temporarily, an important part of the total structure of the language. When phonological and grammatical facts are mutually dependent, the treatment of phonology without reference to grammar is a concealment of part of a most important set of structural facts pertinent to phonology (Pike 1947:155).

These summarizing statements from Kenneth Pike's well-known paper, 'Grammatical prerequisites to phonemic analysis', published some 30 years ago, were directed against the then prevalent notion that phonemic analysis and description could be carried through without any reference to the grammatical organization of speech. I think it is appropriate at this point in the development of linguistics to apply them, mutatis mutandis, to the notion that grammatical analysis and description can be carried out independently of the sociocultural organization of speech, i. e. of the fact that speech is a culturally constituted form of social action.

When Pike spoke of grammatical prerequisites, he meant the facts of how speech signals encode the organization of words and morphemes of the language, or langue, and how a recognition of these grammatical units was a necessary starting point for analyzing perceived phones as same or different, that is, for achieving a phonemic 
statement. He pointed out that at the very least phonemicists must presuppose (or hypothesize) the specification of single morphemes in single free forms or words, in order to carry out a complete phonemic analysis. When I speak here of cultural prerequisites, I mean the facts of how speech signals encode the purposes of speech to achieve particular socially recognized goals in terms of socially constituted role relations--in short, speech organized as an elaborate system of types of discourse events.

I want to point out that grammarians must understand something of this system in order to carry out the specification of any of the types of grammatical analysis and description heretofore proposed. This is necessary because those kinds of grammatical analyses with which we are familiar actually presuppose a very narrow hypothesis about the nature of speech as a discourse system, one that in practice leads to limitations in principle which will have to be overcome if the rapidly expanding aims of linguistics are to be realized.

For, regardless of the recognition of important cultural phenomena embodied in speech--classic examples of which are male and female forms, performativity, deference, taboo forms, naming, joking, and so forth--the explicit principles of grammar construction and grammatical theory in the Western tradition are all variants of the assumption that speech instantiates a grammatical system, or langue, whose elements contribute to speech events of pure reference or denotation. That is, our entire idea of the proper segmentation of speech and the organization of the abstract elements of grammar said to underlie it, rests on what is essentially our folk theory of the representational character of language, language as used to make propositions about exemplars of classes of entities 'out there', which propositions are subject to tests of truth and falsity, determining correct and incorrect reference.

This is the kind of system submerged in the grammarian's postulation of 'the same' underlying structure for distinct surface structures, for example. Surface structures are 'the same' at the underlying level when they achieve 'the same' referential effect in all of their instantiations--salva veritate, as the philosopher would tell us. That is, such surface structures can be taken in all their instantiations as correctly referring usage to pick out 'the same' kinds of entities in certain relations one to another. One may observe that the actual grammatical analysis already makes a distinction, on the one hand, between the abstract 'surface' and 'underlying' structures-(in one dominant idiom of analysis)--on which various grammatical relations are induced by analytic criteria and in terms of which the grammar is stated--and, on the other hand, the infinite class of instances of those grammatical structures, the referential value of which must be constant in every instantiation. Grammatical analysis 
of actual instances of speech, 'tokens' if you will, is achievable only insofar as these are tokens of an abstract 'type' which specifies the constant referential potential of the entire class of tokens.

Now if you object that it is not, in fact, the tokens that are said to be analyzed, because by hypothesis they are mere 'performance' data, you are right. But you realize, of course, that only those aspects of tokens which can be said to be 'the same' independent of instantiation in tokens are subject to analysis as types that make up the so-called 'competence' of a speaker for referential speech. Of course, it is always with tokens, with instances, that we work, though by hypothesis we specify that the particular tokens--uttered, written, taped, whatever the medium--are equivalent to any other token of the postulated grammatical form, the element of the grammar. So such an analysis can succeed only to the extent that there is what one might call tokenindependent referential potential of infinite classes of tokens, each class being a grammatical type. For only with the understanding that, regardless of token, we are dealing with 'the same' grammatical element in analysis and description, can such a strategy succeed. And it is an interesting belief about language that there is a constant, speech-independent referential or descriptive potential which underlies instantiation in actual referential speech, in fact, the very view winnowed into the theories of sense and reference in the Fregean philosophical tradition connecting language and logic, or into theories of generative grammar separating grammaticality from acceptability, and so forth. To the extent that language is really analyzable in this fashion, it is an adequate view.

But it is not. To begin with, we have the class of elements called 'shifters'. Here, the referential value which remains constant must be specified in a curious way, in terms of the actual instantiation of tokens of the type. So, the pronoun I refers to the individual who speaks the token of the pronoun, that is, it refers to the individual who is in the role of 'speaker' in the speech event in which the token is instantiated. One could hardly say that the referential value remained constant, except as one had a notion of the role of speaker, in an event of speech, in which the token of $\underline{I}$ occurred, all of which taken together are themselves tokens of a system of tokens and types of events of referential discourse with certain roles, such as speaker, hearer, audience, etc. defined.

Now I know of no linguist who would shrink from blithely incorporating a specification of the personal pronouns into a grammatical description, and yet, in principle there is a kind of functional basis for the use of these elements which is at variance with the narrowest kind of hypothesis about language embodied in the sense-reference theory I have outlined (or perhaps caricatured). Implicit in the very analysis and description of the types said to underlie the tokens of 
personal pronouns is a recognition of tokens as 'the same' when certain role relations can be called 'the same' (here, in particular, the role of speaker). But these entities, exemplars of speech-event roles, are not 'out there' in any sense; they are created by speech itself.

One might therefore reformulate the rule for referential constancy of the pronoun I thus: $\underline{I}$ as a grammatical type underlying each of its instantiations is the potential for reference to an individual that presupposes the constitution of the individual in the role of speaker in a speech event, which role is created by the instance of speaking including the instantiation of $\underline{I}$. So we are already in the realm of a theory of the types of roles in types of events socially recognized in a society; in other words, in the realm of social anthropology.

Recall that we are still operating under the assumption that speech is referential, serving to pick out entities in certain relationships and communicate this as fact. But even to characterize the seemingly simple pronoum shifters, we have had to redefine the notion of how instantiations or tokens could be considered as of 'the same' type; in particular, we have had to incorporate a theory of certain role relations of social action conventionally understood in behavior. That elements such as pronouns seem to be universals does not argue against the point; it simply means that here is an interesting cultural universal. But this line of reasoning can be pushed further.

I said that the referential value of the pronoun I, or any other such shifter, presupposed the constitution of a social role in an instantiation of certain recognized social action (the instance of speaking). In essence, this 'presupposition' for the referential success of $I$ can be specified as a condition about the context in which the pronoun token occurs, namely, that the token occur in speech (or its equivalent). That is, the description 'There is a speaker (or equivalent) speaking (or equivalent) with language $L^{\prime}--$ a proposition about social roles-must be true, or satisfied, for the possibility of the pronoun's referring. In this sense, one can see what is really to be understood by the notion of presupposition in language: something must be established in the context of the presupposing signal, in order for its functional value to be possible. Presupposition is thus a relationship statable between signal token and context: some proposition must be establishable as true on grounds independent of the signal token itself in order for the signal token to have some specifiable functional effect. For the pronouns and other shifters, the presupposition must be satisfied for the referential value of the shifter to accrue to it.

At the opposite end of the scale are what are called 'performative' (or highly 'creative') tokens of language. Of course, the most famous examples are what have been termed by Austin the 'performative' constructions of English, such as I promise to stop talking soon, I dub thee Sir Winston Churchill, etc. Here some proposition about the 
context must be establishable as true precisely (and in the maximal case, uniquely) because of the occurrence of the signal token. To quote this philosopher (Austin 1975:145-146), who tries to draw a distinction between 'constative' constructions and 'performative' constructions:

(a) With the constative utterance, we abstract from the illocutionary (let alone perlocutionary) aspects of the speech act, and we concentrate on the locutionary; moreover, we use an over-simplified notion of correspondence with the facts-over-simplified because essentially it brings in the illocutionary aspect. This is the ideal of what would be right to say in all circumstances, for any purpose, to any audience, etc. Perhaps it is sometimes realized.

(b) With the performative utterance, we attend as much as possible to the illocutionary force of the utterance, and abstract from the dimension of correspondence with facts.

Austin's characterization, being that of a philosophical but anthropologically naive native speaker, is based on a distinction among locutionary, illocutionary, and perlocutionary effects (in what I call here 'speech events'), which can be characterized as follows. Locutionary effects are the philosopher's traditional sense-andreference of a propositionally based notion of the meaning of speech. As has been seen, and as Austin realizes, such things as shifters already are sufficient properties of referential uses of speech to show that 'the ideal of what would be right to say in all circumstances, for any purpose, to any audience, 'etc.', cannot be defined as the exclusive meaningfulness even of referential elements of language. Once there are context-signal interactions such as the presuppositions of shifters, one is in the realm of conventionalized (socially defined) necessary conditions for these aspects of speech to be referential at all--what Austin calls 'felicity' or 'happiness' conditions. Hence, by his own definition, one is in the realm of illocutionary effects.

These are the effects of speech events which, by convention, are constituted to accomplish certain culturally specified ends or goals of speech as social action. Obviously, one must, with Austin, see that describing or stating is itself one such goal of speech, the phenomenon at the level of speech-as-social-action that corresponds to the grammatical structure in terms of sense-and-reference of the philosopher. And to the extent that certain units of speech are meaningful--referential--only in terms of that level of social action, their referential quality is decidedly illocutionary in kind, and not locutionary. But they still function in events of describing, or making 
propositions about, which by convention are understood to correspond with and to represent facts.

Performative utterances, on the other hand, create those 'facts' in the very context in which they are uttered, by convention. To the native speaker, Austin proposes, their correspondence with the facts is never at issue; 'we attend as much as possible to the illocutionary force of the utterance', to the nonreferential illocutionary goal which is conventionally created by the occurrence of a particular propositionlike signal in a context presupposed to be of a particular description. It should be observed that while performative constructions have the form of referential speech--subjects and predicates, and so forth, in complete clausal form--they are felt by native speakers such as Austin to accomplish other conventional ends, e.g. swearing, promising, dubbing, marrying, etc.

Why? Because the apparently referential signals, which have the form of a description of a certain sort, include a predicate, e.g. promise that, dub, christen, declare that, etc., that names--refers to--the speech event ongoing in uttering the signals. That is, the predicate refers to the instance of speech in which it occurs as an event of a certain type, conventionally understood to have certain role relations and certain ends as social action. The speech signals therefore become the critical behavior indicating that a certain event leading to a particular conventional goal, i.e. an event of social action which is itself constituted as a speech event, is at hand. In naming the event, as the event-signal, the signal 'creates' the goal, that is, it 'performs' some transformation of socially recognized status or role, right or responsibility, instantiated in the context of occurrence. Whether it succeeds or fails, or has some effect not culturally constituted as the one accruing to this performative construction, is not at issue--this is the level of 'perlocutionary' effect for the native, the actual result recognized in such an instance, and not by convention associated with the speech signal itself as the critical one. The important thing is the conventional recognition that the proposition names the instance as of a particular type of speech event with a conventional goal. So obviously, there is a sense-and-reference to the signal, though the native speaker does not attend to it, and obviously this sense-and-reference depends upon certain presuppositions of the context being satisfied, the signal properly occurring, etc.

The meaningfulness of such a signal is in essence akin to the meaningfulness of any shifter, the difference here being that the signal is the referring form for the entire event that is being instantiated, so that in the occurrence of the signal, the event occurs, once other presuppositions are satisfied. That the signal is crucial, i,e. the unique sign ultimately, because of the conventional constitution of this event as a speech event, is translated into Austinian parlance as 
its 'performative' value, what we might call the highly 'creative' value of such a construction in speech in relation to what it refers to, namely, the event and its implied goal of transformation of social categories. 'Mlocutionary' force of speech is just one example of the cultural constitution of any social behavior as effective social action, action that 'takes effect' in changing the recognized relations of cultural entities. Of course, all deference behavior in speech, all sociologically sensitive phonological differentiation, etc. do the same; they are just never conceived of by the English-speaking native as goals of separate event types, with names.

Such an understanding of so-called 'performative' constructions in language puts their performativity in terms of the uniqueness of the particular signal as a context-linked reference to the event occurring, and does not oppose the notion of performativity or even of illocutionary force to that of constativity or locutionary force. (See also Stampe 1975; Leech 1976.) Further, as becomes quite clear in Austin's discussion of what he terms 'explicit' performatives, the whole distinction of illocutionary as opposed to perlocutionary forces rests on the question of whether or not there is a way in which the signal which names an event as of a certain type can do so independently of its context-linkage in a performative utterance, i.e. whether or not the language of a society names certain events as speech events in that goals are accomplished by means of speech. I return to this further on.

It should be clear now, however, that we are analyzing reference as one meaning system of speech, defined in terms of a truthvaluational goal of specifically speech-signalled events. Referential speech is one from among many goals of speech that are conventionally constituted in a society, others, for example, being indicated in English by the performative constructions that severally name distinct kinds of uses of speech. The kind of context-independent referential potential that is the prerequisite to grammatical analysis under the assumptions of traditional theories is thus a very small part of the analysis of a grammatical system. Context-dependent referentiality, as illustrated in shifters or in performatives, broadens our theory of the underpinnings of speech so that certain aspects of the context, presupposed by these elements, must be describable in some culturally derived schema for determining the factors of the speech situation in speech events, including, let us note, types of events themselves, the names of which are related to 'illocutionary' forces.

Both 'creative' and 'presupposing' tokens of context-dependent referential items in language are what we now call, following Peirce (and Jakobson), 'indexical-referential' devices of language. They are indexical in Peirce's sense, because the dependency relationship 
is one of mutually implied cooccurrence, or 'existence' between signal and context: some aspect of the context is either presupposed to exist when the particular element of speech occurs, or is created, brought into existence, when the particular element occurs.

Once we cross-classify elements of speech in terms of function (with respect to speech events) as referential vs. imperative vs. interrogative vs. deferential vs. . . . , and in terms of these creative functions of speech, once we see that there are component indexical relations of relatively presupposing vs. creative nature, we have embarked on the study of pragmatics. As I stated at the outset, the numerous examples of male and female speech, joking, deference, taboo, etc., have been recognized in the literature as systematic formal distinctions made in certain languages. We can now see that these nonreferential functions, with their indexical relations, are beyond the scope of traditional grammar. The basic kind of grammatical theory makes assumptions about the social functions of speech which are incompatible with the proper and systematic analysis and description of these elements in some principled grammatical framework. Such a grammar would treat not only the traditional referential nonindexical elements, and the indexical-referential ones, but also nonreferential indexical elements--in sum, a total pragmatic grammar. And it must be emphasized that such a culturally based grammatical theory is implicit in any grammatical description that purports to treat elements of language such as these. The cultural prerequisites have simply not been made explicit, and grounded in social anthropological theory.

I think this can be made clearer if we reformulate the properties of grammatical systems in terms of the kinds of data that are necessary and sufficient to instantiate the different kinds of meaning systems I have been talking about. Since, as I said earlier, we always actually deal with utterances, that is, the data of performance, though we impute to certain of these data properties that directly give evidence about grammar or competence, we can see that there must exist certain kinds of utterances about speech as a meaningful system which the linguist can use in formulating a grammatical description of sufficient power to handle the different kinds of meaningfulness we have been discussing. In particular, there must be certain utterances of a metalinguistic sort which are taken to be 'metasemantic' speech, that is, speech which refers to semantic structure of referential type in the narrow sense I have been using here (context-independent referentiality), and others which are taken to be 'metapragmatic' speech, that is, speech which refers to pragmatic structure of indexical types. Speech of the first kind, metasemantic, states an infinite set of relations of referential value of forms independent of the context in which any tokens of them are used. 
Speech of the second kind, metapragmatic, states a relationship of indexicality between speech token and its context.

Metasemantic utterances include, most importantly, definitional equation, in which the semantico-referential meanings (contextindependent referential potential) of two stretches of language, $A$ and $B$, are said to be the same. This means that independent of the context in which $A$ or $B$ is used, there is identity of the 'sense' or abstract referential potential; hence, ophthalmologist and eye doctor, dentist and person who fixes teeth, kill and cause to die, and so forth. Such a system of metasemantic equations can be shown to be equivalent to the grammatical system of a language, under the assumptions with which linguists usually operate, that is, to the extent that language is context-independent and referential. In fact, a grammar of the post-Saussurean type (including especially the transformationalgenerative) exists for a language if and only if there is a set of such metasemantic equations. That is, grammar in the narrowest sense, as explaining the context-independent referentiality of underlying types, is the equivalent of a set of metasemantic utterances (analytic sentences), true, as they say, by definition. Notice that this account rejects the fiction of a 'meaning independent' or 'autonomous' syntax and morphology for a language. This much has been clarified for linguists since the discussions of Weinreich, Bendix, G. Lakoff, Postal, McCawley, Dixon, and others.

Metapragmatic utterances include all utterances which characterize the use of speech in various events, defining the events as consisting of a signal token which constitutes the event, in relation to presupposed contextual conditions, such as certain role relations, instantiations of statuses, types of objects, and so forth. It should be clear from the analysis offered here of performative utterances, that the verbs used in such explicit forms are actually a set of such metapragmatic names, the name being an abbreviation or shorthand way of referring to speech conventionally accomplishing certain social ends in events of that name, e.g. promising, affirming, declaring, questioning (or asking), christening, and so forth. Our philosophical tradition has established a technical terminology in terms of referring, predicating, and so forth, also a metapragmatic vocabulary, ultimately characterizing certain types of speech events. All such events are constituted by the occurrence of an instance or token of an appropriate type of signal, in a context which includes tokens of certain presupposed socially based types (Gedanken ones, in the case of philosophy). My definition of the meaningfulness of the indexical type $I_{2}$ the first person pronoun, was also a metapragmatic utterance, specifically showing a detail of a certain kind of referring, namely, to speaker. 
Now it is not obvious on first glance which from among the infinite set of utterances of a natural language are the metasemantic and which the metapragmatic ones. In fact, as Weinreich has observed, there is no natural language known in which the set of definitional (or metasemantic) utterances has a special form; they are continuous with utterances that merely state context-dependent referential equivalence, 'occasion utterances', that is, statements of pragmatic or extensional equivalence, 'folk definitions' of the form $A$ is $B$ which $S$, and so forth. Similarly, there is formal continuity of metapragmatic utterances with certain kinds of metasemantic ones, e.g. 'To promise is to commit oneself to the truth of some proposition', 'To christen is to give a name to someone or something', etc.

That is precisely why, as linguists, we work from the opposite direction. We construct semantico-referential grammatical systems, under control of universal hypotheses about phonological and grammatical categorizations, which, as I said, result in the equivalent of a set of metasemantic sentences (not just utterances). And we must construct pragmatic systems to explain the indexical aspects of speech, under control of universal hypotheses about the social anthropology of speech, that is, hypotheses about how each society uses speech conventionally to signal types of events with certain role relations, etc., from the recognized set of such. As we have seen, to the extent that much of the referentiality of speech comes not from an abstract semantico-referential system, but from the part of the pragmatic system that is indexical-referential (here, the pronouns, deictics, tenses, moods, epistemic modals, performatives, etc.), to that extent the description of even the full referentiality of speech requires a social anthropology as its prerequisite.

But the full description of the pragmatics of language, in functions other than reference, requires a subtle investigation of how speech is constituted as a social system. Pragmatics is not a wastebasket; it seems that way to linguists who assume either that they can ignore the anthropological dimension (trying, for example, to extend various standard theories of semantico-referential grammar to include these facts haphazardly), or that they can investigate the anthropological dimension by introspection.

Thus, to try to say that all 'illocutionary' force of speech comes from extension of basically referential speech 'used' in certain ways will not do. Again, to try to extend the notion of semanticoreferential deep structure to include a so-called 'performative' underlying highest clause is incoherent except as an analogy, a notational device, and one which leads to transformational inconsistency. Finally, to depend on one's own intuitions about the use of speech runs up against the inherent limitations on the awareness of pragmatic facts to which, in varying degrees, all native speakers 
of a language are subject. Reference, as Sapir noted, is the 'official' use of speech in our own (and probably many other) societies; its privileged position comes from a metapragmatic awareness of the speakers constituted by overt, learned, metapragmatic norms: we use speech in order to represent things 'out there'.

To assimilate distinct functional characteristics of speech to this function of reference results in a folk-notion of a grand system of metaphorical transfer of basically referential linguistic categories that is patent only to the native speaker, and to the linguist who imposes this view of the world of social action on speech. Thus Malinowski (1935: Vol. 2), for all his insistence on use of utterances in context of situation, eventually explained away so-called 'magical language' by a 'coefficient of weirdness' from a strictly ostensive definition of referentiality, thereby missing the entire point of the native speakers of Kiriwinian, the Trobrianders.

To assimilate illocutionary forces of speech to a representational schema of underlying 'performative clauses' that are definable only for constant semantico-referential characteristics, under the assumptions of the transformationalists, is to destroy the distinction between conventional representation (reference) and conventional effectiveness of other sorts (creative indexicality). Thus, Austin, for all his insistence that we should not confuse the two (1975:10-11), ultimately builds the notion of illocutionary force from explicit performative constructions which, he claims, are conventionally understood to 'express feelings when they are felt fitting, regardless of whether or not we really feel anything at all we are reporting' (1975:79), leading to the notion that some report (read: referential description) of speaker 'intent' suffices to characterize the force of utterances. This is formally represented in the notation of performative highest clauses in underlying structures.

To assimilate the effectiveness of utterances in context, finally, to the practice of self-report out of context, that is, to introspect what is accomplished by speech signals in context by thinking about them as having context-independent illocutionary potential, is to risk solution by fiat of one of the classic distinctions of social theory, that of the native model or ideology of action vs. the ethnographer's model, not in fact subject to awareness by natives in all of its complexity. In particular, this leads to the creation of 'illocutionary' vs. 'perlocutionary' effects simply on the basis of the native speaker's ability to name with a word the occurrence of some conventional signal as the 'event' in native linguistic ideology, vs. his ability to name with a word the occurrence of some conventional effect as an 'event' subsequently. All culture is conventional, but some conventions are named for one aspect or the other by the natives, and this kind of native 
description in terms of a metapragmatic vocabulary for speech should not be confused with a principled social anthropology of language.

Indeed, I have been circling about a central issue in the limitations of awareness of native speakers about their own pragmatic systems. In general, native speakers of languages can be seen in our very field data to be aware of the pragmatics of their own speech to the extent that the signals involved are segmental, as opposed to nonsegmental, referential (as well as indexical in some other mode concurrently, as for example, In, as opposed to nonreferential, and presupposing, as opposed to creative (or 'performative'), among other characteristics (I have identified two additional ones so far). These kinds of segmental, referential, presupposing indexical (or pragmatic) elements have reality for the native speaker above all else. These forms are also always among the ones for which, in a society, there is metapragmatic terminology in terms of which natives can give metapragmatic characterizations.

Now we can see why metapragmatic shifters such as the explicit performatives have a reality for a native speaker such as Austin, for they are at once segmental (being linearized construction types), referential (referring to the event of speaking a token of them), and presupposing of certain social circumstances, of which Austin speaks readily. Now we can also see why, as Benjamin Lee Whorf (1956) pointed out long ago within the restricted pragmatics of reference itself, the 'lexations' or words of a language have the most reality' for the native speaker, and the native speaker operates with a metapragmatic awareness of ostensive reference: what is a word or segmental grammatical category at the surface of speech is constituted as having real ostensive referential capacity, referring to something independent 'out there', and our conscious understanding of how language is a representation of that 'reality' is basically at the level of words or, more precisely, of surface-segmental stems and affixes.

Whorf was thus the first to point out the nature of a seeming paradox. In the tradition of Boasian linguistics, Whorf pointed out that true referential classifications in grammar were 'unconscious' in the main. But there is a felt reality to which native speakers always seem to have reference in task-oriented behavior, and in terms of which they make explicit the referentiality of speech. This latter reality is a reflection of surface lexical forms, regardless of the complex grammatical system that is required to characterize the referential nature of language. This grammatical system is submerged in a segmentalist; ostensivist, referentialist ideology.

So also, we want to claim, there are several kinds of meaning relations that speech signals have, woven together in overlapping ways in the surface forms of speech. What is presupposed each time a speaker utters forms are a semantico-referential system equivalent in delicacy to the grammar of the usual post-Saussurean type, which 
itself is embedded in a pragmatic system constituting the functions of speech forms as social action. We do not know a priori how these systems are implemented in any given category of language at the surface, and it is an essentially anthropological question as to how the various social functions are coded in the surface forms of speech. Direct native testimony in utterances which purport to be metasemantic equations of glossing or metapragmatic characterizations of usage in events of various types, has its limitations. This is precisely why semantico-referential grammatical analysis and pragmatic grammatical analysis are required, embedded as they must be in a crosscultural study of speech function, in all its complexity. There seems to be no way to do a grammatical analysis, let alone to justify it, without making its cultural prerequisites explicit. Since language is central to social life above all else, there can, of course, be no other conclusion.

\section{REFERENCES}

Austin, J. L. 1975. How to do things with words. Second edition. Cambridge, Mass.: Harvard University Press.

Leech, Geoffrey. 1976. Metalanguage, pragmatics, and performatives. In: Georgetown University Round Table on Languages and Linguistics 1976. Edited by Clea Rameh. Washington, D. C.: Georgetown University Press. 81-98.

Malinowski, B. 1935. Coral gardens and their magic. London: George Allen and Unwin, Ltd.

Pike, Kenneth L. 1947. Grammatical prerequisites to phonemic analysis. Word 3:3.155-72.

Stampe, D. 1975. Meaning and truth in the theory of speech acts. In: Syntax and semantics, 3. Speech acts. Edited by P. Cole and J. L. Morgan. New York: Academic Press. 1-39. Whorf, Benjamin Lee. 1956. Language, thought and reality: Selected writings of Benjamin Lee Whorf. Edited by John B. Carroll. New York: Wiley. 

CULTURAL PRESUPPOSITIONS

AND DISCOURSE ANALYSIS:

PATTERNS OF PRESUPPOSITION AND ASSERTION

OF INFORMATION IN EASTERN POMO

AND RUSSIAN NARRATIVE

\section{SALLY MCLENDON}

Hunter College and The Graduate Center, City University of New York

1. Introduction. Linguists and cultural anthropologists have known for a long time that discourse reflects a great deal of the society in which it is produced. Cultural anthropologists have stressed the value of the traditional sorts of discourse studied by folklorists-myths, tales, songs, etc.--for an understanding of a culture. Boas $(1916,1935)$ even attempted to describe two Northwest Coast societies, the Tsimshian and the Kwakiutl, on the basis of the cultural behavior embodied in their myths and folktales, entitling these studies quite descriptively: Descriptions of the Tsimshian based on their mythology, and Kwakiutl culture reflected in their mythology. More recently, Levi-Strauss $(1967,1971,1972)$ has shown how knowledge of a culture can provide insight into the literary and symbolic meaning of a myth.

Linguists, however, have generally felt that there was little or no possibility of dealing systematically with the cultural information a native speaker brings to the production and interpretation of a discourse. Many linguists have tended, in fact, to consider the sentence the natural frame for linguistic inquiry, leading to a tendency to focus on discourse-independent types of sentences of the sort easily produced by linguists. It seems clear, however, that real sentences in real languages naturally occur almost uniquely in discourse contexts, and considering sentences extracted from their natural contexts necessarily risks excluding information pertinent to understanding their true meaning and function. 


\section{4 / SALLY MCLENDON}

Recent developing interest in questions of language use, in linguistic processes which have largely discourse function, such as topicalization and the operation of anaphora, as well as interest in the structure and nature of discourse itself (such as Grimes 1975, Longacre 1968, 1972)--in part, at least, inspired by practical pressures to provide literacy materials and translations--have suggested the importance of discourse for linguists. And, in fact, some linguists would now argue that discourse, not the sentence, is the natural frame for linguistic inquiry, and that a discourse-based syntax rather than a sentence-based syntax is needed (Givon 1974, 1976).

At the same time, folklore collections from speakers of non-IndoEuropean languages provide numerous examples of narratives which seem hardly narratives at all from the point of view of speakers of Indo-European languages, which yet seem to give members of the societies in which they are told the great pleasure and satisfaction which we associate with a narrative. The narratives of the North American Indians, and more particularly, the Indians of California, have frequently struck non-Indian observers as typifying this problem. Oliver La Farge (1959:7-8), for example, a generally sympathetic observer and chronicler of the American Indian, says in his introduction to Theodora Kroeber's The Inland Whale, a retelling of some California and Northwest Coast narratives:

The literary value of a great deal of primitive literature, whether myths or tales, is nil. That of much of the rest is apparent, in the raw form, only to connoisseurs, . . . In my limited experience, I know of no body of such literature of which these depressing generalizations are more true than they are of the enormous mass of stories of all kinds told--out of sheer boredom, I sometimes expect-by the tribes and tribelets of California.

Claude Levi-Strauss (Hess 1972:2) has said of his four-volume study of mythology:

I started out from that irritation we all felt when we read myths, that these are stories without a tail or a head. It was, after all, the principal way of literary expression for many peoples from prehistoric to modern times; I could not conceive that the men who told these myths were spending their time recounting absurdities.

As these two quotations suggest, there seem to be two possible explanations for this phenomenon. 
(1) Such speakers of non-Western languages have different sensibilities from the rest of us and are therefore content to settle for less in the way of a narrative.

(2) In these societies there are different conventions from ours which condition expectations about the types of information which are: (a) assumed and not specified; (b) considered irrelevant to the narrative told; (c) obligatorily included in a well-formed narrative of a given indigenous genre; (d) optionally included for stylistic effect. That is, the rules which must be assumed to govern narration in a given society will differ with respect to how information is to be coded in each performance. These rules include expectations as to which reality conditions will be directly reflected in the discourse, which will be dealt with symbolically, and which will be ignored or presumed.

Consider, for example, the following children's song recorded by the Berndts (1953:424) from Oldea in the far west of South Australia and reprinted here in its parsimonious entirety.

$\begin{array}{llll}\begin{array}{l}\text { walga } \\ \text { 'marks }\end{array} & \begin{array}{l}\text { reri reri } \\ \text { shivering } \\ \text { with cold }\end{array} & \begin{array}{l}\text { ngenda } \\ \text { a big } \\ \text { snake }\end{array} & \begin{array}{l}\text { dagu } \\ \text { tell you }\end{array} \\ \text { walga } & \text { djuna } & \text { jara } \\ \text { 'marks } & \begin{array}{l}\text { put it } \\ \text { down }\end{array} & \begin{array}{l}\text { a white-blossomed } \\ \text { tree }\end{array}\end{array}$

walga linda

'marks to throw sand with one's hand'

It seems unlikely that any speaker of an Indo-European language could come up with the explanation of the meaning of this narrative which the Berndts offer. 'A man is shivering with cold; he sees the tracks (marks) of a big snake. He tells another man; together they follow the edible snake and kill it near a white-blossomed tree. The last word of the song refers to the digging of a depression in the sand to make a fire for cooking a snake.'

Part of the difficulty an English speaker faces in interpreting this text may result from an inadequate translation of the actual referents of the language, i. e. 'marks' for 'tracks', etc. In the Australian aborigine language in question, reri reri may, in fact, be explicitly marked for number and person of the subject, and the translation may merely fail to supply this information. This would be particularly unfortunate, since our English expectations lead us to try to interpret 'marks' as the subject of 'shivering with cold', making for a very 
surrealistic effect if one succeeds in associating these words with some sort of interpretation.

It also seems likely that songs constitute a special genre which need not be as explicit as other types of narratives.

Nevertheless, part of the difficulty is clearly the result of differences in the cultural matrices which infuse our expectations. Snakes are not considered edible in our society, so no English speaker would ever think to associate a snake with a hunter's search for food, that is, to interpret a snake as a possibly appropriate and desirable goal of a hunting expedition. In our society cooking is rarely carried out with open fires and even then does not presuppose special techniques of preparing the site for a fire.

The effects of being able to come up with such an association (or presupposition) in easing the interpretation can be readily seen if one substitutes the lexical item 'deer' for 'snake', while translating walga as 'tracks' rather than 'marks', as the Berndts suggest is possible:

tracks / shivering with cold / a big deer / tell you tracks / put (i. e. bring ?) it down / a white-blossomed tree tracks / to throw sand with one's hand

The text is still highly elliptical, but no longer as unavailable to interpretation. Moreover, it suggests that different societies might well have different narrative conventions which reflect the culture of those who tell and listen to the narrative and condition the type of information which will be specified in a narrative (the snake, the white-blossomed tree), as well as the types of information which will be assumed and not specified: that the man is shivering with cold while hunting, that the snake is edible, that to put it down is to kill it, that to throw sand with one's hand is a normal stage in preparing to cook food.

This notion that there is information assumed by a narrative, but not specified, or at least not necessarily explicitly specified, which is important to the correct interpretation of a narrative, seems similar to the phenomenon of presupposition recently considered by a number of linguists (Lakoff 1971, Langendoen 1971), but originally identified by the German philosopher, Frege. Thus, the sentence

Pedro regretted being Norwegian.

presupposes that Pedro is a Norwegian and asserts that he regrets this fact. Similarly,

The king of France is bald. 
presupposes that there is a king of France and asserts that he is bald. But the information presupposed in a sentence need not be as directly represented in the actually occurring form of the sentence as these examples suggest. Fillmore (1970) has pointed out that

\section{Leslie is a bachelor.}

presupposes that Leslie is adult and male (although the name Leslie can also be used of females and children), while asserting that he is unmarried. This type of presupposition is very similar to what I would like to call narrative presupposition, in that this is bound to our English-speaking culture, within which Leslie can be both a male and a female name but within which bachelor is a significant social category characteristic of adult males.

I would like to suggest that the notion that information is presupposed as well as asserted by linguistic behavior can be usefully extended to the study of discourse, permitting a systematic consideration of the cultural information a speaker brings to the production and interpretation of discourse, as well as providing a nonsubjective device for interpreting narratives from non-Indo-European societies which seem opaque. By discourse I mean, of course, any naturally occurring sequence of sentences which speakers of a language intuitively conceive of as a unity of some sort, including such well recognized types of discourse as narratives, conversations, prayers, and orations. I shall concentrate on one variety of discourse, narration, and more particularly one type of narration, myths and fairytales, in the discussion that follows, since my current research has been devoted to this type of discourse. I anticipate that other varieties of discourse can be approached in the same way.

In a recent article on the foundations of narrative theory from a linguistic point of view, S. -Y. Kuroda (1975) affirmed the now familiar dictum that a theory of language must include both (1) a theory of performance and (2) a theory of competence. Kuroda then went on to suggest that, since a narrative seems to be a product of linguistic performance, a theory of narration must be a part of a theory of linguistic performance. (I understand he is now inclined, however, to the view I am going to present.)

Any narrative performance, in fact, must be presumed to reflect some underlying narrative competence in addition to linguistic competence for at least three reasons.

(a) All speakers of a language know what a narrative should be like in their language. For example, all English speakers know that a sequence of sentences such as the following does not constitute a narrative, or even a fragment of a narrative. 
She knew it was wonderful.

Only he could make them their own, immortal.

I want to show you a certain wild rose bush.

These sentences lack some internal logical and linguistic cohesion which we expect intuitively that our narratives will demonstrate. However, the following sequence of very similar sentences does conform to our expectations for a narrative and, in fact, derives from a real English narrative, Sons and Lovers, by D. H. Lawrence.

She wanted to show him a certain wild rose bush.

She knew it was wonderful. (But)

Only he could make it her own, immortal.

(b) Many traditional types of narrative exist in different speech communities throughout the world in which no two narrative performances are identical and yet members of that speech community are able to identify certain of these nonidentical performances as instances of the 'same' narrative--that is, as underlyingly the same though different on the surface.

(c) Most mature speakers of a language can reduce a narrative to a synopsis.

Thus, one must assume that a theory of narration, analogous to a theory of language, includes both a theory of performance and a theory of competence.

Narrative performance takes place through linguistic performance but requires narrative competence as well as linguistic competence. (Cf. Colby 1973:659 for another aspect of the difference between linguistic and narrative competence.) Narrative competence is expressed in narrative performance, which, like purely linguistic performance, is subject to performance error.

Narratives are, of course, not the only form which linguistic performance takes. Narratives are rather one of a variety of possible modes in which linguistic competence is expressed in performance. These include conversations, oratory (speeches, academic lectures, sermons), jokes, riddles, verbal dueling (such as the 'sounding' or exchange of ritual insults at which young Black Americans are frequently so proficient), prayers, as well as the verbal behavior characteristically associated with states of heightened awareness, such as trances, or of psychosis, such as schizophrenia. Each of these modes of performance seems intuitively to involve an underlying competence for that mode of verbal behavior distinct from any single performance or from purely linguistic competence (as that is now understood). 
Narrative competence would seem to involve at least three types of knowledge. First of all, it involves knowledge of the formal structure of that particular performance mode or genre, such as Propp (1968) identified for Russian fairy tales or, more recently, Colby (1973) for Eskimo folktales--a type of knowledge which has long concerned folklorists. Second, narrative competence must presumably involve knowledge of how redundancy is appropriately to be handled along two lines: (1) reduction of redundancy through the use of linguistic processes such as anaphora and deixis; (2) manipulation and elaboration of redundancy for aesthetic ends, as through rhetorical techniques such as parallelism. Linguists are currently quite interested in the first, but have tended to leave the second in the hands of literary specialists.

Third, narrative competence involves knowledge as to how information is to be coded in each performance. This knowledge includes expectations as to which aspects of reality, or which reality conditions, will be directly reflected in the discourse, which aspects will be dealt with symbolically, and which aspects of reality will be ignored or presumed.

It is this third type of knowledge, involving both the presupposition and assertion of information, which I want to consider in some detail through a discussion of the patterns of information presupposed and asserted in two types of narratives from two quite different societies: the ma. rir. or myths of the Eastern Pomo, a small Native American group of former hunters and gatherers in northern California, and the 178 performances of Russian fairytales from the collection of Afanás'ev (1866) analyzed by Propp (1968). (Three performances of an Eastern Pomo myth and one performance of a Russian fairytale are given in the Appendix to illustrate these two types of narratives. 1)

The patterns of information presupposed and asserted were determined by examining all collected Eastern Pomo myth performances, 2 and the Russian fairytale performances which were the basis of Propp's study for both (1) recurrent constants and (2) consistent omissions. Hypotheses were then developed which would account for this particular selection of recurrent constants and consistent omissions. Support for the hypotheses regarding Eastern Pomo myths was sought in informant behavior and attitudes. This stage of the study has not yet been carried out with the Russian fairytales, which are, in fact, still being analyzed, and the results presented are therefore quite preliminary. Russian fairytales, unlike Eastern Pomo myths, have been extensively investigated. The study reported in no way attempts to duplicate, much less improve on, the extant literature. Rather, it was designed merely to test the procedure proposed on a non-American Indian narrative tradition that might be presumably more familiar to members of Western societies. The focus on Propp's original corpus 
is designed to illustrate how this approach differs from Propp's study and, I believe, complements it. Additionally, it turned out that considering two quite different narrative traditions brought to light patterns of presupposition and assertion that might otherwise have been missed.

The results, I think, have been quite interesting, and at first surprising, although like many truths, they have a rather prosaic quality of self-evidence once identified.

2. System and drama. A natural occurrence of an Eastern Pomo myth or Russian fairytale presupposes other occurrences of that narrative as well as of other narratives both in terms of purely linguistic performance and narrative performance. Just as there could be no language with only a single phoneme, each phoneme existing by virtue of its opposition with all the others, each performance plays against all other known performances of that narrative and of other narratives of the same genre.

Once one is familiar with one or more performances of an Eastern Pomo myth or Russian fairytale, details which would be confusing if one were hearing the myth for the first time become completely clear. For example, in the third performance of 'Coyote and the Ground Squirrel'3 (see Appendix A), the narrator describes Coyote as looking for 'that abalone shell' and yet this is the first time abalone shell has been mentioned in this narrative. If one is familiar with other performances, however, the lack of referent for the 'that' will not be noticed.

In the Russian fairytale (see Appendix B, Afanas'ev's tale \#98), in the second paragraph the mouse says to the good stepdaughter, '. . put out the light and crawl under the stove; I shall run about and ring the little bell', although no little bell has been mentioned before this point. In the next to the last paragraph the bear says to the bad stepsister, after inviting her to play blindman's bluff as he had the first girl, 'Here's a little bell. Run, I will try to catch you.' Presumably, in other versions he says the same thing to both girls, which is why the mouse offers to run about and ring a definite bell.

Moreover, as Jacobs (1959) and Toelken (1969) have pointed out for Clackamas Chinook and Navaho oral literature, performances of Eastern Pomo myths have much more in common with Western theatre than with Western narrative or poetry. As a result, Eastern Pomo performances that Eastern Pomos find satisfying abound in direct quotations of the protagonist's verbal exchanges. (Tedlock (1972b) has pointed out a similar emphasis on direct quotation in at least one type of Zuni narrative--the telapnaawe.) Actual performances of Eastern Pomo myths, as opposed to synopses, are characterized by extensive use of direct quotations. Compare the extensive use of 
direct quotations in Versions 2 and 3 of the Eastern Pomo myth in the Appendix to Version 1, which uses direct quotations only at the end and is therefore largely a synopsis. These direct quotes are for rather were, since the ma. ra. are rarely performed now) delivered dramatically--with changes in voice, gestures, mime, etc., the communicative richness of which largely eludes current techniques of reducing such oral literature to writing. (But cf. Tedlock 1971, $1972 \mathrm{a}$, and 1972b for an interesting attempt in this direction.) When reduced to writing, these direct quotations frequently lose much of their point--contributing to the boring effect La Farge noted.

Examination of the Eastern Pomo myths also reveals the at first surprisingly overwhelming importance of the ecology of the Eastern Pomo.

3. Location, direction, and truth. References to physical location are frequent and precise. In the opening sentence of a myth, the protagonists are commonly described as living at named locations (which, in fact, really existed in precontact times; most of them can still be identified by the oldest generation of speakers in the 1970s). Moreover, all performances of the same myth will either agree in specifying that a given episode takes place at the same named location (thus providing a convenient criterion for identifying differing performances as reflections of the same underlying myth), or will specify the myth as taking place in the same geographical area.

When protagonists move around these named locations they are described as doing so in terms that directly reflect the real topography of that location. Thus, in the initial episode of 'Coyote Steals the Daylight Sack', Coyote and Wolf are described as living at the foot of a hill, ku. sá-da.no-yo.. When Coyote turns back from a planned hunting expedition in order to spy on Wolf, he is described as going on the west side of an intervening hill, and then moving up the back side of ku. saá-da. nò-yo: to the top, from which he could look downhill towards the house which was next to the creek which ran there. The Eastern Pomo are extremely familiar with the terrain that they inhabit and the trails formerly used to traverse it. A contemporary Eastern Pomo narrator can indicate the actual location, geographically, where Coyote changed his mind and turned back, or the location of the house he shared with Wolf--although there is not sufficient detail in the narrative for an outsider to do the same thing. References to physical location in Eastern Pomo myth, then, as well as descriptions of movement through named areas of the geography, presuppose familiarity with the actual territory which the Eastern Pomo inhabit. The physical appearance of the terrain through which the protagonists pass is never described. Presumably, the precise reference to real geographical areas functions to call forth an image of the area itself. 
An Eastern Pomo who could indicate the location where Coyote changed his mind and turned back would also know what that spot looked like-what trees and shrubs grew there, what kinds of human activities were usual in that location (hunting, root digging, acquisition of supernatural power), and what other events were associated with that spot.

All myths begin by describing the protagonists as living at a named real site, in order to orient the audience geographically. If the protagonists subsequently travel in a certain direction, say east or west, the audience knows exactly what geographical area is being traversed, and therefore what its physical appearance is.

Thus, the directional and locational detail in Eastern Pomo myths presupposes knowledge of their terrain and makes unnecessary the kinds of details concerning the physical appearance of the setting which we would find useful. Knowledge of these locations was passed on in conjunction with the telling of the myths, but apparently not uniquely through the telling. (since there is not enough locational detail to identify these geographical locations through the myths alone). Presumably, part of the education of a child involved not only telling him the myths, but at some point, independent of the telling, pointing out to him the exact location of the named spots important in a myth. (Marvin Harris [personal communication] has suggested that this aspect of the myth may have had the important practical function of orienting the young appropriately to the terrain.)

Moreover, one of the most elemental narrative presuppositions involved in the performance of Eastern Pomo myths must be that they are true, that they describe events and activities that once really took place, the proof of which is that these events and activities always take place in real, named geographical locations familiar to the Eastern Pomo. That is, the assertion of locational and directional detail involves the presupposition that the myths are true. 4

I received unexpected corroboration for the reality of the first of these two narrative presuppositions on a recent fieldtrip to the Eastern Pomo. The most gifted myth teller alive to my knowledge insisted he no longer could remember a certain myth, but agreed to tell me as much as he could recall. I turned on the tape recorder and he spoke for over one-half hour, covering all the episodes which had been included in other collected performances, in a thoroughly satisfactory manner. I was pleasantly stunned, having been prepared for a brief fragment, except that no location was given initially for the action. Thinking my hypothesis might be in error, I asked where the narrative action had been located and he replied with great discomfort, 'That's just it, I don't remember all of the myth. I don't remember where it begins. They used to tell where it happens. This one I don't know.'

A symptom of not fully remembering the myth, then, is not being able to locate its action geographically, and the collected performances 
which lack such location are either clearly brief short fragments or were told by speakers who initially claimed not to recall the myth in question.

It is interesting that no one innovates or invents with respect to this initial geographical location of the protagonists. It suggests, I think, the significance which the initial locating of the protagonists had for the correct appreciation of the myth.

During the same field trip, additional Eastern Pomo corroboration of these two narrative presuppositions became apparent. While out driving with the same myth teller one day in an area we did not usually traverse, he suddenly commented that we were passing the spot where a certain episode of 'Coyote and the Two Skunk Brothers' (which he had recently told me) took place and that he could show me where all the other episodes occurred. 'Coyote and the Two Skunk Brothers' was, in fact, the myth which he had initially claimed not to remember because he could not remember the location at which it began. He proceeded to point out the specific locations where each subsequent episode took place, despite the fact that none of the significant landmarks remained! The rock under which the Skunk Brothers had made their house had been dynamited into gravel in the construction of the road we were driving on. The stunted oak tree that had grown into Coyote's anus when he stopped to defecate while chasing the Skunk Brothers had been uprooted to build a barn, the former shore of the lake was no longer visible since the lake had been drained in this area, and the former shoreline was now the middle of a pasture--yet he could identify with precision where they all had been. He then volunteered somewhat hesitantly, 'They used to say these ma.rú. were true, really happened long ago, and I guess that must be true.'

The importance of location in Eastern Pomo myths contrasts strikingly with Russian fairytales, which almost never locate the action in a real place (the one exception in Propp's corpus is \#148, Nikita the Tanner, which begins: 'A dragon appeared near Kiev . . .' Russian fairytales begin either with a bald naming of the initial protagonists, as in the fairytale in the Appendix: 'A widowed peasant with a daughter also married a widow who also had a daughter', or by placing the action in a nonspecified location.

In a certain kingdom . . .

In a certain land, in a certain kingdom ...

In a certain kingdom, in a certain land ...

In a certain land, not in our kingdom . . .

In a certain village . . .

In a certain land, in a certain big village... 
Occasionally the action takes place in a clearly imaginary location which turns up with frequency as the goal of quests in these tales.

In a certain kingdom, beyond the thrice ninth land, in the thrice tenth realm ...

Russian fairytales, unlike Eastern Pomo myths, are characterized by a number of features which signal that they are not to be taken as true, one of the most striking of which (from the Eastern Pomo point of view, at least) is the lack of locational and directional detail.

4. Subsistence and male prestige. Virtually all Eastern Pomo myths describe the protagonists as involved in food-acquiring activities which do not seem to have any obvious relation to the subsequent plot development. Why would such apparently parsimonious myth tellers waste time on such a detail when so many other seemingly more important details are omitted? One possibility is that it was merely a device for getting the protagonists out of the villages into areas where Eastern Pomo agree that marvelous experiences are most likely to happen. However, only certain food-acquiring activities are mentioned: deer-hunting, trapping of small game, hunting of water fowl, fishing, and, in one myth performance, grasshopperburning. In another set of performances of a single myth, clovergathering, as well as small game-trapping, are mentioned. The most frequently occurring activities, deer-hunting, small gametrapping, and the hunting of water-fowl, were all uniquely male activities. Grasshopper-burning, some varieties of fishing, and perhaps clover-gathering, involved both men and women and were restricted to an extremely short season of not more than a few weeks. Typically female activities, such as seed-gathering, root-digging, buckeye-gathering, simply do not occur in the myths. Thus, the myths present a man's point of view at least in terms of the subsistence activities focused on, which is perhaps correlated with the fact that all but ten performances of all myths collected were told by men.

The Eastern Pomo subsistence seems to have been heavily dependent on the collection of several varieties of fish. Though the Clear Lake area where the Eastern Pomo live has frequently been described as teeming with fish, in precontact times the Eastern Pomo capitalized on the peculiarities of the life cycle of the fish which moved to shallower waters to spawn each spring. The eight or more varieties of fish caught in large quantities during the spring spawning season were dried, stored, eaten throughout the rest of the year, and even traded to neighboring groups. The various mammals eaten by the Eastern Pomo (with the possible exception of deer meat) were not stored and seem never to have been acquired in sufficient quantities 
to make storage a necessity. Fish were the staple then, although mammals may have been more highly valued. The acquisition of fish was an activity women shared in (they prepared the fish for drying as they were caught), while the acquisition of mammals was a uniquely male activity, from which women were not only excluded, but to which their presence, at least in the case of deer-hunting, could positively bring bad luck.

Lee (1968:40) has pointed out that for Kung Bushmen hunters and gatherers, 'hunting is a high-risk, low-return subsistence activity [carried out uniquely by men], while gathering is a low-risk, highreturn subsistence activity [carried out by women]'. What ethnographic data we possess suggests that for the Eastern Pomo, also, hunting was a relatively high-risk, probably relatively low-return but high-prestige, uniquely male subsistence activity, while fishing and gathering were clearly low-risk, high-return subsistence activities, the first done primarily by men, the second primarily by women. Several myth performances make explicit an opposition between fishing and mammal-hunting which the older tellers were overtly conscious of--since they consistently pointed out the inversion to the collector (in an aside recorded in the field notes to the actual performance). Either the hunting techniques associated with the acquisition of fish versus mammal protein are reversed, deer being caught in fish traps in one myth, for example; or the storage techniques are reversed, ground squirrels being treated like fish in the myth in the Appendix; or the rules regulating the distribution of these sources of protein are broken. Thus, it seems that mention of a food-acquiring activity serves as a leitmotif to ecological themes of symbolic concern and male orientation, specifically, a male preoccupation with hunting --presumably, a source of male prestige--as opposed to fishing--the actual major source of nonplant protein.

5. Protagonist naming. The first sentence of a myth locates the myth protagonists at a named geographical site. The protagonists are primarily animals and are referred to either by the animal name alone, e.g. ţá. ța 'sparrow hawk', xa.náriwa 'turtle'; or by the animal name compounded with a member of an extremely small grammatical class of words which I have called personal nouns (McLendon 1975), which has certain unique grammatical properties (such as marking the plural suppletively) and which distinguishes males and females in four life stages; or with the noun for 'chief' ká. xalikh or 'female chief' dáxa. likh (cf. Figure 1).

The compounding of animal names with personal nouns involves, I think, still another narrative presupposition. The socially unmarked forms dă 'woman' and $\mathrm{ká}^{\mathrm{a}} \mathrm{k} \mathrm{h}$ 'man' are to my knowledge never used in this sort of compound. Only the terms that mark age ('old man' and 
FIGURE 1. The class of Eastern Pomo personal nouns.

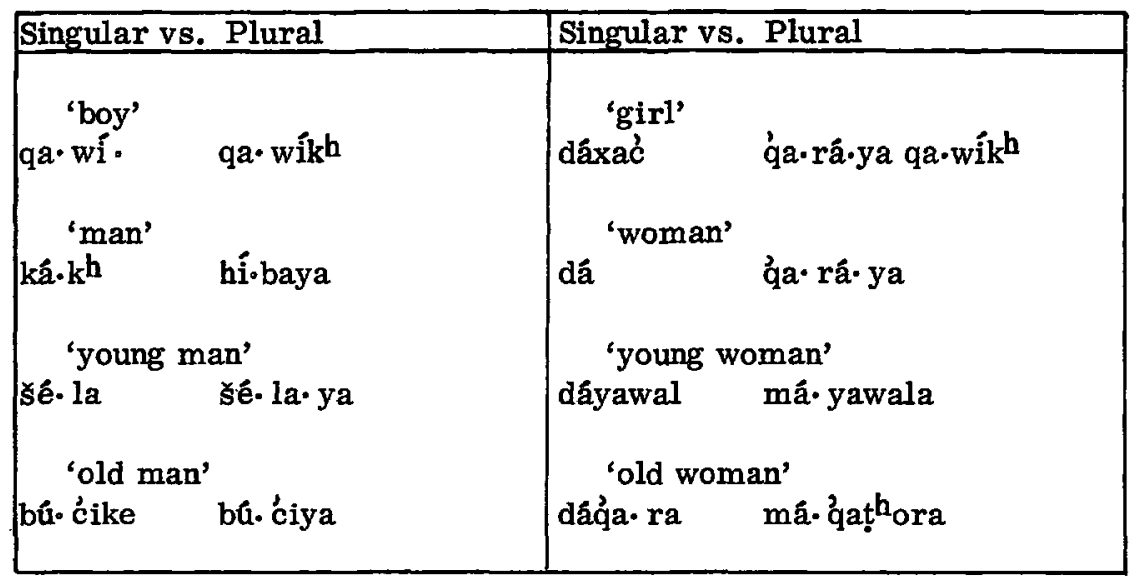

'old woman'), youthful maturity ('young man' and 'young lady'), or immaturity ('boy' and 'girl'), plus the two terms marking the ultimate in social and political status ('male/female chief'), are used. These terms simultaneously characterize the physical appearance of the protagonist, imply social roles and typical daily activities (i. e. children foraged for a lot of their protein; old men made beads, wove nets, etc., and generally stayed close to the village supervising and instructing their grandchildren--particularly their grandsons; while young men did most of the most arduous work, were venturesome, and were frequently away for long periods of time).

Thus, the culture hero/trickster figure who is coyote in this part of California is called ku. nú. la-bù. ćike 'Coyote Old Man' and is commonly referred to in English by the Eastern Pomo as 'Old Man Coyote', whereas Falcon's wife, who is quail in a number of myths, is referred to as sa. gá. $x$-dayawal 'Quail Young Lady'. It is also possible that a protagonist will be identified only in terms of his kinship with an animal-named protagonist, e.g. 'deer's son' or 'the son of bear old lady' or 'crow's brother'. Since the other animal protagonists are generally related to the protagonist specified by a compound name, their relative age, sex, and age-grade determined behavioral characteristics can be inferred from their kin relationship.

6. The symbolism of animal protagonists. Increasingly, the attention of anthropologists has been drawn to the attitudes different people have towards the animals in their environments, more precisely, to the fact that the attitudes towards and perceptions of animals by a given group can in a number of cases be shown to reflect not only a society's notions of the relations between man and nature 
but also of the relations between men (Tambiah 1969, Leach 1964, Bulmer 1967). It is not surprising, then, that the protagonists in Eastern Pomo myths are primarily animals. Eastern Pomo myths, in fact, have sometimes been called 'animal tales'. A wide variety of animals such as coyote, falcon, wolf, skunk, turtle, lizard, eagle, fox, wildcat, sapsucker, grey squirrel, blue jay, bear, cormorant, crane, several varieties of mergansers and fish ducks, as well as others, recur in more than one myth as protagonists. However, some animals, such as rabbit and the many varieties of fish known to the Eastern Pomo, never figure as myth protagonists even though they are important to the Eastern Pomo as sources of food. A close examination of the diets of the animals frequently named as protagonists in Eastern Pomo myths shows that (with one class of exception, to be discussed later) they share the attribute of competing with the Eastern Pomo for at least some of the sources of food available to them, primarily the nonvegetable protein sources. The sources of nonvegetable protein utilized by the Eastern Pomo included: insects, especially grasshoppers, as well as army worms, grubs, and wasps; fish of all sorts and fish eggs; small mammals of all sorts (from field mouse to woodrat to ground squirrel and rabbit, including skunk and raccoon); certain birds (including certain varieties of ducks) and their eggs; deer and elk.

The animals that figure as protagonists can be broadly defined as predators that eat other living creatures as well as plants; frequently, they are scavengers. The major protagonists are the larger mammal predators (from skunk up through bear), the hawks and the fish-eating cormorants, herons, ospreys, etc. They compete among themselves as well as with the Eastern Pomo for an overlapping range of prey sought as food by both animals and man.

The Eastern Pomo were and are superb naturalists. Even today they are intimately familiar with minute details of the appearance, behavior, and diet of all the wild life in their vicinity. It seems unlikely, then, that this characteristic shared by myth protagonists is accidental. On the contrary, it seems reasonable to assume that the competitive role of these creatures in precontact reality beightened the audiences' interest in listening to accounts of their exploits, and constituted an important narrative presupposition: the Eastern Pomo liked to talk about animals who were predators like themselves, who found their food in the same places as the Eastern Pomo, with whom the Eastern Pomo had to share their food supply, and whom the Eastern Pomo sometimes used in order to identify the location of a food supply.

Corroboration for this narrative presupposition also comes from the only performance of the creation myth which was recorded in the Eastern Pomo language (de Angulo 1935). In that performance the 
various animals are created and placed on mountains. The most valued game--deer, hare, and rabbit--are created and grouped on one mountain, while the mammal competitors of Eastern Pomo man-bear, wolf, mountain lion, fisher, coon, coyote, fox, and skunk--are placed on another (all the snakes were placed on a third mountain). That is, the herbivore noncompetitors (deer do eat acorns, of course, and thereby compete) are distinguished from the omnivore and carnivore animal competitors of Eastern Pomo man. The grain- and nuteating smaller mammals which the Eastern Pomo trapped--such as ground squirrel, squirrel, mouse, and woodrat--are omitted, as are all the birds.

7. Nature vs. culture: The symbolic function of Coyote Old Man. The central myth protagonist, Coyote Old Man, is clearly characterized in the plots of the myths as in competition with all the other animals for food. A recurrent theme of myth episodes, in fact, involves Coyote's attempts to take away the prey of fellow predators, usually by trickery. For example, in one performance of 'Coyote and the Two Skunk Brothers', Coyote tricks the Skunk brothers into letting him eat the large amount of grasshoppers they have caught in exchange for a promise to take them out deer-hunting and to give them the best of the deer meat they shoot. In fact, he gives them the worst meat, tricking them again.

A related theme involves Coyote's attempt to learn and emulate the hunting techniques of other predators. Thus, in 'Ground Squirrels Steal Coyote's Shoulder', Coyote asks Hawk for his secret hunting technique and turns himself into a woman to seduce it out of him.

At the same time, the other predators are in competition with Coyote for the prey and attempt to trick him out of it. Thus, other performances of 'Coyote and the Two Skunk Brothers' lack the episode with the grasshoppers and detail how the two Skunk brothers trick Coyote out of the deer they have all caught. In the first episode of 'Coyote Steals the Daylight Sack', Wolf pretends to have a toothache so as not to go out trapping with Coyote at a considerable distance from where they live. Wolf instead stays home and magically catches deer, literally in his own backyard; he eats the deer secretly so as not to share them with Coyote.

Even the prey themselves are far from passive. They resist being caught and cooked, and can pop back to life and run away if Coyote (and therefore people?) are not careful, as the prey did in 'Ground Squirrels Steal Coyote's Arm'.

Thus, Coyote is to the other predators in the animal world, as well as to their prey, as hunting and gathering Eastern Pomo man is to the animal world: in constant, competitive struggle for the same resistant and evasive food supply. Like hunting and gathering Eastern 
Pomo man, Coyote remains constantly alert, curious, and open to new technology, but constantly pays an extremely high price for his willingness to innovate. Coyote and his interactions with his fellow predators or prey reflect Eastern Pomo man's interactions with nature for food--the ecological preoccupations of man's existence.

At the same time, many of the animal protagonists are described as being in a relatively fixed kin relationship with Coyote (but not with each other). Thus, Falcon is always Coyote's grandson, while Frog is traditionally his wife. (Coyote is noted for his amorous dalliances, however, so this association is not so fixed.) 'Flint Young Man' is Coyote's son (but not Falcon's father), while there are always two skunk siblings and they are always members of the first generation below Coyote, either children or nephews, and Wolf and Coyote are always either older and younger brother or mother's brother and sister's son. Interestingly, Coyote has no sister, although he is mother's brother to the two skunks. He has no parents, although he may have a mother's brother.

Coyote interacts with the other animal protagonists, then, both as fellow predator in competition for the same finite resources, and as kinsman bound by cultural expectations regarding the appropriate behavior between certain types of kin. One such behavior with which the myths seem particularly concerned involves the obligatory sharing of certain types of food (some of which were communally collected), such as acorns, deer meat, trapped game, several species of fish caught in large numbers at certain times of the year, and honey. The recurrent plot in the myths of attempting to take away the prey of others entails attempts by Coyote and/or the other animal predators to avoid sharing food, despite the kin ties which unite them. Coyote always fails and is punished in such adventures, as are the other animals, unless their attempt was a response to such an attempt on Coyote's part (in which case they may be successful).

The myths seem, therefore, to be concerned with the relation between man and nature on the one hand, represented by the opposition of Coyote to the other predator protagonists, and man and culture on the other, represented by the kin ties which bind Coyote, despite his competitive instincts, to the other predators. That is, the myths are concerned with the conflicts inherent in man's dual roles of predator in nature and member of a human society whose predatory instincts must be socially constrained in his interactions with other men. These were life and death issues, quite literally, for a hunting and gathering people whose very survival depended on their ability to combine the individual initiative required for successful hunting and gathering with a relatively equal redistribution to all members of the group. 
Support for this interpretation comes not only from the myths themselves, but also from the consistent reactions of the Eastern Pomo to the behavior of the myth protagonists, particularly to the behavior of Coyote. Eastern Pomo audiences laugh at it and frequently laugh in anticipation of the punishment which predictably awaits Coyote, adding comments such as: 'Coyote always wanted too much of everything' or 'He's a tricky old man [said with admiration] but he always comes out on the wrong end'. At least two folklorists have recently pointed out the instructive function of laughter (Toelken 1969). One can only laugh when a certain action is punished if one has accepted the notion of the inappropriateness of that behavior. One's laughter is tantamount to saying, 'I would never do anything as foolish as that' (behavior which elicits ridicule). This laughter is thus coopting since it serves indirectly to inculcate a certain ethical point of view. It suggests the ethical function which these narratives have for the Eastern Pomo.

8. Animals and kin. When Coyote is not a protagonist in a myth, then the animal protagonists involved will be specified as connected by a limited number of types of kin relations which are not binding on that animal throughout the mythology, but may change. The kin relations on which the myths primarily focus are those between brothers, between mother's brother and sister's son, between grandfather and grandson, husband and wife, and between affines, especially parentsin-law and children-in-law, from the point of view of a male ego, just as the food-acquiring activities focused on are almost exclusively those of men. Thus, the animal protagonists, do not constitute a natural kin grouping within which genealogies are permanently established and which is an important narrative presupposition, as in Greek mythology. Rather, certain kin relations are singled out, focused on, in the myths (just as certain food-acquiring activities are singled out from the totality of such activities)--and different sets of animals are variously associated with different ones of these kin relations--salient ecological attributes of the animals being associated with salient sociological attributes of the kin relation. 5

For example, when a marital relationship is focused on, the wife of a couple seems to be consistently chosen from among the animals which are the natural, or possible, prey of that animal which is specified as her husband. Thus, Falcon's wife may be Quail, Meadowlark, or Mouse, while Wild Cat's wife is Deer, and Coyote's wife is traditionally Frog, but is once Skunk and once Duck. This identity of the wife in a marital relationship seems, incidentally, the one area in which a myth protagonist may be chosen which does not directly compete with the Eastern Pomo for the same food chain--Quail does not really seem to, and she only occurs as a myth protagonist in the minor walk-on role of Falcon's wife. 
When the relation focused on is that between brothers or mother's brother and sister's son, however, the protagonists are predators who are rather similar in size and habits and compete for at least some of the same prey--such as Coyote and Skunk or Wolf and Coyote --but differ enough, so that one is larger, stronger, or potentially able to prey on the other, that dominant one being always associated with the older kin role. Thus, Coyote is always the mother's brother of Skunk, but is himself the younger brother or sister's son of Wolf.

Two myths seem at first to constitute an exception to the narrative presupposition that husband and wife will be normally reflected by a predator and his prey. In two performances of the 'Defeat of the Supernatural Kílak', Falcon either pursues Eagle Woman, who accepts him as her husband on her trip to destroy kilak, or he is described as already married to Osprey Woman. In two performances of a second myth, either Wildcat is married to Fox or Mountain Lion is married to another mountain lion. In all four performances, the predatorwife uses her sexuality to kill (or once, disable): Eagle Woman kills kilak when he sleeps with her, Osprey Woman claws kilak so that he bleeds profusely when he sleeps with her, while Wildcat and Mountain Lion attract deer by seductively exposing their genitals and then kill the deer when they come to look. In all four performances the husband separates himself from his spouse as a result. Three of these four performances were told by a woman--the only woman from whom Eastern Pomo myths have been collected. The fourth was told by her sister's son, whose father had been a black man, and who thus could only have learned this myth from his mother's family. This inversion of the normal expectations as to which animals will be associated with a husband and his wife could reflect an aspect of the individual psychology of the single female narrator and her sister, or a more generally distributed difference in men's and women's performances of these myths. In any case, these four performances seem, in fact, to involve deliberate manipulation of the normal narrative presupposition that husbands will be played by predators while their wives will be drawn from their potential prey, and thus confirm its reality.

9. Protagonist, sex, social class, and marriage in Russian fairytales. In the corpus of 178 fairytales examined by Propp, the initially mentioned protagonists are predominantly either tsars and their families, peasants, or old men and women (who are almost always poor, and seem therefore analogous to peasants in social class). Four other classes of people are mentioned: a priest is among the initial protagonists in two tales, a soldier in three tales, a merchant in eight, and a Cossack in one. Animals figure also among the initial protagonists in two more tales. In the rest of the 178 tales the protagonists are chosen from one of the two extremes of the social 
scale in traditional prerevolutionary Russia. Kin relations are not focused on, but those mentioned are between stepmothers and daughters, between stepsisters or brothers, and between parents and children. Many of these tales begin with a birth or with an inventory of the children of tsars or peasants, who then grow up, have adventures, and ultimately marry (as Propp 1968 pointed out). The marriage is inevitably a 'good' marriage involving a wealthier person, one of a higher social class, one of great beauty and fame, a fabled personage, or all of these. The Russian fairytale given in Appendix B of this paper illustrates this characteristic ending, since after getting rid of the evil stepmother and daughter, the widowed peasant is described not only as living 'happily with his daughter all his life' but as '(taking) into his house a wealthy [emphasis mine] son-in-law'. In such tales the main protagonist is either a young girl or a man. The development of the tale is rather different, depending on which sex is picked for the main protagonist.

If a young girl, she must be unfailingly industrious and obedient, doing whatever is asked of her, no matter how odious or impossible, and never challenging authority. The Russian tale in Appendix B illustrates this ideal. The daughter does not attempt to dissuade her father from abandoning her in the woods and despite his betrayal, follows his final instructions to her: 'Here is fire for you, do not let it die out; cook your kasha, sit and spin, and keep the hut locked.' Moreover, when young girls are the main protagonists, the importance of correct behavior as indicated by politeness, sharing of food, and/or proffering of hospitality, is particularly emphasized. The stepdaughter in the tale who refuses to share her food with the mouse pays with her life, while the one who behaves appropriately is not only saved by the mouse, but rewarded with material wealth by the bear villain.

When the main protagonist is a young man, however, he is frequently not industrious, spending all his time in the house or sleeping on the shelf over the stove; or he is not obedient, refusing to work when his sisters-in-law tell him to. Frequently, he argues with Baba Yaga when she comes to count the spoons, even though he has been told not to; or he is foolish and simple, or physically defective (mute, a dwarf), inadequate (a starveling, a weakling); or he is the third and youngest brother. He is often called X-Lie-on-the-Stove or $\mathrm{X}$ the Simpleton. He frequently fails to show respect to a potential donor, and then reconsiders, shows respect, and gets a second chance. A second type of main protagonist is described as super strong, a fully mature male (frequently he is referred to as Champion). Unless the tale is very literary, he does not achieve a successful marriage, or any marriage at all. If he does marry, his wife will trick him. A third type of male protagonist is not inadequate or particularly youthful, but also not super strong. He is usually 
destroyed by stronger adversaries at some point and then rescued and brought back to life by his princess. He sometimes marries, and sometimes does not.

The youthful male and female protagonists almost always reap vividly described material benefits from their sex-appropriate behavior. The good stepdaughter in the tale cited is given 'a drove of horses and a cartful of goods'. In another version of this same fairytale she gets a fur coat, ' $a$ coffer, deep and heavy, full of bedding and petticoats and all sorts of things for her dowry', and a 'robe embroidered in silver and gold'--the stuff clearly of which fairytales are made in Western society, but not, needless to say, in Eastern Pomo society.

Only one Eastern Pomo myth begins with a birth--that of Obsidian Young Man by Old Man Coyote as the result of having been shot with an arrow while stealing from someone's fish dam. It ends with Obsidian Young Man destroying the other human inhabitants of the village where he has grown up, and the subsequent dispersal of Old May Coyote, his wife, Frog Old Woman, and Obsidian Young Man to the locations in the real environment where they are now found, i. e. fields, wet places, and the rocky slope of a volcanic mountain where the Eastern Pomo got their obsidian. Obsidian Young Man never marries, and neither does anyone else in an Eastern Pomo myth. While Russian fairytales usually end with marriages, and 'good' marriages at that, Eastern Pomo myths at most open with a marriage on the rocks, and frequently do not mention marriage at all. In Eastern Pomo myths, protagonists become embroiled in various sorts of conflicts and frequently die. Their kin, either their grandparents or their children, then attempt to bring them back from the dead. These attempts are temporarily successful, but ultimately the dead person returns to the dead and everything is as it was, essentially unchanged, except for the absence of the deceased one.

I would like to suggest that part of what we miss in Eastern Pomo myths is the sense of development, achievement, of virtue materially rewarded, of social mobility successfully realized, which we get in Russian fairytales. Moreover, I would like to suggest that this sense of progress, the focus on material reward for virtue and the achievement of superior social position as marked by a 'good' marriage, all derive from the fact that these tales were told in a socially stratified society, with great discrepancies in social class and access to wealth and power. Eastern Pomo myths, on the other hand, were told in a socially unstratified society with relatively small differences in access to wealth (the concept of wealth existed, however) and little or no social stratification. There was, nevertheless, an intense involvement in the environment, in the frictions between certain kinds of kin, in the need for sharing, and the irreversibility of death. 


\section{4 / SALLY McLENDON}

Socially stratified societies existed in native North America and-at least among those of the Northwest coast, as ethnographers of this area have long realized--what Garfield (1948:33) calls 'the rags to riches' theme is extremely popular. One finds on the Northwest coast that myths frequently begin with births, and describe the growing up and subsequent adventures of the individual thus born, who ultimately achieves material success and hence social prominence. The Tsimshian story of Asdiwal, the topic of a well-known study by Levi-Strauss (1958), for example, follows this format. (However, although the successful Northwest coast heroes usually marry, their marriages are not the badge of social success they are in the Russian fairytales.) One cannot make a universal out of two examples, of course, but it would be interesting to know how often 'the rags to riches' life cycle is associated with socially stratified societies.

Levi-Strauss has long insisted on the importance of knowledge of the ecology and social organization of a group telling a myth for the correct structural analysis of that myth. A consistent examination of patterns of presupposition and assertion of information which I have illustrated here provides a basis for a systematic, nonintuitive, and non-ad hoc means of identifying the aspects of the ecology and the sociocultural institutions which are important for the interpretation of a narrative. It does not by any means constitute a complete analysis of a myth or folktale, but rather provides a necessary background to such an analysis.

Identification of the narrative presuppositions characterizing the oral performance of Easterm Pomo myths permits a nonintuitive definition of what constitutes a well-formed myth performance in Eastern Pomo. This in turn permits a less impressionistic categorization of those performances collected into fragments, of deviant or distorted performances, etc., as well as of well-formed ones. The explicit inventorying of the narrative presuppositions on which the performance of Eastern Pomo myths formerly drew provides also the framework for developing English translations of these myths which will reflect, in a systematic way, not only the words used in telling them, but the whole narrative tradition on which they draw. 6

In addition, recognition of the importance which specific aspects of the ecology have in the structure and content of Eastern Pomo myths suggests a hypothesis for why the culture hero/trickster role is played by different animals in different parts of North America-coyote in the Plains, Plateau area, and California, rabbit in the Southeast, mink and raven on the Northwest coast--even though coyotes existed in the Southeast, and rabbits exist in the West and Northwest. The animal associated with the trickster/culture hero role must be an important but not threatening, competitor with man in that ecological niche. Thus, in the Southeast the native Americans 
were agriculturalists, and rabbits eat crops. On the Northwest coast, on the other hand, mink--the culture hero/trickster in the southern part of the Northwest coast--ate various species of fish, frogs, crayfish, mice, muskrats, rabbits, and many kinds of birds, particularly crippled waterbirds (Ingles 1965:375). Raven, the culture hero/trickster in the northern part of the Northwest coast, ate berries in season, bird eggs, and the carcasses of whales, walruses, and seals, as well as shadowed wolves to glean leftovers from caribou and moose kills (Wetmore 1964).

Thus, the attempt to specify consistent patterns of assertion in narratives and the narrative presuppositions which they entail reveals important concerns of the cultures which tell them, permits a less subjective interpretation of the content of such narratives, providing a consistent basis for a structural analysis, and suggests possible explanations for some types of variations between narratives in different cultures, making infinitely easier the analysis of discourse.

\section{APPENDIX A}

\section{PERFORMANCE 1}

Told in English by Tom Mitchell to S. A. Barrett, December 19, 1902.7

ku. nú lala. 1
'Coyote-patient'

ba. kal

'shoulder blade' que máru. 1a.

'Ground squirrel(s)-agent'

$\mathrm{p}^{\mathrm{h}} \mathrm{u} \cdot$ díyaki.

'steal'

mi Ya ti.límti.lím

'your' 'bone' 'rattling'

At ma. yify-na. $p^{\text {ho }}$ (contemporary Scotts Valley) there lived Coyote alone save for the presence of two old crow women who were blind and lived some distance from his house.

Now Coyote, having the power to transform himself, changed into a woman and threw himself into the path of the hawk who was a very great hunter.

ta. tha (the hawk) fell in love with this comely maiden and married her. That evening, upon being questioned, ta. fa told ku.nu. la (Coyote) just how he managed to catch so many squirrels to eat.

Which was somewhat like this: He went out and placed on his hands some bright bits of abalone shell and placed his hand far down in a squirrel burrow. The squirrels were attracted, came into his hand 
which he then carefully drew forth, and proceeded to kill the squirrels so captured.

Then he repeated the operation.

Although he killed many in this manner there was always just as many left as before he began.

In the morning the hawk's pretty wife had disappeared; Coyote having attained the desired end, had quietly slipped away and changed himself into a coyote again.

He now tried his newly discovered method of trapping game and found it to work admirably the first time or two and succeeded in catching several squirrels.

Very shortly, however, the squirrels looked at the hand more closely when he put it down into a burrow, and discussed the matter as to whether it was the same hand which they liked and decided that it was not. Then they decided to catch and hold Coyote's arm there.

Coyote pulled and wrenched till finally he pulled his arm off at the shoulder joint.

He ran and got some pendant moss and stopped the flow of blood and finally found an elderberry stick which he put in for an arm.

He then went home and a long time passed. Finally one day he went out into the rancheria and preached a long sermon calling upon all his people to come and assist in the building of a sweat house. Of course there was no one there to come since only the two blind crows lived there with him so he set about to build it alone, he dug and dug for a very long time gradually digging out a good sized pit and had it fairly deep (between 3 and 4 feet) when he dug up someone who proved to be ta. ná. (very chunky, medium sized duck very flatbilled, short wings, short tail) [=teal duck].

He now had ta. ná to assist him and it did not take them long to build the sweat house and prepare all things for the dance.

Now the squirrel people seeing that the sweat house was completed decided to walk in and take possession and have a big dance. Accordingly they prepared dancing apparel which was like that used now except that they substituted for the abalone bangles on the headdresses and the poles (used as banners) pieces of the bones of the arm of the coyote which they had stolen.

All things being ready, they started for ma.yí.y-na. $\mathrm{p}^{\mathrm{h}_{\mathrm{o}}}$ carrying their poles and dressed for the dance in high glee singing in order to tantalize Coyote.

$$
\frac{\text { mi }}{\text { Your }} \frac{\text { Yá }}{\text { bone }} \frac{\text { mi }}{\text { your }} \frac{\text { Yá }}{\text { bone }} \frac{\text { ti·límti } \cdot \text { lim }}{\text { rattle rattle }}
$$


Coyote heard them coming and ran out to see what it was. When he saw who it was and that they had his bone, using it for ornaments, and furthermore were singing about it he was very angry but being almost alone he thought discretion the better part of valor so went out and welcomed them most heartily and conducted them to the sweat house where all proceeded to dance.

Along towards midnight they commenced to drop to sleep and he requested that those with the longest hair should sleep closest to the fire with their feet towards the fire, those with hair next longest sleep with their feet between the heads of the preceding and so on. He said that this was the way that everyone did at his rancheria. Accordingly they all took these positions and fell asleep; he then went about among them and tied the hair of the head of each person to the feet of his neighbor nearest: thus tying them into a solid mass.

He had sent ta. ná meanwhile with instructions to bring the greatest possible quantity of wood. ta.na went over to Cow Mountain and pulled up, root and branch, every manzanita on the entire mountain (this is the reason why no manzanita is to be found there now) and carried it home at a single load.

They now piled this on top of sweat house in the door and in the smokehole and set fire to it.

As soon as it began to get hot, the squirrels roused and attempted to escape, but found themselves either held fast by the feet or else held by the hair and they immediately set to fighting, each man his neighbor, because he was holding him by the foot or hair as the case might be.

Thus they were all killed and roasted in this way.

Now Coyote bethought himself how he might save all this meat, which was much, so he went up on the hill to get some mu-típ (a coarse grass which is spread upon the ground for drying fish) intending to dry the surplus. He had not gone far when he saw the blind crow women going toward the sweat house.

He called out 'Here! Don't you go there. I have counted all those squirrels and $I$ want them all for myself. If you steal any of them I will kill you.'

He went on after the mu-típ and the old women took quite a quantity of the meat and carried it home.

Presently Coyote came back with a great load of mu.típ and threw it on the ground near the sweat house whereupon all the squirrels in the sweathouse came to life again and ran off.

Coyote went over to where the old women lived and ate some of the offal which they had thrown away from the meat they had taken.

He said:

'Why did you not take more of those squirrels? I told you to take a great many.' 
The women answered:

'No, you did not; you said you would kill us if we took any of them.' Coyote said:

'No, I did not. I told you to take a lot. Why did you not take more?'

\section{PERFORMANCE 2}

Told in both Eastern Pomo and English by Ralph Holder to Sally McLendon, April, 1975. 8

Old Man Coyote had been walking around, and he heard the news that the eagle chief always killed a lot of food. When he heard that, he made up his mind to go over there and fix himself up so he looked like a young woman. A pretty young woman. Then he was a young woman already and he went over there (to Eagle Chief's village). Then he came to the village. Then he asked the kids playing outside there, 'Where is Eagle Chief's house?' When he asked, they told him. Then he went over there to the place where the old lady was, weaving a basket, and he asked her, 'Where is the eagle chief ?' 'He don't stay home. He goes out looking for food all the time.' That's what the old lady said. 'Sit down here, my daughter-in-law, he'll come home pretty soon.' That's what she said. (He had made himself a pretty young woman before he came.)

Then in the evening, Eagle Chief came home, carrying a lot of ground squirrels. He put them on the ground and she told her son, 'This young woman has come to see you.' Then they ate the ground squirrels and went to bed. After awhile, they were laying there, and he began to make love to the woman (Coyote), but she refused, saying she didn't know about such things and the man stopped bothering her. They were laying there and afterwhile Coyote went outside (to urinate). Coming back inside, on his way to lie down, the grape vine he had tied himself with slipped and his penis slipped off. When it slipped, it sprang back towards the fire and splashed burning coals and ashes on the other side (where the mother was lying). Old Man Coyote ran out and ran away.

Next morning, first thing; he looked for that abalone shell, and made some pendants and putting them on his fingers, went out in the fields to look for ground squirrels. He saw lots of ground squirrels going into a hole and put his hand down in the hole as far as it would reach up to the shoulder. When he put his hand down there he could feel the squirrels getting on his fingers, but it felt like they were coming slowly. The squirrels felt his hand, but it didn't seem to be the hand they were used to, so they went and got an old lady, who never went out anymore, since she was blind, and she felt the hand 
and said, 'This is Old Man Coyote's hand. He's always tricking people, deceiving them.' That's what she said. 'Let's pull, everybody, let's pull it. Everybody get on his hand and pull it.' So they pulled on it and pretty soon they pulled the arm off.

Then old Man Coyote got up and looked around under the trees and found a tree limb that had been blown down and went home and put that limb where his arm was.

After awhile, a ground squirrel came there and told him: 'We're going to come here and dance for you. Come here and dance.' $\mathrm{He}$ said, 'All right, that's good,' and Old Man Coyote began to dig the foundations for a dance house. He dug and dug and dug and finally finished.

Then the ground squirrels came along dancing while they were singing song:

\begin{tabular}{|c|c|c|c|c|c|}
\hline $\begin{array}{l}\text { mi. } \\
\text { 'Your }\end{array}$ & $\begin{array}{l}\text { Yई, } \\
\text { bone, }\end{array}$ & $\begin{array}{l}\text { mi. } \\
\text { Your }\end{array}$ & $\begin{array}{l}\text { Yá } \\
\text { bone, }\end{array}$ & $\begin{array}{l}\text { ti } \cdot \text { lím min, } \\
\text { that's jingling, }\end{array}$ & $\begin{array}{l}\text { ti } \cdot \text { lí }^{\prime} \cdot \min \\
\text { that's jingling' }\end{array}$ \\
\hline & Yá, & mi. & Yá & $\mathrm{ti} \cdot \mathrm{li} \cdot \mathrm{min}$ & $\mathrm{ti} \cdot \mathbf{l} \cdot \min$ \\
\hline & $\overrightarrow{a n o}$ & $\begin{array}{l}\text { mi* } \\
\text { Your }\end{array}$ & bone, & $\begin{array}{l}\text { ti. só. men, } \\
\text { that's what ma }\end{array}$ & t rattling' \\
\hline
\end{tabular}

That's what they were singing while they were dancing along. (That's really what they used to do.) And they went dancing into the dance house. Towards morning, he found out what it's all about. 'They're laughing at me, making fun of me.' He told the skunk girls who were his nieces to go home, in order to burn the Márakh down. Then the girls went out. While the ground squirrels were dancing the old man started running around. 'Boys, something is going to happen to me. I feel good. I'm getting numb, getting worse, boys.' That's what he said, while he's running around. Then he run around and came close to the door and started fire right at the door, so they couldn't come out, and then he ran out. They were hollering and screaming inside, and then they quieted down.

Then he went to the coast to get the poles to build a storage place for the squirrels. He brought those poles to the Márak ${ }^{h}$ and threw them on the ground, at which the ground squirrels started to run, raising lots of dust. When he dropped the poles on the ground, the ground squirrels ran away. He chased them, but only caught one.

\section{PERFORMANCE 3}

Told in English by Dave Thompson to S. A. Barrett, May 30, 1904. 8 Site: Kelseyville $=\underline{\text { nona } \cdot p^{\text {hoti }}}$ 
A duck, pretty one, ba. šába.dålat, was playing around nóna. $\mathrm{p}^{\mathrm{h} \delta t i}$. xa・ báda t țesțes lived at xa. bél on Rodman place on Rocky Point. He went down and found ba. šaba. dalat playing around and stole him.

The people missed the boy and looked for him. And finally one, a fish duck, 'cutkil (diver) went forward and back between these two places.

He found out they missed the boy. He told them that the boy was over at xa॰ bél.

He found out that they had stolen the boy.

Coyote told his boys (10 of them) 'We will have to see those fellows, we'll have to go there.'

'How can we go?' said the boys.

'We got to go by water.'

They fixed up to swim across (boys only) (i. e. stripped). They fixed up for doctors, feathers on head, pepperwood leaves about head.

Old Man Coyote said, 'When you fellows get there you land and go around four times (counterclockwise).'

They did it.

The xa. báda. țestítes said 'Why you fellows come here? That boy is alright. He will be back in four, days.' They had a si. má-q̀o. ?o and when they went around xa. báda. țestes went to sleep and they took the boy out.

The boy had turned different. Human head, body was duck. (When he went there he was all duck.)

While he was asleep they set fire to the house and burned up the whole business, xa. báda. țestetes and all. (This was a sweat house.)

They took the boy back to nona. photi (they all swam).

Coyote said (in all cases here he is called marim? da) 'What we going to do with this.' He wanted to give him another name, but said, 'No, we can't call him different. He is still ba. sába-dalat'.' He was talking to himself.

Coyote went to Chicken Hawk, ?il ?il. (He was going to try to fool ?il ?il.) He (?il?il) used to be a great squirrel hunter. He asked ?11?il 'How do you do when you hunt squirrels? Pd like to hunt just same as you do.'

?il ?il don't want to tell him.

Coyote made himself a woman, a fine looking woman. (He went away to do it and then came back.) She came to ?11?il and ?il ?il got stuck after her.

When they sleep together she asked ?il ?il how he killed so many squirrels. ?ח ?il told him how all these things were done. Coyote took all tricks. When ?1l?il wanted to connect up he found out Coyote was a man. 
Coyote put on the Wil on each finger and stuck the hand down in a squirrel hole. The squirrels got hold of the hand and he pulled it out and got lots of squirrels.

By and by the squirrels got mad some way and all the squirrels got hold of the arm and he can't get it out and they pulled the whole arm off.

Coyote went back and got sick and laid in bed.

He stuck a $\mathrm{p}^{\mathrm{h}} \mathrm{a}$. 16 (dry limb from a mush oak acorn tree) in place of his arm and it was a new arm right away.

He ordered to have a dance at ma. yíy because of his recovery.

There was another marum ?da he said: 'They order to have a dance over here so we will have to build a sweat house.' 'Boys you got to dig the ground so we can have a sweat house.' He dug himself and after awhile he found a duck ta. na. (chub duck called by whites).

He picked it up in his hand and said 'This is a pretty duck' and set him down on the bank. (Don't know how duck came to be there.)

Coyote said 'Now boys get the sticks.' The boys brought the sticks. He told them to build it. They built it.

Coyote called women and told them to help the men cover the house with dirt.

He said 'Now tha. nâ., you go get the wood.' He went up to Cow Mountain. He packed down at one load all the manzanita that grew on Cow Mountain. (There is no manzanita there now at all.) One stick dropped off the load when he got halfway down the Mountain and it is there now growing.

He took it home and covered up the whole sweat house.

The sweat house was all done and people all there. ta.ná., Jay, Lark, Coyote, and lots of other people.

The dance time was come. Ground Squirrel (qu. már) was going to dance. Coyote was captain, so he called people to come up to the dance and they danced inside.

Squirrel danced xêlè (war dance). He stopped dancing and they gave him something to eat. Everybody ate (ma. ?ây yówa kaw).

When they finished, Coyote danced. He said 'When I dance, lay with your heads toward the fire, everybody.' He had si. má-go. ?o. They all went to sleep. He tied the hair all together by braiding it all together. Then he slipped out and set fire to the sweathouse.

Lark flew out and lighted in field.

Jay flew out and lighted in tree.

ta. ná. flew out and lighted in lake.

There was nothing but squirrels left in there.

He gathered up the cooked squirrels and gave the old people, bull frog women who sat in the houses making tule baskets, one each.

He told the bull frog women to take care of all the squirrels while he was gone. 
Then he went to Scotts Valley. There was the only brush there was.

He told them 'Don't you take any of them because I will see you fellows from there.'

He went after sticks to make a willow house to put the cooked squirrels away. He got the willows and brought them along, and dropped them down hard by the squirrels and made a big noise and this startled the squirrels and they all jumped up and run away.

He said to the bull frog women ' $I$ told you to gather up the best ones and put them away. Why didn't you do it?'

So one of the bull frog women got sick because she ate too much squirrel and she died.

They burned the woman and she came back in four days.

Lark and Jay were there when she came back.

Lark said 'What is that that stinks so awful bad?'

Jay said 'You better hush up.' He had xáy-ba. lâw and shoveled fire on Lark.

Coyote said 'From now on I will make people come back in four days.' Then he thought again. 'No, I think that won't be good, I will make them die for good, never come back any more.' Lark said 'The people stink too much when they come back.' That's why Coyote made people not come back. There would be the same old people here all the time. There would never be any young ones born if they came back.

Coyote could make himself old, young, and woman or anything. This is called ma. rum?da.

Coyote went back to nóna.photi and commenced to work on Kelsey Creek, and made it the same day he got there. When he started to make the creek the fish followed right up. He said 'Now fish, don't be in a hurry about it,' and the fish went back. He made the creek clear up into the mountains and the fish didn't come up right away. (The fish come up there now.)

He made dam and trap out of brush. Not by cutting off the withers, he made it right on the bush. He couldn't pick it up because it was fast to the bush. He made a sk-mi. ce and made lots of them. There were lots of people there and he made two for each fellow.

He called: 'Potter Valley, Redwood Valley, Hopland, Yokaya,' etc. Everybody must bring beads and pay for fish. (This is a custom. Those called bring beads and pile up and the residents pile up fish to offset it. Captain of the residents divides the beads among his people and the captain of the visitors divides the fish among his people.) Coyote said 'We will have to go up to $x^{a_{k} h_{a}}$-yàw (Upper Lake) and see how the Captains there are going to do.'

Captain at $x^{a} k^{h_{a} \cdot y a w}$ was another Coyote. He said 'This is the last good time until next fish time (next year).' 


\section{APPENDIX B}

\section{DAUGHTER AND STEPDAUGHTER}

(From Russian Fairy Tales, collected by Aleksandr Afanas'ev, translated by Norbert Guterman, illustrated by Alexander Alexeiff. Copyright 1945 by Pantheon Books and renewed 1973 by Random House, Inc. Reprinted by permission of Pantheon Books, a Division of Random House, Inc.)

A widowed peasant with a daughter married a widow who also had a daughter; thus they each had a stepchild. The stepmother was envious and nagged the old man constantly, saying: 'Take your daughter to the woods, to a mud hut; there she will spin more.' What could the peasant do? He did as his wife told him, took his daughter to a mud hut, gave her a steel and flint and a bag of grits, and said: 'Here is fire for you, do not let it die out; cook your kasha, sit and spin, and keep the hut locked.' Night came. The girl heated the stove and cooked her kasha; from somewhere a little mouse came out and said: 'Maiden, maiden, give me a spoonful of kasha.' 'Oh, little mouse, cheer me in my loneliness, and I will give you more than one spoonful of kasha. I shall let you eat your fill of it.' The mouse ate his fill and left.

At night a bear broke into the hut and said: 'Now, girl, put out the light and let us play blindman's buff.' The mouse ran up the maiden's shoulder and whispered into her ear: 'Fear not, maiden. Say to him, "Very well, let us play." Then put out the light and crawl under the stove; I shall run about and ring the little bell.' So they did. The bear chased the little mouse but could not catch him; he began to roar and hurl logs of wood; he hurled and hurled them but did not hit his mark. He got tired and said: 'Ah, little girl, you're an expert player of blindman's buff. To reward you I shall send you a drove of horses and a cartful of goods tomorrow morning.'

Next morning the old man's wife said: 'Go, old man, visit your daughter, see how much she has spun since yesterday.' The old man went and his wife sat and waited for him to bring back his daughter's bones. Suddenly the dog began to bark: 'Bow-wow-wow, the daughter is coming, with her father driving a drove of horses and bringing a cartful of goods.' 'You're lying, dog! Those are her bones rattling and clattering in my husband's basket.' The gate creaked, the horses ran into the yard, and the stepmother beheld the father and daughter sitting on a cart laden with goods. The woman's eyes gleamed with greed. 'That's not very much,' she cried. 'Now take my daughter to the woods for the night. She will come home driving two droves of horses and bringing two cartfuls of goods.' 
The peasant took his wife's daughter to the mud hut and provided her also with food and fire. At nightfall she cooked gruel. The mouse came and asked her for some kasha. But she cried: 'Oh, you vermin!' And she hurled a spoon at him. The mouse ran away, Natasha gobbled up all the kasha by herself, and, having eaten, put out the light and lay down in a corner. At midnight the bear broke into the mud hut and said: 'Hey, where are you, little girl? Let's play blindman's buff.' The maiden did not answer, but her teeth rattled from fear. 'Ah, so there you are! Here's a little bell. Run, I will try to catch you.' She took the little bell, her hand trembled, the bell rang incessantly, and the mouse said: 'That wicked maiden will meet her death.'

Next morning the wife sent the old man to the woods, saying: 'Go now! My daughter will bring back two cartfuls of goods and drive two droves of horses.' The peasant went and his wife sat at the gate. The dog barked: 'Bow-wow-wow, the wife's daughter is coming, her bones are rattling in the basket, and the old man sits on an empty cart.' 'You're lying, dog! My daughter is driving herds and bringing full carts.' She looked up and there was the old man at the gate. He handed his wife a basket; she opened the basket, saw the bones, began to howl, and grew so angry that from grief and spite she died the next day. But the old man lived happily with his daughter all his life and took into his house a wealthy son-in-law.

\section{NOTES}

The research reported here has been supported by a National Institute of Mental Health grant MH22777-01 on 'Cultural Patterning of Information in Discourse'.

1. William Lessa (1966), motivated also by the problem of making available to Western readers a non-Western narrative in terms that would convey the experience a member of the society might have in hearing it, detailed information asserted and presupposed in a Ulithi narrative ten years ago, without, of course, using these labels.

2. S. A. Barrett (1933) published myths collected from speakers of three related, but mutually unintelligible languages--Eastern Pomo, Northern Pomo, and Central Pomo--of which 37 were collected from five speakers of Eastern Pomo (Myths 5, 11, 23, 26, 30, 31, 36, 42, $44,46,47,51,55,57,59,60,62,63,64,65,67,72,74,75,76$, $77,78,85,86,88,91,94,96,97,98,102,104)$. Eastern Pomo myths have also been published by deAngulo (1927, 1935), by deAngulo and Freeland (1928), by Koreber (1911:343-346), and by McLendon (1977). A. M. Halpern (Fieldnotes, 1939-1940) and McLendon (Fieldnotes, 1959-1976) have collected many more myths in Eastern Pomo which have not yet been published. 
3. Although performances of the same myth do not necessarily agree as to titles used in actual performance (cf. Hymes 1959 for the importance of such titles), for the purposes of this discussion, descriptive titles have been assigned on the basis of the agreement as to plot and protagonists which the various performances demonstrate.

4. Interestingly enough, Tedlock (1972b) discusses one type of Zuni narrative, the telapnaawe, which seems concretely located in real, named locations known to the Zuni. He has had the experience (similar to mine) of driving around Zuni territory and having the locations of certain telapnaawe events pointed out to him. The Zunis with whom he worked, however, expressed reservations about the truth of these telapnaawe which Tedlock interprets as indicating that they are regarded as fiction. Another interpretation also seems plausible. The Zuni responses be cites (such as 'When you are a kid you believe them, but then you grow up and realize they couldn't have happened') seem also interpretable as expressing the sense that the telapnaawe are supposed to represent reality, but individuals who are modern twentieth century Americans as well as Zuni are ambivalent when faced with the implications of a public avowal of belief in the truth of telapnaawe. This does not mean necessarily that they were not formerly regarded as true. In fact, the fact that their telling was restricted to winter and nighttime, the traditional time for telling myths in much of native North America (as well as among the Eastern Pomo) supports the interpretation that the telapnaawe are analogous to what are called myths elsewhere in North America and may formerly, at least, also have been held to be true.

5. Eugene Nida (personal communication) informs me that a similar association of salient ecological attributes of animal protagonists with salient sociological attributes occurs in Venda myths.

6. A number of scholars (Jacobs 1959, Hymes 1975a, 1975b, 1976, and Tedlock 1971, 1972a, 1972b) have proposed interesting ways of dealing with the communicative inadequacies of literal English translations of non-Western narratives. The identification of consistent patterns of narrative presuppositions and assertions proposed here is not an alternative to these, but rather a useful, possibly even essential, preliminary stage of analysis of non-Western narratives compatible with these approaches.

7. Samuel A. Barrett, 'Pomoan Field Notes, 1902-1904', deposited with the Archives of the Survey of California Indian Languages, Linguistics Department, University of California, Berkeley, California. All eastern Pomo forms in these two texts are given in the phonemic transcription of McLendon (1975).

8. Mr. Holder was reluctant to provide a performance of this myth, as he felt he did not remember it well, and only did so after 
much urging. All locational details are missing and Mr. Holder again commented when asked where the narrative began, 'They used to tell where it happened, but this one I don't know.' However, the extensive use of direct quotation is a characteristic mark of a well-formed performance, and he was able to recall not only the words, but the music of the Ground Squirrels' song teasing Coyote, and the humorous detail of Coyote's penis slipping from its binding and giving him away. Mr. Holder added that of course Old Man Coyote's penis was four feet long so it splattered a lot of coals when it slipped out--another narrative presupposition.

\section{REFERENCES}

Afanás'ev, A. No 1866-78. Naródnye rússkie skázki. [Partially translated into English as: Russian fairy tales collected by Aleksandr Afanás'ev. Translated by Norbert Guterman. 1945. New York: Raniom House.]

Barrett, S. A. 1933. Pomo myths. Public Museum of the City of Milwaukee, Bulletin 15.

Berndt, Ronald M., and Catherine Berndt. 1953. A selection of children's songs from Ooldea, western South Australia. Mankind 4: 423-434.

Bickerton, D. 1975. Some assertions about presuppositions about prenominalization. Papers from the Parasession on Functionalism, Chicago Linguistic Society. 24-35.

Boas, F. 1916. Tsimshian mythology. Part II: Description of the Tsimshian based on their mythology. Thirty-first Annual Report of the Bureau of American Ethnology for the years 1909-1916. Washington, D. C.: Smithsonian Institution.

Boas, F. 1935. Kwakiutl culture as reflected in mythology. American Folk-lore Society, Memoir 28. New York: G. E. Stechert and $\mathrm{Co}$.

Bulmer, R. 1967. Why is the cassowary not a bird? A problem of zoological taxonomy among the Karam of the New Guinea highlands. Man, new series, 2: 5-25.

Colby, B. N. 1973. A partial grammar of Eskimo folktales. American Anthropologist 75: 645-662.

deAngulo, J. 1927. ' Texte en langue 'Pomo' (Californie). Journal de la Société des Americanistes de Paris 19:129-144.

deAngulo, J. 1935. Pomo creation myth. Journal of American Folklore 48: 203-262.

DeAngulo, J., and L. S. Freeland. 1928. Miwok and Pomo myths. Journal of American Folklore 41: 244-249.

Fillmore, C. 1970. Types of lexical information. In: Studies in syntax and semantics. Edited by F. Kiefer. Dordrecht: Reidel. 
Garfield, Viola. 1948. The wolf and the raven. Seattle: University of Washington Press.

Givon, T. 1974. Toward a discourse definition of syntax. UCLA manuscript.

Giv6n, T. 1976. Topic, pronoun and grammatical agreement. In: Subject and topic. Edited by Charles N. Li. Austin: University of Texas Press.

Grimes, J. 1975. The thread of discourse. The Hague: Mouton. Hess, J. 1972. The mythical Lévi-Strauss. New York Times Sunday Book Review, February 20.

Hymes, D. 1959. Myth and tale titles of the Lower Chinook. Journal of American Folklore 72:139-45.

Hymes, D. 1975a. Breakthrough into performance. In: Folklore and communication. Edited by D. Ben-Amos and K. S. Goldstein. The Hague: Mouton.

Hymes, D. 1975b. Folklore's nature and the sun's myth. Journal of American Folklore 88:345-369.

Hymes, D. 1976. Louis Simpson's The deserted boy. Poetics $5: 119-155$.

Ingles, L. G. 1965. Mammals of the Pacific states. Stanford, Calif.: Stanford University Press.

Jacobs, Melville. 1959. The style and content of an oral literature. Chicago: University of Chicago Press.

Kroeber, A. L. 1911. The languages of the coast of California, north of San Francisco. University of California Publications in American Archaeology and Ethnology 9:273-435.

Kuroda, S. -Y. 1975. Reflexions sur les fondements de la théorie de la narration. In: Langue, société, discours: pour Émile Benveniste. Edited by J. Kirsteva, J.-C. Milner, N. Ruwet. Paris: Aux éditions du Seuil. [This article was originally written in English, albeit for the Benveniste volume; circulated in English in a mimeographed version dated June 1973, and was published in English in: Pragmatics of language and literature. Edited by Teun A. van Dijk. Amsterdam: North-Holland, 1976.]

LaFarge, O. 1959. Foreword. In: The inland whale. By Theodora Kroeber. Berkeley and Los Angeles: University of California Press.

Lakoff, G. 1971. Presupposition and relative well-formedness. In: Semantics. Edited by D. Steinberg and L. Jakobovits. London and New York: Cambridge University Press.

Langendoen, D. T. 1971. Presupposition and assertion in the semantic analysis of nouns and verbs in English. In: Semantics. Edited by $D$. Steinberg and L. Jakobovits. London and New York: Cambridge University Press. 
Leach, E. 1964. Anthropological aspects of language: Animal categories and verbal abuse. In: New directions in the study of language. Edited by E. J. Lenneberg. Cambridge, Mass.: MIT Press.

Lee, R. B. 1968. What hunters do for a living, or how to make out on scarce resources. In: Man the hunter. Edited by R. B. Lee and I. De Vore. Chicago: Aldine.

Lessa, W. 1966. 'Discoverer-of-the-sun': Mythology as a reflection of culture. In: The anthropologist looks at myth. Edited by M. Jacobs and J. Greenway. Journal of American Folklore 79, \#311.

Levi-Strauss, C. 1958. La Geste d'Asdiwal. Annuaire, 1958-1959, Ecole pratique des hautes etudes. Section des sciences religieuses, Paris, 3-43. Reprinted in Les Temps Modernes, No. 179, March 1962. Translated into English as The story of Asdiwal. In: The structural study of myth and totemism. Edited by E. Leach.

London: Tavistock, 1968. Reprinted with a Postscript and a few modifications in: Structural anthropology II. By C. Levi-Strauss. New York: Basic Books, 1976.

Levi-Strauss, C. 1971. L'Homme Nu. Paris: Plon.

Levi-Strauss, C. 1972. Structuralism and ecology. Gildersleeve

Lecture delivered at Barnard College, New York, March 28.

Longacre, Robert A. 1968. Discourse, paragraph, sentence structure in selected Philippine languages, Vol. I. Santa Ana: SIL.

Longacre, Robert A. 1972. Hierarchy and universality of discourse constituents in New Guinea languages: Discussion. Washington, D. C.: Georgetown University Press.

McLendon, S. 1975. A grammar of Eastern Pomo. University of California Publications in Linguistics, Vol. 74. Berkeley and Los Angeles: University of California Press.

McLendon, S. 1977. Bear kills her own daughter-in-law, Deer. In: Northern California Texts. Edited by V. Golla and S. Silver. To appear in: IJAL Native American Texts Series, Vol. 2. Propp, V. 1968. Morphology of the folktale. Austin and London: University of Texas Press. [Originally published as: Morfologija skazki. Leningrad, 1928.]

Tambiah, S. J. 1969. Animals are good to think and good to prohibit. Ethnology 8:424-459.

Tedlock, D. 1968. The ethnography of tale-telling at Zuni. Ph.D. dissertation, Tulane. Ann Arbor, Mich.: University Microfilms.

Tedlock, D. 1971. On the translation of style in oral literature. Journal of American Folklore 84:114-133. [Reprinted in: Toward new perspectives in folklore. Edited by A. Paredes and R. Bauman. Austin: University of Texas Press.] 
Tedlock, D. 1972a. Finding the center: Narrative poetry of the Zuni Indians. New York; Dial.

Tedlock, D. 1972b. Pueblo literature style and verisimilitude. In: New perspectives on the Pueblo. Edited by A. Ortiz.

Albuquerque: University of New Mexico Press.

Toelken, Barre. 1969. The 'pretty languages' of Yellowman: Genre, mode, and texture in Navaho coyote narratives. Genre 2:211-235. [Reprinted in: Folklore genres. Edited by D. BenAmos.]

Wetmore, A. 1964. Song and garden birds of North America. Washington, D.C.: National Geographic Society. 

SOCIOCULTURAL KNOWLEDGE

IN CONVERSATIONAL INFERENCE

JOHN J. GUMPERZ

University of California, Berkeley

'Conversational inference', as I use the term, is the 'situated' or context-bound process of interpretation, by means of which participants in a conversation assess others' intentions, and on which they base their responses. Conversational inference is ultimately a semantic process, but it is distinguished from linguists' assignment of meaning to utterances or classification of speech acts, as well as from the social scientists' measurement of attitudes. Both conventional linguistic analysis and social science measurement involve the labeling of utterances by other utterances, more often than not after the fact. Conversational inference, by contrast, is part of the very act of conversing. One indirectly or implicitly illustrates one's understanding of what is said through verbal and nonverbal responses, by the way one builds on what one hears to participate in a conversation, rather than through talking about it in abstract terms. It follows that analysis of such processes requires different and perhaps more indirect methods of study which examine meaning as a function of the dynamic pattern of utterances and responses as they occur in conversation.

Recent studies of conversation from a variety of linguistic, psychological, anthropological, and sociological perspectives, have shed light upon a number of issues important to the study of conversational inference. It is generally agreed that grammatical knowledge is only one of several factors in the interpretation process. Aside from physical setting, participants' personal background knowledge, and their attitudes toward each other, sociocultural assumptions concerning role and status relationships, as well as social values associated with various message components, also play an important role. So 
far, however, treatment of such contextual factors has been primarily descriptive. The procedure has been to identify or list what can potentially affect interpretation. With rare exceptions, there have been no systematic attempts to show how social knowledge is used in situated interpretation. Yet we know that social presuppositions and attitudes change in the course of interaction, often without a change in extralinguistic context. Therefore, the social input to conversation is not entirely constant. Assumptions about role and status relationships vary as the conversation progresses, and these changes are signalled through speech itself (Gumperz and Cook-Gumperz 1976). The signals by which this is accomplished can be regarded as a metalanguage or a meta-signalling system. So far, however, we know very little about this metalanguage. In this paper I want to suggest at least the outlines of a theory which deals with the question of how social knowledge is stored in the mind, how it is retrieved from memory, and how it is integrated with grammatical knowledge in the act of conversing.

To put what I have to say in context, it is necessary to begin with a brief outline of some of the major research traditions that have dealt with social factors in speech, so that we can evaluate their contributions. The three traditions that have made significant inroads in this area are (1) the ethnography of speaking, (2) linguistic pragmatics, and (3) ethnomethodology, or the sociology of verbal interaction.

The first systematic treatment of the role of social knowledge in conversation can be found in the literature of the ethnography of speaking (Hymes 1962, Gumperz and Hymes 1972, Bauman and Scherzer 1975). One express goal of this work is, as Hymes puts it, 'to fill the gap between what is usually put into ethnography and what is usually put into grammar.' Ethnographers of speaking point out that there is a great lack of descriptive ethnographic information on the social norms of speaking, and therefore they have called for empirical cross-cultural research to fill this gap. The theoretical concepts developed in the ethnography of speaking are primarily intended to guide the search for descriptive data. Since traditional grammatical analysis does not provide sufficient information on actual patterns of language usage, ethnographers of speaking suggest concentration should be on what they call 'the means of speaking', that is, the totality of ways in which social meaning is expressed.

Among the most important of these 'means of speaking' is the concept of 'linguistic repertoire' as developed in recent work on speech communities, in which the language behavior of a community is described in terms of all varieties, dialects, or styles used in a particular socially defined population, and the constraints which govern the choice among them. Other means of speaking are the 'genres' or various art form in terms of which language is 
characterized, such as myths, epics, tales, narratives, or jokes, and their structural characteristics and communicative function. Also included are the various acts of speaking prevalent in a particular group ('act' is used here broadly, in Austin's sense, to suggest function such as questions, responses, etc.), and finally the 'frames' that serve as instructions on how to interpret a sequence, to distinguish between such acts as jokes, verbal games, and the like (Bauman and Scherzer 1975).

The means of speaking are put into practice and related to cultural norms in the performance of particular speech events. A speech event consists of a sequence of verbal acts bounded in time and space and performed by actors in a particular social group. Participation in such events is governed by norms of behavior specifying such things as who can take part, what the role relationships are, what role people are acting, what kind of content is admissible, in what order information is to be introduced, and what speech etiquette applies. To describe such events, the ethnographer uses anthropological methods of interviewing and participant observation to collect social information, while deriving linguistic data from grammatical analysis.

In a purely descriptive statement about communities, this combination of data collected by two different methods, one anthropological and the other linguistic, does not necessarily present a problem. However, in tackling the question of how people integrate social knowledge in interaction, this bipartite approach clearly is not sufficient; a single perspective is needed. Nevertheless, in spite of these limitations from the point of view of conversational inference, ethnographers of communication have collected highly valuable descriptive data, illustrating, for example, the enormous range of verbal resources available in various cultures, as well as many culturally specific ways that rules of speaking vary with context. But analysis has concentrated on the relatively formal named and bounded kinds of talk recognized by all concerned as distinct from everyday speaking. Furthermore, the sociological theory underlying ethnography of speaking is basically a structural-functionalist one which suggests that verbal behavior can be described in terms of discrete systems, consisting of analytically separate variables. The task of analysis, then, is to specify the interrelationship of such variables in particular cultures. The question of how cultural boundaries are to be defined is not dealt with, nor are the questions of how members themselves recognize that an event has taken place, how social inputs vary in the course of an interaction, and how the interpretation of specific messages is affected by social knowledge.

The effect of context and social knowledge on message interpretation is of primary concern in the second tradition of significance to conversational inference, that of linguistic pragmatics, which has 
developed in the last few years primarily as an outgrowth of the earlier work of generative semanticists. In contrast to the descriptive emphasis of the ethnography of speaking, pragmatics has been motivated primarily by a concern with abstract linguistic theory. In a sense it can be seen as an effort to give linguistic substance to the philosophers' notions of speech act and verbal games, growing out of the work of Wittgenstein (1953) and Austin (1965). The key here is Grice's definition of meaning (1957). Departing from the earlier logicians' concept of meaning as the relationship of words to things, Grice is concerned with meaning as it reflects conversationalists' communicative intent. Linguistic pragmaticists deal with what Searle (1973) calls speaker meaning rather than utterance meaning.

As in generative grammar, pragmatic analysis focuses on what conversationalists must know to identify a particular act as, for example, a question or an answer, or to distinguish between such acts as a suggestion and a request. In contrast to syntax oriented linguists, however, linguistic pragmaticists agree that identification of specific speech acts always implies presuppositions about social as well as grammatical knowledge. They have suggested various mechanisms to bring such social or contextual factors into the process of interpretation. Perhaps the most useful from the point of view of conversational inference is Fillmore's (1977) notion of culturally specific scenes which are part of the lexical meaning of sentence frames. For example, the English sentence $I$ went home last night differs from the German Ich bin gestern nach Hause gefahren. The English evokes a scene which is neutral with regard to means of locomotion, whereas in the German sentence, means of locomotion is partly specified. Fahren means 'go by vehicle'. Such lexical differences are not merely matters of sentence interpretation but have important implications for conversational inference. If somebody told me, Ich bin gestern nach Hause gefahren, I could not reply by asking, Did you walk? Conversational inference, then, is more than simply a matter of sentence decoding; it is also a matter of being able to produce an appropriate response, that is, following lines of thematic progression which take the form of linguistically and culturally sanctioned relationships between utterances. In other words, conversing is rather like collaborating in the production of a play, where each person's contribution is constrained by what the others can do and what the audience will accept.

Thematic progression and the grammatical means by which it is established have been treated in considerable detail in a pioneering study by Halliday and Hasan (1976). Although this treatment is very extensive, it deals almost entirely with grammatical devices seen from a structural point of view. The semantic implications of this 
process have not been explored. It is my hypothesis that in conversation, choice of lexical and grammatical forms triggers 'structures of expectation' (Tannen 1977) which are integrated into culturally specific notions of what lines of argument or thematic progressions are possible. Thus, a semantic notion of theme and thematic progression are important and will have to be integrated into any theory of conversational inference; however, semantics alone is not sufficient to account for the process of situated interpretation.

While linguistic pragmaticists have had a great deal to say about context and about the nature of what they call 'conversational rules' (Gordon and Lakoff 1973), actual research in this field has dealt primarily with single sentences or at best with brief utterance sequences, or with literary texts rather than with spoken conversation. There has been no attempt to account for the phenomenon of interspeaker coordination. Meaning in conversations is usually jointly produced. Furthermore, to the extent that linguistic pragmaticists refer to speakers' background knowledge, it is seen in purely cognitive, psychological terms, such as 'plans' or 'scripts' (Schank 1975), implying that speakers approach an interaction knowing what they want to say and how to say it. In other words, what is emphasized is the individual's ability to plan rather than how plans are modified and constrained by what can be made clear in a particular cultural context. Moreover, neither psychologists nor linguists have addressed themselves to the basic issue of how scripts and plans are accessed.

The first tradition to consider conversations as cooperative endeavors has been ethnomethodology, which focuses on sociological analysis of verbal interaction. The incentive for work in this tradition derives from the sociologists' attempts to find alternatives to the symbolic interactionists' measures of small group interaction, which relied on statistical counts of a priori categories of content. Such categories had repeatedly been criticized as having no demonstrable relationship to actual behavior. In a brilliant series of experiments, Harold Garfinkel $(1967,1972)$ demonstrates that social knowledge cannot be adequately characterized in the form of statistically countable abstract categories such as scalar ratings of role, status, or personality characteristics. He argues that social knowledge is revealed in the process of interaction itself, that is, interactants create their own social world by the way in which they behave. He then goes on to suggest that sociology should concentrate on describing the mechanisms by which this is done in what he calls 'naturally organized activities,' rather than staged experiments or interview elicitations.

Harvey Sacks and his collaborators (Sacks 1972, Garfinkel and Sacks 1970, Schegloff 1972, Sacks, Schegloff and Jefferson 1974, Turner 1974) were the first to focus systematically on conversation as the simplest instance of a naturally organized activity, and to 
attempt to study the process of conversational cooperation as a thing in itself without making any a priori assumptions about social and cultural background of participants. Rather than attempting to elicit context independent judgments of appropriateness, however, as most sociolinguists tend to do, Sacks concentrated on isolating the verbal strategies such as turn taking techniques (rules governing the change of speakers); tying phenomena (how speakers establish semantic relations between utterances); asides and side sequences; ways of controlling and channeling the course of an interaction through interjections; and ways of opening and closing conversations.

The ethnomethodologists' work in conversational analysis over the last few years has demonstrated beyond question that not only formally distinct speech events but all kinds of casual talk are rule-governed, and that the mechanisms which underlie speaker coordination can be studied empirically by examining recurrent strategies, responses they elicit, and ways in which they are modified as a result of those responses.

Many of the ethnomethodologists' findings are basic to the study of conversational inference. For example, they have shown that if a speaker is to make himself or herself understood, it is necessary to establish through talk the contextual condition that makes the desired interpretation possible. Thus, to end a conversation, one must lay the groundwork for an ending; otherwise, the ending is likely to be misunderstood. Or, to interpret an answer, one must be able to identify the question to which that answer related. To understand a pun, one must be able to reexamine and reinterpret something that was said earlier in an interaction. It is clear that we rely on all these phenomena in interpreting daily conversation, as, for example, in distinguishing when Come and see us is an invitation, and when it is a formulaic closing. These are the sorts of distinctions that are so troublesome for nonnative speakers of any language.

One of Sacks' key contributions to conversational analysis is his recognition that principles of conversational inferences are quite different from rules of grammar. Rather than 'rule', he uses the term 'maxim', which is reminiscent of Grice's (1973) notion of implicature, to suggest that interpretations take the form of preferences rather than obligatory rules. The point is that at the level of conversation, there are always many possible alternative interpretations, many more than exist at the level of sentence grammar. Choice among these is constrained by what the speaker intends to achieve in a particular interaction as well as by expectations about the other's reactions and assumptions. Yet once a particular interpretation has been chosen and accepted, the tendency is toward consistency; that is, to maintain the same interpretive strategy, until something occurs in the conversation to make the speaker aware that a change in 
strategy is indicated. Interpretations are thus negotiated rather than unilaterally conveyed.

To sum up, ethnomethodologists have gone a long way toward producing a theory which treats conversation as a cooperative endeavor, subject to systematic constraints. However, a number of important questions still remain to be answered. A social view of language such as the one ethnomethodologists advocate must be able to account for interspeaker difference, yet, so far, only the pan-cultural aspects of conversational control mechanisms have been dealt with. A sociolinguist needs to know how speakers use verbal skills to create contextual conditions that reflect particular culturally realistic scenes. Furthermore, how is speakers' grammatical and phonological knowledge employed in carrying out these strategies? For example, if regular speaker change is to take place, participants must be able to scan phrases to predict when an utterance is about to end. They must be able to distinguish between rhetorical pauses and turn-relinquishing pauses. Although speaker overlap is an integral part of interaction, conversational cooperation requires that speakers not be interrupted at random. To follow the thematic progression of an argument, moreover, and to make one's contribution relevant, one must be able to recognize culturally possible lines of reasoning. To account for all these phenomena, it is necessary to show how the ethnomethodologists' control mechanisms are integrated into other aspects of speakers' linguistic knowledge.

To this end, we will look at two examples of actual conversation, to illustrate the limitations of the three traditions so far discussed (the ethnography of communication, linguistic pragmatics, and ethnomethodology), and to suggest a way of utilizing the insights provided by these three traditions to build a more functional theory of conversational inference. We will analyze two short sequences which occurred in public situations. They are representative of a much larger body of data we have collected, both by chance, as in these examples, and in connection with systematic programs. The first interaction is one which any native speaker of English would be able to interpret. The second constitutes an interethnic encounter, and we will show how habitual conversational inferences led to a misinterpretation of intent.

The first incident occurred when I was sitting in an aisle seat on an airplane bound for Miami, Florida. I noticed two middle-aged women walking towards the rear of the plane. Suddenly, I heard from behind, 'Tickets, please! Tickets, please!' At first I was startled and began to wonder why someone would be asking for tickets so long after the start of the flight. Then one of the women smiled toward the other and said, 'I TOLD you to leave him at home'. I looked up and saw a man passing the two women, saying, 'STEP to the rear of the bus, please'。 
Americans will have no difficulty identifying this interchange as a joke, and hypothesizing that the three individuals concerned were probably traveling together and were perhaps tourists setting off on a pleasure trip. What we want to investigate is what linguistic knowledge forms the basis for such inferences, and to what extent this knowledge is culturally specific.

The initial utterance, 'Tickets, please', was repeated without pause and was spoken in higher than normal pitch, more than usual loudness, and staccato rhythm. For this reason it sounded like an announcement, or like a stock phrase associated with travel situations. My first inkling that what I heard was a joke came with the woman's statement to her friend, 'I TOLD you to leave him at home'. Although I had no way of knowing if the participants were looking at each other, the fact that the woman's statement was perfectly timed to follow the man's utterance was a cue that she was responding to him, even though her comment was addressed to a third party. Furthermore, the stress on told functioned to mark her statement as another stock utterance, contributing to the hypothesis that she and he were engaging in a similar activity. If the statement of the man or the woman had been uttered in normal pitch and conversational intonation, the connection between them might not have been clear. Only after I was able to hypothesize that the participants were joking, could I interpret their utterances. My hypothesis was then confirmed by the man's next statement, 'Step to the rear of the bus, please'. This was also uttered in announcement pitch, loudness, and intonation. In retrospect, we may note that both of the man's utterances were formulaic in nature, and thus culturally specific and context-bound. He was exploiting the association between walking down an aisle in a plane and the similar walk performed by a conductor on a train or a bus. In identifying the interaction as a joke, I was drawing on the same situational-association knowledge, as well as on my awareness of the likelihood of joking among travelers bound for Miami.

Thus, suprasegmental and other surface features of speech are crucial to understanding the nature of an interaction. Such features have been extensively discussed in the linguistic literature, but most treatments have dealt with the referential meaning of individual sentences. When seen in isolation, sentences can have many intonation and paralinguistic contours, without change in referential meaning. The prevalent view is that these features add expressive overtones to sentences. Moreover, the signs by which listeners recognize these overtones tend to be seen as language-independent. If, however, we look at conversational inference rather than referential meaning, we see that paralinguistic and intonation contours play an important role in the identification of interpretative frames. 
This identification of specific conversational exchanges as representative of socioculturally familiar activities is the crucial process I call 'contextualization'. It is the process by which we evaluate message meaning and sequencing patterns in relation to aspects of the surface structure of the message, called 'contextualization cues'. The linguistic basis for this matching procedure resides in 'cooccurrence expectations', which are learned in the course of previous interactive experience and form part of our habitual and instinctive linguistic knowledge. Cooccurrence expectations enable us to associate styles of speaking with contextual presuppositions. We regularly rely upon these matching processes in everyday conversation, but they are rarely talked about. In fact, they tend to be noticed only when things go wrong, and even then, the conclusions drawn are more likely to be about the other person's attitudes than about differences in linguistic conventions. Yet, as our next example shows, contextualization expectations are highly culturally specific; that is, they are dependent upon interactants' ethnic or communicative background.

The second incident $I$ am going to relate took place in London, England, on a bus driven by a West Indian driver/conductor. The bus was standing at a stop, and passengers were filing in. The driver announced periodically, 'Exact change, please', as London bus drivers often do. When passengers who had been standing close by either did not have money ready or tried to give him a large bill, the driver repeated, 'Exact change, please'. The second time around, he said 'please' with extra loudness, high pitch, and falling intonation, and he seemed to pause before 'please'. One passenger so addressed, as well as others following him, walked down the bus aisle exchanging angry looks and obviously annoyed, muttering, 'Why do these people have to be so rude and threatening about it ?' Was the bus driver really annoyed? Did he intend to be rude, or is the passengers' interpretation a case of cross-cultural misunderstanding?

To understand what happened here and why it happened, it is necessary to go into some more detail about the nature of contextualization cues and their function in conversation. The term 'contextualization cue' refers to any aspect of the surface form of utterances which, when mapped onto message content, can be shown to be functional in the signalling of interpretative frames. In the examples given in this paper, the cues are largely prosodic and paralinguistic, but many other signalling mechanisms can function as contextualization cues, including lexical or phonological choice; use of idiomatic or formulaic expressions such as greetings, openers, interjections, or frozen sequences; or code-switching (Gumperz 1976, Gumperz and CookGumperz 1976). In the present discussion, however, we concentrate on prosody (i.e. intonation and stress) and paralinguistics (pitch 
register, rhythm, loudness, etc.) since some aspects of these features are always involved in conversation.

A great deal of work has been done in recent years on matters of prosody and paralinguistics by acoustic phoneticians as well as such general linguists as Halliday (1967), Bolinger (1972), Crystal (1975), and Trim (1976). However, as I have pointed out, this work has so far dealt almost exclusively with isolated sentences. In what follows, we attempt to interpret these linguistic findings in relation to our notion of conversational inference. In other words, we try to show how prosody and paralinguistic cues function in signalling frames of interpretation.

Prosody consists of three basic signalling mechanisms (Smeall 1976): tone grouping; tonic or nucleus placement within a tone group; and tune, the direction of the tonal change which characterizes the nucleus. Paralinguistic features include, among others, pitch register, loudness, rhythm, and tempo, and apply to the tone group as a whole, rather than to parts thereof.

Among prosodic cues, tone grouping refers to the use of intonation and stress to chunk larger stretches of speech into separable bits of information that are to be processed as single units. Our example:

Exact change please //

could be uttered as a single chunk, as it was the first time the driver said it, or as two chunks:

Exact chạng / pleàse //

as he said it the second time. To treat please as a separate bit of information implies that it is worthy of separate attention. We recognize two types of tone group boundaries: minor tone group, $(/)$ which suggests that the preceding message portion is semantically related to others within a larger whole, and a major tone group, $(/ /)$ which suggests finality.

The second element of prosody, tonic or nucleus placement, refers to the selection of one or another of the stressed syllables in a tone group as the nucleus, or the part on which the tonal shift occurs. Nucleus placement is predictable in many types of sentences. Normally, it identifies that portion of the message that is to be regarded as new, as compared to what can be assumed to be shared or given (Chafe 1974). Note, however, that this is not merely a matter of syntax or lexicon but also a matter of culturally specific practice. If I say 
it is the object, paper, which is assumed to carry the new information. In

\section{I'm cancelling my paper //}

the verb is normally stressed, since cancelling, in our culture, is not a customary activity in relation to paper giving.

The third prosodic mechanism, tune, refers to the falls and rises in tone such as are associated with the intonational contrast between questions and answers. We furthermore distinguish two levels on which the fall or rise can occur: high or low.

\section{please//}

pleàse//

A shift to high level generally calls special attention to the segments so marked; a shift to low level often indicates that an item of information is known or expected.

Note that in English, tune is also important in signalling thematic progression. It is used, for example, to show the distinction between dependent and independent clauses.

\section{Because I'm bussy/ I don't want to be interrupted//}

If busy were spoken with a fall rather than a rise, this sentence would sound odd.

Paralinguistic cues, finally, are the relative pitch level or loudness of an entire tone group, rather than part of the group as in nucleus placement, and the rhythm or tempo of the utterance. In English, these cues usually signal special discourse functions, such as distinctions in degree of formality; they can also mark quotes, interjections or asides, or indicate, for example, announcing style as in Tickets, please.

To be understood at all, all sentences must carry some kind of tone grouping, nucleus placement and tune. When these are in keeping with expectations based on content, no additional meanings are signalled. However, there are also certain optional uses of prosody to highlight unexpected information which function to suggest indirect inferences. For example, isolating an utterance segment as part of a separate tone group, as the bus driver did in my second example, assigns it special importance and invites the listener to infer the reason. Note, however, that in British as well as in American English, tone grouping options are constrained by pragmatic rules. Of the following examples, (1), (2), and (3) are all possible. 
(1) See that chair over there in the corner.//

(2) See that chair / Over there in the comer.//

(3) Put that chair over there in the corner.//

(4) Put that chair / Over there in the cormer.//

Example (4) seems odd, however, since over there is semantically a part of the predicate, rather than part of a separate adverbial complement.

Optional nucleus placement on an item which under ordinary conditions would count as given, is unexpected. The hearer's attempt to understand the speaker's motivation constitutes the conversational inference. The woman plane passenger in my first example uses this device in saying 'I told you to leave him at home' and, given our knowledge of similar situations and of the extralinguistic setting, we use this information to identify her utterance as formulaic.

Similarly, the use of high rise or fall when low rise or fall is expected can serve to signal special emphasis. I use the term 'normal information flow' to indicate uses of prosody which are expected and signal no indirect inferences. The term 'contrastiveness', on the other hand, refers to those cases where deviations from expected patterns are exploited conversationally.

Note that while short utterances need not show contrastiveness, longer utterances involving complex, connected discourse employ contrastiveness as an essential part of the signalling process. Only through contrastiveness can we scan utterances to determine the relative importance of various bits of information in longer messages. Matters of contrastive stress are treated to some extent in the literature on linguistic pragmatics. It has been pointed out that distinctions between sentences such as

Truman died//

versus

Johǹson died//

signal differences in the relative expectedness of the deaths. Similarly sentences such as Lakoff's example, John called Mary a virgin, and then she insulted him, are cited to show the role of presuppositions in sentence interpretation. What has not been discussed, however, is the way in which tune and other prosodic features are used to suggest how utterances are to be integrated into larger stretches of discourse. 
Note, for example, the following sentence.

Because I'm reading this paper/I can't go to the movies.//

In the example, the word paper normally carries a low/rise tune indicating that the dependent clause (starting with because) precedes the main clause. Falling intonation on paper would be perceived as odd, and a speaker using such intonation would be thought at best to lack fluency. Yet, when the dependent clause follows the main clause, as in

I can't go to the movies/ because $\mathrm{Pm}$ reading this paper//

the first clause can end in either rising or falling intonation. Thus, it is the prosody which permits integration of the two statements, although semantic and syntactic information is crucial as well.

In contrast to prosody, paralinguistic cues are somewhat more optional in English. Nevertheless, they are a regular feature of everyday conversation. In fact, as already suggested, they are our primary means of distinguishing various degrees of formality of talk and degrees of interspeaker involvement, of signaling topic changes, and distinguishing between asides and main parts of the argument. In our first example, the paralinguistic cues enabled us to identify Tickets, please as an announcement.

Let us now return to the second example.

Exact change, please.

As previously noted, the West Indian bus driver said this sentence twice, using different contextualization cues in each case. A speaker of British English in repeating this utterance, could optionally (a) place the nucleus on change or (b) split the sentence into two tone groups with two nuclei: change and please. In (a), the normal interpretation would be, 'I said, "change".' In (b), the separation of please would emphasize that word and call attention to the fact that a request has been made. Note that in (b) please must carry rising tune, to suggest tentativeness and avoid excessive directness, which would seem rude. The bus driver in our example said please with falling intonation as well as increased pitch and loudness. Hence, for speakers using British English contextualization conventions, the conclusion of rudeness is natural.

In order to determine whether the interpretation of rudeness corresponds to West Indian contextualization conventions, we want to look at how prosodic and paralinguistic cues normally function in West Indian conversation. Examination of the contextualization 
conventions employed in our tapes of West Indian Londoners talking to each other, suggests that their use of prosody and paralinguistics is significantly different from that of British English or American English speakers. For example, syntactic constraints on the placement of tone group boundaries differ. West Indians can split a sentence into much smaller tone group units than British English speakers can. Furthermore, their use of rising tone to indicate intersentence connections is much more restricted. Moreover, once a tone group boundary has been established, nucleus placement within such a tone group must be on the last content word of that tone group, regardless of meaning. In contrast to other forms of English, therefore, nucleus placement is syntactically rather than semantically constrained. Finally, pitch and loudness differences serve as a major means of signalling contrastiveness rather than expressiveness. They are regularly used to indicate emphasis without any connotation of excitement or other emotional overtones. To give only one example, in the course of an ordinary, calm discussion, one speaker said,

He was selected/ MAINLY/ because he had a degree//.

The word mainly was separated by tone group boundaries and set off from the rest of the sentence by increased pitch and loudness. The context shows that the word mainly was used contrastively within a line of reasoning which argued that having practical experience was as important as formal education. Our conclusion is that the West Indian bus driver's Exact change / please // was his normal way of emphasizing the word please, corresponding to the British English option (b). Therefore, his intention was, if anything, to be polite.

To summarize, then, we conclude that conversational inference processes such as we have discussed involve several distinct elements. On the one hand is the perception of prosodic and paralinguistic cues. On the other is the problem of interpreting them. Interpretation in turn requires, first of all, judgments of expectedness and then a search for an interpretation that makes sense in terms of what we know and what we have perceived. We can never be certain of the ultimate meaning of any message, but by looking at systematic patterns in the relationship of perception of surface cues to interpretation, we can gather strong evidence for the social basis of contextualization conventions.

The linguistic character of contextualization cues is such that they are uninterpretable apart from concrete situations. In contrast to words or segmental morphemes which, although ultimately also context bound, can at least be discussed in isolation, listed in dictionaries and explained in grammars, contextualization cues are impossible to describe in abstract terms. The same sign may 
indicate normal information flow under some conditions and carry contrastive or expressive meanings under others. We are faced with a paradox. To decide on an interpretation, participants must first make a preliminary interpretation. That is, they listen to speech, form a hypothesis about what routine is being enacted, and then rely on social background knowledge and on cooccurrence expectations to evaluate what is intended and what attitudes are conveyed.

One final question then remains: what is the nature of these routines and how do we integrate utterances into them? It would be tempting to say that a simple process of matching sentence content with contextualization cues leads to the identification of culturally specific, time-bounded speech events, in the sense that this word has been used by ethnographers of communication. But this is too simplistic; it does not account for the fact that the social inputs change as interaction progresses, that interpretations are multiply embedded, and that, as Goffman (1974) has shown, several quite different interactions are often carried on at the same time. To be sure, conversations are indeed anchored in time and space, and interpretation of sentences is to some extent a function of their location within these parameters, and we want to account for time-bounded conversational sequences. We use the term 'scene' for this purpose. Yet in addition, we also need a semantic concept closer perhaps to Frake (1972) and Agar's (1974) use of the term 'event' to account for the perception of thematic connections between elements of one or several scenes. For this purpose, we use the term 'speech activities' (Cook-Gumperz 1977).

The best way of characterizing what I mean by 'speech activities' is to name some, using descriptive phrases such as 'discussing politics', 'chatting about the weather', 'trying to catch someone's attention', and 'lecturing about linguistics'. Such descriptions imply certain expectations about the thematic progression, turn-taking rules, form, and outcome of the interaction, as well as constraints on content. In the activity of discussing, we look for semantic relationships between subsequent utterances, and topic change is constrained. In the activity of chatting, topics change freely, and no such expectations hold. Lecturing, in turn, implies clear role separation between speaker and audience, and strong limitations on who can talk and what questions can be asked.

In a sense, speech activities function a bit like the psychologists' 'plans' or 'scripts'. Note, however, that the descriptive phrases we use contain both a verb and a noun, which suggests constraints on content. Verbs alone, or single nouns such as 'discussion', or 'lecture', are not sufficient to characterize activities. Activities are not bounded and labelable entities; rather they function as guidelines for interpretation which show certain general similarities when considered 
in the abstract but vary in detail from instance to instance. One should not expect ever to be able to find a limited set of speech activities. Moreover, labels used in speech are not necessarily identical with the speech activity enacted. For example, if I say 'Step in my office; I'd like to have a chat with you', no speaker of American English would infer that the activity to follow is 'chatting'.

Although speech activities are thus not precisely labelable or listable, they are the means through which social knowledge is stored in the form of constraints on action and on possible interpretation. In verbal interaction social knowledge is retrieved through cooccurrence expectations of the type we have discussed. Distinctions among such activities as chatting, discussing, taking part in religious rituals, exist in all cultures; but each culture has its own constraints, not only on content but also on the ways in which particular activities are carried out and signalled. Even within a culture, what one person would identify as 'lecturing', another might interpret as 'chatting with one's child', and so on.

Since speech activities are realized in action and since their identification is a function of ethnic and communicative background, special problems arise because modern society is made up of people of widely varying communicative and cultural background. How can we be certain that our interpretation of the activity being signalled is the same as the activity that the interlocutor has in mind, if our communicative backgrounds are not identical? It is in this connection that we need to review a fourth research tradition concerned with small group interaction, the studies of nonverbal behavior which have concentrated on what is called 'conversational synchrony' or gestural and kinesic signals of conversational cooperation.

In contrast to linguists' emphasis on speech production as an individual skill, students of nonverbal behavior have long recognized the double roles of 'speakership' and 'listenership' in conversation. Researchers such as Condon (1969), Kendon et al. (1975), and Byers (1972) have all pointed out that the maintenance of conversation is crucially dependent on the speakers' and listeners' abilities to establish a rhythmic interchange of speakership and listenership signals through gaze direction, posture, head nods, eye blinks, and so on.

Erickson, building on the work just cited, has shown in a pioneering series of studies $(1973,1976)$ of natural interaction, that the ability to establish and maintain this rhythm is directly related to participants' ethnic and communicative background. Erickson filmed a series of counseling interviews where junior college students were advised on course programs and career prospects by counselors of varying ethnic backgrounds. He showed that rhythmic coordination was most easily achieved when counselor and student shared the same background. Moreover, the amount of usable information conveyed 
was a direct correlation of the speakers' ability to establish such a rhythm. Thus, a student of Italian background was able to get most information from a counselor of Italian background; when the student's background was Polish and the counselor was Italian, coordination was less easily achieved and less information was communicated. The interviews were least successful when students and counselors were of widely different backgrounds, such as white and black, or black and Mexican.

In the spirit of this work, I would like to suggest that the signaling of speech activities is not a matter of unilateral action but rather of speaker/listener coordination involving rhythmic interchange of both verbal and nonverbal signs. In other words, a successful interaction begins with each speaker talking in a certain mode, using certain contextualization cues. Then participants, by the verbal style in which they respond and the listenership cues they produce, implicitly signal their agreement or disag reement; thus they 'tune into' the other's way of speaking. Once this has been done, and once a conversational rhythm has been established, both participants can reasonably assume that they have successfully negotiated a frame of interpretation; that is, they have agreed on what activity is being enacted and how it is to be conducted. At this point, a principle of strategic consistency takes over. Speakers continue in the same mode, assigning negotiated meanings to contextualization cues, until there is a perceptible break in rhythm, a shift of content and cues, or until a mismatch between content and cues suggests that something has gone wrong.

It is clear, looking at conversation in this way, that if conversational inference is a function of identification of speech activities, and if speech activities are signalled by culturally specific linguistic signs, then the ability to maintain, control, and evaluate conversation is a function of communicative and ethnic background.

Speaking the same language, in the sense in which that term is understood by linguists, may be enough for short task-oriented instrumental exchanges; but to create conversational involvement and to evaluate intent in longer exchanges, a much greater degree of shared knowledge is necessary. What this knowledge is, and how it is acquired and used either to create social ties or to maintain social distance, has hitherto been one of the major unsolved problems of modern sociolinguistics.

Conclusion. I have suggested a perspective that integrates linguistic and sociological approaches to conversation, focusing on conversational inference and on participants' use of perceptions and interpretive preferences learned through previous communicative experience to negotiate frames of interpretation. Using this perspective, it is possible to account both for shared grammatical knowledge 
and for differences in communicative style and knowledge that characterize our modern, culturally diverse societies.

This approach to speaking has both theoretical and practical significance. On the theoretical level, it suggests a way of carrying out Garfinkel's program for studying naturally organized activities through language without relying on a priori and generally untestable assumptions about what is or is not culturally appropriate. Although it might seem at first glance that contextualization cues are surface phenomena, their systematic analysis can lay the foundation for research strategies to gain insights into otherwise inaccessible symbolic processes of interpretation.

On the practical level, the study of conversational inference may lead to an explanation for the endemic and increasingly serious problems that affect private and public affairs in our society. To illustrate such applications, I end with an example from recent field work on interethnic communication.

In a staff cafeteria at a major London airport, newly hired Indian and Pakistani women were perceived as surly and uncooperative by their supervisors, as well as by the cargo handlers whom they served. Observation revealed that while relatively few words were exchanged, the intonation and manner in which these words were pronounced were interpreted negatively. For example, a person who had chosen meat would have to be asked whether he wanted gravy. A British attendant would ask by saying, Gravy? using rising intonation. The Indian women, on the other hand, would say the word using falling intonation: Gravy. We taped relevant sequences, including interchanges like these, and asked the employees to paraphrase what was meant in each case. At first, the Indian workers saw no difference. However, the English teacher and the supervisor could point out that Gravy, said with a falling intonation, means 'This is gravy', and is not interpreted as an offer but rather as an announcement. When the Indian women heard this, they began to understand the reactions they had been getting all along which had until then seemed incomprehensible. They then spontaneously recalled intonation patterns which had seemed strange to them when spoken by native English speakers. At the same time, supervisors learned that the Indian women's falling intonation was their normal way of asking questions in that situation, and that no rudeness or indifference was intended.

After several discussion/teaching sessions of this sort, both the teacher and the supervisor reported a distinct improvement in the attitude of the Indian workers toward their work and toward their customers. It seemed that the Indian workers had long sensed they had been misunderstood but, having no way of talking about this in objective terms, they had felt they were being discriminated against. We had not taught the cafeteria workers to speak appropriate English; 
rather, by discussing the results of our analysis in mixed sessions and focusing on context-bound interpretive preferences rather than on attitudes and stereotypes, we had suggested a strategy for selfdiagnosis of communication difficulties. In short, they regained confidence in their own innate ability to learn.

\section{NOTE}

Work on this paper was supported in part by NIMH grant MH26831-03. Many of the ideas expressed here were developed in discussion with Jenny Cook-Gumperz. I am grateful to Denise Gubbay and other staff members of the National Center for Industrial Language Training, Southall, Middlesex, England, for cooperation in field work and for sharing with me their many insights into problems of interethnic communication. Deborah Tannen assisted in the preparation and organization of the manuscript and provided many helpful suggestions.

\section{REFERENCES}

Agar, Michael. 1975. Cognition and events. In: Sociocultural dimensions of language use. Edited by M. Sanchez and B. Blount. New York: Academic Press.

Austin, J. L. 1965. How to do things with words. New York: Oxford University Press.

Bauman, R., and J. Scherzer, eds. 1975. The ethnography of speaking. In: Annual Review of Anthropology. Stanford, Calif.: Stanford University Press.

Bolinger, D. L., ed. 1972. Intonation. Harmondsworth, England: Penguin.

Byers, Paul, and Happie Byers. 1972. Nonverbal communication and the education of children. In: Functions of language in the classroom. Edited by Courtney B. Cazden, Vera P. John, and Dell Hymes. New York: Teachers College Press.

Chafe, W. 1974. Language and consciousness. Lg. 50:111-33. Condon, John C., Jr. 1969. Semantics and communication. New York: Macmillan.

Cook-Gumperz, J. 1977. Naturally organized activities. Typescript.

Crystal, D. 1975. The English tone of voice. London: Edward Arnold.

Erickson, Frederick, et al. 1973. Interethnic relations in urban institutional settings. Final technical report for the Center for Studies of Metropolitan Problems. Rockville, Md.: National Institute of Mental Health. 
Erickson, Frederick. 1976. Gatekeeping encounters: A social selection process. In: Anthropology and the public interest. Edited by P. Sanday. New York: Academic Press. 111-145. Fillmore, C. 1977. The case for case reopened. In: Syntax and semantics, Vol. 8. Edited by P. Cole and J. Sadock. New York: Academic Press.

Frake, C. 1972. Struck by speech, the Yakan concept of litigation. In: Directions in sociolinguistics. Edited by J. Gumperz and D. Hymes. New York: Holt, Rinehart and Winston.

Garfinkel, H. 1967. Studies in ethnomethodology. Englewood Cliffs, N. J.: Prentice-Hall.

Garfinkel, H. 1972. Studies of the routine grounds of everyday activities. In: Studies in social interaction. Edited by D. Sudnow. New York: Free Press.

Garfinkel, H., and H. Sacks. 1970. On formal structures of practical actions. In: Theoretical sociology. Edited by J. C. McKinney and E. A. Tiryakian. New York: Appleton-Century-Crofts.

Goffman, E. 1974. Frame analysis. New York Harper and Row. Gordon, D., and G. Lakoff. 1973. Conversational postulates. In: Syntax and semantics, Vol. 3. Edited by P. Cole and J. Morgan. New York: Academic Press.

Grice, H. P. 1957. Meaning. Philosophical Review 66:377-388. Grice, H. P. 1973. Logic and conversation. In: Syntax and semantics, Vol. 3. Edited by P. Cole and J. Morgan. New York: Academic Press.

Gumperz, Jo 1976. Language communication and public negotiation. In: Anthropology and the public interest. Edited by P. Sanday. New York: Academic Press.

Gumperz, J., and J. Cook-Gumperz. 1976. Papers on language and context. Working Papers No. 46, Language Behavior Research Laboratory, University of California, Berkeley.

Gumperz, J., and D. Hymes. 1972. Directions in sociolinguistics. New Yorks Holt, Rinehart and Winston.

Halliday, M. A. K. 1967. Intonation and grammar in British English. The Hague: Mouton.

Halliday, M. A. K., and Hasan, R. 1976. Cohesion in English. London: Longman.

Hymes, D. 1962. The ethnography of speaking. In: Anthropology and human behavior. Edited by T. Gladwin and W. C. Sturtevant. Washington, D.C.: Anthropological Society of Washington. 13-53. Kendon, Adam, Richard M. Harris, and Mary Ritchie Key, eds. 1975. Organization of behavior in face-to-face interaction. The Hague: Mouton. 
Sacks, H., E. Schegloff, and G. Jefferson. 1974. A simplest systematics for the organization of turn-taking for conversation. Lg. 50:696-735.

Schank, R. C. 1975. The structure of episodes in memory. In: Representation and understanding. Edited by D. G. Bobrow and A. Collins. New York: Academic Press.

Schegloff, E. 1972. Notes on a conversational practice: Formulating place. In: Studies in social interaction. Edited by D. Sudnow. New York: Free Press.

Searle, J. 1973. Indirect speech acts. In: Syntax and semantics, Vol. 3. Edited by P. Cole and J. Morgan. New York: Academic Press.

Smeall, C. 1976. Syntax and intonation. Typescript, University of California.

Tannen, D. 1977. Well what did you expect? Berkeley Studies in Syntax and Semantics, Vol. 3. Berkeley: University of California Press.

Trim, J. 1976. English intonation. Typescript, Department of Linguistics, Cambridge University.

Turner, R. 1974. Ethnomethodology. Harmondsworth, England: Penguin.

Wittgenstein, L. 1953. Philosophical investigations. New York and London: Macmillan. 

TRANSLATING MEANS COMMUNICATING:

A SOCIOLINGUISTIC THEORY OF TRANSLATION

\section{EUGENE A. NIDA}

\section{American Bible Society}

A missionary who lived with a group of Amazonian Indians, for whom great prestige was associated with raiding and killing members of enemy clans, endeavored to find the right word for 'good', to be used in talking about the Gospel as 'Good News'. To elicit an adequate term for 'good', he explained that it should be one characteristic of an event bringing great happiness to a person.

Finally, the missionary concluded that his informants had given him the right term, and so he began to use it. But it was not long before someone asked the Indians just when they would use such a word--what would they think of when they heard such a word? Then came the astonishing reply. 'Oh', the Indians said, 'when in raiding a village, we are lying in ambush in the nearby jungle and spy an enemy coming along the path, we silently draw our bows. The moment comes when we know that with the release of the arrows we are certain to kill the man; then is when we feel real happy--then is when we use that word'.

The missionary's basic problem might be described as a lack of a satisfactory sociolinguistic theory of translating; for the meaning of any word or discourse can be adequately determined only on the basis of the total set of communication contexts in which it may occur.

The variety of factors involved in translation. Four basically different types of factors are involved in translation: (1) the message, (2) the audience, (3) the circumstances in which translation takes place, and (4) the circumstances in which the message is received.

The message can be as varied in form as are the different discourse structures; for example, scientific papers, how-to-do-it 
instructions, business correspondence, textbooks, commercial slogans, literary essays, letters (personal, business, letters to the editor), conversation, short stories, novels, lyric poetry, didactic poetry, epic poetry, songs, opera, folktales. The tendency is to range such different types of discourse (often spoken of as 'literary genres') into a continuum based on the degree of formal adaptation necessary to produce satisfactory results (Levy 1969). In reality, however, a single continuum is not enough, for a number of different sets of discourses must be treated, reflecting varying degrees of required restructuring.

Audiences likewise vary greatly. For example, the translation of a folktale may differ appreciably, depending upon whether it is being prepared for linguists, anthropologists, or the general public. Translations of legal codes made for lawyers are generally quite different from those prepared for the average citizen. Likewise, translations of the Bible differ radically, depending upon whether the text is being prepared for (1) educated adults, (2) adults with limited education, (3) educated adolescents, (4) new readers who are adults, (5) new readers who are adolescents, (6) the deaf, or (7) those who have some measure of mental deficiency. But in addition to the factors involving levels of education or communicative alertness, the expectations people have as to what a translation should be must be considered. Some persons, for example, insist that only a literal translation is an accurate one, while others reject literal translations as awkward, old-fashioned, and largely misleading.

The circumstances of translating also affect the form of the translation. A secretary who must dash off a translation of a rush business letter is not expected to give it the same attention as a translator commissioned to produce a translated version of a book of lyric poetry. And a person who must translate a speech, either sequentially (sentence by sentence or phrase by phrase) or simultaneously (with electronic apparatus) to a listening audience will produce a message with quite a different form from the one that would result if he had time to write it out carefully in the quiet of his study, surrounded by his reference dictionaries and encyclopedias. In fact, most discussions of interlingual communication make a radical distinction between translating and interpreting, but essentially the same basic principles are applicable, and any unified theory of interlingual communication must take into consideration the essential similarities as well as the differences.

The circumstances involving the receptors of a translation also influence the form. The translation of a play to be read in the quiet of one's home can be very different from the same play being prepared for production on the stage. Unless the theater audience 
catches the point of repartee immediately, the entire episode will fall flat. The audience has neither opportunity to glance at footnotes nor time to think about subtle nuances based on cognate etymologies. A serious difficulty with many traditional Bible translations is the fact that translators have not realized that more people hear the text read than ever read it for themselves. In 1 Chronicles 25.1, the phrase which reads in the Revised Standard Version 'prophesy with lyres' is heard by audiences as 'prophesy with liars', for a lyre as a musical instrument is now a cultural rarity, while liars who prophesy are in oversupply.

Traditional emphases in analyses of translation. In general, traditional treatments of translation have focused upon two aspects of the process: (1) the intent of the author, often treated largely in psychological terms, and (2) the form of the message. Emphasis upon the author's intent is generally stated in terms of what the author must have been thinking when he wrote such-and-such a word or phrase. If the author is still living, a translator may be able to consult him and try to determine just what he had in mind. But many authors are honest enough to admit that they themselves are not always sure, especially when they review articles written some years before. In fact, most highly creative persons are subject to many influences, of some of which they are usually unaware; hence it is frequently quite impossible for an author to reconstruct what he had in mind or what may have influenced his thinking. It is therefore even more hazardous for the literary critic than for the translator to be dogmatic about what an author must have meant, and why he used certain expressions.

The form of a message is a clear focus of attention in most discussions of translation problems, especially in poetry, where matters of rhyme, rhythm, number of feet, thematic parallelism, antithesis, and chiasm all figure prominently in any attempt at formal correspondence. For prose, the problems of closed or open sentence structure, depth of embedding, lexical registers, and extent of figurative language are crucial issues if the translator is to produce anything like a satisfactory equivalence in a receptor language.

Unfortunately, however, these traditional areas of emphasis almost completely overlook the communicative aspect of the resulting translation. If the role of the receptors is considered at all, it is normally in terms of so-called 'ideal receptors', who are presumably able to appreciate all the subtleties of the translator's art, since they are regarded, though erroneously, as already aware of the form of the source text. Such an approach to translation is obscurantist, for rarely if ever are there ideal receptors. There is no point in making a translation apart from a situation involving real interlingual 
communication and if this is so, then the capacities, attitudes, presuppositions, and potential responses of receptors must be carefully studied.

Traditional approaches to the problems of translation. Traditional approaches to the problems of translation are of two types: philological and (2) linguistic. Philological approaches to the difficulties encountered by translators have emphasized primarily differences in style characteristic of diverse literary genres. Philological theories of translation (e.g. Belloc 1931, Brower 1947, Cary 1956, Goethe 1827, Nabokov 1955, Pasternak 1958, Tytler 1790) have been concerned mostly with so-called literary texts (though there are wide differences of opinion as to what constitutes 'literature'); and the emphases have been on (a) the source of the thematic and formal features of the text, and their later influence upon other literary productions, (b) the stylistic peculiarities of the author, and (c) the thematic structure.

Usually, the principles of translation have been stated in terms of very general rules (e.g. Campbell 1789, Pope 1715, Savory 1957), followed by a series of 'exceptions' applicable to particular types of literary genres. Such series of rules have often been helpful in teaching the skill of translation, and various institutes designed to train translators and interpreters have been rather successful in turning out competent interlingual technicians. Usually, however, such philological approaches to translation have been restricted to statements about what the translator should do. Rarely, if ever, have they attempted to state why a particular procedure or principle should be followed.

Linguistic approaches to translation have generally been broader in their orientation, even as linguistics has traditionally had a larger view of language and communication than philology has had. Linguistic theories of translation (Catford 1965, Chao 1964, Jakobson 1959, Neubert 1973) have usually been based, directly or indirectly, upon some model of communication. They have been concerned with levels of language (registers), types of correspondence, equivalence of language categories, and rules for transfer and restructuring. But in general, the linguistic orientation has paid little attention to either the author or the receptors. The documents in question have been treated essentially as objects in and of themselves, more or less unrelated to actual communication events.

Since both philological and linguistic approaches to translation have tended to overlook, or at least to downgrade, the significance of translation as an act of communication, Nida (1964) and later Nida and Taber (1969) tried to focus attention upon the role of the receptors. This approach involves, for one thing, the change of traditional 
terminology from 'target' to 'receptor'. The receptors, those who must decode and understand the message, are not primarily a target at which the translator aims, but an integral element in the communication process. The capacities, interest, and presuppositions of the receptors are primarily responsible for the success or failure of any translation, and they largely determine the formal features any satisfactory translation must possess.

A sociolinguistic theory of translation in relation to the functions of language. The principal focus of a sociolinguistic theory of translation is 'translation as an act of communication'. This focus necessarily implies the analysis of the source discourse as an act of communication: who said what, to whom, under what circumstances, for what reasons, and for what purpose.

Every discourse has a function, and the discourse cannot be satisfactorily understood apart from an analysis of the function or functions which characterize the communication. Of this communication the discourse is an integral part, but not the whole. The discourse serves essentially as the instrumental link between the source and the receptor (or receptors), and it must always be understood as subordinate to the larger context of the communication.

The five basic functions of communication are: (1) expressive, in which the focus is upon the source; (2) informative, in which the purpose is to influence the cognitive state of the receptor; (3) imperative, which aims to effect a behavioral response on the part of the receptor; (4) emotive, which seeks to produce an emotive reaction, whether pleasurable or painful, in the receptor; and (5) phatic, which serves primarily to link source and receptor, by means of a minimum of transfer of content. However, these five functions of language are more complex than is generally assumed, and most communications involve a combination of functions. The so-called 'poetic function' of language, as described by Jakobson (1959), is perhaps better treated as a formal aspect of language by which certain basic functions of language are effectively realized. The more evident and specialized features of the 'poetic function' are described later in this article as 'rhetorical devices'.

The expressive function of language relates primarily to the source, but there are three principal aspects of this function. In the first aspect, traditionally spoken of as the 'lyric' form of expression, neither the content of the discourse nor the receptors are particularly significant. This kind of language is characteristic of singing in the shower. The lyric poet often writes without regard to any real or potential audience. However, one should not conclude that all lyric poems constitute examples of the lyric function of language. 
In the second aspect of the expressive function of language, which may be regarded as 'reflexive', the source calls attention to himself by means of a discourse which impresses receptors with certain qualities of the source, while transmitting a minimum of content. Academic prose, as well as preaching and political oratory, are often calculated to have precisely such an effect. The purpose in each example may be described as 'making a maximally favorable impression by a minimum of content'. In this type of discourse rhetorical devices are what count, whether they consist of spread-eagle oratory or academic gobbledegook.

The third aspect of the expressive function of language is characterized by a high degree of personal involvement of the source in the content. Such a discourse is normally heavily modal, for the source's personal involvement and interpretation of events are constantly in focus. The themes of such discourses are generally personal experiences, and many sources have little or no concern for the receptors. They will talk to anyone who will listen, for the basic function of such a communication is not to influence the thought or behavior of the receptors, but to provide an opportunity for the source to 'unload his feelings' about some experience which rates high on the scale of his emotion.

The informative function of language, in which the principal purpose is to increase the cognitive state of receptors, consists of two different types of discourses: (1) those in which the thematic content is in focus and (2) those in which the form of the message is emphasized. The first type of informative discourse is by far the more common, but the second type must also be considered. For example, there are poets who have minimal interest in thematic content, but who are keenly interested in formal relations. Whether a poem makes sense is secondary; what counts are the formal relations of such features as sound, rhythm, and format. Some Bible translations belong to this same type of informative function, for both source and receptors may be primarily concerned not with the message, but with the arrangement of words, correspondences in morphological classes, and word-for-word concordance of lexical items. Some persons even contend that such formal features in and of themselves are the key to mystic, metaphysical communication.

The imperative function of language may involve direct commands or it may take the form of intense advocacy. In either case, the purpose is to influence the overt behavior of the receptor. A high percentage of languages possess special grammatical forms to signal precisely such a function.

The emotive function of language involves a wide spectrum of receptor response (e.g. pleasure, humor, contentment, boredom, irritation, pain), and a number of devices may be employed to 
produce the intended results. In general, thematic content is regarded as the primary means of influencing a receptor's emotive responses, but such rhetorical devices and accompanying extralinguistic and paralinguistic features as gestures, grimaces, and voice quality are probably even more important. Some discourse structures, e.g. the joke and humorous repartee, are specifically designed to elicit emotive reactions.

The phatic function of language, defined as sharing feelings rather than communicating ideas, is designed to link the source and receptor in a largely reciprocal relation. Formalized greetings are an especially important part of phatic communication, in which thematic content is either minimal or intentionally overlooked. People will greet each other in English with Good morning! even when the weather is horrible, and they will say, How are you? when they normally do not want an explanation about the other's health. Interpreting greetings as anything other than phatic communication is a serious mistake in acculturation. Literal translations of formalized greetings can be especially misleading, for questions about a person's health are regarded in many cultures as indicative of evil intent, while comments about the weather seem utterly inane.

Idle conversation is also typical of the phatic function in communication. Such conversations are designed primarily to facilitate interpersonal contact, not to convey information. Similarly, the periodic verbal responses of yes or yes yes, with a neutral intonational contour, each ten or fifteen seconds in a telephone conversation, are not expressions of assent to what is being said, though they are often so interpreted by non-English-speaking persons, but serve only to confirm that one is still listening.

As already noted, in a high proportion of actual communications there are complex combinations of language functions. Personal identification with the message, a type of expressive function, may be closely linked with the imperative function. Thus, expressive lyric poetry may be designed to produce a pleasurable emotive response. Similarly, elaborate rhetorical flourishes, so typical of reflexive expressive language, may be combined with a purpose of producing an amusing emotive response.

In any actual communication event these various functions of language are realized by the content and form of the message and the paralinguistic features. In speech, the paralinguistic and extralinguistic features of voice quality so important in indicating irony, sloppiness of enunciation which is often purposeful, gestures, stance, and eye contact are extremely important. In fact, they are regularly judged by receptors as more important and relevant than the verbal content. Those who deal with written communication sometimes think they suffer from paralinguistic deprivation, because they 
lack so many useful accompaniments of oral language. However, a number of features of written language are equally relevant, e.g. orthographic correctness, clarity of format, appropriateness of stationery (love letters are normally not written on grocery sacks!), and handwriting. Even the color of ink may be interpreted as carrying meaning. But it must not bê assumed that conformity to traditional standards is most effective in communication. For example, well-printed Scripture selections prepared for university students in Argentina were rejected in favor of poorly mimeographed newsprint, which seemed to the students much more suitable for the revolutionary message of the Hebrew prophets. A somewhat parallel example occurred in the case of a Mexican Indian church leader who consistently presented his petitions to the government on schoolroom notebook paper, written with pencil, and containing his typical spelling errors. When asked why he did not get a lawyer to formulate his petition and have it typed up in proper form, he responded, 'When government officials see the way I have written, they know that I am an honest man.'

If, in translating, one wishes to produce the closest natural equivalent of the original discourse, one cannot be content merely to look at the page of text apart from the context of the original communication. Nor can one do justice to a text if one overlooks the effect that the form, the content, and the format of the message will have upon the receptors.

Features of language which serve to accomplish the various functions. The features of language which serve to accomplish its various functions can be conveniently divided between (1) routine and (2) rhetorical. The routine features are those which are generally not the result of conscious manipulation or esthetic refinement. In other words, they are not contrived. In contrast, the rhetorical features normally represent conscious effort, and are generally designed to increase impact, embellish the text, and make the form more consistent with the content or with the literary genre.

The two principal routine features of language of particular importance to the translator are (a) lexicon and (b) grammar. The choice of lexical units in the discourse is almost automatically determined by factors of content, receptors' capacities, and the circumstances of the communication.

In the selection of lexical units the content of a discourse must be considered in terms of: (1) the subject matter, e.g. science, religion, sports, news, politics, farming; (2) the usage of the participants quoted or referred to in the content, e.g. their geographical or sociological dialect; and (3) the temporal setting of the content, e.g. historical, present-day, and futuristic (as in some science-fiction 
writing). One of the extremely difficult problems for translators is to produce in a receptor language a corresponding geographical or sociological dialect. For example, how can one decide upon an appropriate 'hillbilly dialect' of Japanese, which will suggest rural background, homespun naiveté, and folksy honesty? Not all discourses dealing with historical events employ obsolete or archaic vocabulary, but a number of recently published stories with medieval setting do contain numerous archaic words, especially those which designate artifacts typical of the culture of those centuries.

But the content of a discourse is only one factor influencing the choice of vocabulary. Even more important are the capacities of the intended receptors. Precisely the same information may be communicated on a technical or nontechnical level, and the choice of a lexical register depends on the receptors for which a translation is being made. Their general educational level, degree of specialization in the subject matter, and willingness to decode the message are all important. A receptor may, for example, be capable of understanding a more or less technical discourse, but he may simply not be willing to expend the energy required to do so. On the other hand, a translation which seems to 'talk down' to its potential receptors may be rejected as paternalizing, and one that 'talks over the heads of its receptors' has little chance of success.

The willingness of receptors to decode a discourse depends largely upon the pressure of circumstances. If a receptor is convinced of the urgency of the content, he is likely to accept a relatively high level of language, or if he is a member of a captive audience, e.g. a student who must understand the contents of a badly translated textbook, he will normally make the necessary effort to decode it. In fact, captive audiences are probably the only reason why so many badly translated textbooks prove to be relatively acceptable. There is simply no alternative.

The fact of a captive audience is not merely a factor in the relative acceptability of translations; it is also a crucial element in the original production of texts. Specialists in a position to require the use of their own discourses, whether written or spoken, sometimes seem to be particularly reluctant to put forth the effort to make them interesting or readily understandable. Compare, for example, the stylistic form of the average textbook with the manner in which similar themes are treated in the Scientific American.

The relationship of subject matter to grammar must be understood in terms not of completely different types of grammatical structures, but of different frequencies and arrangements of such structures. Discourses on science, philosophy, and law are likely to reflect more or less complex grammatical structures, while those dealing with sports, romance, and news tend to be much less elaborate. 
So-called scientific writing is much more likely to employ nominalized verbs, passive constructions (in which agents need not be specified), elaborate embeddings, numerous parentheses, and relatively long sentences. On the other hand, sports writing is characterized by a much higher proportion of verbs as designations of events, overt marking of participants, and short, crisp sentences.

These differences in the frequency and arrangement of grammatical features are so 'normal' and accepted that one might wish to call them a part of the 'multivariant competence' of most users of a language. A shift of subject matter almost automatically triggers a change in the complexity of grammatical structures. To this extent the influence of subject matter upon grammatical usage may be regarded as essentially routine. On the other hand, one can also describe such differences of language 'register' as basically rhetorical, since professional competence in the use of such forms of language requires training or long exposure.

The types and frequencies of grammatical structures to be used in original discourses or in their translation should be determined largely by the capacity of receptors. For new readers, translated material should be very simple, consisting largely of kernel or near-kernel expressions. For specialists, one can employ highly complex structures, but languages differ appreciably in the extent to which certain types of complexities are generally acceptable, even to specialists. For example, the periodic sentences typical of academic German must generally be broken up or radically restructured if they are to be acceptable to an equally well-educated audience of Englishspeaking specialists.

As long as the text to be translated consists primarily of routine features of language, a translator encounters relatively few difficulties, for on the routine level of language the correspondences are more or less obvious. When, however, one must translate nonroutine features, the problems may be said to mount in geometric proportion. Rhetorical elements in language are largely cultural specialties; they are features of language which have been selected by the culture for special development, or to which highly specialized meaning or significance has been assigned. The more specialized any element of culture, the more difficult it is to find a satisfactory equivalent in another culture.

Rhetorical devices of language may be defined as those features of language which are consciously manipulated in order to produce special effects. They involve sounds, graphic devices, semotactic sequences, grammatical alterations, thematic arrangements, and content distortions. They occur typically in slogans, epigrams, proverbs, riddles, poetry, and carefully constructed prose. 
Sounds as rhetorical devices are of two principal types: (1) segmental and (2) suprasegmental. Segmental sounds may be typically either intralinguistic, e.g. alliteration, assonance, rhyme; or extralinguistic, involving onomatopoeic words, e.g. choo-choo, put-put, ding-dong, or expressions which are nonverbal, e.g. zzz, as an imitation of the sound of bees, or tsk tsk as an admonition, normally addressed to children. Though all languages make use of sounds for special effects, they do so in such different ways that the transfer of the specific sound patterns from one language to another is rarely possible. Thus, the translation of rhymed poetry is especially difficult, if not impossible, especially if one attempts at the same time to reproduce a similar accentuation pattern.

The suprasegmental features of stress, length, and tone give rise to highly intricate arrangements of metrical and tonal contour units, and matching such accentual patterns is usually impossible. Even if they can be duplicated, the forms in the receptor language may have quite different meanings. A religious meter in one language can be a sexual one in another language, and a stately rhythm in one language can sound funny when duplicated in another. What is important is not so much the form but its cultural significance. For the translator the crucial issue is how such an arrangement of suprasegmental features will be interpreted by the receptors.

Such graphic devices as capitalization, punctuation, and indentation all carry important nonverbal messages. Duplication of the punctuation of the source text may bring serious objections from receptors, who may resist strongly what they regard as 'undue foreign influence'. In other instances, a failure to reproduce the punctuation of the text in a prestige language may be interpreted as a serious lapse of integrity. Problems of indentation in poetry can be especially difficult, particularly if the committee of translators has not considered the usage of the receptor language. For example, the translation of Hebrew poetry in the New English Bible was printed with indentation based upon the number of accented syllables in the Hebrew text. But this method resulted in a chaotic and unintelligible system for the English reader, accustomed to indentation based upon patterns of parallelism (synonymous and antithetical) and thematic dependency. Even the extent of paragraph marking differs from one language to another. Thus, the marking of direct discourse by indentation and dashes, rather than by quotation marks, is a distinctive feature of several European languages. The translator must make proper adjustments to all these graphic elements if he is to produce a text which will be fully acceptable to sensitive receptors.

Semotactic factors in the rhetorical aspects of language are extremely important, not only in producing congruence of vocabulary within a particular register of language (e.g. intimate, casual, 
informal, formal, and formulaic), but also in reflecting natural combinations of terms. Translations may be perfectly correct syntactically but quite wrong semotactically; e.g. to think in what he did in place of to think of what he did; to sit at the lecture instead of to attend a lecture; fugacious aspiration rather than fleeting breath; and assassinated the tree instead of killed the tree.

Figurative expressions are types of semotactic structures which cause great difficulty for translators. These semantically exocentric expressions, whether worn-out cliches, conventional idioms, or fresh metaphors, pose special difficulties since they are largely language-specific. Whereas in English one may speak of loving with the heart, the same type of emotion is related to the 'abdomen' in most Mayan languages, to the 'liver' in a number of languages in Africa, and to the 'throat' in Marshallese. While in English a person puts in his oar, in Spanish one 'puts in his spoon'. In English a cat has nine lives, but in Spanish only 'seven'. Similarly, in Spanish one may say tomar el cielo con las manos, literally 'take the sky with one's hands', but the equivalent in English is 'to hit the ceiling'.

The translator is faced with a number of alternatives in dealing with figurative expressions--to translate literally and provide a footnote explanation; to substitute another figurative expression having essentially the same meaning; to employ a nonfigurative equivalent; or to mark the expression as figurative by making it clearly a simile, thus indicating to the reader the semantically exocentric character of the original expression. The translator's choice of one or another of these alternatives depends largely upon the manner in which the prospective receptors are expected to understand and react to the discourse. If the receptors are students of literature who wish to know something about the literary character of a foreign-language text without studying the language, they will probably want a literal translation with footnotes; if they are reading primarily for pleasure, they will probably prefer a substitute figure of speech; if they are primarily interested in an accurate meaning of the original, they will generally opt for a nonfigurative equivalent. As in so many aspects of translating, the choice of alternatives is dictated essentially by the concerns, interests, and expectations of the receptors.

Rhetorical grammatical devices involve primarily shifts in word order, a feature common in poetry to facilitate patterns of rhythm or rhyme, or to highlight certain lexical units by placing them in unusual positions. The poetry of e. e. cummings employs not only radical shifts of order, but also deletions of syntactic constituents (usually so-called function words). The results are often more intriguing than communicative, but they do illustrate what can be done by way of grammatical alterations of routine patterns of language. The translation of e. e. cummings' poems into other languages requires similar 
types of alterations, but certainly not precisely the same ones, for each language has its own limitations of 'syntactic torture'.

The structure of thematic arrangements is an important element in the rhetorical development of texts. These arrangements involve such features as parallelism, inversions (chiasm, whether singular, e.g. abba, or multiple, e.g. abcddcba), antitheses, and generic-specific dependencies. Certain types of thematic arrangements may become so common and natural as to appear almost obligatory. For example, in the translation of Hebrew poetry into some of the languages of Indonesia, a translator is almost compelled to introduce parallel lines, even when the original is not so structured. Since so many lines of Hebrew poetry are parallel, and since the indigenous poetry is almost always strictly parallel, the failure to produce parallel lines is regarded as either an error in the original or an oversight on the part of the translator. On the other hand, Ronald Knox regarded Hebrew poetic parallelism as so tautologically obnoxious that he consistently tried to eliminate the parallelism by reducing two parallel lines to a single line.

The rhetorical manner in which particular themes are treated may also be extremely important to the translator. Understatement (litotes) and overstatement (hyperbole) can be equally confusing in a receptor language which does not employ such expressions in the same types of contexts. All languages appear to employ such rhetorical devices, but not necessarily in the same types of contexts. For example, hyperbole may be typical of honorific poetry, but scarcely acceptable in such a statement as occurs in Mark 1.5: 'Everyone from the region of Judea and the city of Jerusalem went out to hear John. They confessed their sins and he baptized them in the Jordan River.' It is little wonder that a Quechua Indian in Bolivia was confused as to why Jesus ever felt constrained to preach in Judea and Jerusalem, if all the people had already believed the message which John the Baptist had preached.

Perhaps irony is the most difficult rhetorical device to translate correctly, for making a statement mean something entirely different from what it says depends greatly upon the local cultural context. Irony appears to exist in all languages and in some of them is highly developed. The praise poems composed by court poets in Lesotho are famous for their overt praise of a chief, while in reality they are often severely critical of the chief's actions, something fully understood by both people and chief, but not subject to censure. Similarly, the ironic taunts of court fools in the Middle Ages were tolerated by rulers and greatly prized by the populace.

The effective use of such rhetorical devices as sounds, format, figurative language, syntactic transpositions, parallelism, inversions, and hyperbole is normally appreciated by receptors, many of whom 
may be highly skilled in their capacity to evaluate and judge appropriateness. In other words, their language experience gives them a discriminating competence by which they can determine the extent to which a source has correctly employed these rhetorical features. Receptors readily sense when such features do not fit the subject matter or the register appropriate to the audience or to the occasion. They quickly spot artificiality and 'purple prose'; and though they may admire oratorical flights of fancy, they are not slow to sense when such rhetoric is merely a mask for empty content. Since their cognitive and emotive responses to form and content are obvious, it becomes necessary for the translator to refer constantly to the effect of renderings upon receptors. The basis for evaluation and the presuppositions as to correctness differ widely from one language to another, and the translator must be aware of these differences.

Literary genres. Important as various rhetorical devices are in their own right, they do not constitute an assortment of features which a speaker or writer chooses at random. Rather, they come in structured clusters and form the basis for the various types of literary genres or discourse types, e.g. aphorisms, proverbs, slogans, jokes, dialogue, conversation, poetry (e.g. lyric, narrative, didactic, epic), myths, folktales, parables, letters, allegories, short stories, novels, essays, textbooks, recipes, obituary notices, want ads, etc.

For the translator, the function of such genres is even more important than their formal features. In ancient Hebaew, didactic poetry was not only popular but also extremely important as a means of making religious and political declarations. Though the Hebrew prophets were accustomed to delivering ultimatums in the form of poetry, present-day preachers do not deliver hell-fire sermons in poetic stanzas! Instead of enhancing the impact of such a message, as was the case with the Hebrew prophets of ancient Israel, the use of poetry in such discourses in present-day English would suggest a mode of unreality or wishful thinking. Similarly, dialogue was for the ancient Greeks the essence of philosophical inquiry, but philosophical dialogue seems unduly tedious and artificial to most modern readers.

The existence or nonexistence of a particular literary genre may significantly influence the way in which receptors accept and interpret translations of such genres from other languages. For example, people who have in their literature numerous cosmological myths, normally regarded as referring to an existential limbo lying somewhere between fact and fancy, seem to have little difficulty in accepting the accounts in the first part of Genesis as belonging in the same category of truth. However, receptors who are largely unacquainted 
with such a literary genre tend to interpret these same biblical accounts in terms of the closest literary structures which they know, namely, history textbook statements about physical events.

A translator's interpretation of a literary genre is often revealed by the way in which he renders a particular discourse. The introduction to the story of the Prodigal Son in the New English Bible, 'There was once a man who had two sons (Luke 15.11)', immediately marks the story as a parable rather than an account of a particular series of historical events. One translation of the Book of Jonah begins 'Once upon a time', and by this device indicates the translator's interpretation of the story as fictional. In some languages the occurrence or nonoccurrence of such markers is obligatory, and in such languages the translator cannot dodge some of the really delicate issues of literary history.

The multiple levels of meaning in discourse pose a number of difficulties for a translator. Aphorisms and proverbs typically have at least two levels of meaning, and a literal translation of them often inhibits the possibility of comprehension by receptors. The Haitian Creole proverb, 'When the tree plays with the wind, it loses its leaves', is readily understandable and has a near equivalent in 'He who plays with fire gets burned'. But another Haitian proverb, 'It's easy to pick up a lightning stone, but hard to put it down', can be understood only if one knows that the phrase 'lightning stone' refers to Indian relics thought to have been produced by lightning. One must also know that many Haitians believe that if one picks up such a relic, he is obliged to become a witch doctor, something which entails very serious responsibilities and obligations.

In some cultures folktales are predominantly moralizing, as, for example, among the San Blas Indians of Panama. In other cultures they may be designed to teach practical wisdom, as in many West African folktales. Cultural differences may be so important as to alter completely an intended meaning of a discourse. For example, people in some cultures react to the story of the Prodigal Son by placing all the blame for what happened on the father, who gave his younger son his part of the inheritance. The father's stupidity, rather than the son's profligacy, becomes the point of the story. Accordingly, the older brother's objections to the dancing and the feast are interpreted as fully justified.

The role of the translator is not the same as that of the exegetical commentator, but no translator can afford to produce a text without considering the manner in which the prospective audience is likely to interpret it. Translating is essentially an act of communication, and if the resulting translation is not understandable, or is generally misunderstood, it is obviously not a satisfactory translation, regardless of the manner in which certain formal devices may have been 
imitated or the lexical units carefully matched. As an event of communication, the translation cannot be regarded merely as a document. It is a message which is to be received, decoded, and responded to by receptors whose background, experience, system of values, and concepts about translational adequacy are almost invariably different from those who received the original communication.

Since, in interlingual communication, languages, cultures, and the settings of communication are all different, and since among various sets of languages there are varying degrees of such differences, a sociolinguistic theory of translation must reckon not only with various types of divergences, but also with varying degrees of such differences. The problems of transfer and restructuring of texts are generally directly proportional to the extent of such differences.

Normally, the greater the number of language and culture specifics, the greater are the number of changes required to produce a functionally equivalent text. But the diverse interests and concerns of receptors tend to modify this basic principle in several ways. If, for example, the receptors are primarily concerned with the form of the original text, they may prefer a more or less literal, formalcorrespondence type of translation with explanatory notes. If their concern is for the uniqueness of the historical events described in the text, they will no doubt prefer a translation which faithfully represents the historical realities. Any present-day implications of such events may then be indicated in marginal notes. Such receptors will prefer to interpret any present-day relevance of the message in terms of the ways in which they perceive the original receptors as having understood the message as it came to them. If the interest of receptors is primarily in the present-day practical implications of a source-language text, they will usually be willing to accept almost any number of adaptations, in order that they may grasp the overall meaning, even though it is expressed in ways formally quite different from the original. And finally, if receptors are principally interested in the pleasure they derive from excellence of form in their own language (as, for example, in the formal qualities of lyric poetry), they will be willing to sacrifice much of the content for the sake of the esthetic qualities of the translation, despite the radical adaptations which must be incorporated to produce in the receptor language something more or less esthetically equivalent to the original.

These four qualifications on the general principle of degrees of adaptation reflect primarily the concerns of receptors who react to a translation not as a document, but as a communication. It is for this reason that translating can be properly understood only as an act of sociolinguistic communication. 


\section{REFERENCES}

Belloc, Hilaire. 1931. On translation. London: Oxford University Press.

Brower, Reuben. 1947. Seven Agamemnons. Journal of Historical Ideas 8:383-408.

Campbell, George. 1789. The four Gospels, Vol. 1. London: Strahan and Cadell.

Cary, Edmond. 1956. La traduction dans le monde moderne.

Geneva: Georg et Cie.

Catford, J. C. 1965. A linguistic theory of translation, London: Oxford University Press.

Chao, Yuen Ren. 1964. Translation without machine. In: Proceedings of the Ninth International Congress of Linguists. Edited by H. G. Lunt. The Hague: Mouton. 504-510.

Goethe, J. W. V. 1827. Letter to Carlyle, 20 July. GoetheBriefe. Berlin: D. Eisner.

Jakobson, Roman. 1959. On linguistic aspects of translation. In:

On translation. Edited by Reuben Brower. Cambridge: Harvard University Press. 232-239.

Levf, Jiri. 1969. Die literarische Übersetzung: Theorie einer Kunstgattung. Frankfort-am-main: Athenaum Verlag.

Nabokov, Valdimir. 1955. Problems of translation: 'Onegin' in English. Partisan Review 22:496-512.

Neubert, Albrecht. 1973. Theorie und Praxis firr die Übersetzungswissenschaft. Linguistische Arbeits Berichte 7:120-144. Leipzig: Karl-Marx University.

Nida, Eugene A. 1964. Toward a science of translating. Leiden: E. J. Brill.

Nida, Eugene A., and Charles R. Taber. 1969. The theory and practice of translation. Leiden: E. J. Brill.

Pasternak, Boris. 1958. Translating Shakespeare. Twentieth Century 164:213-228.

Pope, Alexander. 1715. Preface to his translation of Homer's lliad. London: Donaldson, 1769; New York: D. Appleton, 1901. Savory, Theodore H. 1957. The art of translation. London: Jonathan Cape.

Tytler, Alexander Fraser. 1790. Essay on the principles of translation. London: Dent. 


$$
\text { . }
$$




\section{APPLYING SOCIOCULTURAL VARIABLES \\ IN THE SPECIFICATION \\ OF COMMUNICATIVE COMPETENCE}

\section{JOHN MUNBY}

\section{The British Council}

0 . Introduction. Specifying the target communicative competence of a foreign-language learner requires a sociolinguistic approach to syllabus design. Such an approach should involve, first, the systematic identification of the communication needs of a particular participant or category of participant, and then the interpretation of the resultant profile of needs in terms of the skills, functions, and forms required for its realisation. There is not the time here to consider all the parameters of communication needs. In this paper, therefore, I am mainly concerned with the application of three of the sociocultural variables, viz. setting, interaction, and key (although I shall need to touch on communicative event), in the specification of the target communicative competence. More specifically, I discuss psychosocial setting and social relationships, and the derivation from them of the communicative key in which the communicative activity takes place. I then consider the sociosemantic processing of such an activity and its keys. The resultant units of meaning are presented as micro-functions marked for attitudinal-tone. The example language realisations of these units reflect the influence of these sociocultural variables, among other things, on the English required by a particular participant category for a specific purpose.

1. The view of knowledge and communication taken here is sociolinguistic, where the contextual or environmental factors which constrain competence, or are involved in the development of communicative competence (Hymes 1971), or in the realisation of meaning potential (Halliday 1971 and 1972), are predominantly sociocultural. 
Knowledge about the target language, in the sense of knowing whether and to what extent something in the language is systematically possible, may not be sufficient for effective communication. Hymes, Cooper (1968), Widdowson (1971), and others have drawn attention to the equally important factor of contextual appropriacy: 'There are rules of use without which the rules of grammar would be useless'. Therefore we should teach the rules of use and language features appropriate to the relevant social context. It follows that in specifying communicative competence, which subsumes both grammatical and contextual competence, dealing with one component alone will usually not be valid.

Here it may be worth drawing attention to the continuing distortion of the concept of communicative competence as formulated by Hymes, which is to be seen in statements where linguistic competence (in the restricted sense of grammatical competence) and communicative competence are either polarised as competing goals or treated as concepts of coordinate status. Hymes' formulation, by incorporating grammatical (along with sociocultural, etc.) under communicative competence as one of its parts, emphasises the all-important relationship, rather than the pedagogically less relevant contrasts, between the grammatical and the sociocultural and psycholinguistic aspects of a person's competence. It further avoids two possible and misleading conclusions that might arise from separating grammatical competence and communicative competence: (1) that grammatical competence and communicative competence should be taught separately, or in that order (this actually happens); and (2) that grammar is not an essential factor in communicating through language, or that it is somehow not related to communicative ability. The point is just that Hymes' formulation, apart from the merit of its interactional goal, logically does not admit of such conclusions.

A sociocultural orientation focuses on the social function of language and displays a learner-centered approach. Before deciding what to teach the learner we want to know his requirements in terms of, for example, communicative purpose, setting, and activities, and the relationships between him and his interlocutors. In other words, the specification of communication requirements or needs is prior to the selection of speech functions or rhetorical acts to be taught.

Halliday's concept of meaning potential draws attention to the sociosemantic basis of linguistic knowledge and indicates the central and metamorphosing role of the semantic options (available to a person) in translating options in behaviour into options in linguistic form. This meaning potential relates behaviour potential to lexicogrammatical potential: what the speaker can do $\rightarrow$ can mean $\rightarrow$ can say. 
Our approach, then, is grounded in a sociocultural orientation to communication that relates target proficiency directly to communication needs, and a communicative view of meaning that focuses on the pragmatic value of the utterance or text.

Before turning to the variables themselves, I would like to make the point (which may seem obvious but can be missed) that communicative competence specification is not the same thing as variety analysis. A stylistician starts with the text (spoken or written) that is representative of the putative variety and investigates features according to the descriptive linguistic and stylistic categories of his analytical framework. Distinctive characteristics of formal distribution, frequency of occurrence, etc., are noted and such features, formulated as descriptive statements or rules of use, are then postulated as the markers of the hypothetical variety. By contrast, I start with the person (a language participant or category of participant) and investigate his particular communication needs according to the sociocultural and stylistic variables which interact to determine a profile of such needs. Such a profile is eventually translated into the syllabus specification that indicates the target communicative competence of the participant. Our approaches, therefore, are bound to be different since we are doing different things. The stylistician is working backwards from the text whereas I am working forward to the text.

2. Setting is the situational variable that refers to both the physical and nonphysical environment in which the target language will be used. I here follow Hymes (1972) in positing physical setting and psychosocial setting (Hymes' 'psychological setting' or scene) as the two categories of this parameter. I am not here concerned with the spatial and temporal subcategories of physical setting, but with the different types of psychosocial environment which are objectively specifiable as corollaries of the former, e.g. intellectual for a university. This type of setting provides the kind of information which, when joined with the subsequent specification of social relationships (from the Interaction variable), will assist in the derivation of the 'communicative keys' that affect the language the participant has to understand or produce.

Information previously identified about the participant's identity, communicative purpose, and especially physical setting, points to the types of environment that apply in that particular case. For example, let us take a mid-twenties, female, Mexican air stewardess working for Mexicana, who needs English for communicating with Englishspeaking passengers in flight. The psychosocial setting that derives from this specification would be: 
nonintellectual; occasionally aesthetic; public; familiar physical; unfamiliar human; fairly demanding; hurried; generally formal.

'Hurried' refers to an environment where there is little or no time for reflection when using the target language; 'occasionally aesthetic' refers to occasions when she is asked to advise on places to visit, local art and craft to sample, national dishes to try. A different example would be a Saudi Arabian female student in a university faculty of medicine, who needs English for academic study purposes. The relevant environments that derive from this input would be:

sex discriminating; intellectual; nonaesthetic; religious; quasiprofessional; private and public; familiar physical; familiar human; fairly quiet; demanding; mainly unhurried; semiformal; authoritarian; very serious.

An inventory of psychosocial environments, from which the foregoing elements would be taken, would also include items such as: political, hierarchic, argumentative, and unsympathetic. 'Hierarchic' would apply to settings involving the Civil Service, for example, and the armed forces. 'Unsympathetic' refers to a setting that is impersonal or hostile or difficult, e.g. immigrant workers in factories in large urban conurbations, especially when there is a lot of unemployment.

3. Interaction is the variable which identifies the interlocutors with whom the participant communicates in the target language and the relationships that may be predicted as obtaining between them.

I begin this section with a few words about the term 'role'. For Banton (1965) a role may be understood as a set of norms and expectations applied to the incumbent of a particular position. But, as Worsley et al. (1970) point out: 'It is important to note that we are dealing with relationships here; a role exists only in relation to other roles. Thus . . . the role of doctor implies the role of patient'. Further, Banton's definition does not address the problem where there is a lack of role consensus, in which situation it seems realistic to recognise the variability of role conformity. For my purposes I accept the necessity of working with stereotypes, and regard a role as an expected, normatively defined, dynamic pattern of social behaviour associated with a particular position, implying a relationship with other roles, and to which behavioural pattern individuals are likely to conform in varying degrees.

'Role' has obvious utility as a reference term for an important conceptual area that sociolinguists have to concern themselves with. Its deficiencies as an analytical tool ${ }^{1}$ should not obscure the de facto 
reality of role relationships, and the wider social relationships that they imply, which are important matters in the study of communication needs.

Worsley et al. also draw attention to the pressures that arise when status considerations affect role relationships, or when there is conflict between different roles that a person plays, or conflict within the role-set (see further on in this paper). Where such role conflict is predictable we may be able to handle in some measure the communicative implications of role relations. This may be done by specifying the 'communicative key' for particular events where the prior identification of certain social relationships predicts role conflict.

When considering this variable, we start with the participant's 'position'. This is the sociological concept of the term, i.e. position in the structure of society, the typical incumbent of which enacts the role associated with that position, and examples of which might be 'doctor' or 'university student'. Together with information on setting, this enables us to identify the participant's 'role-set', to use Merton's term (1957). This comprises the different people that the participant will interact with in the playing of one particular role or by virtue of a particular position. Here, I am concerned with the 'target language role-set', i. e. only those members with whom he has to communicate in English. The next step is to establish the 'role-set identity'. For each member of the role-set one needs to know the size of the participation, age group, sex, and nationality.

A statement of 'role relationships', e.g. assistant teacher/headmaster, can follow directly from the identification of the role-set. Interaction relationships tend to be expressed in terms of the roles of the participants. However, we propose to specify the 'social relationships', e.g. subordinate/superior, which are implied by the interaction of the participant with each member of his role-set. A social relationship is more significant than a role relationship for determining attitudinal constraints when we come to 'communicative key'. The role relationship itself does not necessarily imply one particular social relationship, i.e. there is no automatic one-to-one correlation between a role relationship and a social relationship. The features identified in terms of the participant's purposive domain and setting enable one to determine a particular social relationship as, for example, subordinate/superior rather than, say, primus inter pares or colleague/colleague, the relationship that may be the case in a small, two-teacher primary school with an informal atmosphere. The assistant teacher/headmaster role relationship in itself may imply any of these three social relationships, or others (given a different input). We need to know which obtains in a particular case if we are to make appropriate decisions when we come to 'communicative key'. In addition, social relationships, a synchronic 
phenomenon, are likely to be (1) stable, i. e. the stereotype takes time to change and is therefore more reliable than that for a role relationship, and (2) a relatively small set (the concept is selfdefining through listing). For English, I have arrived at a tentative set of 61 social relationships compared with role relationships which are legion. Such a set is theoretically finite, although the claim here falls short of this. In attempting as exhaustive a list as possible, I kept in mind the need to include only those relationships which can generate attitudinal constraints on the communicative activities, and then only in the target language. Thus, certain kinship relations which affect language use in the Far East are not included because the language affected would not be English. The process, therefore, of determining the social relationships that follow from the role relationships, taking account of setting, etc., is made manageable by having an inventory such as ours to which to refer. A few more examples from this inventory are: official/public; employer/ employee; therapist/patient; insider/outsider; older generation/ younger generation; male/female; equal/equal; group member/group member; adult/adult.

Social relationships are either symmetrical or asymmetrical. The common denominator of symmetrical relations is cohesiveness, in terms of the degree of solidarity or familiarity between the participants. The underlying characteristic of asymmetrical relations, on the other hand, is mainly power, in the sense of one participant being able to exercise some degree of control over the other. From this it may be seen that I follow Brown and Gilman (1960) in their use of the terms 'power' and 'solidarity' for asymmetrical and symmetrical relations, respectively, while preferring Robinson's (1972) suggestion of 'cohesiveness' for the symmetrical dimension. This is because it subsumes familiarity (which he refers to as intimacy) as well as solidarity, and both need to be covered.

The status obtaining between the participants is based on age, class (social or socio-economic), kinship, occupation, or sex. Additionally, some relationships of power seem to be grounded in the 'educational' or legal standing between the participants. Relationships whose status basis is clear can be marked accordingly. For example, pa would indicate a relationship where the power of one participant over the other derived from his age status, while $\mathrm{C}^{\mathrm{C}}$ would indicate a relationship where the cohesiveness between the participants derived from their same class status. The unmarked forms $P$ and $C$ could then be used where the status basis is not clear or for relationships which are not status based. Of the relationships of power in my list, about 16 have a hierarchic characteristic, e.g. management/worker, senior/junior. Of the relationships of cohesiveness, the majority are of the solidarity 
type, e.g. insider/insider, professional/professional, rather than the familiarity type, e.g. acquaintance/acquaintance.

The degree of cohesiveness varies from the strong solidarity of group member/group member to the total lack of it in enemy/enemy, and from the extreme familiarity of intimate/intimate to the total lack of it in stranger/stranger. It is perhaps worth pointing out that, although three or four of the asymmetrical relations could be characterised partly by cohesiveness, e.g. leader/follower, the underlying characteristic is the control of an area of behaviour by one participant over another, even if such control is exercised obliquely through imposing a sense of obligation, e.g. host/guest. Only, perhaps, in the case of the star/fan relationship is the defining characteristic ambiguous.

I am going to close this section by repeating that the point about specifying the social relationships, that are implied by the interaction of the participant with the members of his target language role-set, is to help us predict the attitudinal constraints on the communicative activities in which the participant has to engage, and to which I now turn.

4. Communicative events result from the interaction of relevant input information deriving from the prior identification of, inter alia, the participant's purposive domain, physical setting, and role-set requirements. The events thus systematically arrived at are what might be regarded as macro-activities, such as 'customs officer checking passengers at airport for illegal export of goods'. The parts, such as 'ensuring passenger understands regulations' and 'arguing over a discovered item', which make up the event, can then be regarded as micro-activities or simply activities.

In the system I am advocating, before such activities are realised as language forms, they are converted into meaning subcategories and marked for attitudinal-tone (see next section). First, we need to consider what qualifies for a meaning unit of this kind, a complex question which involves making a decision as to where we stand over the use of terms like 'function' and 'act'.

The term 'function' is used in both a macro and micro sense. Halliday's (1970) ideational, interpersonal, and textual functions of language are clearly macro-functions, as are Jakobson's (1960) set, and lists such as Robinson's (1972) which derive from one or the other. On the other hand, most of Wilkins' (1976) categories of communicative function, such as suasion and argument, or rather, their subcategories as exemplified by 'threat' and 'agree', respectively, are micro-functions, as are the speech functions such as 'elicit' and 'interrogate' to be found in the analysis of doctorpatient communication by Candlin, Leather, and Bruton (1976). 
Widdowson's (1971) use of the term 'rhetorical act' covers speech acts in the Austin/Searle sense, such as promising and ordering, as well as acts such as defining and classifying. ${ }^{2}$ One can say that an utterance is a 'promise' (has the communicative value of promising) by looking at its 'social context', so functions/acts like this are of the order of 'sociolinguistic meaning'. One can say that an utterance is a 'definition' (has the communicative value of defining) by looking at its 'discoursal context', so functions/acts like this are of the order of 'contextual meaning'. 3

I am concerned with 'micro-functions', as exemplified by many of Wilkins' subcategories of communicative function or Widdowson's rhetorical acts, both of which subsume illocutionary acts. I am going to call every such function or act a 'micro-function'. This is to be distinguished from what is called a 'communicative activity' ('activity', for short), such as 'describing mechanical processes' (Jupp and Hodlin 1975), which is a higher order unit at the behavioural level of communicative event. I avoid the potentially useful term 'communicative act' because it is too easily confused with other uses of the term 'act', and because it has been used as a catchall term which conflates the distinction it seems necessary to make between behaviour and meaning. These micro-functions, therefore, are units of meaning operating as an inter-level, between events and their formal realisations. The point is that, whereas a micro-function (suitably contextualised) is ready for verbal and nonverbal realisation, an activity such as 'arguing over a discovered item' is not. The latter needs to be processed into micro-functions 4 before any decisions about utterance realisations can be made. Furthermore, these micro-functions have to be attitudinally constrained, which brings us to 'key'.

5. The term 'key' is taken from Hymes (1972), for whom it was 'the tone, manner, and spirit in which an act is done'. In considering the communicative event variable, the activities that the participant needs to handle are worked out; here, I specify the 'keys' that need to be understood or produced for each of those activities. This specification is based on input information from relevant derivational sources, viz.., the participant's identity, role-set identity, social relationships, and psychosocial setting. It is worth noting that these sources of input information are different from the derivational sources for communicative events (see Section 4). The 'keys' are selected from a taxonomy of such features, which I have devised for this purpose and for the subsequent marking of micro-functions for attitudinal tone.

In order to select 'keys' it was necessary to have a set of such features from which to make a selection. As no such set existed, I 
was faced with the formidable problem of, in effect, categorising a major part of the universe. One such categorisation, although for different purposes, already exists in Roget's Thesaurus (1966 edition by $R$. A. Dutch). This difference of purpose is reflected in the way it is organised and set out, which is unsuitable for a purpose such as mine. However, it proved invaluable as the primary source for my investigations. In devising the system I worked through Roget, with regular recourse to other sources of lexical reference, searching for those affective, volitive, and other features which affect the choice of linguistic realisations for communicative activities. Then, using Lyons' (1968) tests for determining antonymy and hyponymy, I have organised the results of that search into an 'attitudinal-tone index'. This consists of a potentially finite set of continua (51 in the present organisation), each one labelled with a pair of antonymous keys which are superordinate to the other terms on that continuum (see the Appendix for some examples). These other terms, each of which is therefore in a relationship of hyponymy to its own superordinate term, are defined as the more likely attitudinal tones (no intention to be exhaustive) for each continuum. In a few cases, where a superordinate does not call up its more familiar hyponyms except with difficulty, or where no superordinate appears to exist, the continuum is labelled with the most representative cohyponyms. The relationships between individual cohyponyms is deliberately not explicit since such differences do not in any way affect the selection process, and the only semantic relationships that are material to this framework are antonymy (horizontal axis) and hyponymy (vertical axis), not synonymy, etc.

I would stress that the horizontal axis is a continuum, not a cline. The postulation of a continuum indicates that the attitudinal tones on each side of the continuum are not polarised as independent qualities but are in a 'more than' and 'less than' relationship to some relevant implicit norm (Lyons 1968). For example, a person who says Take off your shoe, with a high fall intonation pattern, is polite rather than impolite (or at least, not impolite) with respect to the norm relevant for the doctor/patient interview situation, but impolite rather than polite with respect to the norm relevant for the shop assistant/ customer situation. Furthermore, cohyponyms vary in the comparative degree to which they imply their superordinate key. For example, apprehensive and afraid are at different points on the 'fearing' half of their continuum. A continuum also allows for the specification of those attitudinal tones which are midway with respect to the extremes of their continua, e.g. half-satisfied, halfserious, semi-sophisticated, semi-optimistic, half-caring, semiformal, half-willing, semi-official, half-certain. 
The micro-functions we discussed in Section 4 are semantic subcategories of a predominantly pragmatic as well as logical kind (rather than the kind found in conventional semantics). Therefore, the conversion of activities into such functions and their marking for 'attitudinal tone' can be described as essentially sociosemantic processing. Each micro-function of an activity is now mapped against an applicable key continuum in the 'attitudinal-tone' index, and the selection of the particular item is based on the prior identification of sociocultural information in the setting and interaction variables.

Finally, to emphasise the importance of 'communicative key' as an independent variable in communication, I return to Hymes (1972): 'The significance of Key is underlined by the fact that, when it is in conflict with the overt content of an act, it often overrides the latter (as in sarcasm)'.

6. I now come to an illustration of this sociosemantic processing and of the realisation of the resultant units of meaning in terms of language forms. This exemplifies the application of the variables under discussion. For this purpose I consider a customs officer, . mid-thirties, male, Fantasian, in Fantasia, who needs English for carrying out his duties with certain interlocutors. Within the event 'checking passengers at airport for illegal export of goods', I focus on the activity 'arguing over a discovered item'. The input information from the interaction, setting, and key parameters is as follows:

Role-set identity: individuals; adult; mixed sex; some Fantasian, but mainly UK speakers of British English.

Social relationships: official to member of the public; investigator to subject; authority to offender; male to female; stranger to stranger; adult to adult.

Psychosocial environments: nonintellectual; ethical; mainly public; familiar physical; unfamiliar human; basically unhurried; formal; semi-authoritarian; argumentative; reserved; unsympathetic.

Communicative keys--productive: formal; patient; disinterested; unexcitable; authoritative; certain; uncertain; dissenting; regretting.

Communicative keys--receptive: hoping; displeased; regretting; excitable/unexcitable; resolute/irresolute; inducive/dissuasive; certain/uncertain; dissenting.

Given the foregoing input information, here are some of the micro-functions marked for attitudinal tone, with some appropriate 
language realisations, that the participant needs to be able to produce or understand. Comments follow the items, which form only a sample of the possible specification for this particular activity.

\section{Productive command.}

\section{(1) accuse [+ formal], [+ dispassionate]}

You have been discovered attempting to export this illegally.

The choice of attitudinal tone for accuse is crucial if the participant is to avoid unnecessary confrontation. From the input information we can decide that the social relationship relevant to this function in this activity is potentially authority to offender as well as actually official to member of the public, and that the relevant psychosocial environment is public, formal, and unsympathetic. With these factors in mind, and working from the communicative key specification, by marking this function as [+ formal], [+ dispassionate] we seek to ensure that the resultant language is appropriate for this participant with this interlocutor. Here, the further marking of this function with, for example [+ authoritative] would add little or nothing to the constraints provided by the tones already specified. Without the [+ formal] tone the utterance could read 'We've caught you red-handed trying to smuggle this out of the country', and without the [+ dispassionate] it might include the speaker's culturally determined view on the iniquity of the attempt.

(2) warn [+ disinterested], [+ unruffled]

(2a) I don't think you should continue in this way--it won't help your case.

(2b) I hope you are not making an improper suggestion.

(3) maintain [+ patient]

(3a) Yes, I do understand your point but that does not alter the matter.

(3b) You still have to have a clearance certificate.

The tone marking [+ unruffled] for warn indicates that we expect this function to be a response rather than an initiative. The utterances at (2) are the participant's stylistically appropriate reactions to the unacceptable pressure and blandishments of the interlocutor's advise [+ intimidating] at (10), and invite [+ seductive] at (11), respectively. Items (2) and (3) are responses to pressures of different kinds from the interlocutor, the tone markings reflecting the stranger-tostranger, adult-to-adult social relationship, in an ethical, unhurried, formal, and reserved environment. 
(4) question [+ detached], [+ patient]

Where did you get this from? . . . Why did you not obtain a clearance certificate from the National Museum? ... Can you verify that?

(5) query (a) [+ sceptical]

(b) [+ suspicious]

(a) That's hardly 'likely, is ît?

(b) Where did you buy it?

In (4) the participant is an official seeking answers he requires from a member of the public, whereas in (5) be is the investigator on the offensive against his subject. All the questions listed at (4) are asked in a detached and patient way. This distinguishes them from the very different kind of utterance at (5), where the rising nucleus on the first syllable of $(5 \mathrm{~b})$ makes it into a suspicious query, while scepticism is produced through the fall-rise intonation of $(5 \mathrm{a})$.

(6) contradict [+ dispassionate], [+ calm], [+ formal]

If you thought that, why did you attempt to conceal it?

(7) reject [+ doubting]

I find that difficult to believe.

The language realisation here reflects the investigator-to-subject relationship in a sttuation where the customs officer needs to disagree with or reject the passenger's explanation without actually calling him a liar.

Receptive command.

(8) beg [+ apologetic], [+ frantic], [+ urging]

I'm terribly sorry I haven't got a clearance certificate, but couldn't you possibly make an exception, just this once? Please!

(9) suggest [+ hoping]

You could decide that it is a category $\mathrm{C}$ jtem?

(10) advise [+ intimidating]

Well you had better believe me. I happen to be a friend of and I don't think he would be happy with the way you treat a visitor to your country. 
(11) invite [+ seductive]

I wonder if you and I could come to some . . . arrangement.

Items (8)-(11) constitute functions one or more of which the participant may have to understand if his interlocutor resorts to suasion rather than argument. Where the passenger is in the wrong, such tactics would reflect the offender-to-authority social relationship. In (8) the [+ frantic], [+ urging] marking required is realised through the use and heavy stressing of terribly, possibly, just this once, and please! (including its end position). This may be contrasted with the lack of an overt verbal indicator for the [+ hoping] tone of item (9), where it is the choice of linguistic form for the function, including the rising intonation on the last word, which makes this an appropriate realisation for a hopeful suggestion.

(12) question [+ annoyed], [+ protesting]

How am I supposed to know that a clearance certificate is required for this?

(13) dispute [+ incredulous]

You can't be serious! Anyone can tell this is a common copy.

Unlike the official, who is expected to contain his feelings of irritation or even outrage towards the public, the member of the public sometimes displays his displeasure or incredulity, as exemplified at (12) and (13). These units of meaning reflect the (indignant) subject-to(reserved) investigator relationship in an argumentative and unsympathetic environment. We might note here that the second sentence in the utterance at (13) is a dispute because of its position in the discourse and not because of anything in the sentence itself.

(14) concede [+ half-certain], [+ qualifying]

All right, it's possible I need a certificate, but I don't see how I could have got one.

Even if it is an original, I wouldn't have thought it was worth anything.

This complex unit of meaning anticipates the possibility of the offender-to-authority relationship indicated in the input information. It is worth noting the use of the attitudinal tone [+ qualifying] from the 'dissenting' key. The participant needs to be able to realise when his interlocutor is conceding only part of his argument or conceding a point while continuing to dispute its application. In the language 
realisations at (14) the concession contained in the first clause is qualified by the second clause. According to the specification, this unit of meaning is not only a partial concession but also a half-certain one. This tone is realised by the words even if and it's possible.

(15) deny [+ wavering]

No, it's not. Well, I don't think it is, is it?

(16) explanation [+ vacillating]

Nobody told me I had to have a clearance certificate

for such items--well, not at least until a few days ago

--and then it was too late to do anything about it, I'm afraid.

The wavering denial of (15) is realised through its fall-rise intonation and question tag. Another way of encoding irresolution can be seen at (16). It is clearly desirable for the customs officer to be able to recognise such attitudinal tones in the passenger's communication.

7. Conclusion. In this paper I have tried to show how certain sociocultural variables can be used in the specification of communicative competence. Inevitably, in a presentation of this length, a lot has had to remain unsaid. For a full picture of how these variables interact with others in the systematic processing of profiles of communication needs, and of how such profiles are interpreted in terms of language micro-skills as well as micro-functions, and also for a more detailed treatment of the theoretical argumentation behind this approach to communicative syllabus design, I have to refer the interested reader to Munby (to appear). Within the context of the broader claim made there (and for which a prima facie case has hopefully been established here) that it is not only desirable but possible to proceed systematically from the identification of a participant's communication needs to the specification of the target communicative competence, I have here tried to give some indication of the part played by certain sociocultural variables in this process.

\section{APPENDIX}

Sample from Attitudinal-tone Index (Munby to appear. Specifying communicative competence: A sociolinguistic model for syllabus design. Cambridge: At the University Press. Used with permission.) 
Hoping:

expectant, sanguine, optimistic, encouraging, wishful, hopeful

\section{Caring:}

concerned, interested, enthusiastic, eager, keen, personal, anxious, worried, curious, fascinated

Formal:

ceremonious, punctilious, correct, detached, stiff, conventional

Courteous: chivalrous, polite, civil, urbane, dignified, gracious, gallant

Resolute:

determined, firm, persistent, stubborn, obstinate, constant, adamant, militant

Inducive:

persuasive, encouraging, provocative, inciting, urging, seductive, recommendatory

Certain:

sure, unequivocal, unambiguous, confident, believing, opinionated, dogmatic, trustful, convincing
Hopeless:

despairing, desperate, pessimistic, unhopeful

Indifferent:

uncaring, unconcerned, uninterested, lukewarm, impersonal, unenthusiastic, incurious, nonchalant, apathetic, perfunctory

Informal:

unceremonious, casual, familiar, intimate, chatty, relaxed, irregular

Discourteous: ungallant, impolite, rude, offhanded, boorish, ungracious, brusque, abrupt, offensive

Irresolute:

hesitating, vacillating, indecisive, capricious, half-hearted, wavering

Dissuasive:

discouraging, damping, intimidating, cautionary, deprecatory, threatening, ominous

Uncertain:

unsure, ambiguous, puzzling, vague, doubting, sceptical, incredulous, distrustful, suspicious, unconvincing

\section{NOTES}

1. Cf. Cicourel (1973) and Jackson, ed. (1972), especially the paper by Coulson: 'Role: A redundant concept in sociology?'.

2. Cf. Sinclair and Coulthard (1975) for their use of the term 'act'.

3. See Candlin (1976) for a discussion of four layers of meaning. 
4. For this purpose one needs an item-bank of such microfunctions from which to select; $c$. the appropriate sections of Wilkins (1976) and Leech and Svartvik (1975).

\section{REFERENCES}

Banton, M. 1965. Roles, London: Tavistock.

Brown, R., and A. Gilman. 1960. The pronouns of power and solidarity. In: Psycholinguistics. Edited by $R$. Brown. New York: Free Press; London: Collier-Macmillan.

Candlin, C. N. 1976. Communicative language teaching and the debt to pragmatics. In: Georgetown University Round Table on Languages and Linguistics. 1976. Edited by C. Rameh. Washington, D. C.: Georgetown University Press, 237-256.

Candlin, C. N., C. J. Bruton, and J. H. Leather, 1976. Doctors in casualty: Applying communicative competence to components of specialist course design. In: IRAL 1976.3.

Cicourel, A. 1973. Cognitive sociology. Harmondsworth, Middlesex: Penguin Education.

Cooper, R. L. 1968. An elaborated language testing model. In: Language learning: Special issue No. 3 on Problems in foreign language testing.

Halliday, M. A. K. 1970. Language structure and language function. In: New horizons in linguistics. Edited by J. Lyons. Harmondsworth, Middlesex: Penguin.

Halliday, M. A. K. 1971. Language in a social perspective. In: Explorations in the functions of language. London: Edward Arnold, 1973.

Halliday, M. A. K. 1972. Towards a sociological semantics. In: Explorations in the functions of language. London: Edward Arnold.

Hymes, D. H. 1971. On communicative competence. Philadelphia: University of Pennsylvania Press.

Hymes, D. H. 1972. Models of the interaction of language and social life. In: Directions in sociolinguistics. Edited by J. J. Gumperz and D. H. Hymes. New York: Holt, Rinehart and Winston.

Jackson, J. A., ed. 1972. Sociological studies 4--Role. Cambridge: At the University Press.

Jakobson, R. 1960. Closing statement: Linguistics and poetics. In: Style in language. Edited by T. Sebeok. Cambridge, Mass.: MrT Press; New York: Wiley.

Jupp, T. C., and S. Hodlin. 1975. Industrial English: An example of theory and practice in functional language teaching. London: Heinemann Educational. 
Leech, G. N., and J. Svartvik. 1975. A communicative grammar of English. London: Longman.

Lyons, J. 1968. Introduction to theoretical linguistics. Cambridge: At the University Press.

Munby, J. L. (to appear). Specifying communicative competence: A sociolinguistic model for syllabus design. Cambridge: At the University Press.

Robinson, W. P. 1972. Language and social behaviour. Harmondsworth, Middlesex: Penguin Education.

Roget, R. Dutch, ed. 1966. Thesaurus of English words and phrases. Harmondsworth, Middlesex: Penguin.

Searle, J. 1969. Speech acts. Cambridge: At the University Press.

Sinclair, J., and R. M. Coulthard. 1975. Towards an analysis of discourse. London: Oxford University Press.

Widdowson, H. G. 1971. The teaching of rhetoric to students of science and technology. In: CILT Paper 7: Science and technology in a second language. London: Centre for Information on Language Teaching.

Widdowson, H. G. 1975. EST in theory and practice. In: English for academic study. ETIC occasional paper. London: The British Council.

Wilkins, D. A. 1976. Notional syllabuses. London: Oxford University Press.

Worsley, P. et al. 1970. Introducing sociology. Harmondsworth, Middlesex: Penguin Education. 

TEACHING THE CULTURAL CONTEXT

OF INTERCULTURAL COMMUNICATION

\section{H. NED SEELYE}

International Resource Development, Inc.

A couple of years ago, two anthropologists visiting my wife and me in Guatemala returned upset and disheveled from a visit to the local market. Vendors had thrown tomatoes at them! Our friends wanted to know what in hell was going on in the 'land of eternal springtime'.

The trouble began two weeks earlier when a dozen United States Embassy officials and their wives paused during a Sunday outing to eat and swim at a good provincial restaurant. The seemingly uneventful excursion was jarred by the agitated complaints of another patron who said there were children present and the Americans should control their wives better. The confused American response sparked further recriminations about moral degeneracy and the promiscuous behavior of the American women. A brawl ensued involving two dozen would-be pugilists. Monday's frontpage headline advised, 'Americans Riot in Escuintla'. Frontpage heads continued for four days; coverage was then shifted to page two for another week. Past wounds inflicted by 'yanqui cultural imperialism' vividly came to the forefront of popular consciousness; hence, the tomatoes.

The restaurant owner was a friend of the family so I asked him what had happened. 'Two hundred and fifty dollars worth of furniture and dishes were broken', he replied. I pressed to discover what had provoked the incident. 'Well', he said, 'in front of everyone this American woman got out of the pool and took off her bra!' Was she standing up when she did this? 'No', he explained, 'she was lying down on her stomach near the pool. She reached behind her and just unsnapped her halter!' Needless to say, the moral degeneracy of this dastardly act was lost on the gamboling gringos. 
Since Mark Twain, much has been said of the miscommunication which plagues American travelers. University communication classes often try to alert students to the particular pitfalls of crosscultural communication in order to reduce overt hostility when an American meets a stranger from another culture. 1

There are three initial steps to be taken in teaching cultural concepts. ${ }^{2}$ The first is that the teacher must identify the skills involved in intercultural communication and understanding that can be developed in communication classes. Seven of these skills are outlined in this paper. These skills become the goals of cultural instruction. Trivial, purposeless activities often can be redeemed by relating them to a goal through the posing of significant questions. The second step, writing end-of-course student performance objectives that are goal-related, is illustrated in this paper by an example geared to the mass media. Performance objectives spell out what a student should be able to do at the end of a course. The skill or knowledge needed to accomplish the end-of-year objectives will not be developed unless the teacher is able to provide the necessary experience either in class or through out-of-class assignments. These goal-related learning activities, the third step in planning cultural instruction, are illustrated by a brief unit based on a newspaper ad. 3

1. Seven communication skills. The first task is to identify the instructional goal of a given class. Seven communication skills are suggested here. One or more of these skills might comprise the scope of a course in foreign languages or intercultural communication.

Cultural Goal 1 (the sense, or functionality, of culturally conditioned behavior): The student should demonstrate an understanding that people act the way they do because they are using options the society allows for satisfying basic physical and psychological needs.

Today's newspaper featured a frontpage photo of the State Department's leading international diplomat holding hands with an Arab diplomat of the same sex. Our international expert was using, appropriately, an Arab gesture to express friendship with an Arab. The intent of Goal 1 is to see the logic behind any example of crosscultural behavior--however bizarre or perplexing the behavior initially may appear to ethnocentric eyes.

When an individual attempts to satisfy a basic need he usually has to employ many interacting cultural patterns that form a relatively cohesive structure. Some of these patterns are linguistic; others are not. For example, maintaining the respect of male peers in upper-class Guatemala City might involve skill in telling jokes and discussing literature, knowledge of English and of wines and liqueurs, having a resort home in which to entertain guests away from the city, and dressing conservatively. After the foreign 
language student has identified a basic need and translated it into the cultural pattern of the target culture, questions can be directed toward perceiving the relationship among different patterns. When any one cultural pattern is tugged, one finds that it is tied to all the other patterns in the culture.

Cultural Goal 2 (interaction of language and social variables): The student should demonstrate an understanding that such social variables as age, sex, social class, and place of residence affect the way people speak and behave.

No two people speak the same language. Voiceprints are as personal as fingerprints. Individual differences are an important part of the personality a person projects, as any amateur mimic knows. Of much greater interest to a student of the foreign culture, however, are the systematic variations in the speech of large numbers of people which are caused by differences in age, sex, social class, and place of residence. An eight-year-old talks differently from an eighty-year-old. The speech of a dock worker is not often confused with that of a college professor, nor is the drawl of a Southerner (of any country) mistaken for that of a Northerner.

Cultural Goal 3 (conventional behavior in common situations): The student should indicate an ability to demonstrate how people conventionally act in the most common mundane and crisis situations in the target culture.

Custom resolves the awkwardness of responding spontaneously to the same situation over and over again by conventionalizing the response. When you meet someone new, in English you say How do you do or in some settings, simply $\underline{\mathrm{Hi}}$. Some cultures provide conventionalized linguistic responses where others do not. For example, the linguistic dilemma of what to write to an acquaintance upon the death of his mother is simplified in Spanish by the convention Mi más sentido pésame, whereas the English, of my dialect at least, does not provide a conventionalized linguistic response. In the Spanish world $\underline{\mathrm{Mi}}$ más sentido pésame affords both parties satisfaction in a difficult encounter; in the English world the same function is performed by mailing commercial sympathy cards to the bereaved.

All conventional responses share several characteristics: (1) they are cued by common social situations; (2) both verbal and kinesic responses are limited to a prescribed few; (3) while utterance of the expected response is mildly rewarding to the involved persons, absence of an expected response produces considerable anxiety. This is true of conventional responses to a mundane occurrence, such as wishing someone a happy birthday, as well as of responses to a crisis situation, such as consoling someone who has suffered a divorce or serious illness. The sociological foundation for conventional behavior is elaborated by Goffman. 4 
Cultural Goal 4 (cultural connotations of words and phrases): The student should indicate an awareness that culturally conditioned images are associated with even the most common target words and phrases.

The thought of a beautiful woman might conjure up to a desert Arab sensuous images of a 250-pound lovely, while to an American, lexically equivalent words in English might connote a slim but disproportionately big-busted lass. One Italian neighbor of mine complains that in Italy men did not pay much attention to her because she was too skinny at 110 pounds, while in the United States the same fate has befallen her now that her weight is $\mathbf{1 7 0}$ pounds. If only she could be 'fat' in Italy and 'skinny' in the United States, she would be 'beautiful' everywhere. The cultural connotations of words can make the difference between an active social life and staying home.

How can an understanding of the relation between culture and semantics be developed? One way is for students to experience directly the cultural connotations of common words such as man, house, standing, walking, by observing these objects and activities as they occur in the target culture. This experience need not be limited to students studying abroad. The graphics of magazines, newspapers, and movies are well suited to convey these objects and activities in the target culture.

One of the many requisites to thinking like a native, besides fluency in the target language, is the conditioned ability to visualize culturally appropriate images which language evokes. Whether it is the fat Arab coquette or the pleasantly cool mud home of the Masai, communion with a native of another language demands sharing meanings that go beyond listless dictionary definitions.

Cultural Goal 5 (evaluating statements about a society): The student should demonstrate the ability to evaluate the relative strength of a generality concerning the target culture in terms of the amount of evidence substantiating the statement.

For the rest of his life the student will be hearing things about other cultures. He must learn to differentiate judgments that serve the ethnocentric bias of national politics from judgments that have an adequate empirical base. There are many prerequisite skills for sorting through the pronouncements of our species. Among these are skill in balancing the evidence with the generality, in separating speculation from objective observation, and in discerning vested interest.

Cultural Goal 6 (researching another culture): The student should show that he has developed the skills needed to locate and organize information about the target culture from the library, the mass media people, and personal observation. 
Of utmost import are the classroom skills that stay with a student during the years after he leaves our tutelage. Many students lose their hard-earned linguistic fluency, but none loses the need for continuing his education. Despite historic precedents replete with isolationism and anti-intellectualism, we have been made painfully aware that even distant small countries have an important influence on our daily options. In the best of times, knowledge of another culture is tantamount to moving out of a dark, dank corner of the cave into more illumination; understanding other cultures is frequently a matter of life or death.

The average college graduate has been the recipient of an education costing more than twenty-five thousand dollars. Most of the content of this education soon becomes obsolete. This is not a criticism of the education; it is a tribute to our commitment to pushing back the frontiers of knowledge. Still, education is difficult to justify on the basis of the 'facts' learned. Alfred North Whitehead in The Aims of Education 5 utterly rejects this notion. The learning of facts, he writes, has not justified education since the establishment of libraries and the availability of paperbacks. If the actual content of education has little currency, what is of inestimable value is learning how to learn. Practically all learning of any value is accomplished outside a formal classroom. Learning, however, can be greatly enhanced by an educational system that develops skill in pursuing knowledge.

Cultural Goal 7 (attitudes toward other cultures): The student should demonstrate intellectual curiosity about the target culture and empathy toward its people.

Teachers tend to ascribe all the problems involved in the teaching of cultural understanding to attitudinal variables. 'We must change the students' attitude', they tell us. Much of what we do in the name of cultural understanding is seen as contributing to this affective change. To avoid the obvious danger of converting Goal 7 into yet another impotent supergoal encompassing just about anything and everything, its scope must be defined somewhat narrowly. Two components of attitude--curiosity and empathy--are good starters.

2. End-of-course performance objective. The second task, once one's instructional goals have been identified, is to operationalize the goal in terms that can be observed in the student at the completion of instruction. This level of specificity is called end-of-course performance objective.

To illustrate a student performance objective an end-of-year task is presented here for measuring the amount of skill developed relative to Goal 5 (evaluating statements about a culture). Following Mager's 
This content has been removed due to copyright restrictions. To view the content on p.254, please refer to the print edition of this work. 
Many learning activities may be necessary to achieve any given performance objective. Likewise, several different performance objectives may be required to demonstrate reasonable progress toward any of the seven communication goals. The organizational schema briefly outlined in this paper can facilitate the development of at least seven skills useful to intercultural communication.

NOTES

1. An excellent book by a sociologist from Antioch College analyzes communication problems that occur among American guests in Colombian homes: Raymond Gorden. Living in Latin America: A Case Study in Cross-Cultural Communication. Skokie, Illinois: National Textbook Company, 1974.

2. The subject of this paper is developed at much greater length in a book: H. Ned Seelye. Teaching Culture: Strategies for Foreign Language Educators. Skokie, Illinois: National Textbook Company, 1974.

3. The brief newspaper unit included here is one of the two dozen learning activities which are included in The Newspaper: Spanish Mini-Culture Unit. H. Ned Seelye and J. Laurence Day. Skokie, Ilinois: National Textbook Company, 1974. Other units have been published by National Textbook Company for French and German.

4. Erving Goffman. Relations in Public: Microstudies of the Public Order. New York: Basic Books, 1971.

5. Alfred North Whitehead. The Aims of Education. 1928.

6. Robert F. Mager. Preparing Instructional Objectives. Palo Alto, California: Fearon, 1962. 



\section{THE SOCIOLINGUISTIC DIMENSION IN STANDARDIZED TESTING}

\section{ORLANDO TAYLOR}

\section{Howard University}

During the past several years standardized tests have come under increased attack by a wide segment of the American population-scholars, parents, teachers, students, legislators, community leaders, and lawyers--especially those from nonmainstream and minority communities. These attacks are not surprising since it has become apparent that the use--and misuse--of standardized tests has resulted in the misassessment of a wide number of human traits, including aptitude, achievement, personality, intelligence, employment potential, and language.

Language is used as the vehicle of assessment in virtually all standardized tests irrespective of academic discipline. Thus, a comprehensive evaluation of standardized tests must, by necessity, include inputs from linguistics and other language sciences.

In general, most standardized tests are verbal, and presuppose that the test taker has a knowledge of the language, culture and values of the test maker(s). While it is reasonable to argue that standardized tests may be needed to assess behaviors in numerous subject areas, it is absolutely unreasonable for such tests to be constructed from the perspective of a monocultural model, when the test population is heterocultural. Monocultural tests are at best inhumane and, in the United States, they appear to be illegal. For example, Judge J. Skelly Wright of the District of Columbia Circuit Court ruled in 1967 that the use of culturally biased intelligence tests to place students in educational programs deprive low-income Black children of equal educational opportunity, as defined by the Fifth Amendment. Public Law 93-380 requires each state to guarantee that procedures be developed to 'insure that testing and evaluation 
materials and procedures utilized for the purpose of classification and placement of handicapped children will be selected and administered so as not to be racially or culturally discriminatory' (Sec. 613a).

Since standardized tests typically have some type of language component, and since linguists specialize in language, I argue that linguists need to become more activist in the area of standardized testing in general, and in the area of test bias in particular. Linguists have been too passive in these areas; indeed, they have had their heads in the sand.

The fact that there are so many negative results from biases in standardized tests in so many important aspects of life dictates that humane scholars should not only be concerned about the problems, but should seek to apply their technical skills to help reduce or eliminate them. The negative results of biased standardized tests are a matter of public record--job discrimination, poor self-concepts, negative teacher attitudes, low school placements, inaccurate educational diagnoses, discriminatory admissions to colleges and universities, etc.

The main thesis of this paper is that a test taker's chances for success on a standardized test are related to the similarity between the test taker's linguistic competence and the linguistic presuppositions of the test. Further, many sociocultural factors--ethnicity, socioeconomic class, region, situation, etc.--contribute to mismatches between the language of test takers and that of test makers. It is also the case that the styles of written language used in many tests are uncharacteristic of most people's speaking styles. Writing tends to form a layer of language distinct from and above colloquial speech, especially that of non-White and/or working-class children. Thus, we may assume that formal or frozen speech styles of tests are rarely heard, and that rare forms will invariably discriminate against any ethnic, racial, or cultural group which is not from the culture's mainstream.

In addition, the relative ease or difficulty involved in the decoding of a message is obviously related to the decoder's acquaintance with the general inferential context of the message. If this context--the so-called pragmatics of the linguistic message--is outside the decoder's experience, decoding may become difficult or impossible. Therefore, we may add another assumption: the chance of successful decoding of a written message decreases in proportion to the decoder's lack of familiarity with the contextual framework of the message. Measurement of linguistic abilities may contain strong biases because the language of the test taker may vary from the language he or she is presumed by the examiner to have. This fact has been apparent to sociolinguists for some time. Labov (1969), for example, is on record as stating that tests in standard English cannot possibly 
measure the ability of nonstandard speakers. Cazden (1966) called for the creation of 'dialect fair' tests of language development over ten years ago.

Research on sociolinguistic variations has defined many of the culturally determined differences that exist within a language. These differences can occur at all levels of language, including the phonological, semantic, and grammatical levels, as well as the aforementioned referential contexts of language. In tests where specific components of language and language skills are assessed--e.g. tests of auditory discrimination, articulation, vocabulary, etc.--one may discover the most overt examples of how language differences can influence test performance. However, language differences can influence test performance on other kinds of tests as well, because language is used in virtually all tests to give directions and to encode the information content of items.

To date, the study of linguistically caused sources of test bias have focused chiefly on diagnostic tests of general language ability, rather than on other types of tests. Yet, there have been some important exceptions in such studies as those of Griffin, Wolfram, and Taylor (1974), which have analyzed the Armed Forces Vocational Aptitude Test; and of Hoover, Politzer, and Taylor (1975), which have analyzed numerous reading and achievement tests.

Wolfram, Williams, and Taylor (1974) have shown that bias exists in numerous tests used by speech pathologists to assess the presence or absence of speech, language, and hearing disorders. For example, in the Wepman Test of Auditory Discrimination, a test in which examinees are asked to make phonological discriminations between minimal pairs in such words as pin/pen and wreath/reef, speakers of Southern English and/or speakers of Vernacular Black English-as opposed to Standard Black English--may encounter difficulty because many of the minimal pairs contain words which are pronounced alike in their social dialects. In other words, the test requires these examinees to make phonemic distinctions which may have no relevance in their dialects. Thus, this test is likely to underestimate the development of auditory perceptual skills in young children from these populations.

In another test, the Illinois Test of Psycholinguistic Abilities (ITPA), Wolfram et al. (1974) have shown that test takers who use grammatically nonstandard forms, e.g. hisself for himself or two cent for two cents, not only have their responses scored as being incorrect, but are falsely categorized as being delayed in language acquisition. Roberts (1970) has claimed that at least 13 of the first 50 items on the widely used Peabody Picture Vocabulary Test are biased against speakers of non-Standard English. In this particular test, each item carries an age weighting of approximately three 
months. If a person taking the test were to fail all 13 of these potentially biased items, the result would be a 39-month error in the assessment of the test taker's vocabulary development.

While language ability tests like the Wepman Test of Auditory Discrimination, the ITPA, and the Peabody Picture Vocabulary Test are diagnostic instruments for language function, they are also used widely, especially in the primary grades, to diagnose reading problems and to determine 'readiness' for reading instruction. They are also frequently used to estimate mental age equivalencies. Thus, biased interpretations on these tests not only lead to depressed assessments of linguistic development, but give rise to self-fulfilling hypotheses concerning the probable sources of reading and educational failures among groups of children who do not speak Standard English. Obviously, language does not exist as an isolated entity in testing, but contributes to the evaluation and interpretation of numerous other functions.

It should be noted that bias in standardized tests is not limited to the items themselves, but may be found also in the cultural and linguistic aspects of the total testing situation. Linguistic and cultural differences in the very activity called 'testing' can be sources of bias. These factors alone may have considerable impact on test performance. For example, a basic assumption of standardized testing is that it is perfectly appropriate for the testee to (a) be willing to provide obvious information--e.g. How many eyes do you have? --and (b) give a performance for a total stranger--the examiner. These basic social assumptions may be in direct conflict with interactional rules for individuals in some cultures. That is, some children may fail to respond to items on a test for reasons that are unrelated to the items themselves, but are related to the task expected. For example, it might be hypothesized that students from workingclass populations, especially Blacks, are less oriented to public performance of what is obvious to an audience of unfamiliar adults, than are middle-class children, particularly Whites. It might even be argued that the child rearing practices used by White, middle-class parents, which encourage public verbal performances for strangers, 'program' their children for eventual success on standardized tests.

Among older children from non-White working-class populations, there may also be an awareness of the fact that testing has been used as a vehicle of discrimination against non-Whites. It would be unrealistic to deny that this awareness, together with the test taker's total perception of the testing situation, might influence test behavior and performance.

By this point, it should be obvious to the reader that bias in standardized tests is not just a race issue. Test bias affects any group of persons who speak nonmainstream varieties of English. 
These groups would include, for example, those in which English is not the first language, or those who live in geographically isolated areas.

While there are many socioculturally related language factors which contribute to test bias, some of the most obvious examples are found when linguistic characteristics of Vernacular Black English are taken into account. In a very thorough analysis, Hoover, Politzer, and Taylor (1975) have documented specific sources of bias against speakers of this dialect on many standardized reading tests. 1 Their model is useful for analyzing any type of verbal standardized test.

At the phonological level, many reading tests discriminate against bilingual/bidialectal speakers in that they are asked to make distinctions among items which are homophones in their oral language. As stated earlier, the validity of this type of item is questionable. For example, Melmed (1971) has demonstrated that while many Black children have homophones in their speech that speakers of mainstream dialects do not have, this aspect of their phonology does not necessarily interfere with their comprehension. Shuy (1969), for example, has stated that many Black speakers need not find it difficult to discover that 'jus' is realized in print as j-u-s-t. The phonological rule might be that $[-s]$ in the word final position is realized as '-st' in print. This view is certainly no more unreasonable than other phonological rules which state that two graphemes are realized as one phoneme, e.g. [ $\theta$ ] in 'thumb', or [m] in 'thumb'.

Given that phonology need not interfere with visual comprehension, Hoover, Politzer, and Taylor have argued that the belief that discriminations between similar words out of the context of a sentence is an indication of 'reading proficiency' is not valid, particularly when the words are homophones in a social dialect. Two problems are created by the use of this type of item. First, teachers are led to the false assumption that the phonology of some Black children is incorrect. Second, the testing of discrimination of very similar words outside the context of a sentence can contribute to the mistaken notion that because sound-symbol relations for children who speak nonmainstream dialects may be different from those of other children, a phonic approach to teaching reading is not useful for them. This conclusion deprives these children of a major successful technique for teaching reading. There is some evidence which shows that a phonic decoding method in which teachers teach the spelling patterns of English from the context of the student's phonology is successful in teaching many nonstandard speakers to read.

Many subtests within standardized reading tests are designed to measure students' knowledge of sound/letter relationships in decoding. The Metropolitan Achievement Test contains a subtest of this type. 
It requires test takers to identify a dictated word from among several words. A careful analysis of the test shows many biased items, inasmuch as they contain possible homophones for dialect speakers, including certain groups of Black, Southern, and Chicano speakers, e.g. this/these; tap/tab; right/ride; fur/for.

With respect to syntactic sources of test bias, several examples can be shown. For instance, on the comprehension subtest of the Gates-MacGinitie Reading Test, the following phrases are found: 'Only the person to whom you make it out' and 'However in and of itself'. That such constructions often convey less information than do nonstandard forms has been demonstrated by Labov (1969). Yet, the directions imply that the comprehension test 'measures the student's ability to read complete prose passages with understanding'. But, these complete prose passages are written primarily in a form of language which discriminates against working-class children.

On the language expression subtest of the Comprehensive Test of Basic Skills, the test taker is supposedly assessed for his/her skills in oral expression. The test actually assesses how well students can discriminate between standard and vernacular English. For example, the examinee is asked to identify the following specific structures as 'wrong'.

They sees Rosa.

Don't never use too much.

You done it wrong.

Mother didn't let me eat no candy.

My brother has never et.

On the Oral Comprehension Subtest of the Stanford Early School Achievement Test, examinees are asked a series of questions on the poem 'Who Has Seen the Wind? Neither You nor I'. This segment uses the negative formation, 'neither you nor I', which would be superstandard to most children, awkward to most nonstandard speakers, and foreign to speakers of vernacular Black English. In addition, the poem is likely to be culturally alien to most working-class children.

A very specific source of syntactic bias that can arise in test construction is seen in tests which employ the multiple-choice technique. This technique frequently requires testees to 'pick a correct statement' from a group of incorrect ones. The instructions are often presented in a paradigm which contains the statement, 'None of the following is true except'. This kind of wording is probably confusing to a large number of persons, including linguists, regardless of ethnic or social background. The problem is related to the fact that one response is correct as described by a negation ('except') of 
a negation ('none'). Speakers of several dialects of American English, including most nonstandard dialects, typically operate with the syntactic rule that a double negative, or the negation of a negation, is simply an emphatic negative. Thus, for these speakers, 'none of the following is true except' could be interpreted as meaning that very definitely all of the following are false. Of course, if one uses the nonstandard negation rule, he/she is destined to fail items on which the information content may actually be known.

Cultural and vocabulary biases also contribute to test bias. Because of sociocultural factors, a testee may fail an item in a test because he or she is totally unfamiliar with the information contained in the item, or has a slightly different variation or interpretation of what he knows about the item, or sees it as a confusing piece of information which is very close to the item information. In each case, a person may fail an item--not because he cannot read, or is retarded, or is emotionally disturbed or perceptionally handicapped-but because of sociocultural factors. Examples of the above points may be as follows.

(1) Unfamiliarity. 'Point to the picture of the toboggan'. A person from South Florida may be totally unfamiliar with what a toboggan is, above and beyond unfamiliarity with the word.

(2) Different interpretation. 'Is this a picture of a house?' If a picture of a high-rise housing project building is shown, the respondent might say 'yes', while the test may presume 'no' if houses are thought to be always single detached units.

(3) Similar information. 'Are trains the only thing that run on tracks?' Some urban dwellers may say 'no' to the question since subways also run on tracks, while the test may presume 'yes'.

There is a general cultural bias in terms of the scene and subject matter of the comprehension and vocabulary sections of many tests. For example, the Comprehension Subtest of the Gates-MacGinitie Test has 34 paragraphs containing only a few pictures which are workingclass oriented. In most of the tests, middle-class values are assumed. In the Vocabulary Subtest of the Stanford Achievement Test, students are asked to respond to the following: 'If a person does something against the law, he is an (a) Ambassador, (b) Offender, (c) Official, (d) Officer'. Now the correct answer might not only be Offender, as accepted by graders of the SAT, but, depending on the respondent's political and social views, terms relating to persons who commit crimes might well be identified as All of the above. 
On the Vocabulary Subtest of the Gates-MacGinitie Test, the testee is asked to pick the best synonyms for inequality. Among the possible responses are 'absence', 'foreign', 'difference', 'similarity', and 'poor'. All except 'absence' and 'similarity' could be correct in a cultural group which perceives that 'difference', 'poverty', and 'foreign' are clearly associated with inequality.

So what should be done about test bias? Obviously, the mere elimination of test bias will not remove social biases or value judgments relative to the superiority of one language variety over another. However, culturally and linguistically biased tests reinforce these biases and give them the appearance of reflecting measurable scientific objectivity. The society generally presumes that speakers of certain language varieties--usually nonstandard varieties--are likely to have less ability and fewer skills, and the results of these tests only serve to reinforce these myths. Equally sad is the fact that all too often neither test makers nor the general public realize that the myths are based on a circular process. The communication habits and language of a specific ethnic group in a social class are somehow assumed to be 'worse' than those of another and, therefore, are not utilized in the test. The result is that speakers of these nonprestigious dialects do, in fact, score lower on the tests, thereby reinforcing the original myths and stereotypes. In other words, certain aspects of negative language attitudes have become institutionalized in tests.

The ultimate tragedy of test bias in schools is that both students and teachers seem to learn only too well the lessons that are implicitly taught by the tests. Research evidence shows that teachers' expectations of students are heavily influenced by speech style. For example, current research by Politzer and his colleagues at Stanford shows that teachers rate speakers of nonstandard Black English speech varieties as being less likely to succeed in school than speakers of standard Black English. The Black students of these very same teachers concur with their teachers' judgments. Obviously, these judgments can contribute to the 'pygmalion' effect discussed elsewhere by Rosenthal and Jakobson (1968).

What are some of the solutions to linguistic and cultural bias in tests? Should the tests be thrown out? Should they be revised? Should test content be altered, or should new tests simply be constructed? In regard to the first option, it seems reasonable to argue that linguistically and culturally fair assessment devices are needed to assess accurately potential development and achievement. Culturally fair tests could also be useful in determining appropriate educational placements and teaching strategies for students.

If the total elimination of tests is not a viable solution, then it is the bias and not the tests which must be eliminated. Various means 
could be employed to eliminate language-related test biases. One obvious first step would be to treat some of the specific sources of test bias mentioned in this paper as hypotheses to be tested in controlled experiments. In those cases where the hypotheses are confirmed, biased items would be removed or replaced. Also, test makers must be sure that new or revised tests contain items which reflect primary characteristics of nonmainstream cultures. In this way, nonmainstream persons will not always be placed in the position of having to perform from the perspective of the mainstream's culture and language. Obviously, these new and revised tests will have to be standardized on heterogeneous samples of the American population. In some cases, it may be necessary to develop a number of norms for a single test which are geared for specified populations.

No matter what approach is used to increase support for the elimination of test bias, it will probably not be effective if attacks on tests are done in a generalized way. Neither the general public nor the academic community is likely to be persuaded. On the other hand, concerns about test biases are much more likely to be raised if it is shown that item $X$ on subtest $Y$ of a particular test presupposes a linguistic rule which is likely not to exist in a given group of speakers. The case is made even more powerful when the specific impact on subtest and total test scores is demonstrated. Imprecision on the subject is likely to be perceived as 'excuse making' for those groups who do not do well on standardized tests.

In conclusion, it should be stressed that the linguistic and cultural biases in standardized tests are probably reflective of biases in the society as a whole. Thus, the total removal of cultural and linguistic bias from standardized tests may become possible only to the extent that the social stratifications which lead to linguistic and cultural distances are removed from, or at least reduced in society. The attempt to remove linguistic and cultural bias from standardized tests must therefore be part of the effort to make the United States a more humane society.

\section{NOTES}

1. A detailed analysis of several commonly administered reading tests is presented by Hoover, Politzer, and Taylor (1975).

\section{REFERENCES}

Cazden, C. 1966. Subcultural differences in child language: An interdisciplinary review. Merrill-Palmer Quarterly of Behavior and Development, 12. 
Griffin, P., W. Wolfram, and O. Taylor. 1974. A sociolinguistic analysis of the Armed Services vocational aptitude battery. Unpublished final report. Arlington, Va.: Center for Applied Linguistics.

Hoover, M., R. Politzer, and O. Taylor. 1974. Bias in achievement and diagnostic reading tests: A linguistically oriented view. Unpublished paper. National Conference on Test Bias, National Institute of Education.

Labov, W. 1969. The logic of nonstandard English. In: Georgetown University Round Table on Languages and Linguistics 1969. Edited by James E. Alatis. Washington, D.C.: Georgetown University Press.

Melmed, P. 1971. Black English phonology: The question of reading interference. Berkeley, Calif.: Language Behavior Laboratory.

Roberts, E. 1970. An evaluation of standardized tests as tools of measurement of language development. Language Research Reports, No. 1. Cambridge, Mass.: Language Research Foundation.

Rosenthal, R., and L. Jakobson. 1968. Pygmalion in the classroom. New York: Holt, Rinehart and Winston.

Shuy, R.W. 1969. A linguistic background for developing beginning reading materials for Black children. In: Teaching Black children to read. Edited by J. Baratz and R. W. Shuy. Washington, D.C.: Center for Applied Linguistics.

Wolfram, W., R. Williams, and O. Taylor. 1974. Workshop on linguistic and cultural bias in testing. American Speech and Hearing Association conference, San Francisco, Calif. 


\section{LANGUAGE AND POLITICS \\ IN THE UNITED STATES}

\section{SHIRLEY BRICE HEATH}

\section{Winthrop College and Stanford University}

0. Introduction. Currently, language and politics in the United States are inextricably meshed in the minds of many linguists, social scientists, and policy-makers. Exactly how the two are intertwined and how students of language and society can work with policy-makers to make the relatively recent union of language and politics a happy one is not clear. From an historical viewpoint, we know little about the role of law, public opinion, or educational institutions on relationships between language and politics. Yet daily we face folk notions about language in the political arena considered by those who hold these notions to be historically derived: English is the national language, national unity depends on a national language, good English reflects proper behavior, and facility in reading and writing insures socioeconomic advancement and fulfillment of the 'American dream'. As social scientists and linguists, we may suspect many of these folk notions, if subjected to empirical research, to be false. Moreover, when attitudes behind folk notions have been investigated, social scientists have not wished to prove them either true or false, but to show the relevance of attitudes to sociolinguistic topics and to point out the important social functions they serve (cf. Agheyisi and Fishman 1970, Shuy and Fasold 1973). Policy-makers find themselves constantly forced to admit the ideological bases of folk notions and the psychological support for identification and group membership they provide citizens. Those in politics often feel they have to defer to majority folk notions (especially those held by the mainstream), however unscientific they may be. Those who approach language and society empirically may insist that widely held notions, if found to be inaccurate and invalid, should not continue to lead to or be 
supported by policy decisions. Therefore, if policy-makers and social scientists are to work together--and they must--both groups have to recognize the unlikelihood of reaching total agreement on matters involving language and politics.

In order to effect as much cooperation as possible, however, both groups must work to separate myth from reality by describing with some precision relationships between language and politics, both in an historical context and from the viewpoint of theoretical research on the nature of politics and human language. Our purpose here is to clarify some relationships between language and politics through the use of data from social history. Focusing special attention on the role of constitutional and statutory law in educational policies, I am going to examine language and politics in three of those contexts in which they are most frequently linked in the United States today: multilingualism, literacy, and legalese. 1 Other language-related issues, such as sexism and obscenity, are also of importance and merit in-depth historical investigation. Discussion of the three issues selected here suggests, however, the complexities of examining areas of social behavior in which language is increasingly becoming a political concern. Moreover, two of the issues examined here, multilingualism and literacy, are and have been matters over which legislative and legal decisions have exercised direct and indirect control. The third area, 'legalese', has not generally been the object of legislative or judicial decision-making; yet use of this form of language provides certain aspects of control of governmental and legal agents and agencies. Politics is here broadly defined to include decision-making by political and judicial powers, and also concerns which U.S. citizens are currently expressing to legislators and personnel in government agencies (Crick 1972).

I place particular emphasis on the dual and often contradictory views of language as tool and symbol. Exploring these issues from an historical perspective will help us specify areas of research and application for social scientists and linguists, and new considerations for policy-makers regarding connections between language and politics in private and public domains.

1. Multilingualism, literacy, and legalese. That language and politics are related in the United States is for many a new revelation which has come in response to bilingualism in schools, public services, and courts. Forced recognition of the linguistic diversity of the nation has added to the uneasiness with which policy-makers and populace respond to the complex issues already surrounding the popularly bandied-about term 'cultural pluralism'. In addition, the populace may agree with Edwin Newman's prediction that Americans may well be the death of English (1974). Alarming reports that many 
high-school graduates are functional illiterates who can neither read, write, nor speak Standard English seem to provide ready support for those who argue for a return to the 'basics' instead of continuation of what they regard as the current frivolity in the teaching of reading and writing. Ironically, many of these same criers of doom complain out of the other side of their mouths that their own education and literate state do not qualify them to interpret many government publications affecting areas of their daily living such as housing, drugs, foods, insurance, and taxation. Alas, the basics they had in school did not prepare them for comprehension of 'technical talk', or legalese.

Language in politics focuses on the use of language as both tool and symbol. Broadly speaking, the political consideration of language as a tool has emphasized what a speaker may do with language. However, language is also instrumental in the benefits or denial of benefits its use may provide the speaker. The concept of language as a symbol emphasizes what language does for the speaker. However, individual speakers, especially those in politics, often recognize the active role of language as symbol, as well. Linguists and social scientists have demonstrated in sociolinguistic research the importance and strength of language as both tool and symbol. At times, the importance of language as a symbol may exceed its power as a tool; often a speaker's language does more for him as a symbol than he can do with it as a tool.

1.1 Multilingualism. Of the three major aspects of current relationships between language and politics, multilingualism is perhaps the most obvious. It is also the aspect most directly related to constitutional and statutory law. The Declaration of Independence and its 'self-evident truths' asserted axioms on the equality of all mankind, God-given rights to life, liberty, and the pursuit of happiness, and the rights of a people to reshape a government which did not honor these rights. The Declaration of Independence presented an egalitarian ethic which has shaped constitutional law. The fundamental, substantive goals pursued by the political system, specific rules which determine operations of that system, and patterns of access to participation in political decisions are established in constitutional law. Statutory law applies these basic fundamentals to specific categories and is enacted, amended, and repealed by legislative bodies in routine ways. At the bureaucratic level, governed primarily by legislative interpretations of constitutional law and by statutory law, the government allocates certain goods and services.

Neither the Declaration of Independence nor the United States Constitution specified language choice for U.S. citizens; the Founding Fathers did not single out English as the national or official language. 
In the terms of today's language planners, they did not select a specific code which would undergo elaboration and codification, and be the object of social and educational programs of implementation (Rubin and Jernudd 1971). Yet many language-related problems of the American colonies were similar to those faced by today's newly independent nations. For these nations, choice of an official language may be a recommendation from language planners and politicians alike. Linguistically and culturally diverse internal populations, the necessity of increased participation in worldwide science and business, and the need for widespread access to educational institutions were language-related problems which faced the Founding Fathers just as they do developing nations today (Fishman, Ferguson, Das Gupta 1968). But the leaders of the United States did not propose a solution to these problems at the constitutional doctrinal level. Nor did their private recommendations for statutory laws applying fundamental law to specific categories of behavior include designation of an official language, publicly sponsored plans for standardization, or restrictions on the uses of varieties of languages. 2

Given the diversity of languages, both Native American and European, and the Founding Fathers' plans to encourage immigration from all parts of the world, the framers of the Constitution could have proposed any of the following solutions had they considered multilingualism a problem: (1) establish a national language for official purposes, (2) provide relatively equal support of all languages, (3) proscribe certain languages, or (4) designate one national language and tolerate others without government support. Early national leaders chose not to endorse any language policy at the federal level. Instead, they recognized that decisions on language choice and change would be made at local and regional levels by citizens responding to communicative needs and goals they themselves identified. Moreover, early political leaders recognized the close connection between language and religious/cultural freedoms, and they preferred to refrain from proposing legislation which might be construed as a restriction of these freedoms. Moreover, the use of different languages and varieties of language helped to legitimate the political system by spreading word of its goals to a wide variety of citizens (Heath 1977). The intellectual climate of the times, which depended upon communication across language groups (especially in the sciences), supported maximum flexibility in language use. Some of the Founding Fathers, e.g. Thomas Jefferson, were themselves intensely interested in the study of languages; therefore, they recognized language as a total system and weighed its social effects in both private and public domains of usage. 
Whether or not the framers of the Declaration of Independence and the Constitution intended freedom of speech to include the freedom to use the specific language variety of one's choice will never be absolutely known. We have, however, been more certain through the years that the egalitarian ethic of these documents should be a legal and political consideration in matters of language choice. The fact that the U.S. Constitution contains no statement on the official language of the land is often ignored and replaced by the common assumption that English was the unspoken official choice. Many presume this choice did not need to be designated because the role of English as the majority language was so obvious as to make official declaration of its status unnecessary. Such an assumption belittles the intelligence and the political and linguistic sensitivity of the nation's early leaders. Examination of some of the ideas of the Founding Fathers illustrates their views of the multiple roles different languages and varieties of English could play in politics.

Perhaps best known are the views of John Adams, who held up English as a language of power in international politics. As a diplomat abroad immediately following the Continental Congress' struggles to draft the Articles of Confederation, Adams became firmly convinced that the power of a nation's language correlated positively with its political prowess. In Adams' view, Holland had not achieved the prominence in European affairs it deserved, because of a failure to extend the Dutch language beyond its national borders. Adams therefore judged it necessary for the United States to shape and maintain English for promotion of both language and patria. Moreover, Adams shared the conviction of many Europeans that without a people's continual awareness of laws of their language as well as of the political rules of their nation, both language and nation would 'naturally' degenerate. Adams suggested an American academy of language to codify English for presentation and extension to other nations along with the political philosophy of the new nation. English was to be self-consciously manipulated and expanded to make the United States distinguished abroad. Adams proposed the symbolic intertwining of language and politics as symbols of national prominence. The Continental Congress did not seriously consider his proposal. And though Adams supported the idea well into the nineteenth century, he did not propose it to Congress. 3

Though Adams seemed alone in recognizing the power of language in international politics, he was not alone in recognizing the importance of language in domestic politics. He and other Founding Fathers accepted the merits of speaking English, but they did not propose that English should displace other languages. Just as English represented a tool through which American citizens maintained access to British literature and political writings, so did other 
languages represent tools with similar practical purposes. Benjamin Rush, a strong proponent of the retention and spread of modern languages in the United States, expressed the concern that 'narrowminded' people, fearful of retention of the German language among Pennsylvania's citizens, would not recognize the benefits a 'German College' might provide the nation. The spread of learning among citizens, no matter what their native tongues, was crucial to the cause of the government. 4 Jefferson was concerned with what he considered the low quality of instruction in foreign languages in the United States, and took up this matter at great length in letters to young correspondents. He recommended the learning of numerous foreign languages, and whenever possible, in the context closest to the political heart of the United States. French should be learned in Canada, not France. 5 Joseph Story, a dominant figure in molding American equity jurisprudence, denied that a language could be built up which did not depend for its flexibility on borrowings, knowledge of other languages, and exchange of information available in languages other than English (Moore 1857:433). The dual goals of maintaining foreign languages in the United States and enabling those who did not speak English natively to learn English were pursued in the young nation. Attitudes in the late nineteenth century fostered the notion that these two goals were contradictory. Continuation of this view is perhaps the strongest deterrent to allowing language diversity in the public sector of the United States today.

To enable speakers of other languages to learn English easily, William Thornton, commissioner of the City of Washington in the 1790 s, forwarded to George Washington his plan 'respecting a Regulation of our Language' and asked that the President consider the work's potential contribution to national aims. This program, aimed primarily at those who wished to learn English as a second language, proposed a universal alphabet which included a single distinct character to correspond to each sound. Thornton had developed the plan after trying to teach his servant to speak and read English. He judged that diversities within the structure of English, particularly in phonology and inflection, had to be regularized to reduce the difficulties they presented to foreigners learning English. Moreover, he thought the orthography should be brought in line with the phonological system in order to enable native English speakers to learn to read more easily. Envisioning the application of his plan not only to the written languages of Europe and Asia, but also to the many unwritten languages of the world, Thornton wanted the U.S. to sponsor his scheme for the obvious benefits he believed it held for American citizens, and also for the credit it would bring the United States when the project spread to other nations and other languages. Apparently interpreted as an attempt to do away with the alphabet and considered 
too great an intrusion into the private lives of American citizens, the plan was never proposed for federal sponsorship. 6

The view that language was not an area for political manipulation was articulated most comprehensively in the responses of members of the political elite to an 1821 proposal for an American Academy of Language (Heath 1977a). Responses reflect an understanding of language as a total system and a keen awareness of the social basis of language. Men like Thomas Jefferson, John Marshall, and John Trumbull argued that though the designation of a standard English by mandate of a national agency might have value as a national symbolic gesture, the nature of language defied 'fixing' it. Unlike other national symbols, language was a tool--flexible, changing, and serving a multiplicity of purposes for the various sectors of American society. Moreover, language could not be a fixed symbol, for it was acquired in different settings amidst different speakers. Language in the United States was a matter of individual choice, either fated or fulfilled. One could choose to retain the speech of one's family and primary speech community, or an individual might choose to alter his language, select various styles or other languages in order to fulfill specific social or economic goals. Language choice was a matter of concern for social mentors, grammarians and rhetoricians, not politicians. Jefferson warned that the proper view should 'give strength and copiousness to language and enable it to be the vehicle of new ideas'. John Marshall proposed that the geographic and social mobility of Americans and the intermingling of classes would preserve 'an identity of language through the United States', but this identity should derive from choices made by individuals, not by public bodies. 7

The question of how precisely early national leaders perceived issues relating linguistic freedom and cultural diversity will, no doubt, remain open. However, it is clear that, at the very least, they supported individual choice in language matters and believed that no legal force should either proscribe or prescribe the use of various languages or varieties of English. Choice of language without coercion and maintenance of institutions by diverse language groups were, in the words of Benjamin Rush, 'the only possible means, consistent with their [citizens] liberty of spreading English' (Rush 1951:I, 366). Some state constitutions specifically provided for the publication of laws in languages other than English. In 1805, the laws of the Commonwealth of Pennsylvania were published in German, and the state legislature supported this practice until 1850. The laws of Louisiana were printed in both English and French from 1804 until 1867. Numerous volumes of Indian laws were published in the Indian languages in the nineteenth century. Newspapers, schools, clubs, and church activities promoting other languages throughout the nation were accepted. 8 
A mid-century shift of attitude toward various languages and language varieties is signified in the legend that an 1850 government proclamation held that the language of all diplomatic negotiations should henceforth be 'American English'. Attempts to dictate language choice were reflected in the political process. Contrary to the attitude of tolerance for instruction and use of languages other than English which had prevailed before mid-century, after 1850 statutory laws and local policies began to favor literacy in English, to restrict the teaching of other languages, and to limit opportunities for those who did not speak English (Leibowitz 1969, 1971, 1976). The sectionalism which preceded the Civil War heightened consciousness about regional speech variations and made Southerners particularly unwilling to use Northern grammar books in their schools (cf. Bullions 1864: 'an exposition of Grammatical science as applied to our language, and as used by the best Speakers and writers in the Confederate States'). Rigid attitudes about 'correct Standard English' were frequently expressed, and textbooks emphasized the cooccurrence of 'good talk' with good behavior, a moral character, and an industrious nature (Heath, to appear, b). The Civil War intensified awareness of language as a mark of social and economic background; citizens were more anxious than ever to use language as a mark of social and educational security. Increasing numbers of immigrants were illiterates from a wide variety of national and linguistic backgrounds. In 1850, the Pennsylvania legislature repealed all previous acts of its assembly providing for printing legislative journals and laws in the German language. During the next half century, nearly all the states which had at one time provided for the publication of laws in languages other than English repealed these provisions; at the turm of the twentieth century, only the legislature of New Mexico provided for publication of its sessions' laws in a language other than English (Fedynskyj 1971).

The concerned voices of those who advocated maintenance of language diversity in the United States died out quickly, as other voices rose to proclaim that study of the correct language would lead men to the truth, higher morals, and the social promises of America. Schools were operated as 'cultural factories' (Schultz 1973) and, increasingly, statutory laws failed to carry out the egalitarian thrust of the Constitution. The way of dealing with 'strangers' and their differences was to educate them to use 'good American speech', and motivate them to conform in the Americanizing process (Carlson 1975, McLean n. d.). The individual's right to deviate from Standard English as a tool was now limited by the application of the symbol in educational institutions. The notion that individuals who were illiterate needed to have their choice of culture and paths of assimilation chosen for them in order that they might become 'equal' was voiced 
with more frequency. Continuation of these ideas throughout the First and Second World Wars is well known, as language prejudice against German and Japanese was codified in state laws. The xenophobia of these wars and the fears that those who did not speak English would not support the U.S. cause led to restriction of information transmission as well as to forced methods of assimilation through acquisition of a national symbol and tool (Kloss 1966).

We are only beginning through attitude studies by social psychologists to learn about language prejudice. However, Allport's classic (1954) on prejudice and a recent study (Black 1976) of the behavior of law' point out that laws and public policies establish ethical norms for individual behavior; laws discriminating against languages other than English provided private citizens with rationales for their personal prejudicial conviction.

Of special import in approaching issues of language and politics in the twentieth century is the issue of constitutional and statutory law just discussed. Certainly, most recent decisions related to language have made us conscious of being involved with law at the policy level where political decisions determine specific substantive allocation of values. Specific individuals and groups attempt to realize their personal interests in support of one or another policy decision. Recently, in particular, there has developed an essentially unidimensional conception of politics. Oriented toward maximizing personal interests within constraints imposed by society, the political process has increasingly become bogged down in the matter of bargaining for policies designed to achieve the ends of one or another interest group--now often specific cultural or ethnic groups. Frequently, constitutional law is either ignored or obfuscated. Moreover, some recent judicial decisions which make social policy are not 'interstitial' statutory interpretation; instead, they counter the legislative history of the statutes. This charge has been specifically made with respect to the Lau vs. Nichols Supreme Court decision (Horowitz 1977).

Therefore, though we may be more conscious of policy and process than we are of fundamental law, we need to remember it is the nature of our political system not to separate this level from constitutional law. One difficulty has been that though statutory law is intended to apply the basic fundamentals of constitutional law to specific categories, amendments have introduced into constitutional law consideration of areas of application as well, in provisions related to education, patents, copyrights, public debts, etc. This has been particularly the case as the constitutions of individual states--for example, California--have become increasingly detailed (Brennan 1977). Hence, in areas of language, as in many other areas, conflicts arise between the federal and state constitutions and between 
statutory law and constitutional law. Legitimating myths or presuppositions often develop which support policies and processes but which deny or contradict the fundamental goals and rules of operation of the political system.

The specific section of the Federal Constitution which is perhaps most related to language decisions is Section One of the Fourteenth Amendment, which reads: 'No state shall make or enforce any law which shall abridge the privileges or immunities of citizens of the United States, nor shall any state deprive any person of life, liberty, or property without due process of law, nor deny to any person within its jurisdiction the equal protection of the laws.' Many essential elements of the Bill of Rights are incorporated into the Fourteenth Amendment, including due process of law. The amendment has been used to protect freedom of speech, press, and assembly from interference by the states. Section Five of the Fourteenth Amendment grants Congress the power to enforce provisions of this article by appropriate legislation. However, interpretations and statutory provisions made by the legislative branch may be viewed by the courts as not providing equal protection. 9

One major area of concern where statutory provisions and policies may contradict constitutional law is the need of a state to classify its citizens for various purposes and to treat some differently from others. Any major legislative program may require many population classification decisions expressed in statutory laws. These classifications may be challenged as denying equal protection. Only if a classification can be shown to include all of those persons similarly situated with respect to the purpose of the law can it be interpreted as insuring equal protection. If a purpose which is discriminatory and denies equal protection can be ascribed to the classification, the court may rule against statutory provisions. Classifications in education on the basis of tests of language dominance or fluency, and class or track assignments according to standardized tests of intelligence and performance in Standard English are thus being challenged in the courts of New York and Illinois. Inference of motives for classification introduces the matter of whether or not the teaching of English is to be considered a necessity because of an implicit assumption that education should be an institution of compulsory standardization. Of particular importance in this respect is the distinction courts make between congenital characteristics, such as race and lineage, and traits which may be altered, such as nationality and language. Should greater protection from discrimination be provided by law for those exhibiting congenital traits than for those characterized by traits viewed as alterable if the individuals involved wish to be altered? 
This is a gray area with respect to language in the U.S., because of two primary considerations--the nature of the differences between first and second language acquisition, and the association of marked or minority languages with racial classification. In the words of Karl Deutsch (1975:7),' 'Language is an automatic signaling system, second only to race in identifying targets for possible privilege or discrimination'. The child born into a family which does not speak Standard English must initially learn the language of his home. Once past early childhood, he cannot easily change his language or acquire a second language. He is in many respects stuck with the language of his early environment or, at the very least, with specific linguistic features or habits which signal his native tongue or dialect and mark him as a passive target for discrimination. The courts have traditionally concerned themselves with judicial treatment of 'suspect traits', i. e. any classification, such as race, which has historically been perceived in America as a stigma of inferiority. There are some who argue that the current intent of compensatory-transitional bilingual programs is to 'salvage the child' by replacing his marked language with an unmarked language. If so, is this not evidence that having any native tongue other than English is a stigma? Unless maintenance of the marked language becomes a recognized viable goal for communities of both marked and unmarked languages, compensatory-transitional bilingual programs will continue to have the support of the general view (which has developed in our society since the late nineteenth century) that speaking a language other than English is a deficit, not an asset. Moreover, there is a growing suspicion that maintenance programs have the greatest chance of success in the U.S. in terms of both student and community support when the marked language (for example, French) is not generally associated with racially visible minorities. Can maintenance programs for Hispanic or Native American languages, linked in the minds of U. S. citizens with racially visible minorities, have the same kind of success that Maine's French bilingual programs have had? Within these, improvements in both language skills and attitudes toward French have resulted (Lambert and Giles n.d.). The fact that, in the U.S., language prejudice intensifies with not only class differences but also racial differences has implications for the courts' realistic consideration of language as a 'suspect trait'. It is conceivable that the courts may determine that opprobrium readily attaches to language. If so, further judicial treatment of language classifications may be forthcoming.

This is not an issue which has been faced squarely by the courts. Justice Holmes in 1927 referred to the Fourth Amendment as 'the last resort of constitutional arguments' (Buck vs. Bell 274 U. S. 200, 209). Courts prefer to rely instead on statutory laws. The Lau vs. 
Nichols decision of 1974 relied on Title VI of the Civil Rights Act of 1964 which outlaws discrimination in federally funded programs. Using this statute, the Supreme Court determined that there was not equality of treatment merely by providing students who spoke only Chinese with the same facilities, textbooks, and curricula as those who spoke English (414 U.S. 563). The details of the Lau case, the 'Lau Remedies' of 1975 , and difficulties of bilingual programs attempting to determine methods by which to remedy the discrimination have been reviewed elsewhere. 10 Most important for our purposes here is the fact that lower courts ruled that uniform use of English did not constitute unlawful discrimination because of the Americanizing purpose of U.S. schools and the central role of English in that process. The Supreme Court ruled simply that the Chinese-speaking minority received fewer benefits than the English-speaking majority and were thus denied a meaningful opportunity to participate in federally funded education. The majority and concurring opinions did not directly address basic issues raised in the lower courts: what is the role of English in the schools as Americanizing institutions? is linguistic discrimination the same as discrimination on the basis of 'race, color, or national origin'?

Specific ways of remedying the discrimination against non-Englishspeaking students were not provided for in the law. The court did not hold that any specific action should be taken; it simply forbade inaction. Particular programs of action are now being debated by policy-makers, social scientists, and educators, and representatives of different language groups are making intense efforts to realize the specific goals of their own culture group with respect to language. To further complicate implications of Lau, spokesmen for various language groups are calling for changes in public services and private industries which will insure a bilingual work force in specific regions of cities and states where there is a predominance of non-English speakers. Under the suggestions made by such spokesmen, bilingual services would be provided in all sectors of public service: government social intervention agencies, courts, transportation, fire protection, communications, and publishing (Reyes 1977). The issue of the purpose of public schools and consequently the role of language choice and control in educational institutions has yet to be clarified. Expediency in responding to policy decisions and the courts' interpretation of statutory law have masked some very basic and critical issues related to rights and privileges. In the flurry of implementing and enforcing Lau and its remedies, we cannot say whether or not the egalitarian thrust of constitutional law extended to language in the early nation is today in force. Whether the goal of Americanization supersedes the egalitarian intent of the Constitution is not clear: does the question of all persons being equal mean that this is a principle to be 
honored in treating all persons so that their opportunities are the same or does the equality issue imply making all persons the same? In Meyer vs. Nebraska in 1923, Justice McReynolds (dissenting) recognized this issue: 'The protection of the Constitution extends to all, to those who speak other languages as well as to those born with English on the tongue. Perhaps it would be highly advantageous if all had ready understanding of our ordinary speech, but this cannot be coerced by methods which conflict with the Constitution--a desirable end cannot be promoted by prohibited means' (Meyer vs. Nebraska, 262 U.S. $390,401)$. However, the decision went ahead to state that the court did not question the power of the state to compel attendance at school and to make English the language of instruction. The central issue of equality in language choice remained unresolved then and in the wake of the Lau case as well.

1.2 Literacy. Literacy, the ability to read and write, is valueladen, and many of the specific values attached to literacy are not explicitly laid out in policies. Yet, legislative and legal decisions promoting or requiring literacy are made in response to and in support of these values. Quite apart from the basic communicative functions of literacy, society values 'correctness' in orthography, punctuation, vocabulary choice, verb agreement, etc. Attention to 'proper' use of language as tool is important. However, of greater importance for policy implications are assumptions about the instrumental benefits--social, economic, political, and aesthetic--of literacy and the denial of these benefits to illiterates. An underlying assumption has been that a literate public was one provided for by the educational process. An informed literate citizen could effectively participate in the political process and could also improve his chances of economic success. Laws restricting voting to only those literate in English were based on the notion that if one could read English, one would therefore comprehend and apply knowledge acquired through reading to make judgments more sensible than those made on the basis of opinions and information received in other ways. This notion contradicted assumptions made during the early period of U.S. history when, in spite of a relatively high literacy rate, the transmission and debate of ideas for political analysis and evaluation was primarily oral. Stump meetings, the lyceum movement, debating clubs, and literary societies give evidence of the society's emphasis on talk for exchange of information. Conversation across various sectors of society was highly valued for the immediate review and challenge of ideas it offered (Heath, to appear, a). Legitimation of the nation was dependent not only upon literacy, but also on a public willing to debate ideas orally. The records of Congress were printed 
originally not to inform the American people, but rather to preserve the records for historical purposes.

After the mid-nineteenth century, literacy came to be viewed as the predominant means of gaining access to political information, and newspapers became the primary means of exchanging ideas. Even before mid-century, there had been forecasters of the switch from dependence on public debate and oratory to reliance on newspapers. The public speaker who formerly spoke only to citizens of his own town could 'speak' to a nation through the press. Grimke noted (1834:29):

He [the orator] speaks not merely to influence the hundreds who hear him; but thousands and tens of thousands who never see his face or attend to his voice. To them he must speak thro' the press, that master-piece of modern genius, that master-workman in the cause of the people. Delivery the all of eloquence, becomes the almost-nothing of eloquence, in the judgment of the American orator.

Americans turned their attention away from analyses of conversation and promotion of public oratory to

... the eloquence of the literary department, whether of the periodical press, of anniversary orations and addresses, or of occasional pamphlets, written for the instruction and to promote the welfare of the people. What a vast amount of writing solely for the people! (and indeed all that is written and spoken in this country is for them). (Grimke 1834:30-31)

Literacy and literate sources were both tool and symbol of knowledgeability. Verbal art as performance shifted in both audience and channel.

This shift from oral transmission of information to dependence on written sources gave ammunition to those who argued that literacy among immigrants was necessary because they must be able to read English in order to assess the relative merits of political candidates and to participate in the U.S. political process. This stress placed great emphasis on education for assent, not dissent. The teaching of values through literacy in English was a given. The use of Standard English in writing became a matter of cultural imposition. Judgments of society on the need to emphasize reading and writing a standard form of English affected the schools' policies and legal decisions on the use of other languages in public and private education (Kluwin 1977, Heath 1977b). The student was introduced to texts in which basic rules were enshrined, and the implication was that if he 
made a mess of his language and consequently his life, the responsibility would be his own.

Everywhere those who felt it necessary to justify the imposition of standards proclaimed that industrialism and nationalism demanded literate citizens. However, in practice, literacy as a tool was not necessary for the mass of workers. Learning through doing was the major training method. Language came, however, to be viewed as symbolic of an individual's morals and commitment to the work ethic and national membership. Education was used to demarcate as well as to acculturate. 11 In the late nineteenth and early twentieth centuries, an increasing number of states passed rulings restricting the use of languages other than English in the schools. Congressional bills proposing to restrict immigration by requiring that immigrants be literate in 'English or some other language' shifted to a call for literacy in English. Before 1906, there was no prerequisite in naturalization laws that an alien either speak or be literate in English. However, the Nationality Act of 1906 required that an alien speak English in order to become naturalized. Codified in the Nationality Act of 1940, this requirement was extended in the Internal Security Act of 1950 to include demonstration of an ability to read and write English (Leibowitz 1976).

Today, the symbolic value of literacy for economic advancement and political participation remains. Yet since 1920, the increase of radio and cinema and the current dominance of $\mathrm{TV}$ in our lives make us question the extent to which literacy is actually used as a tool for accomplishing those purposes which we have ascribed to it. For example, vocational programs replace traditional curricula for many students. Reading and writing skills are minimized; the apprentice or demonstration system is used instead of the composition-centered approach. Many industries, such as textiles and food processing, make minimal use of written materials in their on-the-job training programs.

The question of literacy as a tool necessary for economic survival is one which we do not wish to face, because in doing so, we seemingly attack a set of instrumental and symbolic values we have held in connection with liberty and equality in our democratic educationoriented systems. Nevertheless, the question must be addressed today in terms of language and politics. Compulsory attendance requires that students remain in school for a certain period of their lives; the assumption is that these students will acquire literacy and skills necessary for their own maintenance in our society. However, recent research has shown that many of those who become minimally literate fail to retain their literacy once they leave school, presumably because television rather than printed matter provides information and entertainment, and the telephone replaces the letter as a means 
of personal communication. Do those who hold many jobs basic to our society's economy need to be able to read at an 8th grade level to train for and hold their jobs or to understand political choices? That question is made all the more debatable, because many who can read do not choose to do so when making political judgments or training for jobs. Instead they form their decisions on the basis of conversations with others, newscasts, TV editorials, and headlines and photos. Supposedly, newspaper reading has increased; but the language has grown simpler, and the proportion of sports, comics, social and psychological guides and pictures has increased (Lewis 1953). One of my students summarized the situation when he said, 'Who needs to read? I can learn all I need to know by keeping my ears and eyes open.' Current case histories of the illiterate individual in U.S. society illustrate the wide range of coping mechanisms adopted by those individuals in a society which increasingly accompanies written matter in public arenas with pictures and symbols. 12

In developing countries, there is a move from formal education to informal education (LaBelle 1976). Should the exclusively traditional emphasis on the acquisition of literacy skills which may not relate realistically to the motivations or needs of many of those in the job market be continued, when other emphases may be more effective? Does literacy have an unlocking effect on productive human potential? Development economists have answered these questions negatively for other parts of the world (Engelsing 1973). Here in the United States, recent studies of colonial New England show that an increase in literacy did not necessarily correlate with socioeconomic advancement (Lockridge 1974). A recent social history of the nineteenth century suggests that the striking shift which the emphasis on literacy and standardization brought during the second half of the century produced widespread 'f reezing of accomplishment at a superficial level' and 'intellectual evasions' (Calhoun 1973:321). However, in spite of the questions research has raised, educational policy-makers accept the myth that choice of English, acquisition of literacy skills, and use of standard 'correct' language will 'improve' individuals.

Why do we cling to this myth? Institutionalized in a great variety of concrete ways, myths often persist beyond their ' $f i t$ ' with the realistic circumstances of the society. Consequently, such seemingly useful myths as 'literacy is good for all' may remain outside definitive periodic reexamination, because they are institutionalized in schools and national political agencies. Moreover, myths become symbols of collective identity seemingly shaped from a continuous reconstruction of symbols existing from past traditions, such as those which developed around literacy in the second half of the nineteenth century, when education seemed the way to achieve equality in the American dream. Particularly in a time of renewed 
examination of national unity, we may ritualize symbols on personal and collective levels. We reinforce these by claiming a positive connection between their role in our own personal identities and their import as symbols of the political and social order (Eisenstadt 1972). Thus literacy, because it has served the mainstream professional who makes policies related to language in education, is recognized by such individuals as not only a personal value, but also as a collective national symbol and a tool, which if adopted by others would surely bring them personal benefits.

1.3 Legalese. Directly related to both the multilingualism and literacy issues is the extensive use in private and public domains of terminology and grammatical structures peculiar only to 'technical talk' and legalistic documents. This language is marked by an abundance of special vocabulary, usually highly latinate; prepositions, including suffixed prepositions (such as hereafter, herein); internally modified phrases and clauses; and passive voice. Minimal use of punctuation often adds to the ambiguity of the relations among words and phrases in the long and complex sentences of legalese. As a result of the need to standardize treatment of individuals in government social intervention programs, guidelines issued to stipulate controls within these programs contain standard formulae of what has come to be known as 'legalese'. These documents are generally issued only in English, even in areas where most residents do not speak English as their native tongue. To get into these programs and to participate in many other routine aspects of daily living requires extensive use of questionnaires and applications which also abound with formulaic language. Entering school, moving into government housing, registering weapons, purchasing a car, getting insurance, or reading directions and descriptions on drug packages necessitates the use of forms and formulaic language. This legalese is often justified by the fact that the government must protect itself from suits and must therefore be certain that all individuals receive the same information, and that this information contains no 'loopholes' for misinterpretation (cf. Quirk 1968:167-68). The government is concermed with equality and protection, and it does not want to be charged with unequal treatment in social intervention programs.

However, many sources of information which do not involve the need for legal protection of either party are now written in this language. For example, those who move into government housing may be given recommendations for care of their house which include such statements as 'Wood when subjected to conditions of moisture tends to deteriorate.' One senior citizen, distressed over this kind of 'foolish' language asked, 'Why can't they simply say "when wood gets wet, it rots?"' In another town, the conditions of occupancy issued for 
inhabitants of federal housing contained this statement: 'The tenant must provide at least one standard 35 gallon galvanized garbage receptical [sic] and a lid. The tenant must keep this area orderly and provide other adequate garbage recepticals [sic] with lids if conditions are such that otherwise the area would not be maintained in a sanitary condition.' One response to this statement was 'Why, my goodness, I wouldn't know what to do with my trash!' (cf. Gumperz 1968).

An implicit assumption in education, and one on which many parents from lower socioeconomic classes often depend, is that if children are taught to read and write in school, they will acquire tools which will enable them to function more effectively in society than those who do not acquire such tools. However, no schools teach the comprehension of sentences such as those which direct individuals in public housing in such details of daily living as how to maintain floors and select garbage cans. Filling out forms and understanding legalese are not skills explicitly taught in schools. If this language is to become the 'standard' guiding many aspects of our daily lives, we have to face squarely the question of either teaching its use and comprehension in schools or providing interpreters at local levels. Although given the task of implementing guidelines, carrying out directives, and effecting the implications of literate materials and institutionalization on the private domains of many citizens, local branches of federal offices often provide no personnel who are able effectively to translate or interpret legalese for clients.

We can better understand how this is possible when we realize that even the most academically successful graduates of educational systems often cannot understand legalese. However, they get by, and even profit, because they come from cultures in which they have been taught how to ask what specific items mean, or because they are able to pay professional interpreters, such as lawyers or CPAs, whose specialized task it is to understand such language. The compulsion for using legalese has washed over into many areas of life other than specifically government-related activities; advertisements, insurance circulars, and local consumer publications often use a kind of legalese to give their messages 'authority'. Current efforts at 'truth in advertising' and simplification of the language of insurance stem from recognition that numerous individuals are persuaded (and sometimes deceived) by language which seems to carry authority. Legalese, probably intended initially to be a language of protection, has become a symbol and, perhaps unconsciously, a tool of deception for many sectors of the population.

2. Conclusions. We have promised directions of reorientation for social scientists, linguists, and policy-makers, and we have 
suggested the benefits which new research and evaluation emphases might bring to language and politics in the United States.

From anthropologists, we ask for ethnography of communication studies in what Dell Hymes (1976) has termed terra incognita, the communities of the United States. Policy-planners could benefit from knowing about the evaluations and uses of language (or languages), literacy, and methods of coping with legalese within specific cultures. We often know more about these issues for groups in remote areas of European villages and African societies than we do about groups in our own nation. Such information is critical to the determination and implementation of bilingual programs; we need information to help us determine how community and school may interact in these programs, what functions specific communities hold for their native language-religious or recreational/social, secret or public, and how and where they incorporate English. Such data are obviously important for education programs where the teaching of language and literacy is a prominent issue. However, the knowledge gained from ethnography of communication studies has wide application in programs of 'normalization' and intervention involving the most intimate areas of the daily lives of members of different cultures: mental health, birth control, alcoholism, child rearing, and housing.

From sociologists, especially those housed in departments with social work programs, we ask for institutional studies of the uses of language in public assistance agencies interacting with individuals from different cultures. A few such studies carried out by my students have shown what we perhaps might have expected: individuals hired at the lower levels of agencies to interact with people from their own communities quickly adopt legalese and become rigid in their use of technical talk. Higher level administrators, who rarely interact with the public, are not afraid to translate or interpret documents or break away from technical talk. Empirical studies may help influence specific considerations of language use in training programs for personnel of public assistance agencies.

Political scientists have traditionally not been concerned with language as a total system, but have concentrated instead on uses of language in mass media, political rhetoric, and societywide responses. 13 Either community or institution-specific analyses of the power of language as a total system and the role of what Weinstein (1976) has called 'language strategists' are needed. The work of William O'Barr and his associates in anthropology, political science, and law has contributed much to our knowledge of the power of varieties of language on witnesses and juries in North Carolina. 14 Such work should increasingly include lawyers and judges, if linguists and social scientists hope to influence decisions to change the language of jury 
instructions and to insure that legal notices are issued in the language of the recipient. 15

Political scientists have also, perhaps more than those of us in other social science disciplines, brought value theory into the open. Some political scientists are now stressing the need for gathering information to more effectively evaluate the relative efficacy of alternative means for realizing political ends. 16 Recognition of diversities of cultures and languages and different valuations of language within different social groups requires new justifications of normative judgments made by policy-makers. For example, Van Dyke (1976) has pointed out the normative nature of interpretations of language policies and the principle of equality and nondiscrimination with respect to that portion of the UN Charter which requires member nations to promote human rights 'without distinction as to race, sex, language, or religion'. For the United States, normative inquiry may help clarify what constitutes equality and what constitutes discrimination in language for both internal affairs and for the nation's commitment to the terms of the UN Charter.

For linguists, especially those who will accept historical sociolinguistics as a viable field, language and politics provide a wealth of unexamined materials. which will contribute to the development of a societally based theory of language. For example, court decisions on the First Amendment provide the evolution of legal stances in answer to the question: 'What does language do in society?' In the cases of the $1940 \mathrm{~s}$, language was viewed as having the prime purpose of communicating ideas as a step toward the determination of truth; it was believed that truth would lead to the improvement of society, which was the ultimate goal of the free speech guarantee. Later decisions considered the need to weigh the harm speech can do to listeners against the value it has for the speaker. Other issues in recent cases have been the social value of communication of ideas versus communication of emotions, and the equation of violent language with violent behavior. 17

Other questions of interest to linguists which will remain unanswered without holistic, cross-cultural, and historical-legal approaches are: What aspects of oral communication change most rapidly when a traditionally oral community becomes literate? How did the notion of a Standard English evolve among people of the United States? An ongoing language survey of Montana indicates there are seventeen different languages, excluding American Indian languages, in use in institutions in that state (Beltramo, to appear). Recent census data indicate there are far more bilinguals and monolinguals in languages other than English than earlier census materials revealed (Waggoner 1976 and to appear). Yet we know little about the history of language use and maintenance among specific immigrant 
groups in different parts of the country. How does the language of groups speaking the same language in different parts of the country differ in structure and function, and what have been the relative strengths of specific sources of change on both the language and language attitudes? What forces patterned and conditioned language standards in certain contexts in the past? In the early nineteenth century, women (even when not highly literate) were believed to have the greatest amount of influence on the speech of professional men; yet today we believe such models must come from only professional materials and highly literate individuals.

Perhaps of more immediate connection with the Lau remedies than all of the questions I have listed are requests that linguists show a specific concern with definitions of the terms used in Lau, tests of language fluency and dominance, and methods of assessing strategies of language teaching for students of various ages. At present the most pressing problem is tests used for student classification. There seem to be no satisfactory measures of language dominance or fluency, and no tests which reflect the child's use of language in his own environment. Is this because such tests cannot be devised or is it because linguists have not placed the task of devising and evaluating these tests high on their research priority lists? As language and politics continue to be critically meshed in policy-making and legal decisions, linguists and social scientists will be held accountable to different audiences than those to whom they have been accustomed in the past. Recently, linguists and social scientists have found their work 'on trial' in courts in cases involving tests of fluency for admission to bilingual education programs, questions of synonomy in advertising, and issues of intelligibility when legalese used in corporation information statements may have made comprehension by workers difficult, if not impossible. As legalese becomes more of an issue in the political arena, linguists may expect to be called on to provide new tests of comprehensibility.

Research strategies formerly applied to materials removed from legal decisions and educational policy-making will increasingly have to be tested on new language data in different contexts. Methods of analysis used to treat presuppositions and anaphora in folk tales and myths could, if applied to texts of basal readers, tell us much more than we now know about cues for comprehension which are specific to mainstream school contexts. Coupled with knowledge of oral traditions, expected paths of narrative progression, and materials from ethnographies of communication in communities of nonreaders, these data would provide much-needed information about cross-cultural interferences in the process of acquiring literacy. The current work of Cook-Gumperz on the socialization of children into literacy promises to give us both formal and substantive knowledge about specific 
features of the preschool child's experience with a predominantly oral culture which can be incorporated into teaching reading skills. This work points out that children enter school without knowledge of the assumptions underlying the written word which the school holds. Accurate and complete descriptions of language socialization, both inside and outside school settings, must delineate the components of social-developmental learning which entry into a reading and writing world (where the text often becomes its own internal referent) requires. The work of Labov (1976) on oral narratives and the carryover of skills in this verbal art to writing abilities, provides data useful for teaching literacy to adolescents and adults.

For policy-makers, the union of language and politics and the relationships of this union to policy decisions in education, housing, consumer affairs, and social intervention programs have resulted in the need for reassessment of the role of social scientists and social science data and techniques in the policy-making process. 18 Decision-makers must demand comprehensible reports of social science research, clear statements of data bases and statistical assumptions, and commitments for involvement in implementing decisions. Policy-makers must be particularly careful to determine whether or not social science data are used for interpretive or causal judgments; causal judgments in social science are often based on correlations of social phenomena which are open to rapid change and arbitrary selection. Interpretive judgments must be framed in the vocabulary and value system of the community in question; moreover, their embedded position in the culture complex of the group being described must be made clear. Social science research can help policy-makers question the basis of decisions which may have radically different effects in communities of different cultures. Policymakers need social science data to help answer such questions as the following. How might the teaching of ways to interpret legalese affect efficiency of operation for regional and local government agency offices? Can informal education in nonschool contexts take the place of some literacy teaching in school settings? Requests for proposals to be submitted to government agencies for funding should require that a basic description of the research data base, methods, and conclusions be provided in format and language comprehensible to lawyers, judges, and policy-makers. In turn, policy-makers need to examine the necessity for their own use of legalese and technical talk in many publications unrelated to areas in which legal protection may become an issue.

For social scientists, linguists, and policy-makers, the most important recognition is that we must not have closed minds about an open system; we must be both skeptical and inventive about language as tool and symbol in politics within the United States. In that 
context, we may find relevant the historical perspective given in the observations of an early American on our three central concerns of multilingualism, literacy, and legalese. In the period between 1792 and 1815, American periodical readers were treated to installments of Modern Chivalry, a lengthy and somewhat chaotic expression of the political and social philosophy of the early national period. One chapter (Brackenridge 1937:419-22) tells of a town fair, in which language and politics in the United States come in for a large share of the bite of the author's satire. The fair contains a 'learned pig' who speaks numerous tongues. A Scotsman in the crowd asks 'Has he the Tongues ?' This question prompts a dialogue between the Scotsman and a passerby, who answers, 'He has two. The Hebrew and the Erse--No, the squeel [sic] and the gruntle.' 'That is his vernacular,' said the Scotsman, 'but I mean his acquired language.' 'I do not know that he has acquired any,' said the passerby, 'but he is considerably perfected in those that he had before.'

The conversation is interrupted by a political candidate bitterly protesting his opponent's charge that he has a rèputation as a scholar. 'I a learned man? it is a falsehood. See me reading! He never saw me read. I do not know a B for a bull's foot. But this is the way to injure a man in his election.'

The fair is later disrupted by a crowd of people singing a song containing this verse:

Down with the sessions and down with the laws; They put me in mind of the school-master's taws.

There's nothing in nature that gives such disgust

As force and compulsion to make a man just.

\section{NOTES}

1. This paper was written while the author was a visiting scholar in the Department of Linguistics at Stanford University. The paper is written from an anthropological and linguistic perspective of language form and function in society, but it utilizes methods and materials from social history, political science, and law. It has benefited from discussions with and materials provided by Joan Rubin, William O'Barr, Brian Weinstein, and Jonathan Pool, each of whom has contributed to research on the topic of language and politics. The shortcomings in the paper remain in spite of their efforts.

2. England had not formulated language policy for the American colonies. Instead, the mother country provided policies directed toward other areas of sociopolitical and economic control. These policies provided a configuration out of which local agents formulated and implemented policies in response to language problems (Heath 
1976). For a specific discussion of responses of the political elite to the idea of authority in language choice between 1776 and 1820 , see Heath 1977a.

3. Adams, Diary II. 446-48; Works, IX. 509-10; Papers of the Continental Congress, Item 84 .

4. Rush, Letters I.365-68.

5. See, for example, Jefferson to Peter Carr, Aug. 19, 1785; to John Banister, Jr., Oct. 15, 1785; to Dugald Stewart, June 21, 1789, Papers.

6. Thornton to G. Washington, June 12, 1794, Vol. I, Cadmus, Vol. XI, Thornton MSS., Library of Congress; Transactions, American Philosophical Society 1966: III. 262-79.

7. Marshall to Webster, Jan. 14, 1831, Noah Webster MSS., New York Public Library; American Academy of Language and Belles Lettres, Circulars I-III.

8. Compilations of laws regarding languages in the United States are inconsistent in format and incomplete in coverage; however, they are invaluable research tools for scholars unfamiliar with techniques of legal research; cf. Fedynskyj (1971), Kloss (1971), Geffert et al. (1975). See also Fishman (1966), Ch. 1.

9. For a general review of issues related to the Fourteenth Amendment, see Developments (1969) and Asch (1968).

10. For discussions of the legal-educational aspects of the case since its appearance in the lower courts, see Grubb (1974), Sugarman and Widess (1974), and Martinez (1974). See Castañeda (1977) for an analysis of the political issues raised by Lau vs. Nichols. The legal perspective is most comprehensively presented in Teitelbaum and Hiller (1977).

11. For an overview of the role of increased standardization in language areas of the curriculum and the effects on cognitive development, see Calhoun (1973), especially $\mathrm{IIb}$, III. The role of language norms in Americanization efforts of the late nineteenth, early twentieth centuries is discussed in Tyack $(1974: \mathrm{V}, 4)$. An account of the specific shift in method of and attitudes toward teaching Standard English is in Heath (to appear, b).

12. Drew Faust, American Civilization Department, University of Pennsylvania, personal communication.

13. See, for example, Graber (1976), Lohisse (1973), and the analysis of political scientists' research on language in Weinstein (1976), which points out that books on communication written by political scientists often contain no reference to language or languages. A promising development which may make future political science students more cognizant of language as a total system is the offering of courses which carry titles such as 'language and politics' or 'language policy and cultural identity.' Such courses are currently being 
offered by Jonathan Pool, SUNY, Stony Brook; Brian Weinstein, Howard University; Carol Eastman, University of Washington; Charles Ferguson, Stanford University; and Evelyn P. Stevens, Case Western Reserve.

14. O'Barr and O'Barr (1976) provides the most complete discussion to date of theoretical and political issues related to language and politics. Articles most pertinent to United States policy are: W. O'Barr (1976:1-30, 405-21), Rubin (1976), Bretton (1973), and Leibowitz (1969, 1971, 1976). Linguistic and anthropological analyses of speech in use in courts appear in papers prepared for Duke University's Law and Language Project; see especially Lind and O'Barr (1977), Conley and O'Barr (1975). O'Barr (1976) discusses lawyers' views of effective language; Northrup (1962) presents this issue with respect to values and the philosophy of language.

15. See Chang and Araujo (1975) and El derecho de aviso (1973). For a discussion of problems of comparative linguistic analysis and international law, see DeVries (1963).

16. The approach of 'normative inquiry' assumes that research into normative judgments can employ validating tools of analysis similar to those used for scientifically valid kmowledge. Topics of interest are: the logical implications of certain ethical principles for social or political action, ways in which the values of a given culture may guide political priorities, and effective ways of evaluating alternative means in political programs of social intervention (Kalleberg and Preston 1975). A scheme for implementing some of the ideas of normative inquiry is given by Snyder, Hermann and Lasswell (1976).

17. Compare Chaplinsky vs. New Hampshire 315 U. S. 586 (1942) with Winters vs. New York 333 U. S. 507 (1948), Roth vs. U. S. 354 U.S. 476 (1957), and Gooding vs. Wilson 405 U.S. 581 (1972). See also Rutzick (1974), Murphy (1972), and Paletz and Harris (1975).

18. Judicial decisions related to education policy have most recently pointed out the problem of social science research as evidence; see Levin and Moise (1975), Weinberg (1975), Rosen (to appear), and National Institute of Education (1976). The specific role of evidence from anthropologists' 'research is evident in Equal Protection (1977); here the question of consistency of classification with respect to the values of the Indian tribes in their current culture is critical to interpretation of Indian rights under the Fourteenth Amendment and the Indian Civil Rights Act.

\section{REFERENCES}

Adams, John. 1961. Diary and bibliography of John Adams. 4 vols. Edited by L. H. Butterfield. Cambridge: Harvard University Press. 
Adams, John. 1856. Life and works of John Adams. 10 vols. Boston: Little, Brown.

Agheyisi, R., and J. A. Fishman. 1970. Language attitude studies:

A brief survey of methodological approaches. Anthropological

Linguistics 12. 137-57.

Allport, Gordon W. 1954. The nature of prejudice. Reading, Mass.: Addison-Wesley.

Asch, Sidney H. 1968. Civil rights and responsibilities under the Constitution. New York: Arco.

Beltramo, Anthony F. (to appear). Profile of a state: Montana.

In: Language in the USA. Edited by Charles A. Ferguson and Shirley Brice Heath.

Black, Donald. 1976. The behavior of law. New York: Academic Press.

Brackenridge, Hugh W. 1937. Modern chivalry. Edited by Claude M. Newlin. New York: American.

Brennan, William J., Jr. 1977. State constitutions and the protection of individual rights. Harvard Law Review 90.489-504.

Bretton, Henry L. 1973. Power and politics in Africa.' Chicago: Aldine.

Bullions, Peter. 1864. An analytical and practical grammar of the English language. New York.

Calhoun, Daniel. 1973. The intelligence of a people. Princeton: Princeton University Press.

Carlson, Robert A. 1975. The quest for conformity: Americanization through education. New York: John Wiley.

Castañeda, Salvador. 1977. Legal standards for implementation of bilingual education: Memorandum of points and authorities. Washington, D. C.: National Institute of Education.

Chang, Williamson B. C., and Manuel U. Araujo. 1975. Interpreters for the defense: Due process for the non-English-speaking defendant. California Law Review 63.801-23.

Conley, John M., and William M. O'Barr. 1975. Behavioral analysis of the American criminal courtroom. Paper, American Anthropological Association.

Cook-Gumperz, Jenny. 1977. Situated instructions: The language socialization of school-age children. In: Child discourse. Edited by Claudia Mitchell-Kernan and Susan Ervin-Tripp. New York: Academic Press.

Crick, Bernard. 1972. In defense of politics. Chicago: University of Chicago Press.

Deutsch, Karl W. 1975. The political significance of linguistic conflicts. In: Les êtats multilingues. Edited by Jean-Guy Savard and Richard Vigneault. Quebec: Laval. 
Developments in the law--equal protection. 1969. Harvard Law Review 82.1065-77.

DeVries, Henry P. 1973. Choice of language. Virginia Journal of International Law 3. 26-34.

Eisenstadt, S. N., ed. 1972. Post-traditional societies. New York: Norton.

El derecho de aviso: Due process and bilingual notice. 1973. Yale Law Journal 83.385.

Engelsing, Rolf. 1973. Analphabetentum und Lektuir; zur Sozialgeschichte des Lesens in Deutschland zwischen feudaler und industrieller Gesellschaft. Stuttgart.

Fedynskyj, Jurij. 1971. State session laws in non-English languages: A chapter of American legal history. Indiana Law Journal 46.46378.

Fishman, Joshua A. 1966. Language loyalty in the United States. The Hague: Mouton.

Fishman, Joshua A., Charles A. Ferguson, and Jyotirindra Das Gupta. 1968. Language problems of developing nations. New York: John Wiley.

Geffert, Hannah N., et al. 1975. The current status of bilingual education legislation. Washington, D. C.: Center for Applied Linguistics.

Graber, Doris A. 1976. Verbal behavior and politics. Urbana: University of Illinois.

Grimké, Thomas Smith. 1834. Oration on the comparative elements and dutys [sic] of Grecian and American eloquence. Cincinnati, Ohio. [Pamphlet in collection at the University of South Carolina Library, Columbia, S. C. ].

Grubb, Erica Black. 1974. Breaking the language barrier: The right to bilingual education. Harvard Civil Rights-Civil Liberties Law Journal 9.52-94.

Gumperz, John J. 1968. Language, communication and control in North India. In: Language problems of developing nations. Edited by J. A. Fishman, C. A. Ferguson, and J. Das Gupta. New York: John Wiley.

Heath, Shirley Brice. 1976. Colonial language status achievement: Mexico, Peru, and the United States. In: Language in sociology. Edited by A. Verdoodt and R. Kjolseth. Louvain: Editions Peeters.

Heath, Shirley Brice. 1977a. A national language academy? Debate in the new nation. IJSL 11.

Heath, Shirley Brice. 1977b. Our language heritage: A historical perspective. In: The language connection: From the classroom to the world. ACTFL foreign language education series, Vol. 9 . Skokie, Ill., National Textbook Co. 
Heath, Shirley Brice. (to appear, a). Early American attitudes toward variation in speech: A view from social history and sociolinguistics. In: Language variation in America: Approaches to the study of American English. Edited by Carol F. Justus. Austin: University of Texas.

Heath, Shirley Brice. (to appear, b). Standard English: Biography of a symbol. In: Variation in the structure and use of English. Edited by Timothy Shopen. Englewood Cliffs, N. J.: Winthrop. Hymes, Dell H. 1976. Towards linguistic competence. Studium generale 4. 217-39.

Jefferson, Thomas. 1950-74. The papers of Thomas Jefferson. 19 vols. Edited by J. P. Boyd. Princeton, N. J.: Princeton University Press.

Kalleberg, A. L., and L. M. Preston. 1975. Normative political analysis and the problem of justification: The cognitive status of basic political norms. Journal of Politics 37.650-84.

Kloss, Heinz. 1966. Excerpts: The national minority laws of the United States of America. Honolulu: East-West Center.

Kloss, Heinz. 1971. Laws and legal documents relating to problems of bilingual education in the United States. Washington, D.C.: ERIC, Center for Applied Linguistics.

Kluwin, Bridget Mary. 1977. Coping with language and cultural diversity: A study of changing language instruction policy from 1860 to 1930 in three American cities. Ph. D. dissertation, Stanford University.

LaBelle, Thomas J. 1976. Nonformal education and social change in Latin America. Los Angeles: UCLA Latin American Center.

Labov, William. 1976. What's behind the basics? Public lecture, NEH Symposium, University of North Carolina, Greensboro.

Lambert, Wallace E., and Howard Giles, n.d. Language attitudes in a French-American community. Unpublished paper.

Leibowitz, Arnold H. 1969. English literacy: Legal sanction for discrimination. Notre Dame Lawyer 45. 7-67.

Leibowitz, Arnold H. 1971. Educational policy and political acceptance: The imposition of English as the language of instruction in American schools. Washington, D. C.: Center for Applied Linguistics.

Leibowitz, Arnold H. 1976. Language and the law: The exercise of political power through official designation of language. In: Language and politics. Edited by William O'Barr and J. F. O'Barr. The Hague: Mouton.

Levin, Betsy, and Philip Moise. 1975. School desegregation litagation in the seventies and the use of social science evidence: An annotated guide. Law and Contemporary Problems 39.50-133. 
Lewis, M. M. 1953. The importance of literacy. London: Harrap. Lind, E. Allan, and William O'Barr. (to appear). The social significance of speech in the courtroom. In: Language and social psychology. Edited by Howard Giles and Robert St. Clair.

Lockridge, Kenneth A. 1974. Literacy in colonial New England. New York: Norton.

Lohisse, Jean. 1973. Anonymous communication. London: George Allen.

Martínez, Virginia. 1974. Bilingual education: A privilege or a right? An Ilinois report. Depaul Law Review 24.990-98. McLean, Margaret Prendergast. n. d. Good American speech. New York: E. P. Dutton.

Moore, Frank. 1857. American eloquence. New York: D. Appleton. Murphy, Paul. 1972. The meaning of freedom of speech: First Amendment freedom from Wilson to FDR. Westport, Conn.: Greenwood.

National Institute of Education. 1976. Education, social science, and the judicial process. Washington, D.C.

Newman, Edwin, 1974. Strictly speaking. New York: Dell.

Northrup, S. C. 1962. Law, language, and morals. The Yale Law Journal 71.1017-1048.

O'Barr, William M. 1976. Legal assumptions about language. Unpublished paper presented at Fifth Conference on New Ways of Analyzing Variation in English, Georgetown University, Washington, D. C.

O'Barr, William M., and Jean F. 1976. Language and politics. The Hague: Mouton.

Paletz, David L., and William F. Harris. 1975. Four-letter threats to authority. Journal of Politics 37.955-79.

Quirk, Randolph. 1968. The use of English. Second ed. New York: St. Martin's.

Reyes, Rogelio. 1977. Transitional program for a multicultural society in Atzlan: Texto y contexto. Unpublished paper presented at Conference on Language Variety and its implications for American cultural pluralism, University of Chicago.

Rosen, Larry. (to appear). Anthropologist as expert. American Anthropologist.

Rubin, Joan. 1976. Language and politics from a sociolinguistic point of view. In: Language and politics. Edited by William O'Barr and Jean F. O'Barr. The Hague: Mouton.

Rubin, Joan, and Björn Jernudd, eds. 1971. Can language be planned? Sociolinguistic theory and practice for developing nations. Honolulu: University of Hawail.

Rush, Benjamin. 1951. Letters of Benjamin Rush. 2 vols. Edited by L. H. Butterfield. Princeton, N. J.: Princeton University Press. 
Rutzick, Mark C. 1974. Offensive language and the evolution of First Amendment protection. Harvard Civil Rights-Civil Liberties Law Review 9.1-28.

Schultz, Stanley K. 1973. The culture factory: Boston public schools, 1789-1860. New York: Oxford University Press. Shuy, Roger, and Ralph W. Fasold, eds. 1973. Language attitudes: Current trends and prospects. Washington, D.C.: Georgetown University Press.

Snyder, Richard C., D. F. Hermann, and H. D. Lasswell. 1976. A global monitoring system: Appraising the effects of government on human dignity. International Studies Quarterley 20.221-60.

Sugarman, Stephen D., and Ellen G. Widess. 1974. Equal protection for non-English-speaking school children: Lau vs. Nichols. California Law Review 62.157-82.

Teitelbaum, Herbert, and Richard J. Hiller. 1977. Bilingual education: The legal mandate. Harvard Educational Review, 47(2). 138-170.

Tyack, David B. 1974. The one best system: A history of American urban education. Cambridge: Harvard University Press.

Van Dyke, Vernon. 1976. Human rights without distinction as to language. International Studies Quarterly 20.3-38.

Waggoner, Dorothy. 1976. Results of the survey of languages supplement to the July 1975 current population survey. Paper, Fifth International Bilingual Bicultural Education Conference, San Antonio, Texas.

Waggoner, Dorothy. (to appear). Statistics on language use. In: Language in the USA. Edited by Charles A. Ferguson and Shirley Brice Heath.

Weinberg, Meyer. 1975. The relationship between school desegregation and academic achievement: A review of the research. Law and Contemporary Problems 39.241-70.

Weinstein, Brian. 1976. Language strategists: Redefining political communities on the basis of linguistic choices. Unpublished paper, Woodrow Wilson International Center for Scholars, Washington, D.C.

Weinstein, Brian. 1977. Political science perspectives on language. To appear in: Bilingual education 1976-1977: The state of the art. Arlington, Va.: Center for Applied Linguistics. 


\title{
LANGUAGE, ETHNICITY, AND RACISM
}

\author{
JOSHUA A. FISHMAN
}

\section{Yeshiva University}

In Irish, not merely does our mind react to the same beauty, the same delicacy of inflection and suggestion that delighted our fathers, but we can still share through it the desires and hopes, the failures and successes, the nobility and even, in a healing manner, the human weakness of practically the whole of our recorded history (Brennan 1969:71).

Language and ethnicity: Overlooked variables in social theory and in social history. Many discussions of ethnicity begin with the struggle to define 'it'。 While I am certainly interested in defining (or delimiting) ethnicity, I am ever more interested in what the definitional struggle in this day and age reveals, namely, that we still lack an intellectual tradition in connection with this topic. Social scientists and social theorists have neither reconstructed nor developed with respect to ethnicity (nor, indeed, with respect to language and ethnicity) either a sociology of the phenomenon per se or a sociology of knowledge concerning it, much less a synchronic view of the link between the two, in any major part of the world of social life and social thought. Thus, here we are, in the late twentieth century, with God only knows how few or how many seconds remaining to the entire human tragi-comedy on this planet, still fumbling along in the domain of ethnicity, as if it had just recently appeared and as if three millenia of pan-Mediterranean and European thought and experience in connection with it (to take only that corner of mankind with which most of us are most familiar), could be overlooked. Obviously that is patently not our attitude toward other societal manifestations such as the family, urbanization, religion, technology, etc. 
For all of these we manifestly delight in the intellectual traditions surrounding them. I must conclude that our intellectual discomfort and superficiality with respect to ethnicity and our selective ignorance in this connection are themselves ethnicity-related phenomena which merit consideration if we are ultimately to understand several of the dimensions of this topic that are still waiting to be revealed.

This is not the place to undertake so grand an expedition, nor have I the ability to take you everywhere that this topic (the sociology of language and ethnicity and the sociology of knowledge with respect to it) must lead us. I can only give you a promissory note: namely, that a colleague (Vladimir Nahirny) and I have outlined for ourselves what is probably a lifetime inquiry into language and ethnicity--both their social history and their social theory. During the past two years we have made slow but significant progress in mapping some of the continents that we know are there (Nahirny and Fishman, n. d.) for a very few ages and places (scanning the pan-Mediterranean and European world from classical times to today), we have already succeeded in locating some of the finer detail of the language and ethnicity landscape as well. Nevertheless, this presentation is my first attempt to report what we are up to, to my (socio-) linguistic peers, having recently made similar attempts in connection with colleagues in East European studies, on the one hand (Fishman, to appear), and in connection with social science specialists in ethnicity on the other (Fishman, in press).

Suffice it to say that we are trying to carry both the reconstruction and the analysis of social history and social theory from classical Hebrew and Greek times through to the 20th century, up to and including the 'rebirth of ethnicity' in many Western locales during the past decade. In the process we plan to attend to the Roman Empire, both in the West and in the East; to the early Church and the Church Fathers; to Islam as a Euro-Mediterranean presence, to medieval and renaissance life and thought throughout Europe; to the reformation and counter-reformation; to the commercial and industrial revolutions viewed both as social change/continuity and as stimulants to social thought and social theory; and finally, to the rise of modern intellectual schools and social movements. In this last we particularly plan to examine the capitalist-Marxist clash, and the MarxistHerderian-Weberian differences in sociological and anthropological thought and in political and economic action, both in the ominous 19th and in the cataclysmic 20th centuries. At this time I can only try to select a few themes here and there that may provide some clues to language and ethnicity viewed in such a perspective.

What is ethnicity? Since one of our objectives is to disclose what social theorists have said about ethnicity, including how they have 
defined it, our definitional passions can be satisfied at a general orientational level which gives us as much latitude as possible to attend to all forms and definitions of ethnicity (see Isajiw 1974, for detailed attention to the definitional issue). What we are interested in is both the sense and the expression of 'collective intergenerational continuity', i. e. the sensing and expressing of links to 'one's own kind (one's own people)', to collectivities that not only purportedly have historical depth but, more crucially, share putative ancestral authenticity and, therefore, the gifts and responsibilities deriving therefrom. Thus, what we are interested in may or not be identical with all of society and culture, depending on the extent to which ethnicity does pervade and dictate all social sensings, doings and knowings, or alternatively (and as is increasingly the case) only some of these, ${ }^{1}$ particularly those that relate to the questions: who are we? from where do we come? what is special about us?. It is in this context that we also want to monitor whatever link there may be to language as an aspect of presumed authenticity.

The theme of fundamental 'essence'. Both ancient Israel and ancient Greece conceived of the world as made up of a finite number of ethnicities with characteristic and fundamental biological 'essences' and, therefore, histories or missions of their own. This theme, with its undercurrent of bodily continuity and triumph over death, has its counterpart in modern Herderian and nationalist thought and has been continually present in the pan-Mediterranean and European world, as well as in much of the African, Asian, and Native American worlds. This essence is transcendental and ultimately of superhuman origin, and language is naturally a cooccurring part of this essential blood, bones, or tears. Thus, the view that the deity necessarily speaks to each ethnicity in its own language and could not conceivably do otherwise, is also a recurring view (one that is not always accepted and, therefore, one that is also contradicted). It is a view, related to a cosmology in which language-and-ethnicity collectivities are seen as the basic building blocks of all human society. In more modern thought, the superhuman origin of this cooccurrence and its dependence on biological essences are questioned. However, many theoreticians and philosophers still hold that ethnicity and ethnogenesis (i.e. the coming into being of ethnicities and of languageand-ethnicity linkages) is a natural and necessary fact of human social life (for a recent Soviet view along these very lines, see Bromley 1974). Eastern European and Eastern Mediterranean thought is particularly noteworthy along these latter lines (Jakobson 1945) and it is here that we find today most universally and insistently the view that language authenticity is a natural and necessary part of a mystically inescapable collective continuity. 
The theme of metamorphosis. Seemingly at odds with the above view, but at times subscribed to in addition to it, is the view that ethnicities can be transcended and that a new or 'higher' level can be arrived at, including the level of terminal de-ethnicization, i. e. of no ethnicity at all. The argument between those who view it as endlessly mutable begins with Plato and Aristotle, the former proposing that a group of de-ethnicized Guardians of the City be created so that uncorrupted and uncorruptable, altruistic and evenhanded management of the polity could be attained. There would be no husband-wife relationships among them since all women would belong to all men and vice versa. Similarly their offspring would have no fathers and no mothers since all male adults would be fathers to all children, all female adults would be their mothers, all children would belong equally to all adults and vice versa. Only a group such as this--a group whose members had no differentiating intergenerational biological continuities--could devote itself to the public weal, since, having neither property nor family, it could view the general need without bias, without favoritism, without greed, without conflict of interest, all of which Plato considered necessary accompaniment of ethnicity. Aristotle hotly contested this view and stressed that whatever the dangers of ethnicity might be, those who do not initially love and feel uniquely bound to specific 'others' could not then love mankind or have the benefit of generalized 'others' firmly in mind. A child who belongs equally to one and all belongs to no one. The challenge of ethnicity, as Aristotle saw it, was one of augmenting familial love, expanding the natural links to one's own 'kind', so that these links also include others who are more distantly related, rather than doing away with the initial links and bonds at all.

This theme too is developed consistently--the expansion and transmutation of language and ethnicity to a higher, more inclusive level of both being repeatedly expressed by early Christian thought, Roman thought, medieval thought (including much of moral philosophy) and by capitalist statism. Going even further, de-ethnicization and linguistic fusion are expressed as ultimate, millenial goals by some Christian social theorists, by classical Marxists as well as classical capitalists, and as inevitable if regrettable outcomes of modern industrial society by Weber and the entire 'grand tradition' of modern social theory from Saint-Simon to Parsons (Nahirny and Fishman n. d.).

Ethnicity as disruptive, irrational, and peripheral. The darker side of ethnicity is commented on by almost all ancient and medieval thinkers, but usually as only one side of the coin, i. e. as only half of the entire phenomenon which has both positive and negative features. However, the more completely negative view begins with Plato, as 
already mentioned, in relation to matters of state. In this connection it receives its quintessential formulation by Lord Acton, John Stuart Mill, and other establishment-oriented defenders of Western capitalist democracy. For them, state-forming ethnicity was nothing but the disrupter of civility, a base passion, a nightmare, a wild evil that still lurked in the backward parts of Europe but that had, thank God, already been tamed and superseded in Great Britain, France, Spain, Holland, and in the other early and enlightened beneficiaries of political consolidation and stabilization.

This view coincided with a developmental theory defining 'legitimate' language-and-ethnicity, namely, that the link between them and the currency that they both enjoyed in the West were by-products of political and economic stability. That is, they were the legitimate creations of centuries of continuous governmental, commercial, military, and religious stability. This view, that the state creates the legitimate nationality, was long the dominant view in the West. The thought that the nationality might undertake to create a state for itself was anathema, viewed as unnatural, unjust, unwise, and simply a wild and wanton disruption of peace and civility. The thought of a Breton or Romanian ethnicity was as roundly abhorred by 'proper' society then as the thought of a Quebecois ethnicity is in some circles today. Indeed, the evil instinctual penchant of illegitimate languageand-ethnicity movements to undertake disruptive state formation was thought to be the basic dynamic of minority ethnicity, and so it is for some to this very day. Thus, the confusion of ethnicity with politically troublesome collectivities, with rambunctious minorities, with 'difficult' peripheral and vestigial populations, began long ago.

However, classical Marxism was not very different from capitalist establishment statism in this respect. Mill had held that the language and ethnicity movements, particularly in their nationality-into-state phase, were despicable 'irrationalities' that had to be contained at all costs, evils to be compromised with only grudgingly if the established political order was to be maintained (note, for example, the compromise escape clause of 'once defeated but historical nations' as an interstitial category between Mill's and Acton's two major categories of 'goodies': 'peoples with histories', and 'baddies': 'peoples without histories'). Initially, Marx and Engels were equally vituperative with respect to nation-into-state language and ethnicity movements (and, ultimately, made equally grudging and opportunistic exceptions in connection with them), due to their obviously disruptive impact on the class struggle and on proletarian unity. However, if language-andethnicity movements for Mill were merely vile passions, they were for the early Marx vile figments, lies, and chimeras, objectively no more than mere by-products of more basic economic causes, phantoms 
manipulated by leading capitalist circles in order to fragment and weaken the international proletariat.

Needless to say, both Mill and Marx have their followers today, who ascribe to language and ethnicity linkages all manner of evil and evil alone, including genocide. Furthermore, this purportedly objectivist view is still very much alive among those social scientists who deny any subjective validity or functional need for ethnicity, and who see it only as an essentially manipulated (and therefore, basically unauthentic), manufactured by-product of elitist efforts to gain mass support for political and economic goals (Gellner 1964). They basically sympathize with Engels' lament of a century ago (1866):

There is no country in Europe where there are not different nationalities under the same government. The Highland Gaels and the Welsh are undoubtedly of different nationalities to what the English are, although nobody will give to these remnants of people long gone by the title of nations, any more than to the Celtic inhabitants of Brittany in France . . . The European importance, the vitality of a people, is as nothing in the eyes of the principle of nationalities; before it the Roumans [sic] of Wallachia, who never had a history, nor the energy required to have one, are of equal importance to the Italians who have a history of 2,000 years, and an unimpaired national vitality; the Welsh and Manxmen, if they desired it, would have an equal right to independent political existence, absurd though it be, with the English! The whole thing is absurdity. The principle of nationalities, indeed, could be invented in Eastern Europe along where the tide of Asiatic invasion, for a thousand years, recurred again and again, and left on the shore those heaps of intermingled ruins of nations which even now the ethnologist can scarcely disentangle, and where the Turk, the Finnie Magyar, the Rouman, the Jew and about a dozen slavonic tribes live intermixed in interminable confusion.

To this very day ethnicity strikes many Westerners as being peculiarly related to 'all those crazy little people and languages out there', to the unwashed (and unwanted) of the world, to phenomena that are really not fully civilized and that are more trouble than they are worth.

Ethnicity as creative and healing. Autochthonous ethnicity theories commonly refer to the responsibilities incumbent upon the carriers of the intergenerational essence, i. e. to the duties that those of 'one's own kind' have, duties to be and to do in particularly authentic ways; and of course, these theories also refer to the rewards of such 
faithfulness. However, various more generalized ethnicity theories have taken this kind of thinking a step higher. Classical Hebrew thought contains a recurring emphasis on the perfectability of ethnicity, i.e. an emphasis on its highest realization via sanctification. It was not only Jewish ethnicity which could be so elevated and attuned with the Creator's designs and expectations (Fishman and Fishman n.d.), although Hebrew thought is, understandably, repeatedly more concerned with the theoretical perfectability of Hebrew ethnicity (just as it is with the actual shortcomings of Hebrew ethnicity). Hebrew thought is an early source for the recurring message that sanctified ethnicity is ennobling, strengthening, healing, satisfying. Hebrew thought proclaims the message of the joy, the wholeness, the holiness of embodying and expressing language-andethnicity in accord with the wishes of the Master of the Universe: 'for they are our life and the length of our days'. Whosoever lives in the midst of his own kind, speaking his own language and enacting his own most ennobled traditions in accord with these wishes, has all that one could hope for out of life.

The joys of one's own language and ethnicity are subsequently expressed over and over again, from every corner of Europe and in every period. In modern times this feeling has been raised to a general principle, a general esthetic, a celebration of ethnic and linguistic diversity per se, as part of the very multisplendored glory of God, a value, beauty, and source of creative inspiration and inspiring creativity--indeed, as the basic human good. It is claimed that it is ethnic and linguistic diversity that makes life worth living. It is creativity and beauty based upon ethnic and linguistic diversity that make man human. Absence of this diversity would lead to the dehumanization, mechanization, and utter impoverishment of man. The weakening of this diversity is a cause for alarm, a tendency to be resisted and combatted. In Herder and in Mazzini, in the Slavophiles and in Kallen--indeed, in much of modern anthropology-the theme of ethnic diversity and the sheer beauty of cultural pluralism provide an unending rhapsody. This view both tantalizingly merges with and also separates from general democratic principles, with the rights of man, and the inalienable privilege to be one's self, not only to be free but to be free to be bound together with 'one's own kind' (Talmon 1965). On the one hand, democracy also subsumes an alternative reason, namely, to be free from ethnicity, i.e. the right and ability to be a citizen of the world rather than a member of one or another traditioned ethnic collectivity. On the other hand, democracy guarantees the right to retain one's ethnicity, to enable one's children to join the ranks of 'one's own kind', to develop creatively, and to reach their full potential without becoming 
ethnically unauthentic, colorless, lifeless, worse than lifeless: nothingness.

Dimensions of language-and-ethnicity. The foregoing themes and others provide us with many insights into language and ethnicity, and into how language and ethnicity have been viewed in a particularly influential part of the world as well. The themes themselves are not independent of each other. Many of them relate to a putative ethnic essence that is intergenerationally continuous among 'one's own kind' and is absorbed via the mother's milk. Thus, there is commonly a 'being' component to ethnicity, a bodily mystery, a triumph over death in the past as well as a promise of immortality in the future, as the putative essence is handed on generation after generation. There are a few escape hatches in, and a few escape hatches out, and a terrifying state of liminality in between, but the physical continuity of a corpus mysticism continues. And language is part of that corpus. It issues authentically from the body, it is produced by the body, it has body itself (and, therefore, does not permit much basic modification).

Just as commonly, language is part of the authentic 'doing' constellation and the authentic 'knowing' constellation that are recurringly assumed to be dimensions of ethnicity. Ethnic doing and knowing are more mutable and, therefore, in danger of unauthenticity. Ethnic doing is a responsibility that can be shifted. Ethnic knowing is a gift that can be withheld. The basic desideratum, ethnic being, is necessary but not sufficient. There is everything to be gained and everything to be lost, and language is recurringly part and parcel of this web. In premobilizational ethnicity it is naturally, unconsciously so (Fishman 1965), whereas in mobilized ethnicity it is a rallying call, both metaphorically and explicitly (Fishman 1972).

Autochthonous theories gravitate toward the metaphorical and metaphysical views of the language and ethnicity link. External objectivists reduce the mystery to the needs of the military and the economy, with the school system merely exploiting language and ethnicity in preparing recruits for both. Autochthonists see language and ethnicity as initial essences, or causes. External objectivists see them as manipulable by-products. However, both agree that they are generally there together. Hovering over them both is the problem of how to interpret the 'we-they' differences that are, unconsciously or consciously, made in the experience of ethnicity, which brings me to racism.

Ethnicity and racism. Racism is one of many words that have been so broadened in modern, popular usage as to have lost their utility. Democracy and socialism are two other such terms, but 
whereas the latter have become all-purpose terms of approbation (viz. people's democracy, guided democracy, National Socialism, etc.), the former has become an all-purpose put-down. I would like to rescue racism from that dubious distinction, to limit its semantic range, in order more clearly to distinguish between ethnicity and racism as social phenomena and as social theories, and thereby, to focus pejorative usage more tellingly.

Relative to ethnicity, racism is not only more focused on the being component (therefore having even fewer escape hatches from it than does ethnicity), but it also involves an evaluative ranking with respect to the discontinuity between ethnic collectivities. Ethnicity is an enactment (often unconscious) and a celebration of authenticity. Racism inevitably involves more heightened consciousness than does ethnicity, not only because it is an 'ism', but because its focus is not merely authenticity and the celebration of difference or collective individuality, but the evaluation of difference in terms of inherent better or worse, higher or lower, entirely acceptable and utterly objectionable. Ethnicity is less grandiose than racism. It has no built-in power dimension while racism, being essentially hierarchical, must have the concept of dominance in its cosmology and requires the constructs of superior races, dominant stocks, master peoples. By their words and deeds, ethnicity and racism are importantly different.

Herder, though anti-French to the hilt (like many German intellectuals struggling against French cultural hegemony within the disunited German princedoms at the beginning of the 19th century), is rarely, if ever, racist. He proclaims:

No individual, no country, no people, no history of a people, no state is like any other. Therefore, the true, the beautiful and the good are not the same for them. Everything is suffocated if one's own way is not sought and if another nation is blindly taken as a model (Herder, Samtlich Werke, v. 4, p. 472).

Is not this still a dominant ethic and motivating dynamic in cultural anthropology to this very day? Herderian views must be understood as a plea and a rhapsody for an ethnically pluralistic world in which each ethnicity can tend to its own vineyard as a right, a trust, and a point of departure for new beauty and creativity yet undreamed of. Such pluralism is, however, strange to racism, since the dynamics of racism represent a call and rationale for mastery rather than for coexistance. While ethnicity can proclaim live and let live, racism can proclaim only bondage or death to the inferior.

Of course, every ethnicity runs the risk of developing an ethnocentrism, i.e. the view that one's own way of life is superior 
to all others. It may even be true that some degree of ethnocentrism is to be found in all societies and cultures (Bidney 1968), including the culture of secular science itself, to the degree that they are allencompassing in defining experience and exposure. The antidote to ethnocentrism (including acquired anti-ethnic ethnocentrism, which may be just as supercilious and uncritically biased as is ethnic conditioning) is thus comparative cross-ethnic knowledge and experience, transcending the limits of one's own usual exposure to life and values (a theme which has long appeared in the literature of ethnicity). Characteristic of postmodern ethnicity is the stance of simultaneously transcending ethnicity as a complete, self-contained system, but of retaining it as a selectively preferred, evolving, participatory system. This leads to a kind of self-correction from within and from without, which extreme nationalism and racism do not permit.

The modern heroes of racism are Gobineau in France (see, for example, Biddess 1970), Houston Steward Chamberlain (1899) in England, and a chorus of German philosophers, scientists, and politicians (see, for example, Barzun 1937, Gasman 1971, Mosse 1966, Weinreich 1946). From their works it becomes clear that the language link to racism is as invidious as racism per se. Hermann Gauch, a Nazi 'scientist', was able to claim:

The Nordic race alone can emit sounds of untroubled clearness, whereas among non-Nordics the pronunciation is . . . like noises made by animals, such as barking, sniffing, snoring, squeaking ... That birds can learn to talk better than other animals is explained by the fact that their mouths are Nordic in structure (quoted in Mosse 1966, p. 225).

Here we have the ultimate route of racist thought: the demotion of the 'others' to a subhuman level. They are animals, vermin, and are to be subjected to whatever final solution is most effective and efficient.

Concluding sentiments. These remarks must not be taken simply as a defense of ethnicity. Ethnicity has been recognized since ancient times as capable of excess, corruption, and irrationality, this capacity being one of the basic themes accompanying its peregrination across the centuries. The very term ethnicity, derived from the Greek ethnos (used consistently in the Septuagint to render the Hebrew goy, the more negative term for nationality, as distinct from am, the more positive term), has a decided negative connotation in earliest English usage (see OED: ethnic 1470, ethnist 1550 and 1563, ethnicize 1663, ethnicity 1772, ethnize 1847). These connotations-heatheness, superstitition, bizarreness--have not fully vanished 
even from modern popular usage, e.g. ethnic dress, ethnic hairdos, ethnic soul. Thus, we need not fear that the excesses of ethnicity will be overlooked.

Racism itself is one of the excesses into which ethnicity can develop, although racism has often developed on pan-ethnic and perhaps even on nonethnic foundations as well. 2 However, the distinction between ethnicity and racism is well worth maintaining, particularly for those in the language sciences and professions. It clarifies our goals, our problems, and our challenges as we engage in bilingual education, in language planning, in language maintenance efforts, and in a host of sociolinguistic and anthropological enterprises. The distinctions between religion and bigotry, sexuality and sexism, socialism and communism, democracy and anarchy, are all worth maintaining. No less worthwhile is the distinction between ethnicity and racism. Unfortunately, we know more about racism than about ethnicity, and more about the conflictual aspects of ethnicity than about its integrative functions. This is a pity, particularly for American intellectuals, since we too (regardless of our pretense to the contrary) live in a world in which the ethnic factor in art, music, literature, fashions, diets, childrearing, education, and politics is still strong and needs to be understood and even appreciated. Not to know more about ethnicity, about the ethnic repertoires of modern life, the endless mutability of ethnicity since the days of ancient Israel, the variety of prior thought concerning ethnicity, and about the various views as to its power or centrality as a factor in societal functioning and social behavior, is also to limit our understanding of society and of the role of language in society. Language and ethnicity have been viewed as naturally linked in almost every age of premodern panMediterranean and European thought. When ethnicity disappeared from modern social theory in the 19th century, language, too, disappeared therefrom. We may now be at a point just before the reappearance of both in modern social theory and must prepare ourselves, accordingly, to benefit from the sensitivities and perspectives that a knowledge of language and ethnicity can provide, without overdoing them.

\section{NOTES}

1. For an account of racism's more complete domination of modern culture, see Banton's paper in Zubaida (1970). For a preliminary differentiation between ethnicity and racism, see the penultimate section of this paper.

2. The terminology of ethnicity often included the word race (e.g. raza, in the sense of race as employed in this paper). This is but 
one of the semantic variations that Nahirny and I must be aware of and must try to illuminate.

\section{REFERENCES}

Barzun, Jacques. 1937. Race: A study in superstition. New York: Harper.

Biddess, Michael D., ed. 1970a. Gobineau: Selected political writings. London: Cape.

Biddess, Michael D. 1970b. Father of racist ideology: The social and political thought of Count Gobineau. London: Weindenfeld and Nicholson.

Bidney, David. 1968. Cultural relativism. International Encyclopedia of the Social Sciences 3.543-547.

Brennan, Rev. Martin. 1969. Language, personality and the nation.

In: A view of the Irish language. Edited by Brian Ó Cuiv.

Dublin: Stationery Office.

Bromley, Yu. V. 1974. Soviet ethnology and anthropology.

Studies in Anthropology I. The Hague: Mouton.

Chamberlain, Houston S. 1899. The foundations of the nineteenth

century. New York: Fertig.

Engels, Friedrich. 1866. What have the working class to do with Poland? Commonwealth, March 24, March 31, and May 5.

Fishman, Joshua A. 1965. Varieties of ethnicity and varieties of language consciousness. In: Georgetown University Round Table on Languages and Linguistics 1965. Edited by Charles W.

Kreidler. 69-79.

Fishman, Joshua A. 1972. Language and nationalism. Rowley:

Newburg House.

Fishman, Joshua A. (to appear). Language and ethnicity in Eastern Europe. In: Eastern Europe as an area of social science inquiry. Edited by Peter Sugar.

Fishman, Joshua A. (in press). Ethnicity and language. In:

Language and ethnicity in human relations. Edited by Howard

Giles. New York: Academic Press.

Fishman, David E., and Joshua A. Fishman. n.d. Am and goy in the Pentateuch. MS.

Gasman, Daniel. 1971. The scientific origins of National Socialism:

Social Darwinism in Ernest Haeckel and the German Monist League.

London: Macdonald.

Gellner, Ernst. 1964. Thought and change. Chicago: University of Chicago Press.

Herder, Johann G. Samthlich Werke. 10 vols. Reproduction of 1894 edition. New York: AMS Press. 
Isajiw, Wsevolod W. 1974. Definitions of ethnicity. Ethnicity 1.111-124.

Jakobson, Roman. 1945. The beginnings of national selfdetermination in Europe. Review of Politics 2. 29-42.

MacRae, Donald. 1960. Race and sociology in history and in theory. In: Man, race and Darwin. Edited by P. Mason. London: Oxford University Press.

Mosse, G. L. 1966. Nazi culture: Intellectual, cultural and social life in the Third Reich. London: W. H. Allen.

Nahirny, Vladimir, and Joshua A. Fishman. n. d. The role of ethnicity in social theory. MS.

Rjasanoff, N. 1916. Karl Marx und Friedrich Engels Uber die Polenfrage. Archiv für die Geschichte des Socialismus und der Arbeiterbevegung, 6.175-221. Leipzig.

Talmon, Jacob L. 1965. The unique and the universal. London: Secker and Warburg.

Weinreich, Max. 1946. Hitler's professors: The part of scholarship in Germany's crimes against the Jewish people. New York: Yiddish Scientific Institute-Yivo.

Zubaida, S., ed. 1970. Race and racism. London: Tavistock. 




\section{Contents}

Charles A. Ferguson. Linguistics as anthropology.

Richard Bauman. Linguistics, anthropology, and verbal art: Toward a unified perspective, with a special discussion of children's folklore.

Mary Ritchie Key. Males, females, and linguistic and cultural categories.

Joel Sherzer. The ethnography of speaking: A critical appraisal.

Gillian Sankoff. Variability and explanation in language and culture: Cliticization in New Guinea Tok Pisin.

Cecil H. Brown. Lexical universals and the human language faculty.

Erica McClure. Aspects of code-switching in the discourse of bilingual Mexican-American children.

Ben G. Blount. Parental speech to children: Cultural patterns.

Michael Silverstein. Cultural prerequisites to grammatical analysis.

Sally McLendon. Cultural presuppositions and discourse analysis: Patterns of presupposition and assertion of information in Eastern Pomo and Russian narrative.

John J. Gumperz. Sociocultural knowledge in conversational inference.

Eugene A. Nida. Translating means communicating: A sociolinguistic theory of translation.

John Munby. Applying sociocultural variables in the specification of communicative competence.

H. Ned Seelye. Teaching the cultural context of intercultural communication.

Orlando Taylor. The sociolinguistic dimension in standardized testing.

Shirley Brice Heath. Language and politics in the United States.

Joshua A. Fishman. Language, ethnicity, and racism.

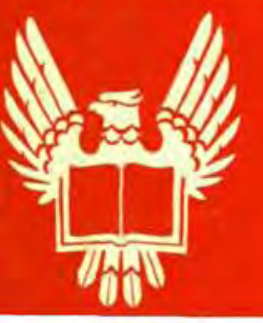

